\title{
Lifestyle modifications for nonalcohol-related fatty liver disease: a network meta-analysis (Review)
}

Buzzetti E, Linden A, Best LMJ, Madden AM, Roberts D, Chase TJG, Freeman SC, Cooper NJ, Sutton AJ, Fritche D, Milne EJ, Wright K, Pavlov CS, Davidson BR, Tsochatzis E, Gurusamy KS

Buzzetti E, Linden A, Best LMJ, Madden AM, Roberts D, Chase TJ G, Freeman SC, Cooper NJ, Sutton AJ, Fritche D, Milne EJ, Wright K, Pavlov CS, Davidson BR, Tsochatzis E, Gurusamy KS.

Lifestyle modifications for nonalcohol-related fatty liver disease: a network meta-analysis.

Cochrane Database of Systematic Reviews 2021, Issue 6. Art. No.: CD013156.

DOI: 10.1002/14651858.CD013156.pub2.

www.cochranelibrary.com 
TABLE OF CONTENTS

HEADER 1

ABSTRACT

PLAIN LANGUAGE SUMMARY

SUMMARY OF FINDINGS

BACKGROUND

OBJECTIVES

METHODS

RESULTS

Figure 1.

Figure 2.

Figure 3.

Figure 4.

Figure 5.

Figure 6.

DISCUSSION

AUTHORS' CONCLUSIONS

ACKNOWLEDGEMENTS

REFERENCES

CHARACTERISTICS OF STUDIES

ADDITIONAL TABLES

APPENDICES

HISTORY

CONTRIBUTIONS OF AUTHORS

DECLARATIONS OF INTEREST

SOURCES OF SUPPORT

DIFFERENCES BETWEEN PROTOCOL AND REVIEW

NOTES 
[Intervention Review]

\title{
Lifestyle modifications for nonalcohol-related fatty liver disease: a network meta-analysis
}

Elena Buzzetti ${ }^{1}$, Audrey Linden², Lawrence MJ Best ${ }^{2}$, Angela M Madden³, Danielle Roberts², Thomas J G Chase ${ }^{4}$, Suzanne C Freeman 5 , Nicola J Cooper ${ }^{5}$, Alex J Sutton ${ }^{5}$, Dominic Fritche ${ }^{6}$, Elisabeth Jane Milne ${ }^{7}$, Kathy Wright ${ }^{8}$, Chavdar S Pavlov ${ }^{9}$, Brian R Davidson², Emmanuel Tsochatzis ${ }^{1}$, Kurinchi Selvan Gurusamy2,9

\begin{abstract}
1Sheila Sherlock Liver Centre, Royal Free Hospital and the UCL Institute of Liver and Digestive Health, London, UK. ${ }^{2}$ Division of Surgery and Interventional Science, University College London, London, UK. ${ }^{3}$ School of Life and Medical Sciences, University of Hertfordshire, Hatfield, UK. ${ }^{4}$ Department of General Surgery, Homerton University Hospital NHS Foundation Trust, London, UK. ${ }^{5}$ Department of Health Sciences, University of Leicester, Leicester, UK. 6 UCL Medical School, London, UK. ${ }^{7}$ Centre for Trust, Peace and Social Relations, Coventry University, Coventry, UK. ${ }^{8}$ Cochrane Hepato-Biliary Group, Copenhagen Trial Unit, Centre for Clinical Intervention Research, The Capital Region of Denmark, Rigshospitalet, Copenhagen University Hospital, Copenhagen, Denmark. ${ }^{9}$ Department of Therapy, I.M. Sechenov First Moscow State Medical University, Moscow, Russian Federation
\end{abstract}

Contact address: Kurinchi Selvan Gurusamy, k.gurusamy@ucl.ac.uk.

Editorial group: Cochrane Hepato-Biliary Group.

Publication status and date: New, published in Issue 6, 2021.

Citation: Buzzetti E, Linden A, Best LMJ, Madden AM, Roberts D, Chase TJ G, Freeman SC, Cooper NJ, Sutton AJ, Fritche D, Milne EJ, Wright K, Pavlov CS, Davidson BR, Tsochatzis E, Gurusamy KS. Lifestyle modifications for nonalcohol-related fatty liver disease: a network meta-analysis. Cochrane Database of Systematic Reviews 2021, Issue 6. Art. No.: CD013156. DOI: 10.1002/14651858.CD013156.pub2.

Copyright @ 2021 The Cochrane Collaboration. Published by John Wiley \& Sons, Ltd.

\section{A B S T R A C T}

\section{Background}

The prevalence of nonalcohol-related fatty liver disease (NAFLD) varies between 19\% and 33\% in different populations. NAFLD decreases life expectancy and increases the risks of liver cirrhosis, hepatocellular carcinoma, and requirement for liver transplantation. There is uncertainty surrounding the relative benefits and harms of various lifestyle interventions for people with NAFLD.

\section{Objectives}

To assess the comparative benefits and harms of different lifestyle interventions in the treatment of NAFLD through a network metaanalysis, and to generate rankings of the different lifestyle interventions according to their safety and efficacy.

\section{Search methods}

We searched CENTRAL, MEDLINE, Embase, Science Citation Index Expanded, Conference Proceedings Citation Index-Science, World Health Organization International Clinical Trials Registry Platform, and trials registers until February 2021 to identify randomised clinical trials in people with NAFLD.

\section{Selection criteria}

We included only randomised clinical trials (irrespective of language, blinding, or status) in people with NAFLD, whatever the method of diagnosis, age, and diabetic status of participants, or presence of non-alcoholic steatohepatitis (NASH). We excluded randomised clinical trials in which participants had previously undergone liver transplantation.

\section{Data collection and analysis}

We planned to perform a network meta-analysis with OpenBUGS using Bayesian methods and to calculate the differences in treatments using hazard ratios (HRs), odds ratios (ORs), and rate ratios (RaRs) with 95\% credible intervals (Crls) based on an available-participant 
analysis, according to National Institute of Health and Care Excellence Decision Support Unit guidance. However, the data were too sparse for the clinical outcomes. We therefore performed only direct comparisons (head-to-head comparisons) with OpenBUGS using Bayesian methods.

\section{Main results}

We included a total of 59 randomised clinical trials (3631 participants) in the review. All but two trials were at high risk of bias. A total of 33 different interventions, ranging from advice to supervised exercise and special diets, or a combination of these and no additional intervention were compared in these trials. The reference treatment was no active intervention. Twenty-eight trials (1942 participants) were included in one or more comparisons. The follow-up ranged from 1 month to 24 months. The remaining trials did not report any of the outcomes of interest for this review.

The follow-up period in the trials that reported clinical outcomes was 2 months to 24 months. During this short follow-up period, clinical events related to NAFLD such as mortality, liver cirrhosis, liver decompensation, liver transplantation, hepatocellular carcinoma, and liverrelated mortality were sparse. This is probably because of the very short follow-up periods. It takes a follow-up of 8 years to 28 years to detect differences in mortality between people with NAFLD and the general population. It is therefore unlikely that differences by clinical outcomes will be noted in trials with less than 5 years to 10 years of follow-up.

In one trial, one participant developed an adverse event. There were no adverse events in any of the remaining participants in this trial, or in any of the remaining trials, which seemed to be directly related to the intervention.

\section{Authors' conclusions}

The evidence indicates considerable uncertainty about the effects of the lifestyle interventions compared with no additional intervention (to general public health advice) on any of the clinical outcomes after a short follow-up period of 2 months to 24 months in people with nonalcohol-related fatty liver disease.

Accordingly, high-quality randomised clinical trials with adequate follow-up are needed. We propose registry-based randomised clinical trials or cohort multiple randomised clinical trials (a study design in which multiple interventions are trialed within large longitudinal cohorts of participants to gain efficiencies and align trials more closely to standard clinical practice), comparing aerobic exercise and dietary advice versus standard of care (exercise and dietary advice received as part of national health promotion). The reason for the choice of aerobic exercise and dietary advice is the impact of these interventions on indirect outcomes which may translate to clinical benefit. The outcomes in such trials should be mortality, health-related quality of life, decompensated liver cirrhosis, liver transplantation, and resource use measures including costs of intervention and decreased healthcare use after a minimum follow-up of eight years, to find meaningful differences in the clinically important outcomes.

\section{PLAIN LANGUAGE SUMMARY}

\section{Lifestyle modifications for people with nonalcohol-related fatty liver disease}

\section{What is the aim of this Cochrane Review?}

To find out if any lifestyle modifications decrease the effect of nonalcohol-related fatty liver disease on lifespan, health-related quality of life, chronic liver disease and its complications, and whether they cause any harms.

Nonalcoholic fatty liver disease (NAFLD) is an accumulation of fat in the liver in people who have no history of significant alcohol consumption, use of medicines, diseases such as hepatitis C virus infection, or other conditions such as starvation that can damage the liver. Fatty liver can lead to liver damage resulting in inflammation (nonalcohol-related steatohepatitis (NASH)) or liver scarring (liver cirrhosis). Various medical treatments have been tried for the treatment of NAFLD. However, there is currently no evidence that any of them work. Lifestyle modifications have the potential to decrease the liver damage, but whether they achieve this is currently unclear. The authors of this review collected and analysed all relevant randomised clinical trials with the aim of finding out what is the best treatment.

We found 59 randomised clinical trials (studies where participants are randomly assigned to one of two treatment groups). During analysis of data, the review authors used standard Cochrane methods, which allow comparison of only two treatments at a time. We also planned to use advanced techniques that allow comparison of multiple treatments at the same time, usually referred as 'network (or indirect) metaanalysis'.

\section{Date of literature search}

February 2021.

\section{What we studied in the review?}

This review looked at people of any sex, age (including children), and ethnic origin, with NAFLD. We excluded studies in people who had previously had liver transplantation. The average age of participants, when reported, ranged from 13 years to 65 years. Participants were given different treatments, ranging from advice to supervised exercise and special diets, or a combination of these and no intervention, in addition to the public health advice. We wanted to gather and analyse data on death, quality of life, serious and non-serious adverse events, severe liver damage, complications resulting from severe liver damage, liver cancer, and deaths due to liver damage ('clinical outcomes'). 


\section{What were the main results of the review?}

The 59 studies included a small number of participants (3631 participants). Study data were sparse. Twenty-eight studies with 1942 participants provided data for analyses. The follow-up of the trial participants ranged from 1 month to 24 months. For trials that reported clinical outcomes, follow-up was 2 months to 24 months. Only two small trials did not raise major concerns for bias (deviation from truth because of the way the trials were conducted), and because of this, there is considerable uncertainty about the findings of this review.

The review shows that:

- During a follow-up period of 2 to 24 months, clinically important outcomes related to NAFLD such as deaths were rare and none of the participants developed liver-related complications such as liver cirrhosis (scarring of the liver), liver decompensation (complications because of scarring of the liver), liver transplantation, liver cancer, or deaths due to liver disease. This is probably because the trial participants were followed for too short a time.

- The evidence indicates considerable uncertainty about the effect of the interventions on any of the clinical outcomes.

- Future well-designed randomised clinical trials are needed to find out the best lifestyle modifications for people with NAFLD. Liver-related complications develop over 8 to 28 years. It is therefore unlikely that differences in clinical outcomes will become apparent in trials with less than 5 years to 10 years of follow-up. Sample sizes also need to be much larger. 


\section{SUMMARY OF FINDINGS}

\section{Summary of findings 1 . Lifestyle modifications for nonalcohol-related fatty liver disease}

Patient or population: people with nonalcohol-related fatty liver disease (NAFLD)

Settings: community or primary care

Intervention: various interventions

Comparison: no active intervention

Follow-up period: 2 months to 24 months

Network geometry plots: because of the sparse data, there were no connected networks

\begin{tabular}{|c|c|c|c|c|c|c|}
\hline \multirow[t]{2}{*}{ Interventions } & \multirow{2}{*}{$\begin{array}{l}\text { Relative effect } \\
(95 \% \mathrm{Crl})\end{array}$} & \multicolumn{3}{|c|}{ Anticipated absolute effect* $(95 \% \mathrm{Crl})$} & \multirow{2}{*}{$\begin{array}{l}\text { Quality of evi- } \\
\text { dence }\end{array}$} & \multirow[t]{2}{*}{ Comments } \\
\hline & & $\begin{array}{l}\text { No active in- } \\
\text { tervention }\end{array}$ & $\begin{array}{l}\text { Various inter- } \\
\text { ventions }\end{array}$ & Difference & & \\
\hline \multicolumn{7}{|l|}{$\begin{array}{l}\text { Mortality } \\
\text { Total studies: } 14 \\
\text { Total participants: } 1216 \\
\text { Follow-up period: } \mathbf{2} \text { to } \mathbf{2 4} \text { months }\end{array}$} \\
\hline No active intervention & Reference & & & & & \\
\hline $\begin{array}{l}\text { Aerobic exercise } \\
\text { (2 trials; } 252 \text { participants) }\end{array}$ & Not estimable & 23 per 1000 & Not estimable & Not estimable & $\begin{array}{l}\text { Very low certain- } \\
\text { ty } a, b, c\end{array}$ & $\begin{array}{l}\text { There were no events in } \\
\text { either group. }\end{array}$ \\
\hline $\begin{array}{l}\text { Dietary advice } \\
\text { (1 trial; } 28 \text { participants) }\end{array}$ & Not estimable & 23 per 1000 & Not estimable & Not estimable & $\begin{array}{l}\text { Very low certain- } \\
\text { ty a,b,c }\end{array}$ & $\begin{array}{l}\text { There were no events in } \\
\text { either group. }\end{array}$ \\
\hline $\begin{array}{l}\text { Dietary advice plus exercise advice } \\
\text { (1 trial; } 265 \text { participants) } \\
\text { (another trial } 25 \text { participants had zero } \\
\text { events in both groups) }\end{array}$ & $\begin{array}{l}\text { HR } \mathbf{0 . 6 3} \\
(95 \% \mathrm{Crl} 0.07 \text { to } \\
4.06) \\
\text { Direct esti- } \\
\text { mate }\end{array}$ & 23 per 1000 & $\begin{array}{l}14 \text { per } 1000 \\
\text { (2 to } 92)\end{array}$ & $\begin{array}{l}\mathbf{9} \text { fewer per } \\
\mathbf{1 0 0 0} \\
(21 \text { fewer to } 69 \\
\text { more) }\end{array}$ & $\begin{array}{l}\text { Very low certain- } \\
\text { ty a,c,d }\end{array}$ & \\
\hline $\begin{array}{l}\text { Mediterranean diet } \\
\text { (1 trial; } 98 \text { participants) }\end{array}$ & Not estimable & 23 per 1000 & Not estimable & Not estimable & Low certainty $b, c$ & $\begin{array}{l}\text { There were no events in } \\
\text { either group. }\end{array}$ \\
\hline $\begin{array}{l}\text { Aerobic exercise plus calorie-restricted } \\
\text { diet } \\
\text { (1 trial; } 100 \text { participants) }\end{array}$ & Not estimable & 23 per 1000 & Not estimable & Not estimable & $\begin{array}{l}\text { Very low certain- } \\
\text { ty } a, b, c\end{array}$ & $\begin{array}{l}\text { There were no events in } \\
\text { either group. }\end{array}$ \\
\hline
\end{tabular}




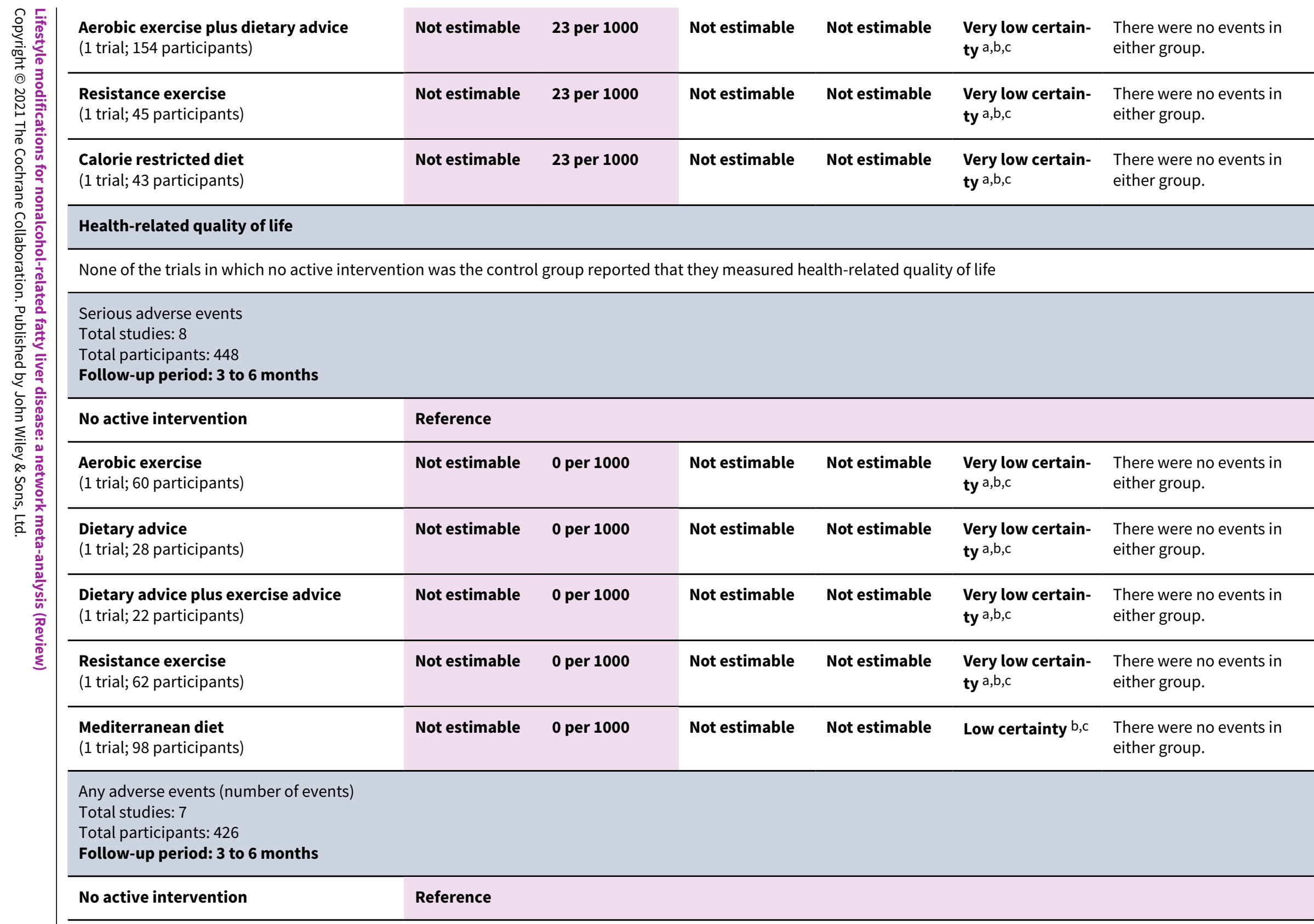




\begin{tabular}{|c|c|c|c|c|c|c|}
\hline $\begin{array}{l}\text { Aerobic exercise } \\
\text { ( } 1 \text { trial; } 60 \text { participants) }\end{array}$ & Not estimable & 0 per 1000 & Not estimable & Not estimable & $\begin{array}{l}\text { Very low certain- } \\
\text { ty } a, b, c\end{array}$ & $\begin{array}{l}\text { There were no events in } \\
\text { either group. }\end{array}$ \\
\hline $\begin{array}{l}\text { Dietary advice } \\
\text { (1 trial; } 28 \text { participants) }\end{array}$ & Not estimable & 0 per 1000 & Not estimable & Not estimable & $\begin{array}{l}\text { Very low certain- } \\
\text { ty } a, b, c\end{array}$ & $\begin{array}{l}\text { There were no events in } \\
\text { either group. }\end{array}$ \\
\hline $\begin{array}{l}\text { Resistance exercise } \\
\text { (1 trial; } 62 \text { participants) }\end{array}$ & Not estimable & 0 per 1000 & Not estimable & Not estimable & $\begin{array}{l}\text { Very low certain- } \\
\text { ty } a, b, c\end{array}$ & $\begin{array}{l}\text { There were no events in } \\
\text { either group. }\end{array}$ \\
\hline $\begin{array}{l}\text { Mediterranean diet } \\
\text { (1 trial; } 98 \text { participants) }\end{array}$ & Not estimable & 0 per 1000 & Not estimable & Not estimable & Low certainty $b, c$ & $\begin{array}{l}\text { There were no events in } \\
\text { either group. }\end{array}$ \\
\hline $\begin{array}{l}\text { Liver transplantation } \\
\text { Total studies: } 7 \\
\text { Total participants: } 411 \\
\text { Follow-up period: } \mathbf{3} \text { to } \mathbf{1 2} \text { months }\end{array}$ & & & & & & \\
\hline No active intervention & Reference & & & & & \\
\hline $\begin{array}{l}\text { Dietary advice } \\
\text { ( } 1 \text { trial; } 28 \text { participants) }\end{array}$ & Not estimable & 0 per 1000 & Not estimable & Not estimable & $\begin{array}{l}\text { Very low certain- } \\
\text { ty } a, b, c\end{array}$ & $\begin{array}{l}\text { There were no events in } \\
\text { either group. }\end{array}$ \\
\hline $\begin{array}{l}\text { Dietary advice plus exercise advice } \\
\text { (1 trial; } 22 \text { participants) }\end{array}$ & Not estimable & 0 per 1000 & Not estimable & Not estimable & $\begin{array}{l}\text { Very low certain- } \\
\text { ty } a, b, c\end{array}$ & $\begin{array}{l}\text { There were no events in } \\
\text { either group. }\end{array}$ \\
\hline $\begin{array}{l}\text { Mediterranean diet } \\
\text { ( } 1 \text { trial; } 98 \text { participants) }\end{array}$ & Not estimable & 0 per 1000 & Not estimable & Not estimable & Low certainty $b, c$ & $\begin{array}{l}\text { There were no events in } \\
\text { either group. }\end{array}$ \\
\hline $\begin{array}{l}\text { Aerobic exercise plus dietary advice } \\
\text { (1 trial; } 154 \text { participants) }\end{array}$ & Not estimable & 0 per 1000 & Not estimable & Not estimable & $\begin{array}{l}\text { Very low certain- } \\
\text { ty } a, b, c\end{array}$ & $\begin{array}{l}\text { There were no events in } \\
\text { either group. }\end{array}$ \\
\hline $\begin{array}{l}\text { Decompensation } \\
\text { Total studies: } 7 \\
\text { Total participants: } 411 \\
\text { Follow-up period: } \mathbf{3} \text { to } \mathbf{1 2} \text { months }\end{array}$ & & & & & & \\
\hline No active intervention & Reference & & & & & \\
\hline $\begin{array}{l}\text { Dietary advice } \\
\text { (1 trial; } 28 \text { participants) }\end{array}$ & Not estimable & 0 per 1000 & Not estimable & Not estimable & $\begin{array}{l}\text { Very low certain- } \\
\text { ty } a, b, c\end{array}$ & $\begin{array}{l}\text { There were no events in } \\
\text { either group. }\end{array}$ \\
\hline $\begin{array}{l}\text { Dietary advice plus exercise advice } \\
\text { (1 trial; } 22 \text { participants) }\end{array}$ & Not estimable & 0 per 1000 & Not estimable & Not estimable & $\begin{array}{l}\text { Very low certain- } \\
\text { ty } a, b, c\end{array}$ & $\begin{array}{l}\text { There were no events in } \\
\text { either group. }\end{array}$ \\
\hline
\end{tabular}




\begin{tabular}{|c|c|c|c|c|c|c|}
\hline $\begin{array}{l}\text { Mediterranean diet } \\
\text { (1 trial; } 98 \text { participants) }\end{array}$ & Not estimable & 0 per 1000 & Not estimable & Not estimable & Low certainty b,c & $\begin{array}{l}\text { There were no events in } \\
\text { either group. }\end{array}$ \\
\hline $\begin{array}{l}\text { Aerobic exercise plus dietary advice } \\
\text { (1 trial; } 154 \text { participants) }\end{array}$ & Not estimable & 0 per 1000 & Not estimable & Not estimable & $\begin{array}{l}\text { Very low certain- } \\
\text { ty } a, b, c\end{array}$ & $\begin{array}{l}\text { There were no events in } \\
\text { either group. }\end{array}$ \\
\hline $\begin{array}{l}\text { Cirrhosis } \\
\text { Total studies: } 7 \\
\text { Total participants: } 411 \\
\text { Follow-up period: } \mathbf{3} \text { to } \mathbf{1 2} \text { months }\end{array}$ & & & & & & \\
\hline No active intervention & Reference & & & & & \\
\hline $\begin{array}{l}\text { Dietary advice } \\
\text { (1 trial; } 28 \text { participants) }\end{array}$ & Not estimable & 0 per 1000 & Not estimable & Not estimable & $\begin{array}{l}\text { Very low certain- } \\
\text { ty } a, b, c\end{array}$ & $\begin{array}{l}\text { There were no events in } \\
\text { either group. }\end{array}$ \\
\hline $\begin{array}{l}\text { Dietary advice plus exercise advice } \\
\text { (1 trial; } 22 \text { participants) }\end{array}$ & Not estimable & 0 per 1000 & Not estimable & Not estimable & $\begin{array}{l}\text { Very low certain- } \\
\text { ty } a, b, c\end{array}$ & $\begin{array}{l}\text { There were no events in } \\
\text { either group. }\end{array}$ \\
\hline $\begin{array}{l}\text { Mediterranean diet } \\
\text { (1 trial; } 98 \text { participants) }\end{array}$ & Not estimable & 0 per 1000 & Not estimable & Not estimable & Low certainty b,c & $\begin{array}{l}\text { There were no events in } \\
\text { either group. }\end{array}$ \\
\hline $\begin{array}{l}\text { Aerobic exercise plus dietary advice } \\
\text { (1 trial; } 154 \text { participants) }\end{array}$ & Not estimable & 0 per 1000 & Not estimable & Not estimable & $\begin{array}{l}\text { Very low certain- } \\
\text { ty } a, b, c\end{array}$ & $\begin{array}{l}\text { There were no events in } \\
\text { either group. }\end{array}$ \\
\hline $\begin{array}{l}\text { Hepatocellular carcinoma } \\
\text { Total studies: } 5 \\
\text { Total participants: } 229 \\
\text { Follow-up period: } \mathbf{3} \text { to } \mathbf{6} \text { months }\end{array}$ & & & & & & \\
\hline No active intervention & Reference & & & & & \\
\hline $\begin{array}{l}\text { Dietary advice plus exercise advice } \\
\text { (1 trial; } 22 \text { participants) }\end{array}$ & Not estimable & 0 per 1000 & Not estimable & Not estimable & $\begin{array}{l}\text { Very low certain- } \\
\text { ty } a, b, c\end{array}$ & $\begin{array}{l}\text { There were no events in } \\
\text { either group. }\end{array}$ \\
\hline $\begin{array}{l}\text { Mediterranean diet } \\
\text { (1 trial; } 98 \text { participants) }\end{array}$ & Not estimable & 0 per 1000 & Not estimable & Not estimable & Low certainty b,c & $\begin{array}{l}\text { There were no events in } \\
\text { either group. }\end{array}$ \\
\hline $\begin{array}{l}\text { Liver-related mortality } \\
\text { Total studies: } 10 \\
\text { Total participants: } 831 \\
\text { Follow-up period: } \mathbf{3} \text { to } \mathbf{1 2} \text { months }\end{array}$ & & & & & & \\
\hline
\end{tabular}




\begin{tabular}{|c|c|c|c|c|c|c|c|}
\hline \multirow{2}{*}{\multicolumn{2}{|c|}{ 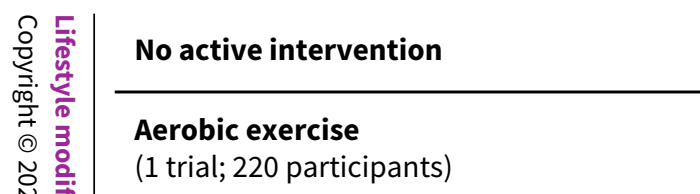 }} & \multicolumn{6}{|l|}{ Reference } \\
\hline & & Not estimable & 0 per 1000 & Not estimable & Not estimable & $\begin{array}{l}\text { Very low certain- } \\
\text { ty } a, b, c\end{array}$ & $\begin{array}{l}\text { There were no events in } \\
\text { either group. }\end{array}$ \\
\hline 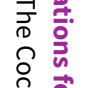 & $\begin{array}{l}\text { Dietary advice } \\
\text { (1 trial; } 28 \text { participants) }\end{array}$ & Not estimable & 0 per 1000 & Not estimable & Not estimable & $\begin{array}{l}\text { Very low certain- } \\
\text { ty } a, b, c\end{array}$ & $\begin{array}{l}\text { There were no events in } \\
\text { either group. }\end{array}$ \\
\hline $\begin{array}{l}\overrightarrow{0} \\
\stackrel{0}{0} \\
\stackrel{0}{0}\end{array}$ & $\begin{array}{l}\text { Dietary advice plus exercise advice } \\
\text { ( } 2 \text { trials; } 287 \text { participants) }\end{array}$ & Not estimable & 0 per 1000 & Not estimable & Not estimable & $\begin{array}{l}\text { Very low certain- } \\
\text { ty } a, b, c\end{array}$ & $\begin{array}{l}\text { There were no events in } \\
\text { either group. }\end{array}$ \\
\hline 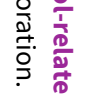 & $\begin{array}{l}\text { Mediterranean diet } \\
\text { (1 trial; } 98 \text { participants) }\end{array}$ & Not estimable & 0 per 1000 & Not estimable & Not estimable & Low certainty $b, c$ & $\begin{array}{l}\text { There were no events in } \\
\text { either group. }\end{array}$ \\
\hline 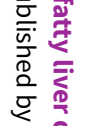 & $\begin{array}{l}\text { Aerobic exercise plus calorie-restricted } \\
\text { diet } \\
\text { (1 trial; } 100 \text { participants) }\end{array}$ & Not estimable & 0 per 1000 & Not estimable & Not estimable & $\begin{array}{l}\text { Very low certain- } \\
\text { ty } a, b, c\end{array}$ & $\begin{array}{l}\text { There were no events in } \\
\text { either group. }\end{array}$ \\
\hline 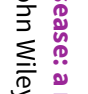 & $\begin{array}{l}\text { Aerobic exercise plus dietary advice } \\
\text { (1 trial; } 154 \text { participants) }\end{array}$ & Not estimable & 0 per 1000 & Not estimable & Not estimable & $\begin{array}{l}\text { Very low certain- } \\
\text { ty } a, b, c\end{array}$ & $\begin{array}{l}\text { There were no events in } \\
\text { either group. }\end{array}$ \\
\hline 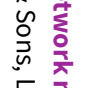 & \multicolumn{7}{|c|}{$\begin{array}{l}{ }^{\star} \text { Ranking was not provided because of the considerable uncertainty in the ranking } \\
\text { Crl: Credible interval; HR: Hazard ratio }\end{array}$} \\
\hline 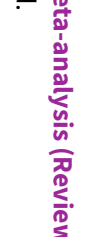 & \multicolumn{7}{|c|}{$\begin{array}{l}\text { GRADE Working Group grades of evidence } \\
\text { High certainty: we are very confident that the true effect lies close to that of the estimate of the effect. } \\
\text { Moderate certainty: we are moderately confident in the effect estimate; the true effect is likely to be close to the estimate of the effect, but there is a possibility that it is } \\
\text { substantially different. } \\
\text { Low certainty: our confidence in the effect estimate is limited; the true effect may be substantially different from the estimate of the effect. } \\
\text { Very low certainty: we have very little confidence in the effect estimate; the true effect is likely to be substantially different from the estimate of effect. }\end{array}$} \\
\hline
\end{tabular}

aDowngraded by one level for risk of bias because the trial(s) included in the analysis was/were at high risk of bias.

bDowngraded by one level as there were no events in either group.

cDowngraded by one level for imprecision because the sample size was small.

dDowngraded by one level for imprecision because the credible intervals were wide (included clinical benefit and harms). 


\section{B A C K G R O U N D}

\section{Description of the condition}

Fatty liver disease is steatosis (accumulation of fat, usually triglycerides) in the parenchymal cells of the liver (NCBI 2021). Nonalcohol-related fatty liver disease (also called non-alcoholic fatty liver disease (NAFLD)) is liver steatosis in the absence of significant alcohol consumption, use of medications such as methotrexate, tamoxifen, or steroids; or other disorders that result in fat accumulation, such as hepatitis $C$ virus infection, Wilson's disease, starvation, and lecithin cholesterol acyltransferase (LCAT) deficiency (Angulo 2002; Chalasani 2012). Fatty liver disease includes a spectrum of disorders ranging from simple steatosis or nonalcoholic fatty liver (NAFL) (fat accumulation without evidence of injury to the parenchymal cells of the liver), nonalcoholic steatohepatitis (NASH) (fat accumulation with injury to the liver's parenchymal cells but without cirrhosis), to NASH cirrhosis (advanced liver fibrosis with current or previous NAFL or NASH (Chalasani 2012; Rinella 2015)). However, it must be noted that the existing non-invasive tests to distinguish NAFLD from alcoholrelated liver disease (ALD) are only about $75 \%$ to $90 \%$ accurate and some people with ALD may be misclassified as NAFLD (Cerovic 2013; Wang 2016a).

The prevalence of NAFLD varies between $19 \%$ and $33 \%$ in different adult populations, depending upon ethnicity, region of origin (also among people of similar ethnicity), being overweight or obese, and having other disorders such as diabetes mellitus or hypertension (Bedogni 2005; Park 2006; Dassanayake 2009; Koehler 2012; Lazo 2013; Fleischman 2014; Li 2014; Shen 2014; Nishioji 2015). NAFLD can also occur in children and adolescents, although the prevalence of NAFLD in children from general populations is around $8 \%$ (lower than in adults), while that in children with obesity is $34 \%$ (equivalent to that in adult populations; (Anderson 2015)). The major risk factors associated with increased prevalence of NAFLD are obesity, being male, increasing age, ethnicity (e.g. MexicanAmericans have higher prevalence of fatty liver than other ethnic groups), genetic susceptibility (e.g. genetic variation in patatinlike phospholipase domain containing 3 gene), hypertension, hypercholesterolaemia, diabetes mellitus, lower socioeconomic status, lower-level educational attainment, poor sleep pattern, and lower physical activity (Bedogni 2005; Park 2006; Dassanayake 2009; Sookoian 2011; Koehler 2012; Lazo 2013; Fleischman 2014; Shen 2014; Bernsmeier 2015; Lonardo 2015).

The mean age of people at diagnosis of NAFLD varies between 40 years and 60 years (Bedogni 2005; Dassanayake 2009; Shen 2014). In studies with long-term follow-up, the mean age of people at diagnosis of NAFLD ranged between 45 years and 50 years (Adams 2005; Bedogni 2007; Soderberg 2010; Onnerhag 2014). After a mean follow-up period of 8 to 28 years, the presence of NAFLD increased overall long-term mortality compared to the general population without NAFLD (Adams 2005; Bedogni 2007; Ong 2008; Soderberg 2010; Onnerhag 2014).

People with NAFLD are at risk of dying before reaching the mean life expectancy at birth (Adams 2005; Bedogni 2007; Ong 2008; Soderberg 2010; Onnerhag 2014). It is widely believed that people with simple steatosis rarely progress to advanced liver disease, but people with NASH may develop cirrhosis (Chalasani 2012). It has been reported that in people with NAFLD, liver fibrosis was the only histological feature associated with increased mortality and requirement for liver transplantation (Angulo 2015; Ekstedt 2015). In a study that followed people with simple steatosis and NASH for a mean of 28 years, similar rates of mortality were observed between participants with simple steatosis and those with NASH, but higher mortality rates were observed in people with severe fibrosis, regardless of whether they had bland steatosis (steatosis without inflammation) or NASH (Soderberg 2010). It is noteworthy that NAFLD is associated with metabolic syndrome, that is, the presence of three of the following factors: hypertension, raised triglycerides, lowered high-density lipoprotein cholesterol, raised fasting glucose, and central obesity (Alberti 2009; Ballestri 2016). Increased mortality in people with NAFLD may therefore be related to metabolic syndrome, rather than to NAFLD alone. Furthermore, alcohol-related liver disease (ALD) has a worse prognosis that NAFLD (Dam-Larsen 2005); the difficulty in distinguishing NAFLD from ALD may also contribute to the higher mortality observed in NAFLD.

Nonalcohol-related fatty liver disease is currently one of the most common causes of liver transplantation. Since 2008, NAFLD has been either the second or third most common reason for liver transplantation each year, and the number of people who have undergone liver transplantation for NAFLD has been similar to that of alcohol-related liver disease since 2008 (Cholankeril 2017). The risk of hepatocellular carcinoma (HCC), the most common type of primary liver cancer in adults, is higher in people with NASH cirrhosis compared to people with NAFLD without cirrhosis and the general population: approximately $2 \%$ to $13 \%$ of people with NASH cirrhosis develop HCC in three to seven years (White 2012). However, HCC can occur in people with NAFLD without them having cirrhosis (Piscaglia 2016).

Fat accumulates within the liver cells when there is an imbalance between the mechanisms that reduce fat in cells (such as oxidation of fatty acids or secretion of lipoproteins) and mechanisms that increase fat in cells, such as increased uptake of fat and increased production of fat. The accumulation of fat leading to NAFLD is believed to be mediated by insulin resistance, because insulin resistance increases the breakdown of peripheral adipose tissue which results in increased influx of free fatty acids (FFAs), promotes the synthesis of new triglycerides within the liver, and decreases the oxidation of FFAs (Abdelmalek 2007; Buzzetti 2016). The accumulation of fat in the liver causes injury due to pro-inflammatory cytokines (Riley 2007). However, the mechanism by which only a proportion of people develop advanced liver fibrosis or primary liver cancer (hepatocellular cancer or hepatocellular carcinoma or HCC) is unclear (Abdelmalek 2007). A 'multiple parallel hits' model, involving nutrition, gut bacteria, and accumulation of fat leading to liver inflammation, has been proposed to explain the development and progression of NAFLD (Tilg 2010; Buzzetti 2016).

Ultrasound is a widely-used method for screening the general population for NAFLD, but it is operator-dependent (Hernaez 2011), and may miss 15 people with fatty liver disease out of every 100 people screened (Hernaez 2011). It may also yield false-positive results in seven out of 100 people without fatty liver disease (Hernaez 2011). While liver biopsy can be considered the definitive investigation to confirm the diagnosis, it is invasive and not suitable for screening the general population. 


\section{Description of the intervention}

Various interventions have been tried in the treatment of people with NAFLD. This review examines lifestyle modifications such as dietary changes or increased physical activity (Abenavoli 2015; Shojaee-Moradie 2016; Zhang 2016; Houghton 2017) (the focus of the present systematic review), or both. Other interventions not included in this review include nutritional supplementation (probiotics, prebiotics, synbiotics, vitamin supplementation, polyunsaturated fatty acid supplementation; (Nabavi 2014; Sharifi 2014; Li 2015; Nogueira 2016; Mofidi 2017)); pharmacological interventions (Lombardi 2017); and weight reduction surgery (bariatric surgery) in obese people with NAFLD (Adorini 2012; Anstee 2012; Chalasani 2012; Paschos 2012; Abenavoli 2013).

\section{How the intervention might work}

Lifestyle modifications, such as dietary changes and increased physical activity, are aimed at decreasing weight and serum lipid profile (Abenavoli 2015; Shojaee-Moradie 2016; Zhang 2016; Houghton 2017). This may lead to resolution or decrease the progression of fatty liver disease (Chalasani 2012). Dietary modifications may also decrease insulin resistance and increase antioxidants, leading to improvement in NAFLD, and improve the vitamins and other micronutrients available naturally from the food (Conlon 2013). Poor sleep pattern is associated with an increased risk of NAFLD due to its correlation with insulin resistance (Bernsmeier 2015). Lifestyle interventions aimed at improving sleep patterns may therefore improve NAFLD by decreasing insulin resistance.

Nutritional supplementation (not included in this review) may work in different ways: vitamin $\mathrm{E}$ decreases oxidative damage to liver cells (Chalasani 2012); the effect of vitamin D supplementation may be mediated through its ability to decrease inflammatory markers and lipid peroxidation (Sharifi 2014), that of probiotics may be mediated through its ability to decrease inflammatory markers and alter lipid profile (Al-Muzafar 2017), and that of polyunsaturated fatty acids may be mediated through ability to alter lipid profile (Chalasani 2012). This may lead to resolution or decrease of progression of fatty liver disease. There is currently no effective pharmacological intervention in people with NAFLD or NASH, but there is significant uncertainty about the effect of pharmacological interventions on NAFLD (Lombardi 2017). The reasons for investigating these pharmacological interventions (not included in this review) have been based on their potential to decrease weight, insulin resistance, and/or oxidative damage to liver cells, to alter lipid profile, or their anti-inflammatory and anti-fibrotic properties (Adorini 2012; Anstee 2012; Chalasani 2012; Thoma 2012; Abenavoli 2013). Surgeries resulting in weight loss (not included in this review) may improve fatty liver by reducing weight (Chalasani 2012).

\section{Why it is important to do this review}

There is currently no effective pharmacological treatment for NAFLD with or without NASH (Lombardi 2017). Research on treatments to decrease NAFLD and NASH have been identified as top research priorities by patients, carers, and healthcare professionals involved in the treatment of liver diseases in the UK (Gurusamy 2019). Lifestyle modifications have the potential for resolution or to decrease the progression of fatty liver disease. Network meta-analysis enables direct and indirect evidence to be combined, and different interventions to be ranked by different outcomes (Salanti 2011; Salanti 2012). There has been no previous Cochrane Review on this topic. It is therefore important to assess the benefits and harms of lifestyle modifications in the treatment of people with NAFLD. With this systematic review and network meta-analysis, we aim to provide the best level of evidence for the benefits and harms of lifestyle interventions in people with NAFLD. We also present results from direct comparisons whenever possible, as well as performing the network meta-analysis.

\section{O B JECTIVES}

To assess the comparative benefits and harms of different lifestyle interventions in the treatment of nonalcohol-related fatty liver disease through a network meta-analysis and to generate rankings of the different lifestyle interventions according to their safety and efficacy.

\section{METHODS}

\section{Criteria for considering studies for this review}

\section{Types of studies}

We considered only randomised clinical trials (including cross-over and cluster-randomised clinical trials, but not quasi-randomised studies) for this network meta-analysis, irrespective of language, publication status, or date of publication. We excluded studies of other designs because of the risk of bias in such studies. Inclusion of indirect observational evidence could weaken our network metaanalysis, but could also be viewed as a strength for assessing rare adverse events. It is well-established that exclusion of nonrandomised studies increases the focus on potential benefits and reduces the focus on the risks of serious adverse events and those of any adverse events. In the protocol, we stated that we would register and perform a new systematic review and meta-analysis of non-randomised studies for adverse events if there was uncertainty in the balance of benefits and harms of effective treatment(s). We did not register a new systematic review because of the findings of this review, i.e. there is uncertainty about whether any of the interventions improve clinical outcomes.

\section{Types of participants}

We include randomised clinical trials with participants who have nonalcohol-related fatty liver disease (NAFLD), irrespective of the method of diagnosis, age or diabetic status of participants, or the presence of non-alcoholic steatohepatitis (NASH). We exclude randomised clinical trials in which participants had previously undergone liver transplantation.

\section{Types of interventions}

We include any of the following interventions for comparison with one another, either alone or in combination.

- Supervised physical activity (for example, exercise classes)

- General physical activity advice

- Rationed diet (for example, daily or weekly rations of different foods, calorie-restricted diet)

- Special diets (for example, Mediterranean diet, Atkin's diet, highfibre diet, or diet with high fruit and vegetable content)

- General dietary advice (for example, information on the fat or carbohydrate content of different foods) 
- Lifestyle modifications that promote sleep (for example, nicotine and caffeine restriction)

- No active intervention (including sham or placebo interventions)

We considered no active intervention as the reference group. We considered each of the above subcategories as a 'treatment node'. We considered variations in the subcategories, for example, different frequencies of exercise or dietary advice, as the same treatment node. We treated each different combination of the categories as different treatment nodes. All the above interventions were considered the 'decision set', i.e. all the above interventions were of direct interest.

We included trials in which the above interventions were combined with other interventions aimed at decreasing NAFLD (but considered these as potential effect modifiers), provided that these co-interventions were administered equally in both arms. We included nutritional supplements in the form of tablets, powder, or solution in a different review (Komolafe 2021).

We evaluated the plausibility of the network meta-analysis transitivity assumption by looking at the inclusion and exclusion criteria in the studies. The transitivity assumption means that participants included in the different trials with different treatments (in this case, for NAFLD) can be considered to be a part of a multi-arm randomised clinical trial and could potentially have been randomised to any of the interventions (Salanti 2012). In other words, any participant that meets the inclusion criteria is, in principle, equally likely to be randomised to any of the above eligible interventions. The transitivity assumption also means that potential effect modifiers are not systematically different across comparisons. This necessitates that information on potential effect modifiers such as diabetic status and co-interventions (not included in the 'decision set'; those included in the 'decision set' were considered as combination of treatments) are similar across trials of different comparisons. Because of the inclusion criteria, the nature of interventions considered in this review, and lack of systematic methodological differences across treatment interventions, we had no concerns about transitivity assumption for these effect modifiers.

\section{Types of outcome measures}

\section{Primary outcomes}

- All-cause mortality at maximum follow-up (time to death)

- Health-related quality of life, as defined in the included trials, using a validated scale such as the EQ-5D or 36-Item Short Form Health Survey (SF-36; (EuroQol 2018; RAND 2021)) at maximum follow-up

- Serious adverse events (during or within six months after cessation of intervention). We defined a serious adverse event as any event that would increase mortality; is life-threatening; requires hospitalisation; results in persistent or significant disability; is a congenital anomaly/birth defect; or any important medical event that might jeopardise the person or require intervention to prevent it (ICH-GCP 1997). However, none of the trial authors defined serious adverse events. We therefore used the list provided by trial authors for serious adverse events (as indicated in the protocol).

* Proportion of trial participants with one or more serious adverse events
* Number of serious adverse events per participant

\section{Secondary outcomes}

- Any adverse events, during or within six months after cessation of intervention. We defined an adverse event as any untoward medical occurrence not necessarily having a causal relationship with the intervention but resulting in a dose reduction or discontinuation of intervention, any time after the start of intervention; (ICH-GCP 1997). However, none of the trial authors defined 'adverse event'. We therefore used the list provided by trial authors for adverse events (as indicated in the protocol).

* Proportion of trial participants with any adverse events

* Number of any adverse events per participant

- Liver transplantation (time to liver transplantation at maximum follow-up)

- Decompensation (time to decompensation at maximum followup)

- Cirrhosis (time to cirrhosis at maximum follow-up)

- Liver-related mortality (time to liver-related death at maximum follow-up)

\section{Exploratory outcomes}

- Resolution of fatty liver disease (time to resolution of fatty liver disease at maximum follow-up)

- Fibrosis score at maximum follow-up

- NAFLD activity score (Brunt 2011) at maximum follow-up

- MELD score (Kamath 2001) at maximum follow-up

We had chosen outcomes based on:

- their importance to patients in a survey related to research priorities for people with liver diseases (Gurusamy 2019);

- feedback from the patient and public representative of this project;

- an online survey about the outcomes promoted through the Cochrane Consumer Network;

- the coreNASH project (Clearfield 2021) (which resulted in the addition of liver-related mortality and MELD score).

\section{Search methods for identification of studies}

\section{Electronic searches}

We searched the Cochrane Central Register of Controlled Trials (CENTRAL) in the Cochrane Library, MEDLINE Ovid, Embase Ovid, Science Citation Index Expanded (Web of Science), and Conference Proceedings Citation Index - Science (Web of Science) from inception to February 2021 for randomised clinical trials comparing two or more of the above interventions, without applying any language restrictions (Royle 2003). We searched for all possible comparisons formed by the interventions of interest. To identify further ongoing or completed trials, we also searched clinicaltrials.gov, and the World Health Organization International Clinical Trials Registry Platform (apps.who.int/ trialsearch/), which searches various trial registers, including ISRCTN and ClinicalTrials.gov. We also searched the European Medical Agency (EMA) (www.ema.europa.eu/ema/) and USA Food and Drug Administration (FDA) (www.fda.gov) registries for randomised clinical trials. We provided the search strategies along with the date of search in Appendix 1. 


\section{Searching other resources}

We searched the references of the identified trials to identify additional trials for inclusion. We also contacted the study authors for any other potential studies of which they were aware.

\section{Data collection and analysis}

\section{Selection of studies}

Two review authors ( $K G$ and $E B, D R, L B$ or $A L$ ) independently identified trials for inclusion by screening the titles and abstracts of articles identified by the literature search, and sought full-text articles of any references identified by at least one review author for potential inclusion. We selected trials that met the inclusion criteria for this review based on the full-text articles. We listed the references that we excluded and the reasons for their exclusion in the Characteristics of excluded studies table. We also listed any ongoing trials identified primarily through the search of the clinical trial registers for further follow-up. We resolved any discrepancies through discussion. We illustrated the study selection process in a PRISMA diagram (see Figure 1).

\section{Data extraction and management}

Two review authors (EB, DR, or $\mathrm{AL}$ ) independently extracted the data below in a prepiloted Microsoft Excel-based data extraction form, after translation of non-English articles. If we found multiple records of the same trial, we collated all the records at the time of data extraction, and obtained the maximum information for the study from the multiple reports.

- Outcome data (for each outcome and for each intervention group whenever applicable):

* number of participants randomised;

* number of participants included in the analysis;

* number of participants with events for binary outcomes, mean and standard deviation for continuous outcomes, number of events and the mean follow-up period for count outcomes, and number of participants with events and the mean follow-up period for time-to-event outcomes;

* natural logarithm of hazard ratio and its standard error if this was reported, rather than the number of participants with events and the mean follow-up period for time-to-event outcomes;

* definition of outcomes or scale used if appropriate.

- Data on potential effect modifiers:

* participant characteristics such as age, sex, diabetic status, method of diagnosis, presence of NASH;

* details of the intervention and control (including dose, frequency, and duration);

* length of follow-up;

* information related to risk of bias assessment (see below).

- Other data:

* year and language of publication;

* country in which the participants were recruited;

* year(s) in which the trial was conducted;

* inclusion and exclusion criteria.

* funding and conflicts of interest
We collected data at maximum follow-up but also in the short term (up to three months), and the medium term (from three months to five years) if these were available.

We attempted to contact the trial authors in the case of unclear or missing information. If there was any doubt as to whether trials shared the same participants, completely or partially (by identifying common authors and centres), we planned to contact the trial authors to clarify whether the trial report was duplicated. We resolved any differences in opinion through discussion.

\section{Assessment of risk of bias in included studies}

We followed the guidance in the Cochrane Handbook for Systematic Reviews of Interventions to assess the risks of bias in included trials (Higgins 2011). Specifically, we assessed sources of bias as defined below (Schulz 1995; Moher 1998; Kjaergard 2001; Wood 2008; Savović 2012a; Savović 2012b; Savović 2018).

\section{Allocation sequence generation}

- Low risk of bias: sequence generation was achieved using computer random-number generation or a random-number table. Drawing lots, tossing a coin, shuffling cards, and throwing dice were adequate if performed by an independent person not otherwise involved in the trial.

- Unclear risk of bias: the method of sequence generation was not specified.

- High risk of bias: the sequence generation method was not random.

\section{Allocation concealment}

- Low risk of bias: the allocation sequence was described as unknown to the investigators. Hence, the participants' allocations could not have been foreseen in advance of or during enrolment. Allocation was controlled by a central and independent randomisation unit, an onsite locked computer, identical-looking numbered sealed opaque envelopes, drug bottles or containers prepared by an independent pharmacist or an independent investigator.

- Unclear risk of bias: it was unclear if the allocation was hidden or if the block size was relatively small and fixed so that intervention allocations may have been foreseen in advance of or during enrolment.

- High risk of bias: the allocation sequence was likely to be known to the investigators who assigned the participants.

\section{Blinding of participants and personnel}

- Low risk of bias: blinding of participants and key study personnel ensured, and it was unlikely that the blinding could have been broken; or rarely no blinding or incomplete blinding, but the review authors judged that the outcome was not likely to be influenced by lack of blinding.

- Unclear risk of bias: any of the following: insufficient information to permit judgement of low risk or high risk; or the trial did not address this outcome.

- High risk of bias: any of the following: no blinding or incomplete blinding, and the outcome was likely to be influenced by lack of blinding; or blinding of key study participants and personnel attempted, but likely that the blinding could have been broken, and the outcome was likely to be influenced by lack of blinding. 


\section{Blinded outcome assessment}

- Low risk of bias: blinding of outcome assessment ensured, and unlikely that the blinding could have been broken; or rarely no blinding of outcome assessment, but the review authors judged that the outcome measurement was not likely to be influenced by lack of blinding.

- Unclear risk of bias: any of the following: insufficient information to permit judgement of low risk or high risk; or the trial did not address this outcome.

- High risk of bias: any of the following: no blinding of outcome assessment, and the outcome measurement was likely to be influenced by lack of blinding; or blinding of outcome assessment, but likely that the blinding could have been broken, and the outcome measurement was likely to be influenced by lack of blinding.

\section{Incomplete outcome data}

- Low risk of bias: missing data were unlikely to make treatment effects depart from plausible values. The study used sufficient methods, such as multiple imputation, to handle missing data.

- Unclear risk of bias: there was insufficient information to assess whether missing data in combination with the method used to handle missing data were likely to induce bias in the results.

- High risk of bias: the results were likely to be biased due to missing data.

\section{Selective outcome reporting}

- Low risk of bias: the trial reported the following predefined outcomes: at least one of the outcomes related to the main reason for treatment of people with NAFLD, namely, all-cause mortality or resolution of NAFLD, along with adverse events. If the original trial protocol was available, the outcomes should have been those called for in that protocol. If we obtained the trial protocol from a trial registry (e.g. ClinicalTrials.gov), the outcomes sought should have been those enumerated in the original protocol if the trial protocol was registered before or at the time that the trial was begun. If the trial protocol was registered after the trial was begun, we did not consider those outcomes to be reliable.

- Unclear risk of bias: not all predefined or clinically-relevant and reasonably-expected outcomes were reported fully, or it was unclear whether data on these outcomes were recorded or not.

- High risk of bias: one or more predefined or clinically-relevant and reasonably-expected outcomes were not reported, despite the fact that data on these outcomes should have been available and even recorded.

\section{Other bias}

- Low risk of bias: the trial appeared to be free of other components that could put it at risk of bias (e.g. inappropriate control or dose or administration of control, early stopping, baseline differences indicating problems with randomisation, baseline differences in clusters, bias due to loss of clusters, and bias due to individuals being recruited after the randomisation of clusters).

- Uncertain risk of bias: the trial may or may not have been free of other components that could put it at risk of bias.

- High risk of bias: there were other factors in the trial that could put it at risk of bias (e.g. baseline differences, early stopping, entire clusters were lost, individuals in cluster RCTs were recruited after the randomisation of the clusters).

We considered a trial to be at low risk of bias if we assessed the trial to be at low risk of bias across all listed risk of bias domains. Otherwise, we considered the trial to be at high risk of bias. At the outcome level, we classified an outcome to be at low risk of bias if the allocation sequence generation, allocation concealment, blinding of participants, healthcare professionals, and outcome assessors, incomplete outcome data, and selective outcome reporting (at the outcome level) were at low risk of bias for objective and subjective outcomes (Savović 2018).

\section{Measures of treatment effect}

\section{Relative treatment effects}

For dichotomous variables (e.g. proportion of participants with serious adverse events or any adverse events), we calculated the odds ratio (OR) with a 95\% credible interval (Crl) (or Bayesian confidence interval; (Severini 1993)). For continuous variables (e.g. health-related quality of life reported on the same scale), we calculated the mean difference (MD) with a 95\% Crl. We planned to use standardised mean difference (SMD) values with $95 \% \mathrm{Crl}$ for health-related quality of life if included trials used different scales. If we calculated the SMD, we planned to convert it to a common scale, for example, EQ-5D or SF-36 (using the standard deviation of the common scale) for the purpose of interpretation. For count outcomes (e.g. number of serious adverse events or number of any adverse events), we calculated the rate ratio (RaR) with a 95\% Crl. This assumes that the events are independent of each other, i.e. if a person has had an event, they are not at an increased risk of further outcomes, which is the assumption in Poisson likelihood. For timeto-event data (e.g. all-cause mortality at maximum follow-up), we calculated hazard ratios (HRs) with 95\% Crls.

\section{Relative ranking}

We estimated the ranking probabilities for all interventions of being at each possible rank for each intervention for each outcome when NMA (network meta-analysis) was performed. We obtained the surface under the cumulative ranking curve (SUCRA) (cumulative probability), rankogram, and relative ranking table with median and $\mathrm{Crl}$ for the ranking probabilities for each outcome when NMA was performed (Salanti 2011; Chaimani 2013).

\section{Unit of analysis issues}

The unit of analysis was the participant undergoing treatment for NAFLD according to the intervention group to which the participant was randomly assigned.

\section{Cluster-randomised clinical trials}

If we identified any cluster-randomised clinical trials, we planned to include them, provided that the effect estimate adjusted for cluster correlation was available or if there was sufficient information available to calculate the design effect (which would allow us to take clustering into account).

\section{Cross-over randomised clinical trials}

If we identified any cross-over randomised clinical trials, we planned to include only the outcomes after the period of the first intervention, because the included treatments could have residual effects. 


\section{Trials with multiple intervention groups}

We collected data for all trial intervention groups that met the inclusion criteria. The codes that we used for analysis accounted for the correlation between the effect sizes from studies with more than two groups.

\section{Dealing with missing data}

We performed an intention-to-treat analysis whenever possible (Newell 1992); otherwise, we used the data available to us. When intention-to-treat analysis was not used and the data were not missing at random (for example, treatment was withdrawn due to adverse events or duration of treatment was shortened because of lack of response and such participants were excluded from analysis), this could lead to biased results; we therefore conducted best-worst case scenario analysis (assuming a good outcome in the intervention group and a bad outcome in the control group) and worst-best case scenario analysis (assuming a bad outcome in the intervention group and good outcome in the control group) as sensitivity analyses whenever possible, for binary and time-toevent outcomes where binomial likelihood was used.

For continuous outcomes, we imputed the standard deviation from $\mathrm{P}$ values, according to guidance in the Cochrane Handbook for Systematic Reviews of Interventions (Higgins 2011). If the data were likely to be normally distributed, we used the median for metaanalysis when the mean was not available; otherwise, we planned simply to provide a median and interquartile range of the difference in medians. If it was not possible to calculate the standard deviation from the $P$ value or the confidence intervals, we planned to impute the standard deviation using the largest standard deviation in other trials for that outcome. This form of imputation can decrease the weight of the study for calculation of mean differences and may bias the effect estimate to no effect for calculation of standardised mean differences (Higgins 2011).

\section{Assessment of heterogeneity}

We assessed clinical and methodological heterogeneity by carefully examining the characteristics and design of included trials. We also planned to assess the presence of clinical heterogeneity by comparing effect estimates (please see Subgroup analysis and investigation of heterogeneity) in trial reports based on the presence of diabetes and NASH, and based on the co-interventions (for example, both groups received nutritional supplements). Different study designs and risks of bias can contribute to methodological heterogeneity.

We assessed statistical heterogeneity by comparing the results of the fixed-effect model meta-analysis and the random-effects model meta-analysis, lack of overlap of $95 \%$ credible intervals of between-study variance $\left(\operatorname{tau}^{2}\right)$ with 0 (after rounding to two decimals), and by calculating the NMA-specific $1^{2}$ statistic (Jackson 2014) using Stata/SE 15.1. When possible, we explored substantial clinical, methodological, or statistical heterogeneity and addressed the heterogeneity in subgroup analysis (see Subgroup analysis and investigation of heterogeneity).

\section{Assessment of transitivity across treatment comparisons}

We assessed the transitivity assumption by comparing the distribution of the potential effect modifiers (clinical: presence of diabetes and $\mathrm{NASH}$, and methodological: risk of bias, year of randomisation, duration of follow-up) across the different pairwise comparisons.

\section{Assessment of reporting biases}

For the network meta-analysis, we planned to perform a comparison-adjusted funnel plot. However, it is necessary to rank the studies in a meaningful way to interpret it, as asymmetry may be due to small sample sizes in newer studies (comparing newer treatments with older treatments), or higher risk of bias in older studies (Chaimani 2012). As there was no specific change in the risk of bias in the studies, sample size, or the control group used over time (the first trial report for this review was published only in 2008), we judged the reporting bias by the completeness of the search (Chaimani 2012). We also considered lack of reporting of outcomes as a form of reporting bias, by looking at the proportion of trials that reported the outcomes.

\section{Data synthesis}

We conducted network meta-analyses to compare multiple interventions simultaneously for each of the primary and secondary outcomes. When two or more interventions were combined, we considered this combination as a separate intervention ('node'). Network meta-analysis combines direct evidence within trials and indirect evidence across trials (Mills 2012). We obtained a network plot to ensure that the trials were connected by interventions using Stata/SE 15.1 (Chaimani 2013). We excluded any trials that were not connected to the network from the network meta-analysis, and we reported only the direct pairwise meta-analysis for such comparisons. We summarised the population and methodological characteristics of the trials included in the network meta-analysis in a table based on pairwise comparisons. We conducted a Bayesian network meta-analysis using the Markov chain Monte Carlo method in OpenBUGS 3.2.3, according to guidance from the National Institute for Health and Care Excellence (NICE) Decision Support Unit (DSU) documents (Dias 2016). We modelled the treatment contrast (i.e. log odds ratio for binary outcomes, mean difference or standardised mean difference for continuous outcomes, log rate ratio for count outcomes, and log hazard ratio for time-to-event outcomes) for any two interventions ('functional parameters') as a function of comparisons between each individual intervention and the reference group ('basic parameters') using appropriate likelihood functions and links (Lu 2006). We used binomial likelihood and logit link for binary outcomes, Poisson likelihood and log link for count outcomes, binomial likelihood and complementary log-log link (a semiparametric model which excludes censored individuals from the denominator of 'at risk' individuals at the point when they are censored) for time-to-event outcomes, and normal likelihood and identity link for continuous outcomes. We used 'no active intervention' as the reference group across the networks, as there is no established 'standard of care' for lifestyle modifications in NAFLD. We performed a fixed-effect model and a random-effects model for the network meta-analysis. We reported both models for comparison with the reference group in a forest plot when the results were different between the models. For each pairwise comparison in a table, we reported the fixed-effect model if the two models reported similar results; otherwise, we reported the more conservative model, i.e. usually the random-effects model.

We used a hierarchical Bayesian model using three different sets of initial values to start the simulation-based parameter estimation to 
assist with the assessment of convergence, using codes provided by NICE DSU (Dias 2016). We used a normal distribution with large variance $(10,000)$ for treatment effect priors (vague or flat priors) centred at no effect. For the random-effects model, we used a prior distributed uniformly (limits: 0 to 5) for the between-trial standard deviation parameter and assumed that this variability would be the same across treatment comparisons (Dias 2016). We used a 'burn-in' of 30,000 simulations, checked for convergence (of effect estimates and between-study heterogeneity) visually (i.e. whether the values in different chains mixed very well by visualisation), and ran the models for another 10,000 simulations to obtain effect estimates. If we did not obtain convergence, we increased the number of simulations for the 'burn-in' and used the 'thin' and 'over relax' functions to decrease the autocorrelation. If we still did not obtain convergence, we planned to use alternate initial values and priors using methods suggested by Van Valkenhoef 2012. We estimated the probability that each intervention ranked at each of the possible positions based on estimated effect sizes and their corresponding uncertainty using the NICE DSU codes (Dias 2016).

\section{Assessment of inconsistency}

We assessed inconsistency (statistical evidence of the violation of the transitivity assumption) by fitting both an inconsistency model and a consistency model. We used inconsistency models employed in the NICE DSU manual, as we used a common betweenstudy standard deviation (Dias 2014). In addition, we used designby-treatment full interaction model and inconsistency factor (IF) plots to assess inconsistency (Higgins 2012; Chaimani 2013) when applicable. We used Stata/SE 15.1 to create IF plots. In the presence of inconsistency (model fit better with inconsistency models than consistency model, $95 \% \mathrm{Crl}$ of 'between-design' variance did not overlap 0 , and the $95 \%$ confidence intervals of inconsistency factor did not overlap 0), we planned to assess whether the inconsistency was due to clinical or methodological heterogeneity by performing separate analyses for each of the different subgroups mentioned in the Subgroup analysis and investigation of heterogeneity section or limit the network meta-analysis to a more compatible subset of trials when possible.

\section{Direct comparison}

We performed the direct comparisons in the randomised clinical trials using the same codes and the same technical details.

\section{Subgroup analysis and investigation of heterogeneity}

We planned to assess the differences in the intervention effect estimates between the following subgroups, and planned to investigate heterogeneity and inconsistency using meta-regression with the help of the codes provided in NICE DSU guidance (Dias 2012a) if we had a sufficient number of trials (when there were at least two trials in at least two of the subgroups). We planned to use the following trial-level markers for subgroup analyses.

- Trials at low risk of bias compared to trials at high risk of bias;

- Participants with NAFLD plus NASH compared to participants with NAFLD without NASH;

- Participants with diabetes mellitus compared to participants without diabetes mellitus;

- Different types of exercises/diets;

- Co-interventions (for example, both groups receive omega-3 fatty acid supplementation);
- Based on the period of follow-up: short-term: up to three months, medium-term: more than three months to five years, and long-term: more than five years;

- Based on the definition used by authors for serious adverse events and any adverse events (ICH-GCP 1997 compared to other definitions).

We planned to calculate a single common interaction term which assumes that each relative treatment effect compared to a common comparator treatment (i.e. 'no active intervention') is impacted in the same way by the covariate in question when applicable (Dias 2012a). If the 95\% Crl of the interaction term did not overlap zero, we considered this statistically significant heterogeneity or inconsistency (depending upon the factor being used as the covariate).

\section{Sensitivity analysis}

If there were post-randomisation dropouts, we re-analysed the results using the best-worst case scenario and worst-best case scenario as sensitivity analyses whenever possible. We also performed a sensitivity analysis excluding the trials in which mean or standard deviation, or both, were imputed, and we used the median standard deviation in the trials to impute missing standard deviations.

\section{Presentation of results}

We followed the PRISMA-NMA statement while reporting (Hutton 2015). We presented the effect estimates with $95 \%$ Crls for each pairwise comparison calculated from the direct comparisons and network meta-analysis. We originally planned to present the cumulative probability of the treatment ranks (i.e. the probability that the intervention was within the top two, the probability that the intervention was within the top three, etc.), but we did not present these because of the sparse data which can lead to misinterpretation of results due to large uncertainty in the rankings (the Crl was 0 to 1 for all the ranks) in graphs (SUCRA; (Salanti 2011)). We plotted the probability that each intervention was best, second best, third best, etc. for each of the different outcomes (rankograms) which are generally considered more informative (Salanti 2011; Dias 2012b), but we did not present these because of the sparse data which can lead to misinterpretation of results due to large uncertainty in the rankings (the $95 \% \mathrm{Crl}$ was 0 to 1 for most of the ranks). We uploaded all the raw data and the codes used for analysis in the European Organization for Nuclear Research open source database (Zenodo). You can find this by clicking here.

\section{Recommendations for future research}

We provide recommendations for future research in the population, intervention, control, outcomes, time of follow-up, and study design, based on the uncertainties that we identified from the existing research.

\section{Summary of findings and assessment of the certainty of the evidence}

We presented summary of findings tables for all the primary and secondary outcomes (see Primary outcomes; Secondary outcomes). We planned to follow the approach suggested by GRADE Working Group (Brignardello-Petersen 2018; Yepes-Nunez 2019). However, network meta-analysis was not performed for any of the clinical outcomes, primary or secondary. We therefore 
rated the certainty of evidence for direct effect estimates using GRADE methodology, which takes into account the risk of bias, inconsistency (heterogeneity), directness of evidence, imprecision, and publication bias (Guyatt 2011). For illustration of the absolute measures, we used the weighted median (Edgeworth 1887), control group proportion, or mean. We did not present the summary of findings tables in a second format presenting all the outcomes for selected interventions (Yepes-Nunez 2019), as the data on clinical outcomes were sparse (noting there is currently no preferred method of lifestyle intervention recommended).

\section{RE S U L T S}

\section{Description of studies}

\section{Results of the search}

We identified 11,810 references through electronic searches of CENTRAL (Wiley) $(n=2294)$, MEDLINE Ovid $(n=3654)$, Embase
Ovid $(n=2311)$, Science Citation Index Expanded and Conference Proceedings Citation Index - Science $(n=2871)$, ClinicalTrials.gov $(n=393)$, WHO Trials register $(n=19)$, FDA $(n=137)$, and EMA ( $n$ $=131$ ). After we removed duplicate references, there were 7141 references. We excluded 7006 clearly irrelevant references through reading titles and abstracts. We retrieved 135 full-text references for further assessment in detail. We excluded 35 references $(29$ studies) for the reasons stated in the Characteristics of excluded studies. Three references are awaiting classification (Bahrololumi 2014; Jia 2018; Grove 2020) and seven references are ongoing trials (IRCT20100524004010N31; NCT03354247; NCT03518294; NCT04283942; NCT04355910; NCT04369521; NCT04440540). We therefore include a total of 59 trials described in 90 references (Characteristics of included studies). The reference flow is shown in Figure 1. Please note that in the reference flow, we have not included the references for which we sought full text to confirm that the reference was not a RCT and that the trial was not about participants with NAFLD. 
Figure 1. Study flow diagram

Date of search: 25 February 2021

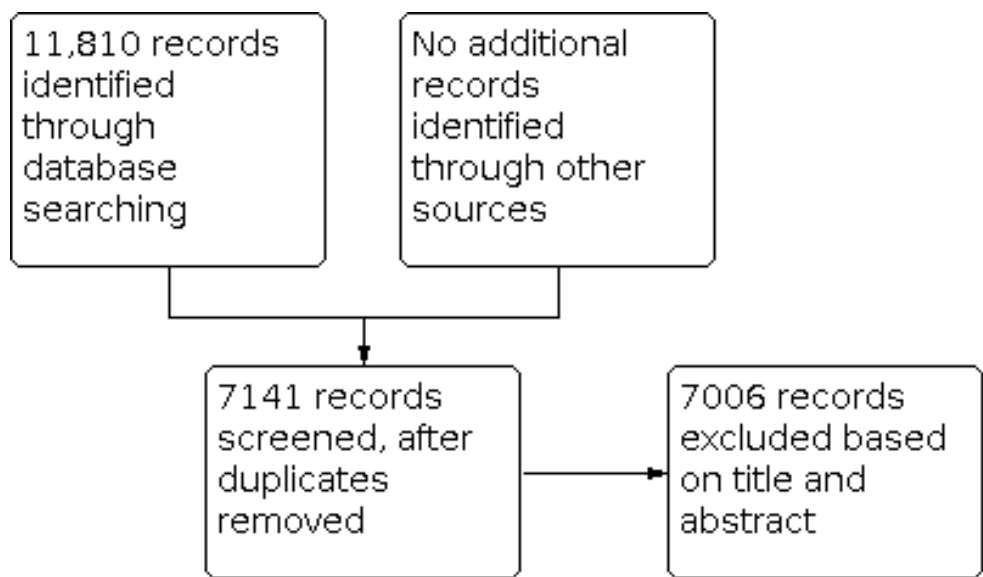

\begin{tabular}{|c|c|}
\hline$t$ & $\begin{array}{l}\text { - } 35 \text { records (29 studies) excluded } \\
\text { o Comparison of variations in treatment } \\
\text { nodes (21) } \\
\text { comparison of lifestyle intervention with } \\
\text { pharmacological intervention or nutritional } \\
\text { supplement (2) } \\
\text { ontervention effects of nutritional } \\
\text { supplementation were studied (i.e. }\end{array}$ \\
\hline \multirow{2}{*}{$\begin{array}{l}135 \text { full-text } \\
\text { records } \\
\text { assessed for } \\
\text { eligibility }\end{array}$} & $\begin{array}{l}\text { co-intervention in all randomised } \\
\text { participants) (2) }\end{array}$ \\
\hline & other reasons (4) \\
\hline
\end{tabular}




\section{Included studies}

We include 59 trials (Wang 2008; De Luis 2010; Hallsworth 2011; Rodriguez-Hernandez 2011; De Piano 2012; Sullivan 2012; Al-Jiffri 2013; Bacchi 2013; Eckard 2013; Hickman 2013; Ramon-Krauel 2013; Wong 2013; Kani 2014; Pugh 2014; Selezneva 2014; Sima 2014; Zelber-Sagi 2014; Hallsworth 2015; Abd El-Kader 2016; Cuthbertson 2016; Dong 2016; Dynnyk 2016; Kaliora 2016; Ramirez 2016; Rezende 2016; Wang 2016; Zade 2016; Zhang 2016; Arab 2017; Axley 2017; Cheng 2017; Houghton 2017; Misciagna 2017; Monica Dinu 2017; Nikroo 2017; Oh 2017; Roy 2017; Schattenberg 2017; Asghari 2018; Chan 2018; Katsagoni 2018; Nishimori 2018; Properzi 2018; Shidfar 2018; Tutino 2018; Yao 2018; Abdelbasset 2019; Johari 2019; Abdelbasset 2020; Chen 2020; Goss 2020; Moradi 2020; Nourian 2020; Panganiban 2020; Abbate 2021; NCT01327443; NCT02679417; NCT03183193; NCT03461562). A total of 3631 participants were randomised to different interventions in these 59 trials. The number of participants in the trials ranged from 17 to 280 . Only a total of 1942 participants from 28 trials were included in one of more outcomes (Wang 2008; Al-Jiffri 2013; Bacchi 2013; Eckard 2013; Hickman 2013; Wong 2013; Abd El-Kader 2016; Dong 2016; Kaliora 2016; Rezende 2016; Zhang 2016; Axley 2017; Cheng 2017; Houghton 2017; Misciagna 2017; Monica Dinu 2017; Nikroo 2017; Oh 2017; Roy 2017; Schattenberg 2017; Chan 2018; Katsagoni 2018; Properzi 2018; Yao 2018; Abdelbasset 2019; Johari 2019; Moradi 2020; Nourian 2020). There are no cluster-randomised trials or cross-over trials included in this review.

Further summary details of the included trials are available in Table 1. The important characteristics, potential effect modifiers, and follow-up in each trial are reported in Table 2. Overall, there do not seem to be any systematic differences between the comparisons, i.e. there was no immediate overt concern about transitivity assumption.

\section{Excluded studies}

The reasons for exclusion of studies are listed in Characteristics of excluded studies. The summary reasons for exclusion of studies are as follows.

- Comparison of variations in the same treatment nodes: St George 2009; Promrat 2010; Arefhosseini 2011; Sun 2012; Aller 2014; Nigam 2014; An 2015; Baldry 2017; Dynnyk 2017; Schweinlin 2018; Rezaei 2019; Austin 2020; Dorosti 2020; Haidari 2020; Nath 2020; Negri 2020; Ristic-Medic 2020; Marin-Alejandre 2021; Simons 2021; NCT04383951; NCT04520724.

- Comparison of lifestyle intervention with pharmacological intervention or nutritional supplement: Dela Cruz 2012; NCT04193982.

- Intervention effects of nutritional supplementation was studied (i.e. lifestyle intervention was used as an co-intervention in all randomised participants): Nobili 2008; Vilar Gomez 2009.

- Other reasons:

* Type of intervention not relevant to this review: Lim 2020; TCTR20200411004

* A cross-over trial in which the cross-over was at six weeks of intervention and the outcomes were not reported before the cross-over: this trial was not designed to address the objectives of this review (i.e. benefits and harms of different lifestyle interventions in the treatment of nonalcohol-related fatty liver disease; (Ryan 2013))

* Included participants with suspected NAFLD rather than those with NAFLD (Whyte 2020).

\section{Risk of bias in included studies}

The risk of bias is summarised in Figure 2, Figure 3, Table 3 (domainlevel summary) and in Table 4 (study-level summary ordered by comparisons). All the trials but two (Misciagna 2017; Monica Dinu 2017) were at unclear or high risk of bias in at least one of the domains and were considered to be at high risk of bias for individual outcomes and overall.

Figure 2. Risk of bias graph: review authors' judgements about each risk of bias item presented as percentages across all included studies.

Random sequence generation (selection bias)

Allocation concealment (selection bias)

Blinding of participants and personnel (performance bias): All outcomes

Blinding of outcome assessment (detection bias): All outcomes

Incomplete outcome data (attrition bias): All outcomes

Selective reporting (reporting bias)

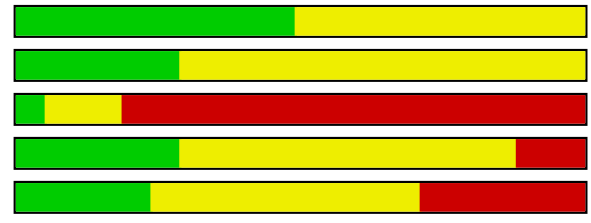

Other bias

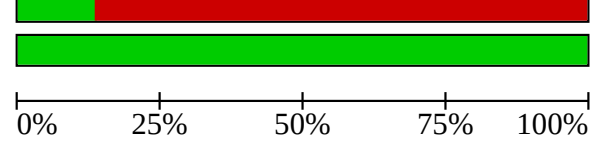

Low risk of bias

Unclear risk of bias

High risk of bias 
Figure 3. Risk of bias summary: review authors' judgements about each risk of bias item for each included study.

Abdelbasset 2019

Abdelbasset 2020

Abd El-Kader 2016

Al-Jiffri 2013

Arab 2017

Asghari 2018

Axley 2017

Bacchi 2013

Chan 2018

Chen 2020

Cheng 2017

Cuthbertson 2016

De Luis 2010

De Piano 2012

Dong 2016

Dynnyk 2016

Eckard 2013

Goss 2020

Hallsworth 2011

Hallsworth 2015

Hickman 2013

Houghton 2017
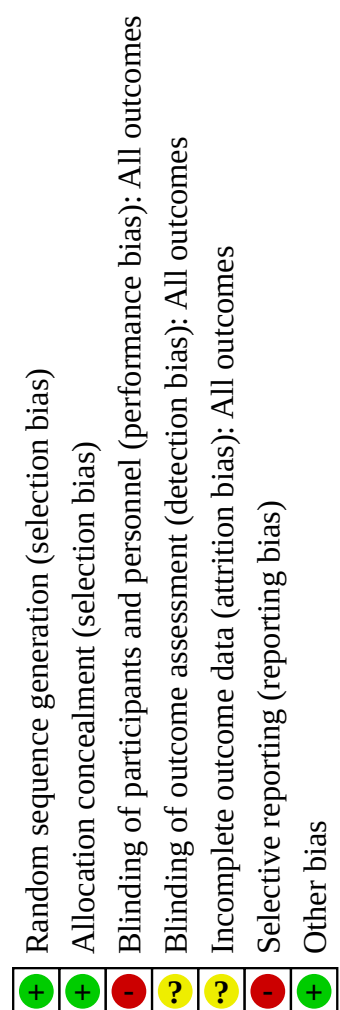
Figure 3. (Continued)

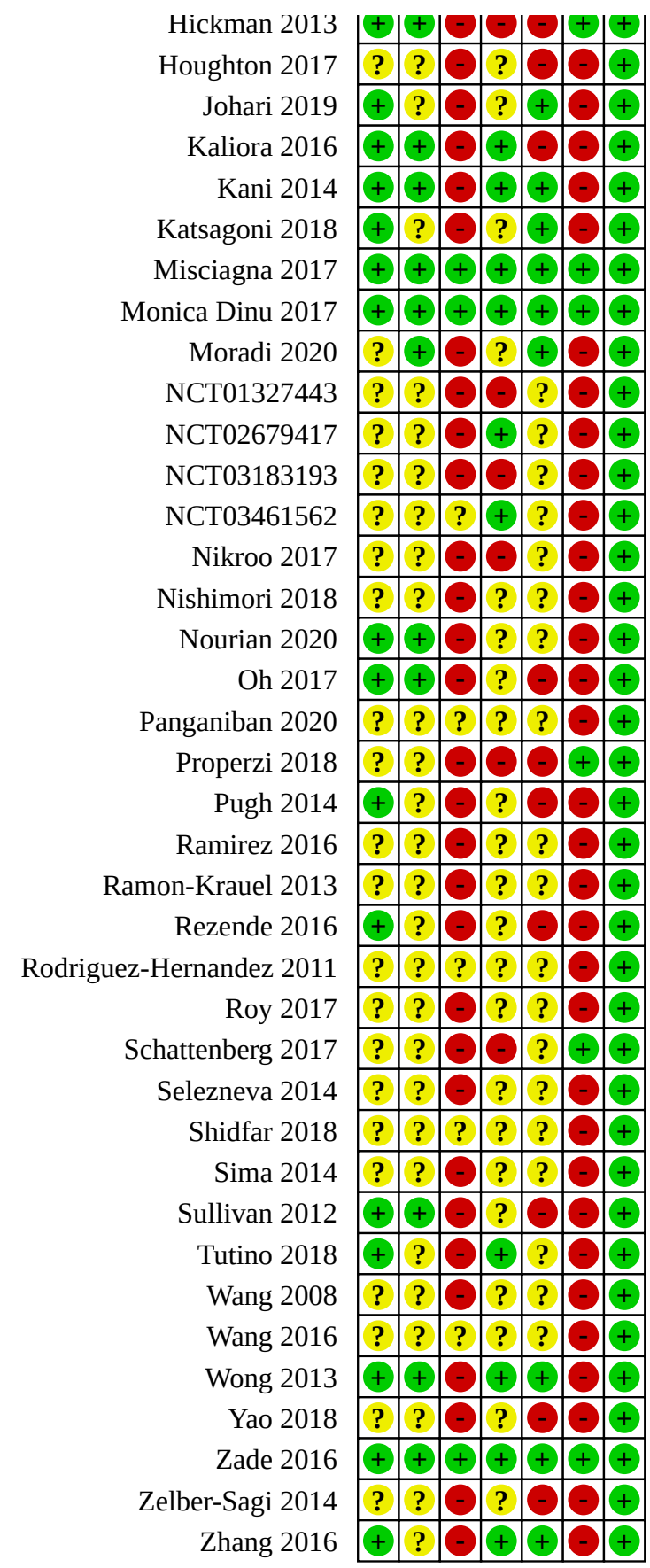

\section{Allocation}

Twenty-nine trials were at low risk of selection bias due to lack of random sequence generation; the remaining 30 trials, which did not provide sufficient information, were at unclear risk of sequence generation bias.

Seventeen trials were at low risk of selection bias due to lack of allocation concealment; the remaining 42 trials, which did not provide sufficient information, were at unclear risk of allocation concealment bias.

\section{Blinding}

Three trials were at low risk of performance bias as the participants and healthcare providers were blinded; eight trials, which did not provide sufficient information, were at unclear risk of performance bias; the remaining 48 trials were at high risk of performance bias.

Seventeen trials were at low risk of detection bias; 35 trials, which did not provide sufficient information, were at unclear risk of detection bias; the remaining seven trials were at high risk of detection bias. 


\section{Incomplete outcome data}

Fourteen trials were at low risk of attrition bias as there were no post-randomisation dropouts or an intention-to-treat analysis was used; 28 trials were at unclear risk of incomplete outcome data bias, because it was not clear whether there were post-randomisation dropouts or whether the post-randomisation dropouts were related to the outcomes (if there were postrandomisation dropouts); the remaining 17 trials were at high risk of attrition bias, as the post-randomisation dropouts were probably related to the outcomes.

\section{Selective reporting}

Eight trials were at low risk of selective outcome reporting bias, as the important clinical outcomes expected to be reported in such trials were reported; the remaining 51 trials were at high risk of selective outcome reporting bias as a protocol published prior to recruitment was not available and clinically relevant and reasonably expected outcomes were not reported.

\section{Other potential sources of bias}

No other potential source of bias was noted in any of the trials.

\section{Effects of interventions}

See: Summary of findings 1 Lifestyle modifications for nonalcoholrelated fatty liver disease

The network plots (where relevant) are available in Figure 4. The inconsistency factor plots (where relevant) are available in Figure 5. The model fit when network meta-analysis was performed is available in Table 5. The effect estimates are available when network meta-analysis was performed in Table 6. 
Figure 4. Network plots: A high resolution version of this image can be found here. The network plots showing the outcomes for which network meta-analysis was performed. The size of the node (circle) provides a measure of the number of trials in which the particular Intervention was included as one of the intervention groups. The thickness of the line provides a measure of the number of direct comparisons between two nodes (Interventions). Abbreviations AdviceDiet: dietary advice

AdviceDiet+AerobicEx: aerobic exercise plus dietary advice

AdviceDietEx: dietary advice plus exercise advice

AerobicEx: aerobic exercise

CalRestrictDiet: calorie restricted diet

CarbRestrictDiet+AerobicEx: aerobic exercise plus carbohydrate restricted diet

FatRestrictDiet: fat restricted diet

FatRestrictDiet+AerobicEx: aerobic exercise plus fat restricted diet

MedDiet: Mediterranean diet

NoActivelntervention: no active intervention

ResistEx: resistance exercise

SupAerobicEx: supervised aerobic exercise

SupAerobicEx+CalRestrictDiet: supervised aerobic exercise plus calorie restricted diet

SupAerobicEx+SupResistEx: supervised aerobic exercise plus resistance exercise
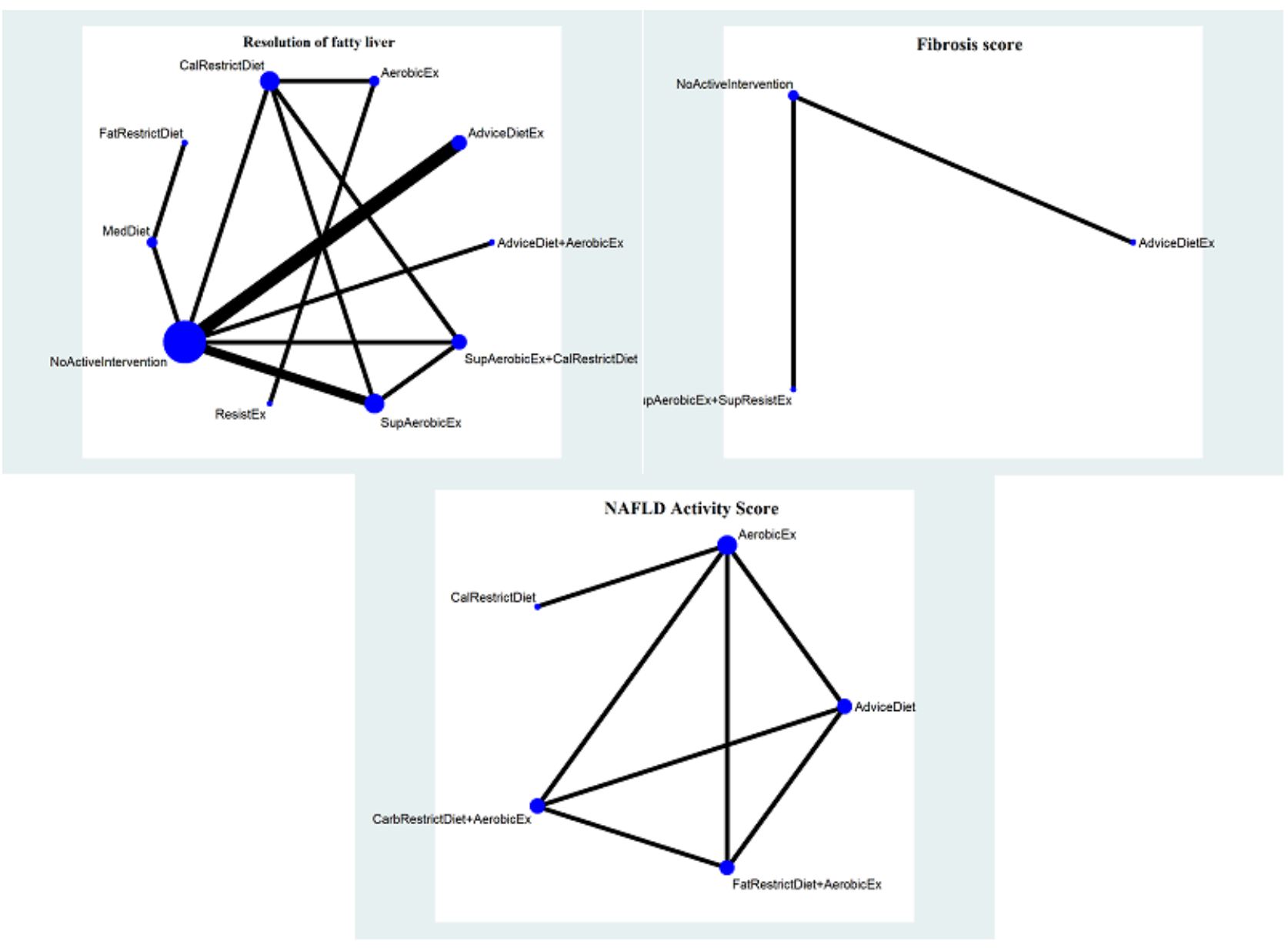
Figure 5. Inconsistency factor plots: The plot shows the inconsistency factors for the only outcome (resolution of fatty liver) where direct and indirect evidence were available for one or more comparisons. Although not attaining formal levels of statistical significance, this may suggest some concern regarding the consistency of the evidence. A higher resolution image of this picture is available here. Abbreviations CalRestrictDiet: calorie restricted diet NoActivelntervention: no active intervention

SupAerobicEx: supervised aerobic exercise

SupAerobicEx+CalRestrictDiet: supervised aerobic exercise plus calorie restricted diet

\section{Resolution of fatty liver}

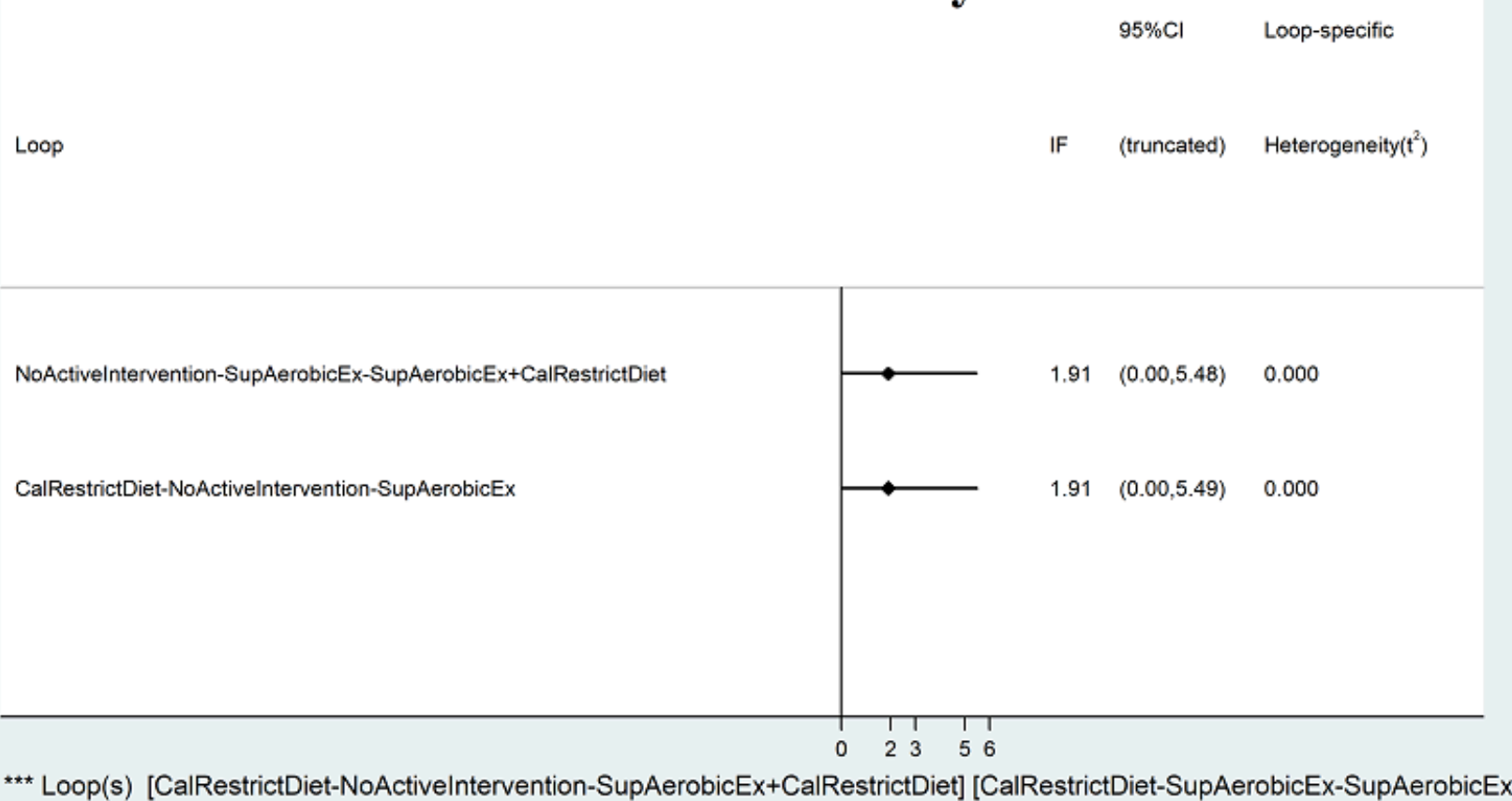

Figure 6. Effect estimates: A picture of Table 6 Effect estimates. Please see Table 6 for further details.

\begin{tabular}{|c|c|c|c|c|c|c|c|c|c|c|}
\hline fatty lwar & No active intervention & Aerobik essarcises & $\begin{array}{l}\text { Calorie roteristed } \\
\text { ditet }\end{array}$ & $\begin{array}{l}\text { Dietary and euerciase } \\
\text { edvice }\end{array}$ & Mentatances esercebse & 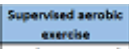 & fat restricteded diet & Mediterranesen diat & $\begin{array}{l}\text { Aerobic exercilue plus: } \\
\text { detery edvice }\end{array}$ & 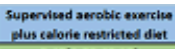 \\
\hline No sctive intervention & & & $5.07(2.22 .57 .41)$ & $6.95(0.22,810.46$ & & $7,45[0.035,5831.33)$ & $\cdot$ & $0.96[0.22,4.28]$ & $4.72(2.60 .0 .05)$ & $5.05[2.56,00.23]$ \\
\hline Aerobic enercibe & $85000.00,159532.03]$ & & $1.71[0.18 .16 .40]$ & & $1.09[0.22,5,71]$ & & ?. & & & \\
\hline Colorie reterikted diet & $14.06[0.03,13974.65]$ & $1.73[0.00,1811.66]$ & & & & $0.26[0.05,0.007$ & . & ?. & . & $1.05(0.43,2.81]$ \\
\hline 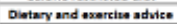 & ZAp & $0.90[0.00,20732.62 \mid$ & $0.54[0,00,115 \mathrm{k}, 04]$ & & . & & . & - & - & \\
\hline Sovistancat everchite & $8.36 \mid 00,1591201,59$ & $1.66[0.0097068]$ & $0.62(0.0099966 .65)$ & $119(0,00,250196003]$ & & $\because$ & ?. & ? & 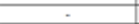 & \\
\hline Suptorised terobis esterist & $8.84[0.07 .6457 .521$ & $1.050 .00,20994.17$ & $0.62[0.00,510.33$ & $1.194[0.00,1954,72]$ & $1.01[0,00172818.99]$ & & ?. & & 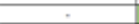 & $4.17[1.24 .20 .27]$ \\
\hline fat restricted diat & $3.82[0.0055826 .28]$ & $0.45[0.00,215325.721$ & $0.27[0.00,10633,65]$ & $0.51[0.00 .113255 .80]$ & $0.43(0.00,2077333.57$ & $0,43[0.00,13835.60]$ & & $0.26[a .06,0.22]$ & . & . \\
\hline Mediturranesean diat & 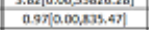 & 0 & $\mid \begin{array}{l}\mid .0 .07[0.00,564.53] \\
\end{array}$ & 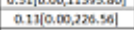 & 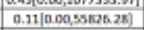 & 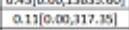 & $0.25[0.00,224.10]$ & & $\div$ & $\because$ \\
\hline $\begin{array}{l}\text { Aerobic everche plus dietay } \\
\text { edvice }\end{array}$ & 4.85][0.01,3801.20] & 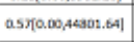 & $0.34[0.00,265<43]$ & $0.65 \mid 0.00,1000.07]$ & $0.55|0.00,268397.29|$ & ass $(0.00,2611.63]$ & 1.2भ[0.00, 2eassass) & 5.03|0.00,67507.91] & & . \\
\hline 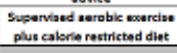 & $15.47[0.03,15914.72]$ & $1.860 .00,27173.57]$ & $1.080 .00 .873 .06]$ & 1.99[000,418.74] & 1.79|0.00,242801.62] & $1.760 .00,697.15]$ & 3.94[0.00,597195.61] & $15.71[0.00,268337.29]$ & $3.14[0.00,52575.21]$ & \\
\hline fibreat woose & No ective intervention & $\begin{array}{l}\text { Deesary sduce phat } \\
\text { eerecise advice }\end{array}$ & 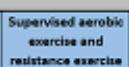 & & & & & & & \\
\hline Ho estive instruention & & $-0.02[-0.58, a 54]$ & $a .52[-1.50,0.46]$ & & & & & & & \\
\hline $\begin{array}{l}\text { Dietary advice plua asezise } \\
\text { asvike }\end{array}$ & $-0.02 \mid-0.57,0.58]$ & & & & & & & & & \\
\hline 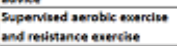 & & $050-163064$ & & & & & & & & \\
\hline & & & & & & & & & & \\
\hline 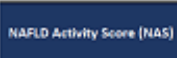 & Aerobic esercine & Calerie restricted diet & Deesary advice & 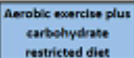 & $\begin{array}{l}\text { Aerobic enereche phos } \\
\text { fat restricted diet. }\end{array}$ & & & & & \\
\hline Derobic extreist & & $-2.00<-4.40,-1.60)$ & $0,00 \mid-1,00,1,001$ & $0.20[-1.201 .60]$ & $|-0,40|-1,50,1,00 \mid$ & & & & & \\
\hline Calorit reteiveted det & $-3.06[-4.37,-1.63]$ & & & & & & & & & \\
\hline Dietary advites & $0.396-0.098,1.80]$ & $3.59[1.44,5.57]$ & & $-0.20]-1.60,1.20]$ & $-0.800-2.20,0.60]$ & & & & & \\
\hline 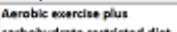 & & $3.20[1.25,5.140]$ & & & & & & & & \\
\hline 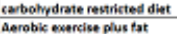 & a $200-1.181 .158]$ & & $-0.28(-159,1.18)$ & & $-0.60 \mid-2,00.0 .801$ & & & & & \\
\hline renricted diat & $-0.40 \mid-1.78,0.97]$ & $260(0,01,4.50)$ & $-0.30(-2,20,0.50)$ & $-0.60 \mid-1.02,0.78]$ & & & & & & \\
\hline
\end{tabular}

The $95 \%$ credible intervals of the probability ranks were wide, and included 0 and 1 in most comparisons for all the outcomes. This was probably because of the sparse data from small trials. We therefore did not present the ranking probabilities (in a table), rankograms, and SUCRA plots, as we considered that presenting this information 
would be unhelpful and potentially misleading, and it would ignore the differences in systematic errors in the trials.

The certainty of evidence was moderate, low, or very low for all the comparisons. This was because all the trials included in the comparisons (except for two trials: Misciagna 2017; Monica Dinu 2017) were at unclear or high risk of bias for at least one risk of bias domain at the outcome level (downgraded by one level). For all direct comparisons and network meta-analysis, the number of events were fewer than 300 and we downgraded by one level for imprecision. In comparisons involving clinical outcomes, the credible intervals were wide and overlapped significant clinical effect and no effect: we therefore downgraded by one more level for imprecision. We were unable to check for heterogeneity for any of the clinical outcomes. Overall, the downgrading of evidence resulted in very low certainty of evidence for all comparisons other than the comparisons of Mediterranean diet versus no active intervention (Misciagna 2017) and Khorasan wheat versus organic semi-wholegrain wheat (Monica Dinu 2017), which were low-certainty evidence.

\section{Mortality}

Fourteen trials (1216 participants) reported mortality at maximum follow-up of 2 months to 24 months (Al-Jiffri 2013; Hickman 2013; Wong 2013; Abd El-Kader 2016; Dong 2016; Zhang 2016; Axley 2017; Misciagna 2017; Monica Dinu 2017; Schattenberg 2017; Properzi 2018; Abdelbasset 2019; Johari 2019; Moradi 2020). A total of 12 interventions (aerobic exercise, calorie-restricted diet, dietary advice, dietary and exercise advice, fat-restricted diet, Mediterranean diet, aerobic exercise plus calorie-restricted diet, aerobic exercise plus dietary advice, resistance exercise, Khorasan wheat-based diet, organic semi-wholegrain-based diet, and no active intervention) were compared with each other in these trials. There were no deaths among 951 participants in 13 of the trials ( $\mathrm{Al}-$ Jiffri 2013; Hickman 2013; Wong 2013; Abd El-Kader 2016; Zhang 2016; Axley 2017; Misciagna 2017; Monica Dinu 2017; Schattenberg 2017; Properzi 2018; Abdelbasset 2019; Johari 2019; Moradi 2020). The evidence was of very low certainty for the comparisons in 11 trials (813 participants; no events; (Al-Jiffri 2013; Hickman 2013; Wong 2013; Abd El-Kader 2016; Zhang 2016; Axley 2017; Schattenberg 2017; Properzi 2018; Abdelbasset 2019; Johari 2019; Moradi 2020)) and of low certainty for the Mediterranean diet versus no active intervention trial (98 participants; no events; Misciagna 2017) and the Khorasan wheat-based diet versus organic semiwholegrain-based diet (40 participants; no events; (Monica Dinu 2017)). In the remaining trial, there were five deaths among 265 participants (1.9\%) during a follow-up period of 24 months (Dong 2016). In this trial, which compared dietary advice plus exercise advice versus no active intervention, two died of cardiovascular diseases, two died of cancers, and one died of a car accident (Dong 2016). The type of cancer leading to the death was not reported. Overall, there was no evidence of difference between dietary advice versus no active intervention: hazard ratio (HR) 0.63 (95\% Crl 0.07 to 4.06 ; 1 trial, 265 participants; very low-certainty evidence).

\section{Quality of life}

One trial (48 participants) reported quality of life at three months (Properzi 2018). The quality-of-life scale used was the Assessment of Quality Of Life (AQoL-8D) tool. A total of two interventions (Mediterranean diet versus fat-restricted diet) were compared in this trial. Since only one trial reported the outcome, meta-analysis could not be performed.

There was no evidence of difference in the health-related quality of life between Mediterranean diet versus fat-restricted diet: mean difference (MD) $-2.89,95 \% \mathrm{Crl}-7.25$ to $1.41 ; 1$ trial, 48 participants; very low-certainty evidence.

\section{Serious adverse events}

Eight trials (448 participants) reported serious adverse events after a follow-up period of three to six months (Al-Jiffri 2013; Hickman 2013; Axley 2017; Misciagna 2017; Monica Dinu 2017; Schattenberg 2017; Properzi 2018; Yao 2018). However, none of the trials clearly reported whether they used the ICH-GCP definition or not. We considered adverse events reported as 'serious' or 'severe' as serious adverse events.

A total of 11 interventions were compared with each other in these trials: aerobic exercise, calorie-restricted diet, dietary advice, dietary exercise plus exercise advice, resistance exercise, fat-restricted diet, Mediterranean diet, aerobic exercise plus calorie-restricted diet, Khorasan wheat-based diet, organic semiwholegrain-based diet, and no active intervention. None of the 448 participants in these trials developed serious adverse events. The evidence was of very low certainty for the comparisons in six trials (310 participants; no events; (Al-Jiffri 2013; Hickman 2013; Axley 2017; Schattenberg 2017; Properzi 2018; Yao 2018)) and of low certainty for the Mediterranean diet versus no active intervention trial (98 participants; no events; (Misciagna 2017)) and the Khorasan wheat-based diet versus organic semi-wholegrain-based diet (40 participants; no events; (Monica Dinu 2017)).

\section{Any adverse events}

Seven trials (426 participants) reported any adverse events after a follow-up period of three to six months (Al-Jiffri 2013; Hickman 2013; Misciagna 2017; Monica Dinu 2017; Schattenberg 2017; Properzi 2018; Yao 2018). However, none of the trials clearly reported whether or not they used the ICH-GCP definition. We considered events reported as 'adverse events' as any adverse events.

A total of 10 interventions (aerobic exercise, calorie-restricted diet, dietary advice, resistance exercise, fat-restricted diet, Mediterranean diet, aerobic exercise plus calorie-restricted diet, Khorasan wheat-based diet, organic semi-wholegrain-based diet, and no active intervention) were compared with each other in these trials. In six trials, none of the 335 participants developed any adverse events. The evidence was of very low certainty for the comparisons in four trials (288 participants; Al-Jiffri 2013; Hickman 2013; Schattenberg 2017; Properzi 2018) and of low certainty for the Mediterranean diet versus no active intervention trial (98 participants; no events; (Misciagna 2017)) and the Khorasan wheat-based diet versus organic semi-wholegrain-based diet (40 participants; no events; (Monica Dinu 2017)). In the remaining trial, which was three-armed, one of 31 participant (3.2\%) who received resistance exercise developed one adverse event (bone fracture by falling down, but not during the exercise sessions; (Yao 2018)). None of the participants in this trial who underwent aerobic exercise (0/29 participants) or no active intervention (0/31) developed any adverse events. The evidence was of very low certainty in the comparisons included in this trial. We did not perform a formal calculation of effect estimates because of the sparse data, i.e. the 
only trials for the comparisons included zero events for at least one of the groups.

\section{Liver transplantation}

Seven trials (411 participants) reported liver transplantation at maximum follow-up of 3 to 12 months (Hickman 2013; Wong 2013; Axley 2017; Misciagna 2017; Monica Dinu 2017; Schattenberg 2017; Properzi 2018). A total of 10 interventions (aerobic exercise, calorierestricted diet, dietary advice, dietary exercise plus exercise advice, fat-restricted diet, Mediterranean diet, aerobic exercise plus dietary advice, Khorasan wheat-based diet, organic semi-wholegrainbased diet, and no active intervention) were compared with each other in these trials. None of the participants in these seven trials underwent liver transplantation. The evidence was of very low certainty for the comparisons in five trials (273 participants; no events; (Hickman 2013; Wong 2013; Axley 2017; Schattenberg 2017; Properzi 2018)) and of low certainty for the Mediterranean diet versus no active intervention trial (98 participants; no events; (Misciagna 2017)) and the Khorasan wheat-based diet versus organic semi-wholegrain-based diet (40 participants; no events; (Monica Dinu 2017))

\section{Decompensation}

Seven trials (411 participants) reported liver decompensation after a maximum follow-up of 3 to 12 months (Hickman 2013; Wong 2013; Axley 2017; Misciagna 2017; Monica Dinu 2017; Schattenberg 2017; Properzi 2018). A total of 10 interventions (aerobic exercise, calorierestricted diet, dietary advice, dietary exercise plus exercise advice, fat-restricted diet, Mediterranean diet, aerobic exercise plus dietary advice, Khorasan wheat-based diet, organic semi-wholegrainbased diet, and no active intervention) were compared with each other in these trials. None of the participants in these seven trials developed liver decompensation. The evidence was of very low certainty for the comparisons in five trials (273 participants; no events; (Hickman 2013; Wong 2013; Axley 2017; Schattenberg 2017; Properzi 2018)) and of low certainty for the Mediterranean diet versus no active intervention trial (98 participants; no events; (Misciagna 2017)) and the Khorasan wheat-based diet versus organic semi-wholegrain-based diet (40 participants; no events; (Monica Dinu 2017)).

\section{Cirrhosis}

Seven trials (411 participants) reported liver cirrhosis after a maximum follow-up of 3 to 12 months (Hickman 2013; Wong 2013; Axley 2017; Misciagna 2017; Monica Dinu 2017; Schattenberg 2017; Properzi 2018). A total of 10 interventions (aerobic exercise, calorie-restricted diet, dietary advice, dietary advice plus exercise advice, dietary advice plus aerobic exercise, fat-restricted diet, Mediterranean diet, Khorasan wheat-based diet, organic semiwholegrain-based diet, and no active intervention) were compared with each other in these trials. In six trials, none of the 390 participants developed liver cirrhosis. The evidence was of very low certainty for the comparisons in four trials (252 participants; no events; Wong 2013; Axley 2017; Schattenberg 2017; Properzi 2018) and low certainty for the Mediterranean diet versus no active intervention trial (98 participants; no events; (Misciagna 2017)) and the Khorasan wheat-based diet versus organic semi-wholegrainbased diet (40 participants; no events; (Monica Dinu 2017)). In one trial, 2 of 13 (15.4\%) participants developed cirrhosis in the aerobicexercise group after a follow-up of six months; none of the eight participants in the calorie-restricted diet group developed cirrhosis in this trial (Hickman 2013). This trial included non-diabetic people with and without NASH, and the evidence was of very low certainty. We did not calculate effect estimates for this trial because of the sparse data, i.e. the only trial for this comparison included zero events for one of the groups (very low-certainty evidence).

\section{Hepatocellular carcinoma}

Five trials (229 participants) reported hepatocellular carcinoma after a maximum follow-up of three to six months (Hickman 2013; Axley 2017; Misciagna 2017; Monica Dinu 2017; Properzi 2018). A total of eight interventions (aerobic exercise, calorierestricted diet, dietary exercise plus exercise advice, fat-restricted diet, Mediterranean diet, Khorasan wheat-based diet, organic semiwholegrain-based diet, and no active intervention) were compared with each other in these trials. None of the participants in these five trials developed hepatocellular carcinoma. The evidence was of very low certainty for the comparisons in three trials (91 participants; no events; Hickman 2013; Axley 2017; Properzi 2018) and low certainty for the Mediterranean diet versus no active intervention trial (98 participants; no events; (Misciagna 2017)) and the Khorasan wheat-based diet versus organic semi-wholegrainbased diet (40 participants; no events; (Monica Dinu 2017)).

\section{Liver-related mortality}

Among the 14 trials which reported mortality, there were deaths in only one trial (Dong 2016) (please see 'Mortality at maximum follow-up'). The reasons for death in this trial were cardiovascular diseases (2), cancers (2), and a car accident (1) (Dong 2016). The type of cancer leading to the death was not reported and our attempts to contact the authors were unsuccessful. It is therefore not clear whether there was liver-related mortality in this trial: the trial could not be included for the analysis of liver-related mortality. In the remaining 13 trials (951 participants), there were no deaths from any cause (including liver-related causes) after a follow-up of 2 to 12 months (Al-Jiffri 2013; Hickman 2013; Wong 2013; Abd El-Kader 2016; Zhang 2016; Axley 2017; Misciagna 2017; Monica Dinu 2017; Schattenberg 2017; Properzi 2018; Abdelbasset 2019; Johari 2019; Moradi 2020). The evidence was of very low certainty for the comparisons in 11 trials (813 participants; no events; Al-Jiffri 2013; Hickman 2013; Wong 2013; Abd El-Kader 2016; Zhang 2016; Axley 2017; Schattenberg 2017; Properzi 2018; Abdelbasset 2019; Johari 2019; Moradi 2020) and of low certainty for the Mediterranean diet versus no active intervention trial (98 participants; no events; (Misciagna 2017)) and the Khorasan wheat-based diet versus organic semi-wholegrain-based diet (40 participants; no events; (Monica Dinu 2017)).

\section{Exploratory outcomes}

\section{Resolution of fatty liver disease}

Thirteen trials (1019 participants) reported resolution of fatty liver disease at maximum follow-up of 1 to 24 months (Wang 2008; Bacchi 2013; Hickman 2013; Wong 2013; Dong 2016; Rezende 2016; Cheng 2017; Misciagna 2017; Monica Dinu 2017; Roy 2017; Chan 2018; Properzi 2018; Nourian 2020). A total of 14 interventions (aerobic exercise, calorie-restricted diet, dietary exercise plus exercise advice, resistance exercise, supervised aerobic exercise, fat-restricted diet, Mediterranean diet, dietary advice, aerobic exercise plus dietary advice, aerobic exercise plus calorie- and fatrestricted diet, supervised aerobic exercise plus calorie-restricted diet, Khorasan wheat-based diet, organic semi-wholegrain wheat- 
based diet, and no active intervention) were compared with each other in these trials. The weighted median proportion of participants who developed resolution of fatty liver was $6.8 \%$.

One trial (57 participants) comparing aerobic exercise plus calorie- and fat-restricted diet (38 participants) versus no active intervention (19 participants) was not connected to the network because it had zero events in both arms after a follow-up period of one month (Wang 2008). Another trial (57 participants) comparing resistance exercise (36 participants) versus no active intervention (33 participants) was not connected to the network because it had zero events in one of the arms after a follow-up period of two month (Nourian 2020). We did not calculate the effect estimate for these trials because of their sparse data, i.e. the only trials for these comparisons included zero events in at least one of the groups. One trial ( 40 participants) was not included in the network meta-analysis because the treatments in this trial (Khorasan wheat diet, organic semi-wholegrain wheat diet) were not connected to the network (Monica Dinu 2017). There was no evidence of differences in resolution of fatty liver disease between the Khorasan wheat diet and organic semi-wholegrain wheat diet groups The remaining 10 trials (853 participants) were included in the network meta-analysis. A total of 10 interventions (aerobic exercise, calorie-restricted diet, dietary exercise plus exercise advice, resistance exercise, supervised aerobic exercise, fat-restricted diet, Mediterranean diet, aerobic exercise plus dietary advice, supervised aerobic exercise plus calorie-restricted diet, and no active intervention) were included in the network.

\section{Direct comparisons}

The first intervention had higher resolution of fatty liver disease than the second intervention in the following direct comparisons:

- Aerobic exercise plus dietary advice versus no active intervention: HR $4.72,95 \% \mathrm{Crl} 2.69$ to $8.83 ; 1$ trial, 154 participants;

- Supervised aerobic exercise plus calorie-restricted diet versus no active intervention: HR 5.45, 95\% Crl 1.36 to 40.13 ; 1 trial, 41 participants;

- Supervised aerobic exercise plus calorie-restricted diet versus supervised aerobic exercise: HR 4.17, 95\% Crl 1.24 to $20.27 ; 1$ trial, 45 participants.

The first intervention had lower resolution of fatty liver disease than the second intervention in the following direct comparisons:

- Supervised aerobic exercise versus calorie-restricted diet: HR $0.26,95 \% \mathrm{Crl} 0.05$ to $0.90 ; 1$ trial, 44 participants;

- Mediterranean diet versus fat-restricted diet: HR 0.26, 95\% CrI 0.05 to $0.91 ; 1$ trial, 48 participants.

There was no evidence of differences between the treatments in the remaining direct comparisons, i.e. the remaining direct comparisons were not statistically significant), as shown in Table 6 .

\section{Network meta-analysis}

There was no evidence of inconsistency according to model fit and inconsistency factor, but there was evidence of inconsistency based on the between-design variance: the between-design variance was 7.39 (95\% Crl 0.04 to 23.89). The between-study variance was 8.90 (95\% Crl 0.62 to 23.83 ). In the network meta-analysis, and there was no evidence of differences in any of the comparisons (Table 6).

\section{Fibrosis score}

Six trials (491 participants) reported fibrosis score (Dong 2016; Kaliora 2016; Houghton 2017; Oh 2017; Katsagoni 2018; Properzi 2018). A total of 11 treatments were compared with each other in these trials (aerobic exercise, dietary advice plus exercise advice, dietary advice, resistance exercise, fat restricted diet, Mediterranean diet, raisins plus dietary advice, Mediterranean diet plus dietary advice, Mediterranean diet plus dietary advice plus exercise advice, supervised aerobic exercise plus resistance exercise, and no active intervention). Four trials were not connected to the network because they had treatments unconnected to network (Kaliora 2016; Oh 2017; Katsagoni 2018; Properzi 2018). The network therefore has only two trials and three treatments (dietary advice plus exercise advice, supervised aerobic exercise plus resistance exercise, and no active intervention). There were no triangular or quadrangular loops, so inconsistency was not checked. Only one trial was included in each of the comparisons, so only a fixed-effect model is applicable.

There was no evidence of difference in any of the direct comparisons or the network meta-analysis, i.e. there was no statistically significant difference in any of the comparisons (Table $6)$.

\section{NAFLD activity score}

Two trials (62 participants) reported NAFLD activity score (Eckard 2013; Hickman 2013). A total of five treatments were compared with each other in these two trials (calorie-restricted diet, dietary advice, aerobic exercise plus carbohydrate-restricted diet, aerobic exercise plus fat-restricted diet, and aerobic exercise). Both the trials were connected to the network.

\section{Direct comparisons}

Calorie-restricted diet had a lower NAFLD activity score than aerobic exercise: MD -3.00 (95\% Crl -4.40 to -1.60$) ; 1$ trial, 21 participants.

There was no evidence of differences between the treatments in the remaining direct comparisons, i.e. the remaining direct comparisons were not statistically significant, as shown in Table 6.

\section{Network meta-analysis}

The only triangular and quadrangular loops were because of a fourarmed trial (Eckard 2013); inconsistency was therefore not checked. Only one trial was included in each of the comparisons, so only a fixed-effect model is applicable.

Calorie-restricted diet had a lower NAFLD activity score than aerobic exercise: MD -3.00 (95\% $\mathrm{Crl}-4.37$ to -1.60$)$; direct comparison: $\mathrm{MD}-3.00(95 \% \mathrm{Crl}-4.40$ to -1.60$) ; 1$ trial; 21 participants.

In the network meta-analysis, the first intervention had a higher NAFLD activity score than second intervention in the following comparisons.

- Dietary advice versus aerobic exercise: MD 3.39, 95\% Crl 1.44 to 5.37; 1 trial; no direct comparison

- Aerobic exercise plus carbohydrate-restricted diet versus aerobic exercise: MD 3.20, 95\% Crl 1.23 to 5.14; no direct comparison 
- Aerobic exercise plus fat-restricted diet versus aerobic exercise: MD 2.60, $95 \% \mathrm{Crl} 0.63$ to 4.53; no direct comparison

There was no evidence of differences between the treatments in the remaining comparisons in the network meta-analysis (Table 6).

\section{MELD score}

None of the trials reported that they measured MELD score.

\section{Subgroup analysis}

We did not perform any subgroup analysis. This is because of the sparse data (as described above).

\section{Sensitivity analysis}

\section{'Best-worst' and 'worst-best' scenario analyses}

We performed the 'best-worst' and 'worst-best' scenario analyses for the sensitivity analysis related to missing outcome data for the only outcomes with binomial distribution where formal analyses were performed: mortality and fatty liver resolution.

For mortality, dietary advice had lower mortality than no active intervention when the best-worst scenario analysis was used dietary advice had higher mortality than no active intervention when the worst-best scenario analysis was used. These results should therefore be interpreted with caution, as the results are susceptible to attrition bias resulting from post-randomisation dropouts.

There were no changes to interpretation of the results for fatty liver resolution based on best-worst or worst-best scenario analyses. The comparisons for fatty liver resolution are therefore robust to post-randomisation dropouts.

\section{Imputation of standard deviation}

We did not perform any imputation of standard deviation.

\section{Assessment of reporting biases}

We performed a thorough search of the literature, including searches of the trial registers. We therefore identified most of the published or registered studies in the clinical trials register. Since the first publication report of a trial is 2008, we expect that we have identified most registered trials on the topic.

Since there was no meaningful way in which to order these studies, i.e. there was no specific change in the risk of bias in the studies, sample size, or the control group used over time, noting that the first published report for this review was in 2008, we were unable to perform a comparison-adjusted funnel plot. Important clinical outcomes were not reported in many trials, despite the high probability of being recorded.

\section{DISCUSSION}

\section{Summary of main results}

We performed a systematic review and network meta-analysis of lifestyle modifications for nonalcohol-related fatty liver disease (NAFLD). We included a total of 59 trials (3631 participants) in this review. The trials compared 33 interventions. Twenty-eight trials including 1942 participants were included for one or more comparisons of this review (Wang 2008; Al-Jiffri 2013; Bacchi 2013;
Eckard 2013; Hickman 2013; Wong 2013; Abd El-Kader 2016; Dong 2016; Kaliora 2016; Rezende 2016; Zhang 2016; Axley 2017; Cheng 2017; Houghton 2017; Misciagna 2017; Monica Dinu 2017; Nikroo 2017; Oh 2017; Roy 2017; Schattenberg 2017; Chan 2018; Katsagoni 2018; Properzi 2018; Yao 2018; Abdelbasset 2019; Johari 2019; Moradi 2020; Nourian 2020). The remaining trials did not report any of the outcomes of interest for this review.

The follow-up period in the trials that reported primary or secondary outcomes was 2 months to 24 months. During this follow-up period, clinical events related to NAFLD such as mortality, liver cirrhosis, liver decompensation, and liver transplantation were sparse. This is probably because of the very short follow-up period. It takes a follow-up of 8 to 28 years to detect differences in mortality between people with NAFLD and the general population (Adams 2005; Bedogni 2007; Ong 2008; Soderberg 2010; Onnerhag 2014). It is therefore unlikely that differences in clinical outcomes will be apparent in trials with less than 5 to 10 years of follow-up.

Because these were lifestyle interventions, there is no mandatory requirement to record and report adverse events. In the one trial that reported that a participant developed an adverse event (Yao 2018), the adverse event did not seem to be directly related to the intervention. While there were some differences between the treatments in the surrogate outcomes, the implication of these differences for clinical outcomes are not known. There is therefore considerable uncertainty about whether any of the lifestyle interventions are beneficial in people with NAFLD. We note that there is also considerable uncertainty whether any pharmacological interventions work in NAFLD (Lombardi 2017) and whether any of the nutritional supplements work in NAFLD (Komolafe 2021). However, this does not mean that there is nothing we can do for people with NAFLD: NAFLD decreases life expectancy and increases liver cirrhosis, hepatocellular carcinoma, and requirement for liver transplantation (Adams 2005; Bedogni 2007; Ong 2008; Soderberg 2010; White 2012; Onnerhag 2014; Angulo 2015; Ekstedt 2015; Piscaglia 2016; Cholankeril 2017).

It is unlikely that the ongoing trials will provide an answer as to whether any of the lifestyle interventions improve clinical outcomes in people with NAFLD. As mentioned earlier, it is unlikely that we will be able to detect any differences in important clinical outcomes before 5 to 10 years. It is important that the lifestyle interventions that are proposed are affordable and sustainable over this period of time. In terms of intervention, this systematic review suggests that some surrogate outcomes such as resolution of fatty liver may increase with aerobic exercise combined with general dietary advice or calorie-restricted diet. There is no current evidence that any specific method to improve adherence to lifestyle interventions is effective in people with NAFLD. Neither is there high-quality and strong evidence that any specific method to improve adherence to lifestyle interventions is effective in people with obesity. But potential interventions to improve adherence to lifestyle, include counselling approaches such as motivational interviewing and self-monitoring using digital technologies (Cavero-Redono 2020; Suire 2020) could be investigated as part of a complex factorial trial design. In terms of the outcomes, the major clinical outcomes should include mortality, health-related quality of life, decompensated liver cirrhosis, and liver transplantation.

Sample size estimation for a parallel RCT was made based on two studies of the natural history of NAFLD that followed participants 
for a median period of around eight years (Adams 2005; Bedogni 2007). The proportion of participants who died was approximately $6 \%$ (Bedogni 2007) and 12.6\% (Adams 2005). The hazard ratio for mortality of people with NAFLD versus those without NAFLD was 1.34 (Adams 2005) and 1.47 (Bedogni 2007). It is therefore reasonable to expect a $20 \%$ relative reduction in mortality by the intervention, but even this will mean that the mortality in people with NALFD is higher than in those without NAFLD. If we assumed a proportional hazards model with an alpha error of 0.05 , power of 0.9 , and the mortality of people who received standard care to be $9 \%$ at eight years, and we estimated a $20 \%$ reduction in mortality by the intervention, with a recruitment period of three years and follow-up period of eight years, we would need 3610 participants in each group prior to loss to follow-up (PS: Power and Sample Size Calculation).

Clearly, such a trial would be expensive to conduct. Some recent and innovative trial designs may allow the conduct of NAFLD trials powered to detect differences in clinically important outcomes rather than relying on unvalidated surrogate outcomes. There are no national registries for NAFLD which can be used for registrybased RCTs. The existing registries for NAFLD, such as European NAFLD, European paediatric NAFLD, and TARGET-NASH study register are observational studies with bio-banking facilities (Barritt 2017; Mann 2018; Hardy 2020). Establishment of a research registry for NAFLD will allow efficient large-scale RCTs (James 2015). In the absence of such registries, another efficient and innovative study design is the cohort multiple RCT (cmRCT; (Relton 2010)), although a staged-informed consent in the design is less contentious in terms of ethical concerns (Young-Afat 2016) than the originally proposed design of $\mathrm{cmRCT}$ where some participants do not know of their participation in an RCT (Relton 2010). There are methodological differences such as sample size calculations in such cmRCTs compared to the standard parallel RCT design (Reeves 2018). Furthermore, below a certain proportion of participants allocated to the intervention group consenting to undergo the intervention, the efficiency of $\mathrm{cmRCT}$ is lost (Reeves 2018). Because of these methodological challenges, feasibility studies may be necessary to determine the optimal design of a cmRCT. Some innovations such as follow-up based on national electronic health record data (the participants should be consented for linking their details to national electronic health record data at the time of consenting to trial participation) will allow assessment of outcomes such as mortality, liver transplantation, and liver cirrhosis for several decades. However, the use of national electronic health record data brings its own challenges, such as data quality and validation, completeness of data capture, and heterogeneity among systems for international trials (Cowie 2017). Besides, the use of national electronic health record data does not allow the capture of healthrelated quality of life. Potential solutions include self-reported health-related quality of life and measuring the health-related quality of life in a sample of participants, but there is no current evidence about the validity of these approaches or the inherent biases. Nesting methodological research projects within NAFLD trials can therefore determine the optimal trade-off between the most valid and most efficient study designs in trials involving people with NAFLD.

\section{Overall completeness and applicability of evidence}

The trials included only NAFLD people with and without NASH. The results of the review are therefore only applicable to people with NAFLD, with or without NASH, who are able to undergo these interventions. The results are not applicable to people who had previously undergone liver transplantation. Different studies used different methods of diagnosis of NAFLD. Having a consensus on minimum standards for definition of NAFLD in clinical trials can help with the applicability of the evidence from future trials.

It should also be noted that the studies made the diagnosis of NAFLD based on the presence of fatty liver in the absence of excessive alcohol consumption. However, there is ongoing debate about what constitutes excessive alcohol consumption in the context of fatty liver (Eslam 2019). It is therefore possible that the fatty liver may have been caused by alcohol consumption, although such alcohol consumption would be considered non-excessive using the current definition of NAFLD. The findings of the review are applicable to people with NAFLD under the current definitions in 2021. This might change in the future if the nomenclature for fatty liver is changed.

Because of the general belief and health-promotion policies of various governments, it is possible that once people are diagnosed with NAFLD they improve their lifestyle without any additional interventions such as additional dietary advice or intensive exercise regimens. The review therefore addresses only the question of whether interventions work that are aimed at lifestyle modifications in people with NAFLD in addition to public health promotion, rather than whether such lifestyle modifications work in the absence of public health promotion, or whether public health promotions work.

It should be noted that we have covered only lifestyle interventions in this review. Any dietary intervention that resulted in an increase in a potential mediator of change in outcomes, if the potential mediator was isolated and manufactured as a nutritional supplement, this was covered in a nutritional supplementation review (Komolafe 2021). The findings of the review are therefore applicable only to lifestyle interventions and not to nutritional supplementation. However, we did not find any nutritional supplementation that improved clinical outcomes in NAFLD (Komolafe 2021).

The review only provides evidence about what happens within the first two years and does not provide any information on what happens beyond two years.

\section{Quality of the evidence}

The overall certainty (quality) of evidence varied between moderate, low, and very low. One of the main reasons for this was the unclear or high risk of bias in all but two trials (Misciagna 2017; Monica Dinu 2017). To provide some information on whether It is possible to perform trials at low risk of bias, we have considered each source of bias. This can give a context for interpretation of the information.

Randomisation can be performed using standard methods, for example, web-based central randomisation; an intention-to-treat analysis can be performed; and a protocol should be published prior to recruitment. However, blinding of healthcare providers and participants may not be possible if advice or exercise interventions are used as one of the interventions. However, it is possible to achieve low risk of performance bias by outlining the protocol clearly for any additional investigations and treatments. Outcome 
assessor blinding can be achieved for all comparisons by use of an observer blinded to the groups to assess the outcomes. If that is not possible, using clear highly-reproducible criteria for outcome definitions can decrease detection bias. Even if we exclude lack of blinding while assessing the overall risk of bias, only the same two trials were at low risk of bias (Misciagna 2017; Monica Dinu 2017). Another major reason for the decreased certainty of evidence was imprecision. Clinical events were extremely sparse, resulting in difficulty undertaking a formal analysis, or in the rare instance when calculation of an effect estimate was possible, the credible intervals were extremely wide. The designs of ongoing trials suggest that this imprecision cannot be addressed by these ongoing trials. We used clinical outcomes, meaning that there is no issue of indirectness due to outcomes. There was no suggestion that the potential effect modifiers were systematically different across comparisons, i.e. there was no concern about the transitivity assumption for most outcomes. However, we were unable to perform a formal analysis to assess this because of sparse data. We therefore cannot rule out inconsistency ('incoherence' according to GRADE terminology).

There was no meaningful way to order these studies, i.e. there was no specific change in the risk of bias in the studies, sample size, or the control group used over time, noting that the first trial dates back only to 2008 and there is no evidence that any additional intervention works.

We have completed a thorough search for studies on effectiveness. However, only 15 of 59 (25.4\%) trials reported mortality; fewer trials reported other clinical outcomes. These are outcomes which would have been recorded in trials of this nature, but were not reported. Many of them were considered as core outcome measures (Clearfield 2021). We acknowledge that the publication of the core outcome set is very recent, but we expect reporting of the clinical outcomes, even if the primary outcomes of these studies were surrogate outcomes. This may suggest reporting bias for these outcomes.

\section{Potential biases in the review process}

We selected a range of databases to search without using any language restrictions, and conducted the network meta-analysis according to NICE DSU guidance. We have also conducted analyses using the fixed-effect model and random-effects models, and assessed and reported inconsistency whenever possible (this was possible only for the exploratory outcomes because of the sparse clinical data). These are the strengths of the review process. We have excluded studies that only compared variations in duration or intensity in the same intervention (treatment node). Hence, this review does not provide information on whether one variation is better than another. The potential effect modifiers in the trials that reported them were broadly similar across comparisons. Concern about the transitivity assumption is therefore low, but cannot be ruled out. However, given the very large uncertainty in the results due to sparse data, this is only of academic interest. We included only randomised clinical trials which are known to focus mostly on benefits and do not collect and report harms in a detailed manner. A significant effort is required to identify non-randomised studies that report on harm, with challenges in assessing their risks of bias. If the ongoing trials result in adequate power to find meaningful differences in mortality and other clinically important outcomes and if the adverse events are collected systematically, a systematic review on adverse events from observational studies may be unnecessary.

\section{Agreements and disagreements with other studies or reviews}

This is the first network meta-analysis on the impact of different lifestyle interventions on clinical outcomes in people with NAFLD. We are therefore unable to compare our conclusions with those of other reviews. Our conclusions differ from those of many study authors included in this review, because we relied on clinical outcomes rather than surrogate outcomes.

\section{AUTHORS' CONCLUSIONS}

\section{Implications for practice}

The evidence indicates considerable uncertainty about the effects of the lifestyle interventions compared with no additional intervention to general public health advice on any of the clinical outcomes after a short follow-up period of 2 months to 24 months in people with NAFLD.

\section{Implications for research}

Further well-designed randomised clinical trials are necessary. Some aspects of the design of the randomised clinical trials are as follows.

Study design: registry-based randomised clinical trial or cohort multiple randomised clinical trial (cmRCT)

\section{Participants: people with NAFLD}

Interventions/control: aerobic exercise and dietary advice versus standard of care (exercise and dietary advice received as part of national health promotion)

Outcomes: Primary outcome: mortality. Secondary outcomes: health-related quality of life, decompensated liver cirrhosis, liver transplantation, and resource-use measures including costs of intervention, decreased healthcare use. Minimum length of followup: eight years

Sample size: If we assume a proportional hazards model, alpha error of 0.05 , power of 0.9 , with mortality of people who received standard care to be $9 \%$ at eight years, estimating a $20 \%$ reduction in mortality by the intervention, and a recruitment period of three years and follow-up period of eight years, one would need 3610 participants in each group prior to loss to follow-up.

Adjustments to sample size should be made to reflect the loss to follow-up and the proportion of participants who accept the intervention in $\mathrm{cmRCT}$.

Other aspects: trials need to be conducted and reported according to the SPIRIT (Standard Protocol Items: Recommendations for Interventional Trials) statement (Chan 2013) and CONSORT statement (Schulz 2010). Methodological research within trials may help with conducting trials in the optimal way.

\section{ACKNOWLEDGEMENTS}

We acknowledge the help of Adam Young, UK, who extracted some data from some studies. We acknowledge the help and support of the Cochrane Hepato-Biliary Group, Cochrane Central Editorial Unit, and copy editors. The authors would also like to thank the peer reviewers listed below who provided comments to improve 
the review. We also thank Amanda Brand, researcher at the Centre for Evidence-based Health Care, Stellenbosch University, South Africa and co-ordinator at Cochrane Nutrition, for comments on the review.

Peer reviewers of protocol: Somaya Albhaisi, USA; Mario Marasone, Italy; Ludovico Abenavoli, Italy

Peer reviewers of review: Amanda Brand, South Africa (Cochrane Nutrition); Takumi Kawaguchi, Japan; Ludovico Abenavoli, Italy; Mario Masarone, Italy; Theresa Moore (Cochrane Editorial and Methods Department), UK

Contact Editors: Christian Gluud (Co-ordinating Editor of the Hepato-Biliary), Denmark; Rachel Richardson (Associate Editor of the Abdomen and Endocrine Network), UK

Sign-off Editor: Cindy Farquhar (Senior Editor of the Abdomen and Endocrine Network), New Zealand

Cochrane Review Group funding acknowledgement: the Danish State is the largest single funder of the Cochrane Hepato-Biliary Group through its investment in the Copenhagen Trial Unit, Centre for Clinical Intervention Research, the Capital Region of Denmark, Rigshospitalet, Copenhagen, Denmark.

This project was funded by the National Institute for Health Research (NIHR) Systematic Reviews Programme (project number 16/114/17) and was supported by the Complex Reviews Support Unit, also funded by the National Institute for Health Research (project number 14/178/29).

\section{Department of Health Disclaimer}

The views and opinions expressed therein are those of the review authors and do not necessarily reflect those of the $16 / 114 / 17$ or 14/178/29 Programmes, the NIHR, the NHS, or the Department of Health.

\section{Danish State and The Copenhagen Trial Unit Disclaimer}

The views and opinions expressed in this review are those of the authors and do not necessarily reflect those of the Danish State or the Copenhagen Trial Unit. 


\section{R E F E R E N C E S}

\section{References to studies included in this review}

Abbate 2021 \{published data only\}

Abbate M, Mascaro CM, Montemayor S, Barberia-Latasa M, Casares M, Gomez C, et al. Energy expenditure improved risk factors associated with renal function loss in NALFD and METS patients. Nutrients 2021;13(2):1-24.

\section{Abdelbasset 2019 \{published data only\}}

Abdelbasset WK, Tantawy SA, Kamel DM, Alqahtani BA, Soliman GS. A randomized controlled trial on the effectiveness of 8-week high-intensity interval exercise on intrahepatic triglycerides, visceral lipids, and health-related quality of life in diabetic obese patients with nonalcoholic fatty liver disease. Medicine 2019;98(12):e14918.

\section{Abdelbasset 2020 \{published data only\}}

Abdelbasset WK, Tantawy SA, Kamel DM, Alqahtani BA, Elnegamy TE, Soliman GS, et al. Effects of high-intensity interval and moderate-intensity continuous aerobic exercise on diabetic obese patients with nonalcoholic fatty liver disease: a comparative randomized controlled trial. Medicine 2020;99(10):e19471.

\section{Abd El-Kader 2016 \{published data only\}}

Abd El-Kader SM, Al-Jiffri OH, Al-Shreef FM. Markers of liver function and inflammatory cytokines modulation by aerobic versus resisted exercise training for nonalcoholic steatohepatitis patients. African Health Sciences 2014;14(3):551-7.

* Abd El-Kader SM, Al-Shreef FM, Al-Jiffri OH. Biochemical parameters response to weight loss in patients with non-alcoholic steatohepatitis. African Health Sciences 2016;16(1):242-9.

\section{Al-Jiffri 2013 \{published data only\}}

Al-Jiffri O, Al-Sharif FM, Abd El-Kader SM, Ashmawy EM. Weight reduction improves markers of hepatic function and insulin resistance in type-2 diabetic patients with non-alcoholic fatty liver. African Health Sciences 2013;13(3):667-72.

\section{Arab 2017 \{published data only\}}

Arab A, Askari G, Golshiri P, Feizi A, Hekmatnia A, Iraj B, et al. The effect of a lifestyle modification education on adiposity measures in overweight and obese nonalcoholic fatty liver disease patients. International Journal of Preventive Medicine 2017;8:10.

\section{Asghari 2018 \{published data only\}}

Asghari S, Asghari-Jafarabadi M, Somi MH, Ghavami SM, Rafraf M. Comparison of calorie-restricted diet and resveratrol supplementation on anthropometric indices, metabolic parameters, and serum sirtuin-1 levels in patients with nonalcoholic fatty liver disease: a randomized controlled clinical trial. Journal of the American College of Nutrition 2018;37(3):223-33.
Axley 2017 \{published data only\}

Axley P, Kodali S, Kuo YF, Ravi S, Seay T, Parikh NM, et al. Text messaging approach improves weight loss in patients with nonalcoholic fatty liver disease: a randomized study. Liver International 2018;38(5):924-31.

\section{Bacchi 2013 \{published data only\}}

Bacchi E, Negri C, Targher G, Faccioli N, Lanza M, Zoppini G, et al. Both resistance training and aerobic training reduce hepatic fat content in type 2 diabetic subjects with nonalcoholic fatty liver disease (the RAED2 randomized trial). Hepatology (Baltimore, Md.) 2013;58(4):1287-95.

\section{Chan 2018 \{published data only\}}

Chan DF, So HK, Hui SC, Chan RS, Li AM, Sea MM, et al. Dietitian-led lifestyle modification programme for obese Chinese adolescents with non-alcoholic fatty liver disease: a randomized controlled study. International Journal of Obesity 2018;42(9):1680-90.

\section{Chen 2020 \{published data only\}}

Chen J, Huang Y, Xie H, Bai H, Lin G, Dong Y, et al. Impact of a low-carbohydrate and high-fiber diet on nonalcoholic fatty liver disease. Asia Pacific Journal of Clinical Nutrition 2020;29(3):483-90.

\section{Cheng 2017 \{published data only\}}

* Cheng S, Ge J, Zhao C, Le S, Yang Y, Ke D, et al. Effect of aerobic exercise and diet on liver fat in pre-diabetic patients with non-alcoholic-fatty-liver-disease: a randomized controlled trial. Scientific Reports 2017;7(1):15952.

Cheng S, Ge J, Zhao C, Wiklund P, Le S, Yang Y, et al. Effects of aerobic exercise and diet intervention on glycaemic control and liver fat content in men and women aged 50-65 years with prediabetes and non-alcoholic fatty liver disease: a multicentre, randomised controlled trial. Lancet Diabetes and Endocrinology 2016;4(Spec 3):S7.

Liu WY, Lu DJ, Du XM, Sun JQ, Ge J, Wang RW, et al. Effect of aerobic exercise and low carbohydrate diet on pre-diabetic non-alcoholic fatty liver disease in postmenopausal women and middle aged men--the role of gut microbiota composition: study protocol for the AELC randomized controlled trial. BMC Public Health 2014;14:48.

\section{Cuthbertson 2016 \{published data only\}}

* Cuthbertson DJ, Shojaee-Moradie F, Sprung VS, Jones H, Pugh CJ, Richardson P, et al. Dissociation between exerciseinduced reduction in liver fat and changes in hepatic and peripheral glucose homoeostasis in obese patients with nonalcoholic fatty liver disease. Clinical Science 2016;130(2):93-104.

Shojaee-Moradie F, Cuthbertson DJ, Barrett M, Jackson NC, Herring R, Thomas EL, et al. Exercise training reduces liver fat and increases rates of VLDL clearance but not VLDL production in NAFLD. Journal of Clinical Endocrinology and Metabolism 2016;101(11):4219-28. 
De Luis 2010 \{published data only\}

De Luis DA, Aller R, Izaola O, Gonzalez Sagrado M, Conde R. Effect of two different hypocaloric diets in transaminases and insulin resistance in nonalcoholic fatty liver disease and obese patients. Nutricion Hospitalaria 2010;25(5):730-5.

\section{De Piano 2012 \{published data only\}}

De Piano A, De Mello M, Sanches P, Silva P, Campos R, Carnier J, et al. Long-term effects of aerobic plus resistance training on the adipokines and neuropeptides in NAFLD obese adolescents. Obesity Facts 2012;5:187.

* De Piano A, De Mello MT, Sanches Pde L, Da Silva PL, Campos RM, Carnier J, et al. Long-term effects of aerobic plus resistance training on the adipokines and neuropeptides in nonalcoholic fatty liver disease obese adolescents. European Journal of Gastroenterology \& Hepatology 2012;24(11):1313-24

\section{Dong 2016 \{published data only\}}

Dong F, Zhang Y, Huang Y, Wang Y, Zhang G, Hu X, et al. Longterm lifestyle interventions in middle-aged and elderly men with nonalcoholic fatty liver disease: a randomized controlled trial. Scientific Reports 2016;6:36783.

\section{Dynnyk 2016 \{published data only\}}

Dynnyk N, Svintsitsky A, Solovyova G, Bogomaz V, Baka O, Gurbych $\mathrm{O}$, et al. Physical activity reduce hepatic apoptosis in patients with non-alcoholic fatty liver disease and visceral obesity. Journal of Hepatology 2016;64(2 Suppl 1):S491.

\section{Eckard 2013 \{published data only\}}

* Eckard C, Cole R, Lockwood J, Torres DM, Williams CD, Shaw JC, et al. Prospective histopathologic evaluation of lifestyle modification in nonalcoholic fatty liver disease: a randomized trial. Therapeutic Advances in Gastroenterology 2013;6(4):249-59.

Hayward CS, Lockwood J, Williams CD, Cole RE, Torres DM, Harrison SA. Lifestyle modification and NAFLD: a prospective, randomized trial. Hepatology (Baltimore, Md.) 2010;52(Suppl S1):622a.

\section{Goss 2020 \{published data only\}}

Dowla S, Pendergrass M, Bolding M, Gower B, Fontaine K, Ashraf A, et al. Effectiveness of a carbohydrate restricted diet to treat non-alcoholic fatty liver disease in adolescents with obesity: trial design and methodology. Contemporary Clinical Trials 2018;68:95-101.

* Goss AM, Dowla S, Pendergrass M, Ashraf A, Bolding M, Morrison S, et al. Effects of a carbohydrate-restricted diet on hepatic lipid content in adolescents with non-alcoholic fatty liver disease: a pilot, randomized trial. Pediatric Obesity 2020;15(7):e12630.

\section{Hallsworth 2011 \{published data only\}}

Hallsworth K, Fattakhova G, Hollingsworth K, Thoma C, Moore S, Day CP, et al. Resistance exercise improves liver lipid and glucose control in people with non-alcoholic fatty liver disease. Diabetic Medicine 2011;28:48.
Hallsworth K, Fattakhova G, Hollingsworth KG, Thoma C, Moore S, Day CP, et al. Resistance exercise improves liver fat and glucose control in people with non-alcoholic fatty liver disease. Diabetologia 2011;54:S246-7.

* Hallsworth K, Fattakhova G, Hollingsworth KG, Thoma C, Moore S, Taylor R, et al. Resistance exercise reduces liver fat and its mediators in non-alcoholic fatty liver disease independent of weight loss. Gut 2011;60(9):1278-83.

Jakovljevic DG, Hallsworth K, Zalewski P, Thoma C, Klawe JJ, Day CP, et al. Resistance exercise improves autonomic regulation at rest and haemodynamic response to exercise in non-alcoholic fatty liver disease. Clinical Science 2013;125(3):143-9.

\section{Hallsworth 2015 \{published data only\}}

Hallsworth K, Hollingsworth KG, Thoma C, Jakovljevic D, MacGowan GA, Anstee QM, et al. Cardiac function improves following high intensity intermittent exercise in adults with nonalcoholic fatty liver disease. Diabetic Medicine 2013;30:38

* Hallsworth K, Thoma C, Hollingsworth KG, Cassidy S, Anstee QM, Day CP, et al. Modified high-intensity interval training reduces liver fat and improves cardiac function in nonalcoholic fatty liver disease: a randomized controlled trial. Clinical Science 2015;129(12):1097-105.

Hickman 2013 \{published data only\}

Croci I, Byrne NM, Chachay VS, Hills AP, Clouston AD, O'MooreSullivan TM, et al. Independent effects of diet and exercise training on fat oxidation in non-alcoholic fatty liver disease. World Journal of Hepatology 2016;8(27):1137-48.

* Hickman I, Byrne N, Croci I, Chachay V, Clouston A, Hills $\mathrm{A}$, et al. A pilot randomised study of the metabolic and histological effects of exercise in non-alcoholic steatohepatitis. Journal of Diabetes \& Metabolism 2013;4(8):1000300. [DOI: 10.4172/2155-6156.1000300]

Hickman I, Byrne N, Croci I, Clouston A, Chachay V, Buzzigoli E, et al. The independent effect of exercise on the metabolic and histological features of nonalcoholic fatty liver disease. Obesity Facts 2012;5:26.

\section{Houghton 2017 \{published data only\}}

* Houghton D, Thoma C, Hallsworth K, Cassidy S, Hardy T, Burt AD, et al. Exercise reduces liver lipids and visceral adiposity in patients with nonalcoholic steatohepatitis in a randomized controlled trial. Clinical Gastroenterology and Hepatology 2017;15(1):96-102.e3.

Houghton DH, Thoma CT, Cassidy SC, Hallsworth $\mathrm{KH}$, Hollingsworth KG, Taylor RT, et al. Exercise reduces liver fat and improves body composition but not insulin sensitivity or inflammatory markers in non-alcoholic steatohepatitis. Diabetic Medicine 2016;33:157.

\section{Johari 2019 \{published data only\}}

* Johari MI, Yusoff K, Haron J, Nadarajan C, Ibrahim KN, Wong MS, et al. A randomised controlled trial on the effectiveness and adherence of modified alternate-day calorie 
restriction in improving activity of non-alcoholic fatty liver disease. Scientific Reports 2019;9(1):11232.

Johari MI, Yusoff K, Haron J, Nadarajan C, Ibrahim KN, Wong MS, et al. Author correction: a randomised controlled trial on the effectiveness and adherence of modified alternate-day calorie restriction in improving activity of non-alcoholic fatty liver disease. Scientific Reports 2020;10(1):10599.

\section{Kaliora 2016 \{published data only\}}

Kaliora AC, Kokkinos A, Diolintzi A, Stoupaki M, Gioxari A, Kanellos PT, et al. The effect of minimal dietary changes with raisins in NAFLD patients with non-significant fibrosis: a randomized controlled intervention. Food and Function 2016;7(11):4533-44.

\section{Kani 2014 \{published data only\}}

* Kani AH, Alavian SM, Esmaillzadeh A, Adibi P, Azadbakht L. Effects of a novel therapeutic diet on liver enzymes and coagulating factors in patients with non-alcoholic fatty liver disease: a parallel randomized trial. Nutrition 2014;30(7-8):814-21.

Kani AH, Alavian SM, Esmaillzadeh A, Adibi P, Haghighatdoost F, Azadbakht L. Effects of a low-calorie, low-carbohydrate soy containing diet on systemic inflammation among patients with nonalcoholic fatty liver disease: a parallel randomized clinical trial. Hormone and Metabolic Research 2017;49(9):687-92.

\section{Katsagoni 2018 \{published data only\}}

Katsagoni CN, Alexopoulou A, Deutsch M, Papadopoulos N, Papageorgiou M, loannidou P, et al. Improvement of metabolic syndrome after intervention based on Mediterranean diet in patients with non-alcoholic fatty liver disease (NAFLD): a randomised-controlled clinical trial. Clinical Nutrition 2016;35:S88.

* Katsagoni CN, Papatheodoridis GV, loannidou P, Deutsch M, Alexopoulou A, Papadopoulos N, et al. Improvements in clinical characteristics of patients with non-alcoholic fatty liver disease, after an intervention based on the Mediterranean lifestyle: a randomised controlled clinical trial. British Journal of Nutrition 2018;120(2):164-75.

\section{Misciagna 2017 \{published data only\}}

Misciagna G, Del Pilar Diaz M, Caramia DV, Bonfiglio C, Franco I, Noviello MR, et al. Effect of a low glycemic index Mediterranean diet on non-alcoholic fatty liver disease. A randomized controlled clinical trial. Journal of Nutrition, Health and Aging 2017;21(4):404-12.

\section{Monica Dinu 2017 \{published data only\}}

Monica Dinu M, Pagliai G, Mangino A, Colombini B, Whittaker A, Casini $A$, et al. Khorasan wheat products' consumption and nonalcoholic fatty liver disease (NAFLD): a randomized, doubleblind trial. European Journal of Preventive Cardiology 2017;24(1 Supp( 1):S22.

\section{Moradi 2020 \{published data only\}}

Moradi B, Rahmati-Ahmadabad S, Farzanegi P, Helalizadeh M, Azarbayjani MA. Effects of non-linear resistance training and curcumin supplementation on the liver biochemical markers levels and structure in older women with non-alcoholic fatty liver disease. Journal of Bodywork and Movement Therapies 2020;24(3):154-60.

\section{NCT01327443 \{published data only\}}

NCT01327443. Exercise versus diet in the treatment of nonalcoholic fatty liver disease. clinicaltrials.gov/ct2/show/ NCT01327443 (First received 1 April 2011).

\section{NCT02679417 \{published data only\}}

NCT02679417. The effects of type of exercise in non-alcoholic fatty liver disease. clinicaltrials.gov/ct2/show/NCT02679417 (First received 10 February 2016).

NCT03183193 \{published data only\} NCT03183193. Fatty liver in obesity: long-lifestyle follow-up (FLIO). clinicaltrials.gov/ct2/show/NCT03183193 (First received 12 June 2017).

\section{NCT03461562 \{published data only\}}

NCT03461562. Effectiveness of exercise applications on hepatic steatosis and physical fitness in patients with NAFLD. clinicaltrials.gov/ct2/show/NCT03461562 (First received 12 March 2018).

\section{Nikroo 2017 \{published data only\}}

Nikroo H, Attarzade HR, Sima HR, Nematy M. Aerobic exercise along with low-caloric diet is more effective than lowcaloric diet alone-in treatment of patients with non alcoholic steatohepatitis. Clinical Biochemistry 2011;44(13 Suppl 1):s17-8.

Nikroo H, Mohammadian M, Nematy M, Sima HR, Hosseini SR. The effect of diet and exercise on improvement of quality of life in patients with nonalcoholic steatohepatitis. Journal of Kerman University of Medical Sciences 2015;22(1):61-72.

* Nikroo H, Nematy M, Attarzadeh Hosseini SR, Sima HR, Razmpour F. How does addition of regular aerobic exercises, influence the efficacy of calorie-restricted diet in patients with non-alcoholic steatohepatatis (NASH)? Hepatitis Monthly 2017;17(5):e45339.

\section{Nishimori 2018 \{published data only\}}

Nishimori E, Ogata S, Naka M. Comparison of effects of lowcarbohydrate diet and calorie-restricted diet on nonalcoholic fatty liver disease in Japanese patients with type 2 diabetes. Diabetes 2018;67(Suppl 1):A199.

\section{Nourian 2020 \{published data only\}}

Nourian M, Askari G, Golshiri P, Miraghajani M, Shokri S, Arab A. Effect of lifestyle modification education based on health belief model in overweight/obese patients with non-alcoholic fatty liver disease: a parallel randomized controlled clinical trial. Clinical Nutrition ESPEN 2020;38:236-41.

\section{Oh 2017 \{published data only\}}

Oh S, So R, Shida T, Matsuo T, Kim B, Akiyama K, et al. Highintensity aerobic exercise improves both hepatic fat content and stiffness in sedentary obese men with nonalcoholic fatty liver disease. Scientific Reports 2017;7:43029. 
Panganiban 2020 \{published data only\}

Panganiban J, Blondet N, Kozlitina J, Iteld L, Puckett-Perez S, Rodriguez-Baez N, et al. Carbohydrate-restricted diet lowers hepatic triglyceride in obese children and adolescents with non-alcoholic fatty liver disease (NAFLD) and metabolic syndrome (MET-S). Hepatology (Baltimore, Md.) 2020;72(1 Suppl):1046a-7a.

\section{Properzi 2018 \{published data only\}}

Properzi C, O'Sullivan TA, Sherriff JL, Ching H, Jeffrey GP, Tibballs $\mathrm{J}$, et al. Hepatic steatosis is significantly reduced by either a low-fat or a Mediterranean-style diet in patients with non-alcoholic fatty liver disease. Journal of Gastroenterology and Hepatology 2017;32:181.

* Properzi C, O'Sullivan TA, Sherriff JL, Ching HL, Jeffrey GP, Buckley RF, et al. Ad libitum Mediterranean and low-fat diets both significantly reduce hepatic steatosis: a randomized controlled trial. Hepatology (Baltimore, Md.) 2018;68(5):1741-54.

Properzi C, Sullivan T, Sherriff J, Adams L, Jeffrey G, Ching H, et al. Ad libitum Mediterranean and low fat diets both significantly reduce hepatic steatosis: a randomized controlled trial. Hepatology International 2018;12(2):S232.

\section{Pugh 2014 \{published data only\}}

Pugh CJ, Cuthbertson DJ, Sprung VS, Kemp GJ, Richardson P, Umpleby AM, et al. Exercise training improves cutaneous microvascular function in nonalcoholic fatty liver disease. American Journal of Physiology - Endocrinology and Metabolism 2013;305(1):e50-8.

* Pugh CJ, Spring VS, Kemp GJ, Richardson P, ShojaeeMoradie F, Umpleby AM, et al. Exercise training reverses endothelial dysfunction in nonalcoholic fatty liver disease. American Journal of Physiology - Heart and Circulatory Physiology 2014;307(9):H1298-306.

\section{Ramirez 2016 \{published data only\}}

* Ramirez CM, Panganiban JA, Blondet N, Kozlitina J, Barraco R, Flores C, et al. Carbohydrate-restricted diet lowers hepatic triglyceride in obese adolescents with metabolic syndrome and non-alcoholic fatty liver disease. Journal of Pediatric Gastroenterology and Nutrition 2016;63:S44.

Shojaee-Moradie F, Cuthbertson DJ, Kemp GJ, Barrett M, Jackson NC, Batt J, et al. Exercise training alters VLDL TG and apoB metabolism in men with non-alcoholic liver disease (NAFLD). Atherosclerosis 2015;241(1):e103.

\section{Ramon-Krauel 2013 \{published data only\}}

Ramon-Krauel M, Salsberg SL, Ebbeling CB, Voss SD, Mulkern RV, Apura MM, et al. A low-glycemic-load versus low-fat diet in the treatment of fatty liver in obese children. Childhood Obesity 2013;9(3):252-60.

\section{Rezende 2016 \{published data only\}}

Rezende RE, Duarte SM, Stefano JT, Perandini LA, Dassouki T, Sa-Pinto AL, et al. Impact of aerobic exercise in postmenopausal women with nonalcoholic fatty liver disease: a 24 weeks randomized clinical trial. Journal of Hepatology 2015;62:S724.
* Rezende RE, Duarte SM, Stefano JT, Roschel H, Gualano B, De Sa Pinto AL, et al. Randomized clinical trial: benefits of aerobic physical activity for 24 weeks in postmenopausal women with nonalcoholic fatty liver disease. Menopause 2016;23(8):876-83.

Rodriguez-Hernandez 2011 \{published data only\}

Rodriguez-Hernandez H, Cervantes-Huerta M, RodriguezMoran M, Guerrero-Romero F. Decrease of aminotransferase levels in obese women is related to body weight reduction, irrespective of type of diet. Annals of Hepatology 2011;10(4):486-92.

\section{Roy 2017 \{published data only\}}

Roy K, Iyer U, Shah R, Vaishnav T. Impact of metabolic syndrome targeted lifestyle modification counselling in the management of non-alcoholic fatty liver disease in type 2 diabetics. Endocrine Practice 2017;23(1):7a-8a.

\section{Schattenberg 2017 \{published data only\}}

Schattenberg JM, Schlegel L, Nier A, Huber Y, Galle PR, Bergheim I. Dietary counselling focusing only on fructose consumption improves hepatic inflammation in patients with NAFLD-a prospective, controlled, randomized open-label study (NUCES NASH). Hepatology (Baltimore, Md.) 2017;66(Suppl 1):1106a-7a.

\section{Selezneva 2014 \{published data only\}}

Selezneva K, Kirillova O, Vorozhko I, Isakov VA, Sentsova T. Short-term effect of low-calorie diet (LCD) versus isocalorie diet (ICD) on blood aminotransferases level and lipids profile in patients with non-alcoholic steatohepatitis (NASH). Journal of Hepatology 2014;60(1 Suppl 1):S353.

\section{Shidfar 2018 \{published data only\}}

Shidfar F, Bahrololumi SS, Doaei S, Mohammadzadeh A, Gholamalizadeh M, Mohammadimanesh A. The effects of extra virgin olive oil on alanine aminotransferase, aspartate aminotransferase, and ultrasonographic indices of hepatic steatosis in nonalcoholic fatty liver disease patients undergoing low calorie diet. Canadian Journal of Gastroenterology \& Hepatology 2018;2018:1053710.

\section{Sima 2014 \{published data only\}}

Sima HR, Nikroo H, Nematy M, Attarzade-Hosseini SR, Mohammadian-Damasaki M, Rad MP, et al. Effect of aerobic exercise added to calorie-restricted diet on non-alcoholic steatohepatitis, a randomized clinical trial. Gastroenterology 2014;146(5 Suppl 1):S-945.

\section{Sullivan 2012 \{published data only\}}

Sullivan S, Kirk EP, Mittendorfer B, Patterson BW, Klein S. Effect of endurance exercise on nonalcoholic fatty liver disease. Clinical and Translational Science 2012;5(2):154.

* Sullivan S, Kirk EP, Mittendorfer B, Patterson BW, Klein S. Randomized trial of exercise effect on intrahepatic triglyceride content and lipid kinetics in nonalcoholic fatty liver disease. Hepatology (Baltimore, Md.) 2012;55(6):1738-45. 
Tutino 2018 \{published data only\}

Franco I, Bianco A, Mirizzi A, Campanella A, Bonfiglio C, Sorino P, et al. Physical activity and low glycemic index Mediterranean diet: Main and modification effects on NAFLD score. Results from a randomized clinical trial. Nutrients 2021;13(1):1-24.

* Tutino V, De Nunzio V, Caruso MG, Bonfiglio C, Franco I, Mirizzi A, et al. Aerobic physical activity and a low glycemic diet reduce the $A A / E P A$ ratio in red blood cell membranes of patients with NAFLD. Nutrients 2018;10(9):13.

Wang 2008 \{published data only\}

Wang CL, Liang L, Fu JF, Zou CC, Hong F, Xue JZ, et al. Effect of lifestyle intervention on non-alcoholic fatty liver disease in Chinese obese children. World Journal of Gastroenterology 2008;14(10):1598-602.

\section{Wang 2016 \{published data only\}}

Wang XG, Huang LH. Therapeutic effect of fasted exercise on nonalcoholic fatty hepatitis. World Chinese Journal of Digestology 2016;24:3417-21.

\section{Wong 2013 \{published data only\}}

Shen J, Wong GL, Chan HL, Chan RS, Chan HY, Chu WC, et al. PNPLA3 gene polymorphism and response to lifestyle modification in patients with nonalcoholic fatty liver disease. Journal of Gastroenterology and Hepatology 2015;30(1):139-46.

Wong VW, Chan RS, Wong GH, Cheung BK, Chu WW, Chan HY, et al. Low glycaemic index dietary intervention for patients with non-alcoholic fatty liver disease in the general population-a randomised controlled trial. Gut 2012;61:A417.

* Wong VW, Chan RS, Wong GL, Cheung BH, Chu WC, Yeung DK, et al. Community-based lifestyle modification programme for non-alcoholic fatty liver disease: a randomized controlled trial. Journal of Hepatology 2013;59(3):536-42.

Wong VW, Wong GL, Chan RS, Shu SS, Cheung BH, Li LS, et al. Beneficial effects of lifestyle intervention in non-obese patients with non-alcoholic fatty liver disease. Journal of Hepatology 2018;22:22.

\section{Yao 2018 \{published data only\}}

Yao JL, Meng MM, Yang SN, Li F, Anderson RM, Liu C, et al. Effect of aerobic and resistance exercise on liver enzyme and blood lipids in Chinese patients with nonalcoholic fatty liver disease: a randomized controlled trial. International Journal of Clinical and Experimental Medicine 2018;11(5):4867-74.

\section{Zade 2016 \{published data only\}}

Zade MR, Telkabadi MH, Bahmani F, Salehi B, Farshbaf S, Asemi Z. The effects of dash diet on weight loss and metabolic status in adults with non-alcoholic fatty liver disease: a randomized clinical trial. Liver International 2016;36(4):563-71.

Zelber-Sagi 2014 \{published data only\}

Zelber-Sagi S, Buch A, Yeshua H, Vaisman N, Webb M, Harari G, et al. Effect of resistance training on non-alcoholic fattyliver disease a randomized-clinical trial. World Journal of Gastroenterology 2014;20(15):4382-92.

\section{Zhang 2016 \{published data only\}}

Zhang H, Pan LL, Ma ZM, Chen Z, Lu Y, Li XY. The long-term effect of exercise intervention on improving fatty liver and cardiovascular risk factors in obese adults: a one-year follow-up study. Diabetologia 2016;1(Suppl 1):S150.

* Zhang HJ, He J, Pan LL, Ma ZM, Han CK, Chen CS, et al. Effects of moderate and vigorous exercise on nonalcoholic fatty liver disease: a randomized clinical trial. JAMA Internal Medicine 2016;176(8):1074-82.

Zhang HJ, Pan LL, Ma ZM, Chen Z, Huang ZF, Sun Q, et al. Long-term effect of exercise on improving fatty liver and cardiovascular risk factors in obese adults: a 1-year follow-up study. Diabetes, Obesity and Metabolism 2017;19(2):284-9.

\section{References to studies excluded from this review}

Aller 2014 \{published data only\}

Aller R, De Luis DA, Izaola O, De la Fuente B, Bachiller R. Effect of a high monounsaturated vs high polyunsaturated fat hypocaloric diets in nonalcoholic fatty liver disease. European Review for Medical and Pharmacological Sciences 2014;18(7):1041-7.

An 2015 \{published data only\}

An YM, Jun DW, Lee SM. Development and application of lowcarbohydrates and low-simple sugar nutrition education materials for non-alcoholic fatty liver disease patients. Clinical Nutrition Research 2015;4(4):250-8.

Arefhosseini 2011 \{published data only\}

Arefhosseini SR, Ebrahimi-Mameghani M, Farsad Naeimi A, Khoshbaten M, Rashid J. Lifestyle modification through dietary intervention: health promotion of patients with nonalcoholic fatty liver disease. Health Promotion Perspectives 2011;1(2):147-54.

\section{Austin 2020 \{published data only\}}

Austin PW, Nachum R, Jackson K, Escheik C, Duric Z, Weinstein AA, et al. Personalized intervention increases free-living physical activity in sedentary individuals with nonalcoholic fatty liver disease (NAFLD). Hepatology (Baltimore, Md.) 2020;72(1 Suppl):986a.

\section{Baldry 2017 \{published data only\}}

Baldry E, Aithal GP, Kaye P, Idris I, Leeder P, Bennett A, et al. Effects of short term very low energy diets prior to bariatric surgery on liver histology and circulating biomarkers: results of a randomised controlled trial (RCT). Journal of Hepatology 2015;62:S716.

Baldry EL, Aithal GP, Idris I, Kaye P, Leeder P, Bennett A, et al. Effects of short-term energy restriction prior to bariatric surgery on liver fat, inflammation and systemic metabolic parameters. Diabetic Medicine 2015;32:52.

* Baldry EL, Aithal GP, Kaye P, Idris IR, Bennett A, Leeder PC, et al. Effects of short-term energy restriction on liver lipid content and inflammatory status in severely obese adults: results of 
a randomized controlled trial using 2 dietary approaches. Diabetes, Obesity and Metabolism 2017;19(8):1179-83.

\section{Dela Cruz 2012 \{published data only\}}

Dela Cruz R, Mappala HT. The efficacy of ursodeoxycholic acid, probiotics vs. diet and exercise in the treatment of NAFLD: an open-labelled prospective randomized trial. Journal of Gastroenterology and Hepatology 2012;27:223.

\section{Dorosti 2020 \{published data only\}}

Dorosti M, Heidarloo AJ, Bakhshimoghaddam F, Alizadeh M. Whole-grain consumption and its effects on hepatic steatosis and liver enzymes in patients with non-alcoholic fatty liver disease: a randomised controlled clinical trial. British Journal of Nutrition 2020;123(3):328-36.

\section{Dynnyk 2017 \{published data only\}}

Dynnyk N, Svintsitsky A, Solovyova G, Baka O, Chernyavskyi V, Yarmenchuk I, et al. Changing eating behavior by motivational and controlled program during 12 weeks reduce weight, cytokeratin 18 levels and steatosis in patient with NAFLD. Journal of Hepatology 2017;66(1 Suppl 1):S427.

\section{Haidari 2020 \{published data only\}}

Haidari F, Hojhabrimanesh A, Helli B, Seyedian SS, AhmadiAngali K, Abiri B. A hypocaloric high-protein diet supplemented with beta-cryptoxanthin improves non-alcoholic fatty liver disease: a randomized controlled trial. BMC Gastroenterology 2020;20(1):349.

* Haidari F, Hojhabrimanesh A, Helli B, Seyedian SS, AhmadiAngali K. An energy-restricted high-protein diet supplemented with beta-cryptoxanthin alleviated oxidative stress and inflammation in nonalcoholic fatty liver disease: a randomized controlled trial. Nutrition Research 2020;73:15-26.

Lim 2020 \{published data only\}

Lim SL, Johal J, Ong KW, Han CY, Chan YH, Lee YM, et al. Lifestyle intervention enabled by mobile technology on weight loss in patients with nonalcoholic fatty liver disease: randomized controlled trial. JMIR MHealth and UHealth 2020;8(4):e14802.

\section{Marin-Alejandre 2021 \{published data only\}}

Marin-Alejandre BA, Abete I, Cantero I, Galarregui C, Elorz M, Tur JA, et al. Depressive symptoms and liver fat in subjects with nonalcoholic fatty liver disease after 6-month weight loss intervention: The FLIO study. Proceedings of the Nutrition Society 2020;79(Oce2):E373.

* Marin-Alejandre BA, Cantero I, Perez-Diaz-Del-Campo N, Monreal JI, Elorz M, Herrero JI, et al. Effects of two personalized dietary strategies during a 2-year intervention in subjects with nonalcoholic fatty liver disease: a randomized trial. Liver International 2021 February 7 [Online ahead of print]. [DOI: doi: 10.1111/liv.14818]

\section{Nath 2020 \{published data only\}}

Nath P, Panigrahi MK, Sahu MK, Narayan J, Sahoo RK, Patra AA, et al. Effect of exercise on NAFLD and its risk factors: comparison of moderate versus low intensity exercise. Journal of Clinical \& Translational Hepatology 2020;8(2):120-6.

\section{NCT04193982 \{published data only\}}

NCT04193982. An investigator initiated prospective, four arms randomized comparative study of efficacy and safety of saroglitazar, vitamin E and life style modification in patients with nonalcoholic fatty liver disease (NAFLD)/ non-alcoholic steatohepatitis (NASH). ClinicalTrials.gov/show/NCT04193982 (First posted 11 December 2019).

\section{NCT04383951 \{published data only\}}

NCT04383951. Safety and efficacy of ketogenic diet for promoting weight loss in obese individuals with compensated NASH cirrhosis. clinicaltrials.gov/ct2/show/NCT04383951 (First posted 12 May 2020).

\section{NCT04520724 \{published data only\}}

NCT04520724. Functional roll for non-alcoholic fatty liver disease. clinicaltrials.gov/show/NCT04520724 (First posted 20 August 2020).

\section{Negri 2020 \{published data only\}}

Negri R, Trinchese G, Carbone F, Caprio MG, Stanzione G, Di Scala C, et al. Randomised clinical trial: calorie restriction regimen with tomato juice supplementation ameliorates oxidative stress and preserves a proper immune surveillance modulating mitochondrial bioenergetics of t-lymphocytes in obese children affected by non-alcoholic fatty liver disease (NAFLD). Journal of Clinical Medicine 2020;9(1):141.

\section{Nigam 2014 \{published data only\}}

Nigam P, Bhatt S, Misra A, Chadha DS, Vaidya M, Dasgupta J, et al. Effect of a 6-month intervention with cooking oils containing a high concentration of monounsaturated fatty acids (olive and canola oils) compared with control oil in male Asian Indians with nonalcoholic fatty liver disease. Diabetes Technology \& Therapeutics 2014;16(4):255-61.

Nobili 2008 \{published data only\}

* Nobili V, Manco M, Devito R, Di Ciomm V, Comparcola D, Sartorelh MP, et al. Lifestyle intervention and antioxidant therapy in children with nonalcoholic fatty liver disease: a randomized, controlled trial. Hepatology (Baltimore, Md.) 2008;48(1):119-28

Nobili V, Manco M, DeVito R, PietroBattista A, Comparcola D, Sartorelli MR, et al. Lifestyle intervention and antioxidants in children with nonalcoholic fatty liver disease: a randomized, controlled trial. Gastroenterology 2008;134(4):a781.

\section{Promrat 2010 \{published data only\}}

* Promrat K, Kleiner DE, Niemeier HM, Jackvony E, Kearns M, Wands JR, et al. Randomized controlled trial testing the effects of weight loss on nonalcoholic steatohepatitis. Hepatology (Baltimore, Md.) 2010;51(1):121-9.

Promrat K, Kleiner DE, Niemeier HM, Jackvony E, Kearns M, Wands JR. Randomized controlled trial testing the effects of weight loss on nonalcoholic steatohepatitis (NASH). Hepatology (Baltimore, Md.) 2008;48(4 Suppl):802a. 
Rezaei 2019 \{published data only\}

Rezaei S, Akhlaghi M, Sasani MR, Barati Boldaji R. Olive oil lessened fatty liver severity independent of cardiometabolic correction in patients with non-alcoholic fatty liver disease: a randomized clinical trial. Nutrition 2019;57:154-61.

Ristic-Medic 2020 \{published data only\}

Ristic-Medic D, Kovacic M, Takic M, Arsic A, Petrovic S, Paunovic M, et al. Calorie-restricted Mediterranean and lowfat diets affect fatty acid status in individuals with nonalcoholic fatty liver disease. Nutrients 2020;13(1):23.

Ryan 2013 \{published data only\}

Ryan MC, Itsiopoulos C, Thodis T, Ward G, Trost N, Hofferberth S, et al. The Mediterranean diet improves hepatic steatosis and insulin sensitivity in individuals with non-alcoholic fatty liver disease. Journal of Hepatology 2013;59(1):138-43.

\section{Schweinlin 2018 \{published data only\}}

Schweinlin A, Ulbrich S, Staubeta S, Teutsch M, Walle H, Basrai M, et al. Comparison of a commercially available, formula-based nutritional therapy enriched with oats fiber with a non-formula isocaloric therapy to treat non-alcoholic fatty liver disease (NAFLD) - a randomized, controlled intervention trial. Zeitschrift fur Gastroenterologie 2018;56(10):1247-56.

\section{Simons 2021 \{published data only\}}

Simons N, Veeraiah P, Simons P, Schaper NC, Kooi ME, Schrauwen-Hinderling VB, et al. Effects of fructose restriction on liver steatosis (fruitless); a double-blind randomized controlled trial. American Journal of Clinical Nutrition 2021;113(2):391-400.

\section{St George 2009 \{published data only\}}

St George A, Bauman A, Johnston A, Farrell G, Chey T, George J. Independent effects of physical activity in patients with nonalcoholic fatty liver disease. Hepatology (Baltimore, Md.) 2009;50(1):68-76.

\section{Sun 2012 \{published data only\}}

Sun WH, Song MQ, Jiang CQ, Xin YN, Ma JL, Liu YX, et al. Lifestyle intervention in non-alcoholic fatty liver disease in Chengyang district, Qingdao, China. World Journal of Hepatology 2012;4(7):224-30.

\section{TCTR20200411004 \{published data only\}}

TCTR20200411004. Text messaging intervention and weight loss in patients with non-alcoholic fatty liver disease: a randomized controlled study. ictrptest.azurewebsites.net/Trial2.aspx? TrialID=TCTR20200411004 (First received 11 April 2020).

\section{Vilar Gomez 2009 \{published data only\}}

Vilar Gomez E, Rodriguez De Miranda A, Gra Oramas B, Arus Soler E, Llanio Navarro R, Calzadilla Bertot L, et al. Clinical trial: a nutritional supplement Viusid, in combination with diet and exercise, in patients with nonalcoholic fatty liver disease. Alimentary Pharmacology \& Therapeutics 2009;30(10):999-1009.

\section{Whyte 2020 \{published data only\}}

Whyte MB, Shojaee-Moradie F, Sharaf SE, Cuthbertson DJ, Kemp GJ, Barrett M, et al. HDL-apoA-I kinetics in response to 16 wk of exercise training in men with nonalcoholic fatty liver disease. American Journal of Physiology - Endocrinology and Metabolism 2020;318(6):E839-47.

\section{References to studies awaiting assessment}

Bahrololumi 2014 \{published data only\}

Bahrololumi S, Shidfar F, Jazayeri S, Taghvaie T. The effects of virgin olive oil-rich diet on fasting serum glucose and lipid profile in non alcoholic fatty liver patients with weight loss diet. Iranian Journal of Endocrinology and Metabolism 2014;15(6):527-37.

\section{Grove 2020 \{published data only\}}

Grove J, Vijay A, Astbury S, Simpson L, Bawden S, Leena KB, et al. Effect of low glycemic index carbohydrate consumption in non-alcoholic fatty liver disease: a community-based pilot randomised controlled trial and mechanistic study. Hepatology (Baltimore, Md.) 2020;72(1 Suppl):369a.

\section{Jia 2018 \{published data only\}}

Jia GY, Han T, Gao L, Wang L, Wang SC, Yang L, et al. Effect of aerobic exercise and resistance exercise in improving nonalcoholic fatty liver disease: a randomized controlled trial. Chung Hua Kan Tsang Ping Tsa Chih 2018;26(1):34-41.

\section{References to ongoing studies}

IRCT20100524004010N31 \{published data only\}

IRCT20100524004010N31. Evaluation of the effects of Fasting Mimicking Diet (FMD) on lipid profile, glycemic, inflammatory and histologic indices in Non-Alcoholic Fatty Liver (NAFLD). www.irct.ir/trial/49958 (First received 19 August 2020).

NCT03354247 \{published data only\} NCT03354247. Lifestyle Intervention in Fatty Liver (NAFLD) (FOIEGRAS). clinicaltrials.gov/ct2/show/NCT03354247 (First received 27 November 2017).

\section{NCT03518294 \{published data only\}}

NCT03518294. Nash fitness intervention in thrombosis trial (NASHFit). clinicaltrials.gov/ct2/show/NCT03518294 (First received 8 May 2018).

Stine JG, Schreibman I, Navabi S, Kang M, Dahmus J, Soriano C, et al. Nonalcoholic steatohepatitis Fitness Intervention in Thrombosis (NASHFit): study protocol for a randomized controlled trial of a supervised aerobic exercise program to reduce elevated clotting risk in patients with NASH. Contemporary Clinical Trials Communications 2020;18:100560.

\section{NCT04283942 \{published data only\}}

NCT04283942. Effect of intermittent calorie restriction on NAFLD patients with disorders of glucose metabolism. clinicaltrials.gov/ct2/show/NCT04283942 (First received 25 February 2020).

\section{NCT04355910 \{published data only\}}

NCT04355910. Intermittent fasting in nonalcoholic fatty liver disease. clinicaltrials.gov/ct2/show/NCT04355910 (First received 21 April 2020). 


\section{NCT04369521 \{published data only\}}

NCT04369521. Evaluation of the effects of a low free sugar diet in patients with nonalcoholic fatty liver disease. clinicaltrials.gov/ct2/show/NCT04369521 (First received 30 April 2020).

\section{NCT04440540 \{published data only\}}

NCT04440540. Alternation of non-alcoholic fatty liver disease (NAFLD) and cardiovascular risks after liftestyle modification: a ultrasound attenuation imaging-based study. clinicaltrials.gov/ ct2/show/NCT04440540 (First received 19 June 2020).

\section{Additional references}

\section{Abdelmalek 2007}

Abdelmalek MF, Diehl AM. Nonalcoholic fatty liver disease as a complication of insulin resistance. Medical Clinics of North America 2007;91(6):1125-49, ix.

\section{Abenavoli 2013}

Abenavoli L, Bellentani S. Milk thistle to treat non-alcoholic fatty liver disease: dream or reality? Expert Review of Gastroenterology \& Hepatology 2013;7(8):677-9.

\section{Abenavoli 2015}

Abenavoli L, Greco M, Nazionale I, Peta V, Milic N, Accattato F, et al. Effects of Mediterranean diet supplemented with silybinvitamin E-phospholipid complex in overweight patients with non-alcoholic fatty liver disease. Expert Review of Gastroenterology \& Hepatology 2015;9(4):519-27.

\section{Adams 2005}

Adams LA, Lymp JF, St Sauver J, Sanderson SO, Lindor KD, Feldstein $\mathrm{A}$, et al. The natural history of nonalcoholic fatty liver disease: a population-based cohort study. Gastroenterology 2005;129(1):113-21.

\section{Adorini 2012}

Adorini L, Pruzanski M, Shapiro D. Farnesoid X receptor targeting to treat nonalcoholic steatohepatitis. Drug Discovery Today 2012;17(17-18):988-97.

\section{Alberti 2009}

Alberti KG, Eckel RH, Grundy SM, Zimmet PZ, Cleeman JI, Donato KA, et al. Harmonizing the metabolic syndrome: a joint interim statement of the International Diabetes Federation Task Force on Epidemiology and Prevention; National Heart, Lung, and Blood Institute; American Heart Association; World Heart Federation; International Atherosclerosis Society; and International Association for the Study of Obesity. Circulation 2009;120(16):1640-5.

\section{Al-Muzafar 2017}

Al-Muzafar HM, Amin KA. Probiotic mixture improves fatty liver disease by virtue of its action on lipid profiles, leptin, and inflammatory biomarkers. BMC Complementary and Alternative Medicine 2017;17(1):43.

\section{Anderson 2015}

Anderson EL, Howe LD, Jones HE, Higgins JP, Lawlor DA, Fraser A. The prevalence of non-alcoholic fatty liver disease in children and adolescents: a systematic review and metaanalysis. PLOS One 2015;10(10):e0140908. [PMID: 26512983]

\section{Angulo 2002}

Angulo P. Nonalcoholic fatty liver disease. New England Journal of Medicine 2002;346(16):1221-31.

\section{Angulo 2015}

Angulo P, Kleiner DE, Dam-Larsen S, Adams LA, Bjornsson ES, Charatcharoenwitthaya $P$, et al. Liver fibrosis, but no other histologic features, is associated with long-term outcomes of patients with nonalcoholic fatty liver disease. Gastroenterology 2015;149(2):389-97.e10

\section{Anstee 2012}

Anstee QM, Day CP. S-adenosylmethionine (SAMe) therapy in liver disease: a review of current evidence and clinical utility. Journal of Hepatology 2012;57(5):1097-109.

\section{Ballestri 2016}

Ballestri S, Zona S, Targher G, Romagnoli D, Baldelli E, Nascimbeni F, et al. Nonalcoholic fatty liver disease is associated with an almost twofold increased risk of incident type 2 diabetes and metabolic syndrome. Evidence from a systematic review and meta-analysis. Journal of Gastroenterology and Hepatology 2016;31(5):936-44.

\section{Barritt 2017}

Barritt AS 4th, Gitlin N, Klein S, Lok AS, Loomba R, Malahias L, et al. Design and rationale for a real-world observational cohort of patients with nonalcoholic fatty liver disease: The TARGETNASH study. Contemporary Clinical Trials 2017;61:33-8.

\section{Bedogni 2005}

Bedogni G, Miglioli L, Masutti F, Tiribelli C, Marchesini G, Bellentani S. Prevalence of and risk factors for nonalcoholic fatty liver disease: the Dionysos nutrition and liver study. Hepatology (Baltimore, Md.) 2005;42(1):44-52.

\section{Bedogni 2007}

Bedogni G, Miglioli L, Masutti F, Castiglione A, Croce LS, Tiribelli $C$, et al. Incidence and natural course of fatty liver in the general population: the Dionysos study. Hepatology (Baltimore, Md.) 2007;46(5):1387-91.

\section{Bernsmeier 2015}

Bernsmeier C, Weisskopf DM, Pflueger MO, Mosimann J, Campana B, Terracciano L, et al. Sleep disruption and daytime sleepiness correlating with disease severity and insulin resistance in non-alcoholic fatty liver disease: a comparison with healthy controls. PLOS One 2015;10(11):e0143293.

\section{Best 2018}

Best LM, Freeman S, Sutton AJ, Hawkins N, Tsochatzis E, Gurusamy KS. Treatment for hepatorenal syndrome in people with decompensated liver cirrhosis: a network meta-analysis. Cochrane Database of Systematic Reviews 2018, Issue 9. Art. No: CD013103. [DOI: 10.1002/14651858.CD013103] 


\section{Brignardello-Petersen 2018}

Brignardello-Petersen R, Bonner A, Alexander PE, Siemieniuk RA, Furukawa TA, Rochwerg B, et al. Advances in the GRADE approach to rate the certainty in estimates from a network meta-analysis. Journal of Clinical Epidemiology 2018;93:36-44. [PMID: 29051107]

\section{Brunt 2011}

Brunt EM, Kleiner DE, Wilson LA, Belt P, Neuschwander-Tetri BA, NASH Clinical Research Network (CRN). Nonalcoholic fatty liver disease (NAFLD) activity score and the histopathologic diagnosis in NAFLD: distinct clinicopathologic meanings. Hepatology (Baltimore, Md.) 2011;53(3):810-20.

\section{Buzzetti 2016}

Buzzetti E, Pinzani M, Tsochatzis EA. The multiple-hit pathogenesis of non-alcoholic fatty liver disease (NAFLD). Metabolism: Clinical and Experimental 2016;65(8):1038-48.

\section{Cavero-Redono 2020}

Cavero-Redondo I, Martinez-Vizcaino V, Fernandez-Rodriguez R, Saz-Lara A, Pascual-Morena C, Álvarez-Bueno C. Effect of behavioral weight management interventions using lifestyle mHealth self-monitoring on weight loss: a systematic review and meta-analysis. Nutrients 2020;12(7):1977.

\section{Cerovic 2013}

Cerovic I, Mladenovic D, Jesic R, Naumovic T, Brankovic M, Vucevic D, et al. Alcoholic liver disease/nonalcoholic fatty liver disease index: distinguishing alcoholic from nonalcoholic fatty liver disease. European Journal of Gastroenterology \& Hepatology 2013;25(8):899-904.

\section{Chaimani 2012}

Chaimani A, Salanti G. Using network meta-analysis to evaluate the existence of small-study effects in a network of interventions. Research Synthesis Methods 2012;3(2):161-76.

\section{Chaimani 2013}

Chaimani A, Higgins JP, Mavridis D, Spyridonos P, Salanti G. Graphical tools for network meta-analysis in STATA. PLOS One 2013;8(10):e76654.

\section{Chalasani 2012}

Chalasani N, Younossi Z, Lavine JE, Diehl AM, Brunt EM, Cusi K, et al. The diagnosis and management of non-alcoholic fatty liver disease: practice guideline by the American Association for the Study of Liver Diseases, American College of Gastroenterology, and the American Gastroenterological Association. Hepatology (Baltimore, Md.) 2012;55(6):2005-23.

\section{Chan 2013}

Chan AW, Tetzlaff JM, Altman DG, Laupacis A, Gøtzsche PC, Krleza-Jeric K, et al. SPIRIT 2013 statement: defining standard protocol items for clinical trials. Annals of Internal Medicine 2013;158(3):200-7.

\section{Cholankeril 2017}

Cholankeril G, Wong RJ, Hu M, Perumpail RB, Yoo ER, Puri P, et al. Liver transplantation for nonalcoholic steatohepatitis in the US: temporal trends and outcomes. Digestive Diseases and Sciences 2017;62(10):2915-22.

\section{Clearfield 2021}

Clearfield E, Miller V, Nadglowski J, Barradas K, Al Naber J, Sanyal AJ, et al. coreNASH: multi-stakeholder consensus on core outcomes for decision making about nonalcoholic steatohepatitis treatment. Hepatology Communications 2021 February 12 [Epud ahead of print]. [DOI: 10.1002/hep4.1678]

\section{Cochrane Scientific Committee 2018}

Cochrane Scientific Committee. Should Cochrane apply error-adjustment methods when conducting repeated metaanalyses? methods.cochrane.org/sites/default/files/public/ uploads/tsa_expert_panel_guidance_and_recommendation_ final.pdf 2018 (accessed 9 April 2021).

\section{Conlon 2013}

Conlon BA, Beasley JM, Aebersold K, Jhangiani SS, WylieRosett J. Nutritional management of insulin resistance in nonalcoholic fatty liver disease (NAFLD). Nutrients 2013;5(10):4093-114

Cowie 2017

Cowie MR, Blomster JI, Curtis LH, Duclaux S, Ford I, Fritz F, et al. Electronic health records to facilitate clinical research. Clinical Research in Cardiology 2017;106(1):1-9.

\section{Dam-Larsen 2005}

Dam-Larsen S, Franzmann MB, Christoffersen P, Larsen K, Becker U, Bendtsen F. Histological characteristics and prognosis in patients with fatty liver. Scandinavian Journal of Gastroenterology 2005;40(4):460-7.

\section{Dassanayake 2009}

Dassanayake AS, Kasturiratne A, Rajindrajith S, Kalubowila U, Chakrawarthi S, De Silva AP, et al. Prevalence and risk factors for non-alcoholic fatty liver disease among adults in an urban Sri Lankan population. Journal of Gastroenterology and Hepatology 2009;24(7):1284-8.

\section{Dias 2012a}

Dias S, Sutton AJ, Welton NJ, Ades AE. NICE DSU technical support document 3: heterogeneity: subgroups, metaregression, bias and bias-adjustment, September 2011 (last updated April 2012). nicedsu.org.uk/wp-content/ uploads/2016/03/TSD3-Heterogeneity.final-report.08.05.12.pdf (accessed 12 February 2021).

\section{Dias 2012b}

Dias S, Welton NJ, Sutton AJ, Ades AE. NICE DSU technical support document 1: introduction to evidence synthesis for decision making, April 2011 (last updated April 2012). nicedsu.org.uk/wp-content/uploads/2016/03/TSD1Introduction.final_.08.05.12.pdf (accessed 12 February 2021).

\section{Dias 2014}

Dias S, Welton NJ, Sutton AJ, Caldwell DM, Lu G, Ades AE. NICE DSU technical support document 4: inconsistency in networks of evidence based on randomised controlled trials, May 2011 (last updated April 2014). nicedsu.org.uk/wp-content/ 
uploads/2016/03/TSD4-Inconsistency.final_.15April2014.pdf (accessed 12 February 2021).

\section{Dias 2016}

Dias S, Welton NJ, Sutton AJ, Ades AE. NICE DSU technical support document 2: a generalised linear modelling framework for pairwise and network meta-analysis of randomised controlled trials, August 2011 (last updated September 2016). www.ncbi.nlm.nih.gov/pubmedhealth/PMH0088912/pdf/ PubMedHealth_PMH0088912.pdf (accessed 12 February 2021).

\section{Edgeworth 1887}

Edgeworth FY. On observations relating to several quantities. Hermathena 1887;6(13):279-285.

\section{Ekstedt 2015}

Ekstedt M, Hagström H, Nasr P, Fredrikson M, Stål P, Kechagias $\mathrm{S}$, et al. Fibrosis stage is the strongest predictor for disease-specific mortality in NAFLD after up to 33 years of follow-up. Hepatology (Baltimore, Md.) 2015;61(5):1547-54.

\section{Eslam 2019}

Eslam M, Sanyal AJ, George J. Toward more accurate nomenclature for fatty liver diseases. Gastroenterology 2019;157(3):590-3.

\section{EuroQol 2018}

EuroQol. EQ-5D Instruments | About EQ-5D, 2018. euroqol.org/ eq-5d-instruments/ (accessed 12 February 2021).

\section{Fleischman 2014}

Fleischman MW, Budoff M, Zeb I, Li D, Foster T. NAFLD prevalence differs among Hispanic subgroups: the multi-ethnic study of atherosclerosis. World Journal of Gastroenterology 2014;20(17):4987-93.

\section{Gurusamy 2019}

Gurusamy K, Walmsley M, Davidson BR, Frier C, Fuller B, Madden $\mathrm{A}$, et al. Top research priorities in liver and gallbladder disorders in the United Kingdom. BMJ Open 2019;9(3):e025045.

\section{Guyatt 2011}

Guyatt G, Oxman AD, Akl EA, Kunz R, Vist G, Brozek J, et al. GRADE guidelines: 1. Introduction - GRADE evidence profiles and summary of findings tables. Journal of Clinical Epidemiology 2011;64(4):383-94.

\section{Hardy 2020}

Hardy T, Wonders K, Younes R, Aithal GP, Aller R, Allison M, et al. The European NAFLD Registry: a real-world longitudinal cohort study of nonalcoholic fatty liver disease. Contemporary Clinical Trials 2020;98:106175.

\section{Hernaez 2011}

Hernaez R, Lazo M, Bonekamp S, Kamel I, Brancati FL, Guallar E, et al. Diagnostic accuracy and reliability of ultrasonography for the detection of fatty liver: a meta-analysis. Hepatology (Baltimore, Md.) 2011;54(3):1082-90.

\section{Higgins 2011}

Higgins JP, Green S (editors). Cochrane Handbook for Systematic Reviews of Interventions Version 5.1.0 (updated March 2011). The Cochrane Collaboration, 2011. Available from training.cochrane.org/handbook/archive/v5.1/.

\section{Higgins 2012}

Higgins JP, Jackson D, Barrett JK, Lu G, Ades AE, White IR. Consistency and inconsistency in network meta-analysis: concepts and models for multi-arm studies. Research Synthesis Methods 2012;3(2):98-110.

\section{Hutton 2015}

Hutton B, Salanti G, Caldwell DM, Chaimani A, Schmid CH, Cameron $\mathrm{C}$, et al. The PRISMA extension statement for reporting of systematic reviews incorporating network meta-analyses of health care interventions: checklist and explanations. Annals of Internal Medicine 2015;162(11):777-84.

\section{ICH-GCP 1997}

International Conference on Harmonisation Expert Working Group. International Conference on Harmonisation of Technical Requirements for Registration of Pharmaceuticals for Human Use. ICH Harmonised Tripartite Guideline. Guideline for Good Clinical Practice CFR \& ICH Guidelines. Vol. 1. Philadelphia (PA): Barnett International/PAREXEL, 1997.

\section{Jackson 2014}

Jackson D, Barrett JK, Rice S, White IR, Higgins JP. A designby-treatment interaction model for network meta-analysis with random inconsistency effects. Statistics in Medicine 2014;33(21):3639-54.

\section{James 2015}

James S, Rao SV, Granger CB. Registry-based randomized clinical trials--a new clinical trial paradigm. Nature Reviews. Cardiology 2015;12(5):312-6.

\section{Kamath 2001}

Kamath PS, Wiesner RH, Malinchoc M, Kremers W, Therneau TM, Kosberg $\mathrm{CL}$, et al. A model to predict survival in patients with end-stage liver disease. Hepatology (Baltimore, Md.) 2001;33(2):464-70. [PMID: 11172350]

\section{Kjaergard 2001}

Kjaergard LL, Villumsen J, Gluud C. Reported methodologic quality and discrepancies between large and small randomized trials in meta-analyses. Annals of Internal Medicine 2001;135(11):982-9.

\section{Koehler 2012}

Koehler EM, Schouten JN, Hansen BE, Van Rooij FJ, Hofman A, Stricker BH, et al. Prevalence and risk factors of non-alcoholic fatty liver disease in the elderly: results from the Rotterdam study. Journal of Hepatology 2012;57(6):1305-11.

\section{Komolafe 2021}

Komolafe O, Buzzetti E, Linden A, Best LM, Madden AM, Roberts D, et al. Nutritional supplementation for nonalcoholrelated fatty liver disease: a network meta-analysis. Cochrane 
Database of Systematic Reviews Under editorial. Art. No: CD013157. [DOI: 10.1002/14651858.CD013157]

\section{Lazo 2013}

Lazo M, Hernaez R, Eberhardt MS, Bonekamp S, Kamel I, Guallar E, et al. Prevalence of nonalcoholic fatty liver disease in the United States: the Third National Health and Nutrition Examination Survey, 1988-1994. American Journal of Epidemiology 2013;178(1):38-45.

\section{Li 2014}

Li Z, Xue J, Chen P, Chen L, Yan S, Liu L. Prevalence of nonalcoholic fatty liver disease in mainland of China: a metaanalysis of published studies. Journal of Gastroenterology and Hepatology 2014;29(1):42-51.

\section{Li 2015}

Li YH, Yang LH, Sha KH, Liu TG, Zhang LG, Liu XX. Efficacy of poly-unsaturated fatty acid therapy on patients with nonalcoholic steatohepatitis. World Journal of Gastroenterology 2015;21(22):7008-13.

\section{Lombardi 2017}

Lombardi R, Onali S, Thorburn D, Davidson BR, Gurusamy KS, Tsochatzis E. Pharmacological interventions for non-alcohol related fatty liver disease (NAFLD). Cochrane Database of Systematic Reviews 2017, Issue 3. Art. No: CD011640. [DOI: 10.1002/14651858.CD011640.pub2]

\section{Lonardo 2015}

Lonardo A, Bellentani S, Argo CK, Ballestri S, Byrne CD, Caldwell SH, et al. Epidemiological modifiers of non-alcoholic fatty liver disease: focus on high-risk groups. Digestive and Liver Disease 2015;47(12):997-1006.

\section{Lu 2006}

Lu G, Ades AE. Assessing evidence inconsistency in mixed treatment comparisons. Journal of the American Statistical Association 2006;101(474):447-59.

\section{Mann 2018}

Mann JP, Vreugdenhil A, Socha P, Janczyk W, Baumann U, Rajwal S, et al. European paediatric non-alcoholic fatty liver disease registry (EU-PNAFLD): design and rationale. Contemporary Clinical Trials 2018;75:67-71.

\section{Mills 2012}

Mills EJ, loannidis JP, Thorlund K, Schünemann HJ, Puhan MA, Guyatt $\mathrm{GH}$. How to use an article reporting a multiple treatment comparison meta-analysis. JAMA 2012;308(12):1246-53.

\section{Mofidi 2017}

Mofidi F, Poustchi H, Yari Z, Nourinayyer B, Merat S, Sharafkhah M, et al. Synbiotic supplementation in lean patients with non-alcoholic fatty liver disease: a pilot, randomised, double-blind, placebo-controlled, clinical trial. British Journal of Nutrition 2017;117(5):662-8.

\section{Moher 1998}

Moher D, Pham B, Jones A, Cook DJ, Jadad AR, Moher M, et al. Does quality of reports of randomised trials affect estimates of intervention efficacy reported in meta-analyses? Lancet 1998;352(9128):609-13.

\section{Nabavi 2014}

Nabavi S, Rafraf M, Somi MH, Homayouni-Rad A, AsghariJafarabadi M. Effects of probiotic yogurt consumption on metabolic factors in individuals with nonalcoholic fatty liver disease. Journal of Dairy Science 2014;97(12):7386-93.

\section{NCBI 2021}

National Center for Biotechnology Information (NCBI). Fatty liver. www.ncbi.nlm.nih.gov/mesh/68005234 (accessed 12 February 2021).

\section{Newell 1992}

Newell DJ. Intention-to-treat analysis: implications for quantitative and qualitative research. International Journal of Epidemiology 1992;21(5):837-41.

\section{Nishioji 2015}

Nishioji K, Sumida Y, Kamaguchi M, Mochizuki N, Kobayashi M, Nishimura T, et al. Prevalence of and risk factors for nonalcoholic fatty liver disease in a non-obese Japanese population, 2011-2012. Journal of Gastroenterology 2015;50(1):95-108.

\section{Nogueira 2016}

Nogueira MA, Oliveira CP, Ferreira Alves VA, Stefano JT, Rodrigues LS, Torrinhas RS, et al. Omega-3 polyunsaturated fatty acids in treating non-alcoholic steatohepatitis: a randomized, double-blind, placebo-controlled trial. Clinical Nutrition 2016;35(3):578-86.

\section{Ong 2008}

Ong JP, Pitts A, Younossi ZM. Increased overall mortality and liver-related mortality in non-alcoholic fatty liver disease. Journal of Hepatology 2008;49(4):608-12.

\section{Onnerhag 2014}

Onnerhag K, Nilsson PM, Lindgren S. Increased risk of cirrhosis and hepatocellular cancer during long-term follow-up of patients with biopsy-proven NAFLD. Scandinavian Journal of Gastroenterology 2014;49(9):1111-8.

\section{Park 2006}

Park SH, Jeon WK, Kim SH, Kim HJ, Park DI, Cho YK, et al. Prevalence and risk factors of non-alcoholic fatty liver disease among Korean adults. Journal of Gastroenterology and Hepatology 2006;21(1 Pt 1):138-43.

\section{Paschos 2012}

Paschos P, Tziomalos K. Nonalcoholic fatty liver disease and the renin-angiotensin system: implications for treatment. World Journal of Hepatology 2012;4(12):327-31.

\section{Piscaglia 2016}

Piscaglia F, Svegliati-Baroni G, Barchetti A, Pecorelli A, Marinelli S, Tiribelli C, et al. Clinical patterns of hepatocellular carcinoma in nonalcoholic fatty liver disease: a multicenter prospective study. Hepatology (Baltimore, Md.) 2016;63(3):827-38 


\section{PS: Power and Sample Size Calculation [Computer program]}

Vanderbilt University PS: Power and Sample Size Calculation. Dupont WD, Plummer Jr WD, Version 3.1.6. Vanderbilt University, 2018.

\section{Puhan 2014}

Puhan MA, Schünemann HJ, Murad MH, Li T, BrignardelloPetersen R, Singh JA, et al. A GRADE Working Group approach for rating the quality of treatment effect estimates from network meta-analysis. BMJ (Clinical Research Ed.) 2014;349:g5630.

\section{RAND 2021}

RAND. 36-Item Short Form Survey (SF-36). www.rand.org/ health-care/surveys tools/mos/36-item-short-form.html (accessed on 16 March 2021).

\section{Reeves 2018}

Reeves D, Howells K, Sidaway M, Blakemore A, Hann M, Panagioti $\mathrm{M}$, et al. The cohort multiple randomized controlled trial design was found to be highly susceptible to low statistical power and internal validity biases. Journal of Clinical Epidemiology 2018;95:111-9.

\section{Relton 2010}

Relton C, Torgerson D, O'Cathain A, Nicholl J. Rethinking pragmatic randomised controlled trials: introducing the "cohort multiple randomised controlled trial" design. BMJ (Clinical Research Ed.) 2010;340:C1066. [PMID: 20304934]

\section{Riley 2007}

Riley P, O'Donohue J, Crook M. A growing burden: the pathogenesis, investigation and management of nonalcoholic fatty liver disease. Journal of Clinical Pathology 2007;60(12):1384-91.

\section{Rinella 2015}

Rinella ME. Nonalcoholic fatty liver disease: a systematic review. JAMA 2015;313(22):2263-73.

\section{Royle 2003}

Royle P, Milne R. Literature searching for randomized controlled trials used in Cochrane reviews: rapid versus exhaustive searches. International Journal of Technology Assessment in Health Care 2003;19(4):591-603.

\section{Salanti 2011}

Salanti G, Ades AE, loannidis JP. Graphical methods and numerical summaries for presenting results from multipletreatment meta-analysis: an overview and tutorial. Journal of Clinical Epidemiology 2011;64(2):163-71.

\section{Salanti 2012}

Salanti G. Indirect and mixed-treatment comparison, network, or multiple-treatments meta-analysis: many names, many benefits, many concerns for the next generation evidence synthesis tool. Research Synthesis Methods 2012;3(2):80-97.

\section{Savović 2012a}

Savović J, Jones HE, Altman DG, Harris RJ, Jüni P, Pildal J, et al. Influence of reported study design characteristics on intervention effect estimates from randomized controlled trials: combined analysis of meta-epidemiological studies. Health Technology Assessment 2012;16(35):1-82.

\section{Savović 2012b}

Savović J, Jones HE, Altman DG, Harris RJ, Jüni P, Pildal J, et al. Influence of reported study design characteristics on intervention effect estimates from randomized controlled trials. Annals of Internal Medicine 2012;157(6):429-38.

\section{Savović 2018}

Savović J, Turner RM, Mawdsley D, Jones HE, Beynon R, Higgins JP, et al. Association between risk-of-bias assessments and results of randomized trials in Cochrane Reviews: The ROBES Meta-Epidemiologic Study. American Journal of Epidemiology 2018;187(5):1113-22.

\section{Schulz 1995}

Schulz KF, Chalmers I, Hayes RJ, Altman DG. Empirical evidence of bias. Dimensions of methodological quality associated with estimates of treatment effects in controlled trials. JAMA 1995;273(5):408-12.

\section{Schulz 2010}

Schulz KF, Altman DG, Moher D. CONSORT 2010 statement: updated guidelines for reporting parallel group randomised trials. BMJ (Clinical Research Ed.) 2010;340:C332.

\section{Severini 1993}

Severini TA. Bayesian interval estimates which are also confidence intervals. Journal of the Royal Statistical Society. Series B (Methodological) 1993;55(2):533-40.

\section{Sharifi 2014}

Sharifi N, Amani R, Hajiani E, Cheraghian B. Does vitamin d improve liver enzymes, oxidative stress, and inflammatory biomarkers in adults with non-alcoholic fatty liver disease? A randomized clinical trial. Endocrine 2014;47(1):70-80.

\section{Shen 2014}

Shen H, Shahzad G, Jawairia M, Bostick RM, Mustacchia P. Association between aspirin use and the prevalence of nonalcoholic fatty liver disease: a cross-sectional study from the Third National Health and Nutrition Examination Survey. Alimentary Pharmacology \& Therapeutics 2014;40(9):1066-73.

\section{Shojaee-Moradie 2016}

Shojaee-Moradie F, Cuthbertson DJ, Barrett M, Jackson NC, Herring R, Thomas EL, et al. Exercise training reduces liver fat and increases rates of VLDL clearance but not VLDL production in NAFLD. Journal of Clinical Endocrinology and Metabolism 2016;101(11):4219-28.

\section{Soderberg 2010}

Soderberg C, Stal P, Askling J, Glaumann H, Lindberg G, Marmur J, et al. Decreased survival of subjects with elevated liver function tests during a 28-year follow-up. Hepatology (Baltimore, Md.) 2010;51(2):595-602. 


\section{Sookoian 2011}

Sookoian S, Pirola CJ. Meta-analysis of the influence of I148M variant of patatin-like phospholipase domain containing 3 gene (PNPLA3) on the susceptibility and histological severity of nonalcoholic fatty liver disease. Hepatology (Baltimore, Md.) 2011;53(6):1883-94.

\section{Stata/SE 15.1 [Computer program]}

Stata/SE. Version 15.1. Texas, USA: StataCorp LLC, 2016. www.stata.com/.

\section{Suire 2020}

Suire KB, Kavookjian J, Feiss R, Wadsworth DD. Motivational interviewing for weight management among women: a metaanalysis and systematic review of RCTs. International Journal of Behavioral Medicine 2020 October 20 [Online ahead of print]. [DOI: 10.1007/s12529-020-09934-0]

\section{Thoma 2012}

Thoma C, Day CP, Trenell MI. Lifestyle interventions for the treatment of non-alcoholic fatty liver disease in adults: a systematic review. Journal of Hepatology 2012;56(1):255-66.

\section{Tilg 2010}

Tilg H, Moschen AR. Evolution of inflammation in nonalcoholic fatty liver disease: the multiple parallel hits hypothesis. Hepatology (Baltimore, Md.) 2010;52(5):1836-46.

\section{Van Valkenhoef 2012}

Van Valkenhoef G, Lu G, De Brock B, Hillege H, Ades AE, Welton NJ. Automating network meta-analysis. Research Synthesis Methods 2012;3(4):285-99.

\section{Wang 2016a}

Wang J, Li P, Jiang Z, Yang Q, Mi Y, Liu Y, et al. Diagnostic value of alcoholic liver disease (ALD)/nonalcoholic fatty liver disease (NAFLD) index combined with gamma-glutamyl transferase

\section{CHARACTERISTICS OF STUDIES}

Characteristics of included studies [ordered by study ID] in differentiating ALD and NAFLD. Korean Journal of Internal Medicine 2016;31(3):479-87.

\section{White 2012}

White DL, Kanwal F, El-Serag HB. Association between nonalcoholic fatty liver disease and risk for hepatocellular cancer, based on systematic review. Clinical Gastroenterology and Hepatology 2012;10(12):1342-59.e2.

\section{Wood 2008}

Wood L, Egger M, Gluud LL, Schulz KF, Jüni P, Altman DG, et al. Empirical evidence of bias in treatment effect estimates in controlled trials with different interventions and outcomes: meta-epidemiological study. BMJ (Clinical Research Ed.) 2008;336(7644):601-5.

\section{Yepes-Nunez 2019}

Yepes-Nunez JJ, Li SA, Guyatt G, Jack SM, Brozek JL, Beyene J, et al. Development of the summary of findings table for network meta-analysis. Journal of Clinical Epidemiology 2019;115:1-13.

\section{Young-Afat 2016}

Young-Afat DA, Verkooijen HA, Van Gils CH, Van der Velden JM, Burbach JP, Elias SG, et al. Brief report: staged-informed consent in the cohort multiple randomized controlled trial design. Epidemiology (Cambridge, Mass.) 2016;27(3):389-92. [PMID: 27035689]

\section{References to other published versions of this review Gurusamy 2018b}

Gurusamy KS, Tsochatzis E, Madden AM. Lifestyle modifications for non-alcohol related fatty liver disease: a network metaanalysis. Cochrane Database of Systematic Reviews 2018, Issue 10. Art. No: CD013156. [DOI: 10.1002/14651858.CD013156]

* Indicates the major publication for the study

Abbate 2021

\section{Study characteristics}

\begin{tabular}{ll}
\hline Methods & Randomised clinical trial \\
\hline Participants & Country: Spain \\
& Number randomised: 155 \\
& Post-randomisation dropouts: 27 (17.4\%) \\
& Revised sample size: 128 \\
& Reasons for post-randomisation dropouts: withdrew consent, lost to follow-up, missing baseline data, \\
& complications \\
& Average age: 53 years \\
& Female: 50 (39.1\%) \\
& NASH: not stated \\
& Diabetes mellitus: $29(22.7 \%)$. \\
& Follow-up in months: 6 \\
& Years of recruitment: $2018-2020$
\end{tabular}


Abbate 2021 (Continued)

Inclusion criteria: aged 40 to 60 years, previous diagnosis of NAFLD by liver ultrasound, body mass index (BMI) between 27 and $40 \mathrm{~kg} / \mathrm{m}^{2}$, and presenting at least 3 of the 5 MetS traits as described in the International Diabetes Federation (IDF) consensus: (1) BMI $>30 \mathrm{~kg} / \mathrm{m}^{2}$ or increased waist circumference: $\geq 94 \mathrm{~cm}$ in men and $\geq 80 \mathrm{~cm}$ in women; (2) triglycerides (TG) levels $\geq 150 \mathrm{mg} / \mathrm{dL}$ (1.7 mmol/L), or specific treatment; (3) reduced high-density lipoprotein cholesterol (HDL-C): $<40 \mathrm{mg} / \mathrm{dL}(1.03 \mathrm{mmol} / \mathrm{L})$ in men and $<50 \mathrm{mg} / \mathrm{dL}(1.29 \mathrm{mmol} / \mathrm{L})$ in women, or specific treatment; (4) raised blood pressure (BP): systolic $\mathrm{BP} \geq 130$ or diastolic $\mathrm{BP} \geq 85 \mathrm{~mm} \mathrm{Hg}$, or treatment of previously diagnosed hypertension; (5) raised fasting plasma glucose (FPG) $\geq 100 \mathrm{mg} / \mathrm{dL}(5.6 \mathrm{mmol} / \mathrm{L})$, or previously-diagnosed type 2 diabetes (T2DM) Exclusion criteria: previous cardiovascular disease, liver disease (other than NAFLD), cancer or a history of malignancy in the previous 5 years, haemochromatosis, previous bariatric surgery, non-medicated depression, alcohol and drug abuse, pregnancy, primary endocrinological diseases (other than nonmedicated hypothyroidism), concomitant therapy with steroids, or inability to provide informed consent

Interventions

Participants were randomly assigned to 3 groups.

Group 1: Mediterranean diet plus supervised aerobic exercise $(n=43)$

Further details: American Association for the Study of Liver Disease (AASLD) recommendations [1] with energy restriction enough to lose $3 \%-5 \%$ of body weight to improve steatosis, and $7 \%-10 \%$ to improve most of the histopathological features of NASH, including fibrosis, following the general guidelines of the U.S. Department of Health and Human Services and U.S. Department of Agriculture (20\% $35 \%$ fat, $10 \%-35 \%$ protein, $45 \%-65 \%$ carbohydrate) + instructed to accumulate a minimum of 10,000 steps a day (recorded by a personal pedometer)

Group 2: Mediterranean diet plus exercise advice $(n=43)$

Further details: The Mediterranean Diet-high meal frequency (MD-HMF) group, which was instructed to adhere to a Mediterranean Diet based on a distribution of macronutrients of $30 \%-35 \%$ fat (mainly MUFA and PUFA from extra virgin olive oil, nuts, and omega-3-containing foods), $25 \%$ protein (mainly from vegetable sources), and $40 \%-45 \%$ carbohydrates $(50 \%-70 \%$ of the total carbohydrate intake should be low on glycaemic index and rich in fibre). The total daily caloric intake of this diet was distributed over 7 meals, with the highest calorie meals to be consumed early during the day + instructed to accumulate a minimum of 10,000 steps a day (recorded by a personal pedometer)

Group 3: Calorie-restricted diet plus exercise advice $(n=42)$

Further details: The Mediterranean Diet-physical activity (MD-PA) group, which followed an energy-restricted Mediterranean diet. Meal frequency would be $4-5$ meals a day including snacks. This group consumed $35 \%-40 \%$ of total calories from fat $(8-10 \%$ of Saturated Fatty Acids, $>20 \%$ of MUFA, $>10 \%$ of PUFA and $<300 \mathrm{mg}$ /day of cholesterol), approximately $20 \%$ of total calories from proteins and $40-$ $45 \%$ or more of total calories from carbohydrates (low glycaemic index). Sodium chloride should not exceed $6 \mathrm{~g}$ a day ( $2.4 \mathrm{~g}$ of sodium), and dietary fibre should be no less than $30-35 \mathrm{~g} /$ day + instructed to undergo 35 min interval training session 3 times a week, in the combination of 2 instructor-led on-site training and 1 remote prescribed training session a week for the whole duration of the trial

Outcomes None of the outcomes of interest were reported

Notes

Source of funding (quote): "Fundació La Marató TV3 (Spain) project ref. 201630.10. Instituto de Salud Carlos III through the Fondo de Investigación para la Salud (Projects PI14/00636 and PI17/01827, and CIBEROBN CB12/03/30038, and Proyecto Intramural CIBER OBN18PI03), Health Department of the Government of Navarra (61/2015), and Grant of support to research groups no. 35/2011 and 23/2012 (Balearic Islands Government), which are co-funded by the European Regional Development Fund. Other funding received: EU-COST Action CA16112, and IDISBA Grants (FOLIUM, PRIMUS, SYNERGIA, and LIBERI). Catalina M. Mascaró received an FPU PhD Grant from the Spanish Ministry of Education". Trial name/trial registry number: NCT04442620 We tried to contact the authors in March 2021

\section{Risk of bias}

\begin{tabular}{lll}
\hline Bias & Authors' judgement & Support for judgement \\
\hline $\begin{array}{l}\text { Random sequence genera- } \\
\text { tion (selection bias) }\end{array}$ & Low risk & $\begin{array}{l}\text { Quote: "Randomization was carried out using the MinimPy desktop minimiza- } \\
\text { tion program". }\end{array}$ \\
\hline
\end{tabular}


Abbate 2021 (Continued)

$\begin{aligned} & \text { Allocation concealment Low risk } \\ & \text { (selection bias) }\end{aligned} \quad \begin{aligned} & \text { Quote: "The randomization process was performed by a dedicated person and } \\ & \text { blinded to all staff and the principal investigator". }\end{aligned}$

Blinding of participants High risk
and personnel (performance bias)

All outcomes

Blinding of outcome as-
sessment (detection bias) $\quad$ Comment: this information was not available

(detection bias)

All outcomes
Comment: because of the nature of the intervention, it is not possible to blind the participants

\begin{tabular}{|c|c|c|}
\hline $\begin{array}{l}\text { Incomplete outcome data } \\
\text { (attrition bias) } \\
\text { All outcomes }\end{array}$ & Unclear risk & $\begin{array}{l}\text { Comment: a considerable proportion of participants were excluded from } \\
\text { analysis. At least } 1 \text { participant was excluded for adverse events, which may be } \\
\text { related to the intervention }\end{array}$ \\
\hline
\end{tabular}

\begin{tabular}{|c|c|c|}
\hline $\begin{array}{l}\text { Selective reporting (re- } \\
\text { porting bias) }\end{array}$ & High risk & $\begin{array}{l}\text { Comment: a pre-published protocol was not available and none of the out- } \\
\text { comes of interest for this review were reported }\end{array}$ \\
\hline
\end{tabular}

\begin{tabular}{ll}
\hline Other bias Low risk Comment: no other bias noted \\
\hline
\end{tabular}

\section{Abdelbasset 2019}

\section{Study characteristics}

\begin{tabular}{|c|c|}
\hline Methods & Randomised clinical trial \\
\hline Participants & $\begin{array}{l}\text { Country: Egypt } \\
\text { Number randomised: } 32 \\
\text { Post-randomisation dropouts: } 0(0 \%) \\
\text { Revised sample size: } 32 \\
\text { Average age: } 55 \text { years } \\
\text { Female: } 13(40.6 \%) \\
\text { NASH: not stated } \\
\text { Diabetes mellitus: } 32(100 \%) \\
\text { Inclusion criteria } \\
\text { All participants were diagnosed with NAFLD, type } 2 \text { diabetes mellitus and class II and III of obesity (BMI } \\
\left.\geq 35 \mathrm{~kg} / \mathrm{m}^{2}\right)\end{array}$ \\
\hline Interventions & $\begin{array}{l}\text { Participants were randomly assigned to } 2 \text { groups } \\
\text { Group 1: Aerobic exercise }(n=16) \\
\text { Further details: Each participant in this group followed a programme of high-intensity aerobic exer- } \\
\text { cise for } 8 \text { weeks, } 3 \text { times a week with each exercise session lasting for nearly } 40 \text { minutes in the morning. } \\
\text { Each participant was instructed to not eat for } 2 \text { hours before the exercise session to avoid exercise-in- } \\
\text { duced airway obstruction } \\
\text { Group 2: No active intervention }(n=16) \\
\text { Further details: No active intervention }\end{array}$ \\
\hline Outcomes & $\begin{array}{l}\text { Outcomes reported: mortality } \\
\text { Follow-up (months): } 1.84\end{array}$ \\
\hline Notes & $\begin{array}{l}\text { Source of funding (quote): "The research did not secure any specific grant or source of funding from any } \\
\text { specific organization in either the private or public sector" } \\
\text { Trial name/trial registry number: not stated } \\
\text { We tried to contact the authors in March } 2021\end{array}$ \\
\hline
\end{tabular}


Abdelbasset 2019 (Continued)

Risk of bias

\begin{tabular}{lll}
\hline Bias & Authors' judgement & Support for judgement \\
\hline $\begin{array}{l}\text { Random sequence genera- } \\
\text { tion (selection bias) }\end{array}$ & Unclear risk & Comment: this information was not available \\
\hline $\begin{array}{l}\text { Allocation concealment } \\
\text { (selection bias) }\end{array}$ & Unclear risk & $\begin{array}{l}\text { Quote: "Randomization was applied using secured envelopes. The examiner } \\
\text { arranged the secured envelopes, which contained a piece of colored paper in- } \\
\text { dicating HIl group and a piece of uncoloredpaper indicating control group". } \\
\text { Comment: further details such as opanens of envelope and consecutive } \\
\text { numbering were not available }\end{array}$
\end{tabular}

$\begin{array}{ll}\text { Blinding of participants } & \text { High risk } \\ \text { and personnel (perfor- } & \begin{array}{l}\text { Comment: because of the nature of the intervention, it is not possible to blind } \\ \text { the participants }\end{array}\end{array}$

mance bias)

All outcomes

Blinding of outcome as- Unclear risk Comment: this information was not available

sessment (detection bias)

All outcomes

Incomplete outcome data Low risk Comment: there were no post-randomisation dropouts
(attrition bias)

All outcomes

\begin{tabular}{ll}
\hline $\begin{array}{l}\text { Selective reporting (re- } \\
\text { porting bias) }\end{array}$ & High risk \\
& $\begin{array}{l}\text { Comment: a pre-published protocol was not available and adverse events } \\
\text { were not reported }\end{array}$
\end{tabular}

\begin{tabular}{ll}
\hline Other bias $\quad$ Low risk $\quad$ Comment: no other bias noted \\
\hline
\end{tabular}

\section{Abdelbasset 2020}

\section{Study characteristics}

\begin{tabular}{ll}
\hline Methods & Randomised clinical trial \\
\hline Participants & Country: Saudi Arabia \\
& Number randomised: 48 \\
& Post-randomisation dropouts: $1(2.1 \%)$ \\
& Revised sample size: 47 \\
& Reasons for post-randomisation dropouts: lack of adherence to intervention \\
& Average age: 55 years \\
& Female: 20 (42.6\%) \\
& NASH: not stated \\
& Diabetes mellitus: 47 (100\%) \\
Inclusion criteria: Diabetic obese patients with NAFLD, aged 40 to 60 years
\end{tabular}

Interventions
Participants were randomly assigned to 2 groups
Group 1: Aerobic exercise $(n=31)$
Further details: High-intensity or moderate-intensity aerobic exercise (decided by random allocation); high-intensity group: each participant in this group followed a programme of high-intensity aerobic ex- ercise for 8 weeks, 3 times a week, each exercise session lasting for nearly 40 minutes in the morning. Moderate-intensity group, each participant in the exercise group was recruited to a MIC aerobic exer- cise programme 3 times weekly for 8 weeks, with a duration of exercise of nearly 40 to 50 minutes Group 2: No active intervention $(n=16)$


Abdelbasset 2020 (Continued)

\begin{tabular}{ll} 
Outcomes & None of the outcomes of interest were reported \\
\hline Notes & Source of funding (quote): "This publication was supported by the Deanship of Scientific Research at \\
& Prince Sattam bin Abdulaziz University" \\
Trial name/trial registry number: NCT03774511 \\
We tried to contact the authors in March 2021
\end{tabular}

\section{Risk of bias}

\begin{tabular}{lll}
\hline Bias & Authors' judgement & Support for judgement \\
\hline $\begin{array}{l}\text { Random sequence genera- } \\
\text { tion (selection bias) }\end{array}$ & Unclear risk & Comment: this information was not available \\
\hline $\begin{array}{l}\text { Allocation concealment } \\
\text { (selection bias) }\end{array}$ & Low risk & $\begin{array}{l}\text { Quote: "Allocation was carried out before commencing the study program by } \\
\text { blinded physiotherapist using secured envelopes, which included a piece of } \\
\text { red sheet indicated HIl group, a piece of green sheet indicated MIC group, and } \\
\text { a piece of white sheet indicated control group" }\end{array}$ \\
\hline $\begin{array}{l}\text { Blinding of participants } \\
\text { and personnel (perfor- } \\
\text { mance bias) }\end{array}$ & High risk & $\begin{array}{l}\text { Comment: because of the nature of the intervention, it is not possible to blind } \\
\text { the participants }\end{array}$ \\
All outcomes & &
\end{tabular}

\begin{tabular}{lll}
\hline $\begin{array}{l}\text { Blinding of outcome as- } \\
\text { sessment (detection bias) } \\
\text { All outcomes }\end{array}$ & Unclear risk & Comment: this information was not available \\
\hline $\begin{array}{l}\text { Incomplete outcome data } \\
\text { (attrition bias) } \\
\text { All outcomes }\end{array}$ & Unclear risk & $\begin{array}{l}\text { Comment: } 1 \text { participant in this small trial was excluded because of lack of } \\
\text { compliance. It is not clear whether this leads to biased effect estimates }\end{array}$ \\
\hline $\begin{array}{l}\text { Selective reporting (re- } \\
\text { porting bias) }\end{array}$ & High risk & $\begin{array}{l}\text { Comment: a pre-published protocol was not available and none of the out- } \\
\text { comes of interest for this review were reported }\end{array}$ \\
\hline Other bias & Low risk & Comment: no other bias noted \\
\hline
\end{tabular}

\section{Abd El-Kader 2016}

\section{Study characteristics}

\begin{tabular}{ll}
\hline Methods & Randomised clinical trial \\
\hline Participants & Country: Saudi Arabia \\
& Period of recruitment: not stated \\
& Number randomised: 100 \\
& Post-randomisation dropouts: not stated \\
& Revised sample size: 100 \\
& Average age (years): 51 \\
& Female: 30 (30.0\%) \\
& NASH: 100 (100.0\%) \\
& Diabetes mellitus: not stated \\
Inclusion criteria: NASH & Exclusion criteria: Smoking, cardiovascular disease, alcohol abuse, hepatic (infectious and viral dis- \\
ease) or renal disease
\end{tabular}


Abd El-Kader 2016 (Continued)

Interventions

Group 1: Aerobic exercise plus calorie-restricted diet $(n=50)$

Further details: 3 months of $3 x$ a week sessions, 30 min treadmill ( 5 min warm-up, 5 min cool down).

1200 low-calorie diet: $15 \%$ as protein, 30 to $35 \%$ as fat and 50 to $55 \%$ as carbohydrate, on average

Group 2: No active intervention $(n=50)$

Further details: control group

\begin{tabular}{|c|c|}
\hline Outcomes & $\begin{array}{l}\text { Outcomes reported: mortality at maximal follow-up } \\
\text { Follow-up (months): } 3\end{array}$ \\
\hline Notes & $\begin{array}{l}\text { Source of funding (quote): "funded by the Deanship of Scientific Research (DSR), King Abdulaziz Univer- } \\
\text { sity, Jeddah, under grant no.(324/290/1434)" } \\
\text { Trial name/trial registry number: not stated } \\
\text { We tried to contact the authors in December } 2020\end{array}$ \\
\hline
\end{tabular}

\section{Risk of bias}

\begin{tabular}{|c|c|c|}
\hline Bias & Authors' judgement & Support for judgement \\
\hline $\begin{array}{l}\text { Random sequence genera- } \\
\text { tion (selection bias) }\end{array}$ & Low risk & $\begin{array}{l}\text { Quote: "The subjects were randomly allocated to the experimental group or } \\
\text { control group. Each subject was given an envelope containing two cards and } \\
\text { was instructed to blindly draw one card on each occasion" }\end{array}$ \\
\hline $\begin{array}{l}\text { Allocation concealment } \\
\text { (selection bias) }\end{array}$ & Low risk & $\begin{array}{l}\text { Quote: "The subjects were randomly allocated to the experimental group or } \\
\text { control group. Each subject was given an envelope containing two cards and } \\
\text { was instructed to blindly draw one card on each occasion" }\end{array}$ \\
\hline $\begin{array}{l}\text { Blinding of participants } \\
\text { and personnel (perfor- } \\
\text { mance bias) } \\
\text { All outcomes }\end{array}$ & High risk & $\begin{array}{l}\text { Comment: because of the nature of the intervention, it is not possible to blind } \\
\text { the participants }\end{array}$ \\
\hline $\begin{array}{l}\text { Blinding of outcome as- } \\
\text { sessment (detection bias) } \\
\text { All outcomes }\end{array}$ & Low risk & $\begin{array}{l}\text { Quote: "This study was single blinded: the person undertaking the assessment } \\
\text { and data analysis was unaware of the group of each patient" }\end{array}$ \\
\hline $\begin{array}{l}\text { Incomplete outcome data } \\
\text { (attrition bias) } \\
\text { All outcomes }\end{array}$ & Unclear risk & Comment: this information was not available \\
\hline $\begin{array}{l}\text { Selective reporting (re- } \\
\text { porting bias) }\end{array}$ & High risk & $\begin{array}{l}\text { Comment: a pre-published protocol was not available and adverse events } \\
\text { were not reported }\end{array}$ \\
\hline Other bias & Low risk & Comment: no other bias noted \\
\hline
\end{tabular}

Al-Jiffri 2013

\section{Study characteristics}

\begin{tabular}{ll}
\hline Methods & Randomised clinical trial \\
\hline Participants & Country: Saudi Arabia \\
& Period of recruitment: not stated \\
& Number randomised: 100 \\
& Post-randomisation dropouts: $0(0.0 \%)$ \\
& Revised sample size: 100 \\
& Average age (years): not stated \\
\hline
\end{tabular}


Al-Jiffri 2013 (Continued)

Females: 0 (0.0\%)

NASH: not stated

Diabetes mellitus: 100 (100.0\%)

Inclusion criteria: NAFLD with T2DM

Exclusion criteria: other liver, metabolic or genetic diseases. Smoking, HTN, CV disease, thyroid dis-

ease, orthopaedic problems inhibiting treadmill training

$\begin{array}{ll}\text { Interventions } & \text { Group 1: Aerobic exercise plus calorie-restricted diet ( } n=50) \\ & \text { Further details: } 3 \text { months of } 3 \times \text { a week sessions, } 30 \text { min treadmill (5 min warm-up, } 5 \text { min cool down). } \\ & 1200 \text { low-calorie diet: } 15 \% \text { as protein, } 30 \text { to } 35 \% \text { as fat and } 50 \text { to } 55 \% \text { as carbohydrate, on average } \\ & \text { Group 2: Calorie-restricted diet ( } n=50) \\ & \text { Further details: } 1200 \text { low-calorie diet: } 15 \% \text { as protein, } 30 \text { to } 35 \% \text { as fat and } 50 \text { to } 55 \% \text { as carbohydrate, } \\ & \text { on average }\end{array}$

Outcomes Outcomes reported: mortality at maximum follow-up, serious adverse events (number of people), any adverse events (number of people)

Follow-up (months): 3

\section{Notes}

Source of funding (quote): "funded by the Deanship of Scientific Research (DSR), King Abdulaziz University, Jeddah, under grant no. (49/142/1432)"

Trial name/trial registry number: not stated

We tried to contact the authors in December 2020

\section{Risk of bias}

\begin{tabular}{|c|c|c|}
\hline Bias & Authors' judgement & Support for judgement \\
\hline $\begin{array}{l}\text { Random sequence genera- } \\
\text { tion (selection bias) }\end{array}$ & Unclear risk & Comment: this information was not available \\
\hline $\begin{array}{l}\text { Allocation concealment } \\
\text { (selection bias) }\end{array}$ & Unclear risk & Comment: this information was not available \\
\hline $\begin{array}{l}\text { Blinding of participants } \\
\text { and personnel (perfor- } \\
\text { mance bias) } \\
\text { All outcomes }\end{array}$ & High risk & $\begin{array}{l}\text { Comment: because of the nature of the intervention, it is not possible to blind } \\
\text { the participants }\end{array}$ \\
\hline $\begin{array}{l}\text { Blinding of outcome as- } \\
\text { sessment (detection bias) } \\
\text { All outcomes }\end{array}$ & Unclear risk & Comment: this information was not available \\
\hline $\begin{array}{l}\text { Incomplete outcome data } \\
\text { (attrition bias) } \\
\text { All outcomes }\end{array}$ & Low risk & Comment: there were no post-randomisation dropouts \\
\hline $\begin{array}{l}\text { Selective reporting (re- } \\
\text { porting bias) }\end{array}$ & Low risk & $\begin{array}{l}\text { Comment: a pre-published protocol was not available, but mortality and ad- } \\
\text { verse events were reported }\end{array}$ \\
\hline Other bias & Low risk & Comment: no other bias noted \\
\hline
\end{tabular}

Arab 2017

\section{Study characteristics}

Methods Randomised clinical trial


Arab 2017 (Continued)

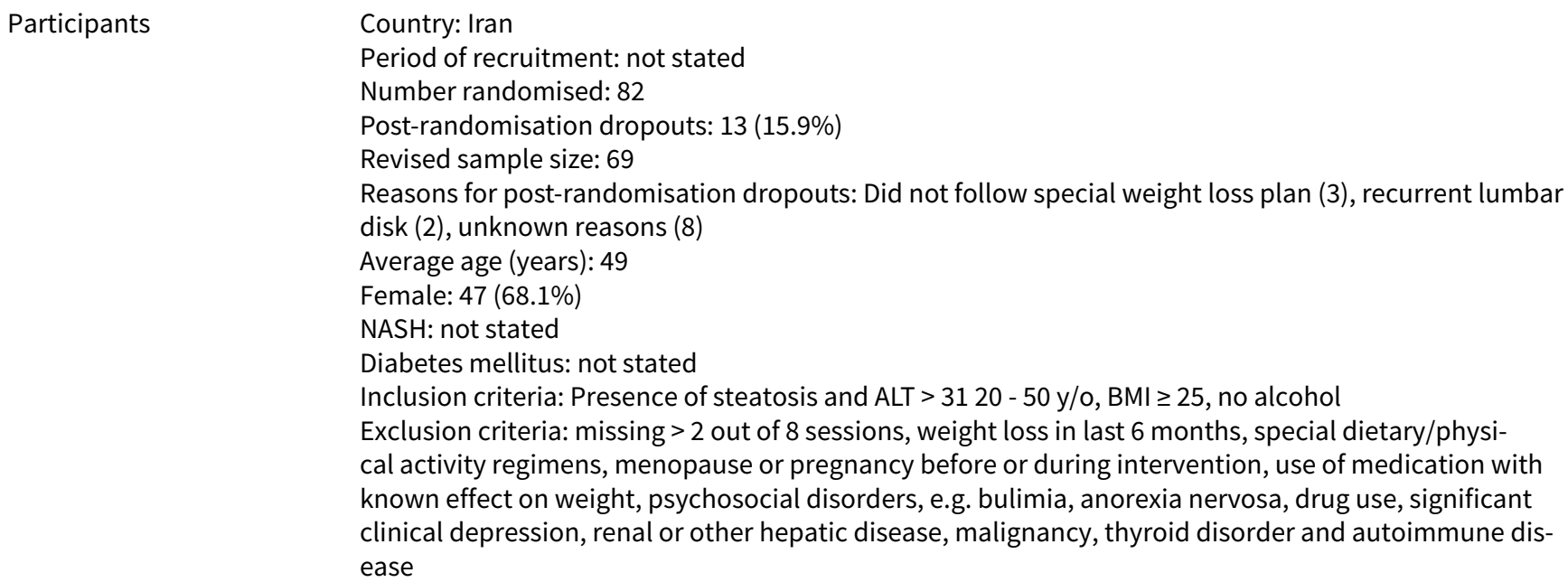

\begin{tabular}{ll}
\hline Outcomes & None of the outcomes of interest were reported \\
\hline Notes & Source of funding (quote): "No financial support provided" \\
& Trial name/trial registry number: IRCT2016071211763N24 \\
& We tried to contact the authors in December 2020
\end{tabular}

\section{Risk of bias}

\begin{tabular}{lll}
\hline Bias & Authors' judgement & Support for judgement \\
\hline $\begin{array}{l}\text { Random sequence genera- } \\
\text { tion (selection bias) }\end{array}$ & Low risk & $\begin{array}{l}\text { Quote: "Randomization was carried out using computer-generated random } \\
\text { numbers" }\end{array}$ \\
\hline $\begin{array}{l}\text { Allocation concealment } \\
\text { (selection bias) }\end{array}$ & Unclear risk & Comment: this information was not available \\
\hline $\begin{array}{l}\text { Blinding of participants } \\
\text { and personnel (perfor- } \\
\text { mance bias) }\end{array}$ & High risk & $\begin{array}{l}\text { Comment: because of the nature of the intervention, it is not possible to blind } \\
\text { the participants }\end{array}$ \\
\hline $\begin{array}{l}\text { Blinding of outcome as- } \\
\text { sessment (detection bias) } \\
\text { All outcomes }\end{array}$ & Unclear risk & \begin{tabular}{l} 
Comment: this information was not available \\
\hline $\begin{array}{l}\text { Incomplete outcome data } \\
\text { (attrition bias) } \\
\text { All outcomes }\end{array}$
\end{tabular} \\
\hline
\end{tabular}


Arab 2017 (Continued)

\begin{tabular}{|c|c|c|}
\hline $\begin{array}{l}\text { Selective reporting (re- } \\
\text { porting bias) }\end{array}$ & High risk & $\begin{array}{l}\text { Comment: a pre-published protocol was not available and neither mortality } \\
\text { nor resolution of fatty liver was reported }\end{array}$ \\
\hline
\end{tabular}

Other bias Low risk Comment: no other bias noted

\section{Asghari 2018}

\section{Study characteristics}

\begin{tabular}{|c|c|}
\hline Methods & Randomised clinical trial \\
\hline Participants & $\begin{array}{l}\text { Country: Iran } \\
\text { Period of recruitment: not stated } \\
\text { Number randomised: } 60 \\
\text { Post-randomisation dropouts: } 0 \text { (0.0\%) } \\
\text { Revised sample size: } 60 \\
\text { Average age (years): } 40 \\
\text { Female: } 16 \text { ( } 26.7 \%) \\
\text { NASH: not stated } \\
\text { Diabetes mellitus: } 0 \text { ( } 0.0 \%) \\
\text { Inclusion criteria: Aged } 20 \text { to } 60 \text { years, BMI from } 25 \text { to } 35 \mathrm{~kg} / \mathrm{m}^{2} \text {, diagnosis of NAFLD via liver ultrasonog- } \\
\text { raphy } \\
\text { Exclusion criteria: pregnancy; breastfeeding and postmenopausal status; professional athlete sta- } \\
\text { tus; smoking; consumption of any alcoholic beverages; following a weight-reducing diet within the } 3 \\
\text { months before the study; known liver disease (viral, etc.); inherited disorders affecting the liver; history } \\
\text { of diagnosed diabetes, thyroid dysfunction and cancer, or cardiovascular, kidney, gastrointestinal, pul- } \\
\text { monary, or autoimmune diseases; recent surgery; use of medications such as corticosteroids, hepato- } \\
\text { toxic drugs, hormonal drugs (e.g. oral contraceptives and/or oestrogen), antidepressants, psychotrop- } \\
\text { ic medications, anticoagulant drugs, or oral antidiabetic and lipid-lowering drugs; and consuming any } \\
\text { kind of supplement } 3 \text { months prior to the study and/or during the study period }\end{array}$ \\
\hline
\end{tabular}

Interventions $\quad$ Group 1: Calorie-restricted diet $(\mathrm{n}=30)$

Further details: CR diet (received a prescribed low-calorie diet) for 12 weeks. Estimated energy requirements at baseline were individually calculated based on the Harris-Benedict equation with a deficit of 500 to $1000 \mathrm{kcal} / \mathrm{d}$ based on body weight, containing $53 \%$ carbohydrate, $30 \%$ fat, and $17 \%$ protein Group 2: No active intervention $(n=30)$

Further details: No active treatment (received 2 identical-appearing capsules to Resveratrol supplement per day each containing $300 \mathrm{mg}$ starch used as placebo for an intervention excluded from this review) for 12 weeks

\begin{tabular}{ll}
\hline Outcomes & None of the outcomes of interest were reported \\
\hline Notes & $\begin{array}{l}\text { Source of funding: not stated } \\
\text { Trial name/trial registry number: not stated } \\
\text { We tried to contact the authors in December } 2020\end{array}$ \\
\hline
\end{tabular}

\section{Risk of bias}

\begin{tabular}{lll}
\hline Bias & Authors' judgement & Support for judgement \\
\hline $\begin{array}{l}\text { Random sequence genera- } \\
\text { tion (selection bias) }\end{array}$ & Low risk & $\begin{array}{l}\text { Quote: "Random allocation software was used for generating a random se- } \\
\text { quence by the study statistician" }\end{array}$ \\
\hline $\begin{array}{l}\text { Allocation concealment } \\
\text { (selection bias) }\end{array}$ & Unclear risk & Comment: this information was not available \\
\hline
\end{tabular}


Asghari 2018 (Continued)

Blinding of participants High risk Quote: "This study was partially blinded. Patients and researchers were unand personnel (perforaware of assignments to resveratrol and placebo groups until the statistical mance bias)

All outcomes analysis was completed."

Comment: although partially blinded for the comparison resveratrol versus placebo (excluded from this review), the participants were probably aware of the interventions included in this review because of the nature of the intervention

\section{Blinding of outcome as- Unclear risk} sessment (detection bias) All outcomes
Quote: "This study was partially blinded. Patients and researchers were unaware of assignments to resveratrol and placebo groups until the statistical analysis was completed"

Comment: although partially blinded for the comparison resveratrol versus placebo (excluded from this review), it was not clear whether the outcome assessors were blinded for the comparison of interest for this review

Incomplete outcome data Low risk Comment: there were no post-randomisation dropouts
(attrition bias)

All outcomes

\begin{tabular}{|c|c|c|}
\hline $\begin{array}{l}\text { Selective reporting (re- } \\
\text { porting bias) }\end{array}$ & High risk & $\begin{array}{l}\text { Comment: a pre-published protocol was not available and neither mortality } \\
\text { nor resolution of fatty liver was reported }\end{array}$ \\
\hline
\end{tabular}

Selective reporting (re- High risk

Other bias Low risk Comment: no other bias noted

Axley 2017

\section{Study characteristics}

\begin{tabular}{ll}
\hline Methods & Randomised clinical trial \\
\hline Participants & Country: USA \\
& Period of recruitment: not stated \\
& Number randomised: 30 \\
& Post-randomisation dropouts: 8 (26.7\%) \\
& Revised sample size: 22 \\
& Reasons for post-randomisation dropouts: Missed 6-month visit (8) \\
& Average age (years): 53 \\
& Female: 19 (86.4\%) \\
& NASH: not stated \\
& Diabetes mellitus: 10 (45.5\%) \\
Inclusion criteria: Aged $25-75$ with NAFLD on US with elevated liver enzymes \\
Exclusion criteria: Other causes of liver disease, alcohol use $>10$ g/day. Hx of decompensation, en- \\
cephalopathy, as cited. Other significant medical/psychiatric or social conditions that would impair \\
participation
\end{tabular}

\section{Interventions $\quad$ Group 1: Dietary advice plus exercise advice $(\mathrm{n}=8)$}

Further details: 6-month intervention: 3 uni- and bidirectional text messages every week. The messages provided education on different domains including nutrition, exercise and stress management of NAFLD and were sent at $9 \mathrm{am}$. All participants received standard of care for liver disease with detailed instructions in the clinic on healthy diet and daily exercise for weight loss

Group 2: No active intervention $(n=14)$

Further details: control group - treatment as usual. All participants received standard of care for liver disease with detailed instructions in the clinic on healthy diet and daily exercise for weight loss

\section{Outcomes} transplantation at maximum follow-up, decompensation (number of people), cirrhosis (number of people), hepatocellular carcinoma 

College of Gastroenterology. Nina Parikh is affiliated with CareMessage, the text messaging software company that was used in this study."

Trial name/trial registry number: NCT03082703

We tried to contact the authors in December 2020

\section{Risk of bias}

\section{Bias}

Authors' judgement Support for judgement

Random sequence genera- Low risk tion (selection bias)

Quote: "computer-generated randomization schedule"

Allocation concealment Low risk
(selection bias)

Quote: "Study coordinator randomizing the patients and physicians evaluating the patients was blinded to the randomization group to which participants were allocated"

Comment: although the precise method was not reported, it is clear that the person who randomised the participants was not aware of the next intervention

\begin{tabular}{|c|c|c|}
\hline $\begin{array}{l}\text { Blinding of participants } \\
\text { and personnel (perfor- } \\
\text { mance bias) }\end{array}$ & High risk & $\begin{array}{l}\text { Quote: "Only healthcare professionals were blinded (author replies)" } \\
\text { Comment: because of the nature of the intervention, it is not possible to blind } \\
\text { the participants }\end{array}$ \\
\hline
\end{tabular}

\begin{tabular}{|c|c|c|}
\hline $\begin{array}{l}\text { Blinding of outcome as- } \\
\text { sessment (detection bias) } \\
\text { All outcomes }\end{array}$ & Low risk & $\begin{array}{l}\text { Quote: "Study coordinator randomizing the patients and physicians evaluat- } \\
\text { ing the patients was blinded to the randomization group to which participants } \\
\text { were allocated" }\end{array}$ \\
\hline
\end{tabular}

\begin{tabular}{|c|c|c|}
\hline $\begin{array}{l}\text { Incomplete outcome data } \\
\text { (attrition bias) }\end{array}$ & Unclear risk & $\begin{array}{l}\text { Comment: there were post-randomisation dropouts, but it was not clear } \\
\text { whether these were related to the intervention or outcomes }\end{array}$ \\
\hline
\end{tabular}

(attrition bias) whether these were related to the intervention or outcomes

\begin{tabular}{|c|c|c|}
\hline $\begin{array}{l}\text { Selective reporting (re- } \\
\text { porting bias) }\end{array}$ & High risk & $\begin{array}{l}\text { Comment: a pre-published protocol was not available, but mortality and ad- } \\
\text { verse events were reported }\end{array}$ \\
\hline
\end{tabular}

Other bias Low risk Comment: no other bias noted

Bacchi 2013

\section{Study characteristics}

\begin{tabular}{ll}
\hline Methods & Randomised clinical trial \\
\hline Participants & Country: Italy \\
& Period of recruitment: not stated \\
& Number randomised: 40 \\
& Post-randomisation dropouts: 10 (25.0\%) \\
& Revised sample size: 30 \\
& Reasons for post-randomisation dropouts: Abandoned study (1), lost to follow up - compliance to MRI \\
& (6), did not have NAFLD (2), discontinued intervention due to lack of time (1) \\
& Average age (years): 56 \\
& Female: 9 (30.0\%) \\
NASH: not stated & Diabetes mellitus: 30 (100.0\%) \\
\hline
\end{tabular}


Bacchi 2013 (Continued)

Inclusion criteria: NAFLD, "Caucasian", aged 40 - 70 y/o, HbA1c 6.5 - 9.0\%, BMI 24 - 36. No insulin use Exclusion criteria: advanced diabetic complications, unstable body weight over last 2 months, no other cause of liver disease and $<20 \mathrm{~g}$ alcohol/day

Group 1: Resistance exercise $(\mathrm{n}=17)$
Further details: 3 times a week for 4 months. Participants performed 9 different exercises involving the
major muscle groups on weight machines (chest press, shoulder press, vertical traction, leg press, leg
extension, leg curl, abdominal crunch) and free weight (biceps, abdominal). After a learning phase, par-
ticipants performed 3 series of 10 repetitions at $70 \%-80 \%$ 1-RM, with 1 minute of recovery between se-
ries
Group 2: Aerobic exercise $(n=13)$
Further details: 3 times a week for 4 months. Participants exercised for 60 minutes per session at $60 \%$ -
65\% of heart rate reserve, as estimated by the Karvonen formula.11 Aerobic activities were performed
on treadmill, cycle, or elliptical machines, and participants were free to change the cardiovascular
equipment used from 1 session to the next. Heart rate monitors were used to standardise exercise in-
tensity

Outcomes Outcomes reported: resolution of fatty liver disease

Follow-up (months): 4

Notes Source of funding (quote): "Supported in part by grants to Paolo Moghetti from the University ofVerona and from the Azienda Ospedaliera Universitaria Integrata of Verona, Verona, Italy. The funding sources had no involvement in the design, execution or analysis of the study."

Trial name/trial registry number: NCT01182948 - Subproject of RAED2 study

We tried to contact the authors in December 2020

\section{Risk of bias}

\begin{tabular}{|c|c|c|}
\hline Bias & Authors' judgement & Support for judgement \\
\hline $\begin{array}{l}\text { Random sequence genera- } \\
\text { tion (selection bias) }\end{array}$ & Unclear risk & Comment: this information was not available \\
\hline $\begin{array}{l}\text { Allocation concealment } \\
\text { (selection bias) }\end{array}$ & Unclear risk & Comment: this information was not available \\
\hline $\begin{array}{l}\text { Blinding of participants } \\
\text { and personnel (perfor- } \\
\text { mance bias) } \\
\text { All outcomes }\end{array}$ & High risk & $\begin{array}{l}\text { Comment: because of the nature of the intervention, it is not possible to blind } \\
\text { the participants }\end{array}$ \\
\hline $\begin{array}{l}\text { Blinding of outcome as- } \\
\text { sessment (detection bias) } \\
\text { All outcomes }\end{array}$ & Low risk & $\begin{array}{l}\text { Quote: "A single radiologist, who was blinded to participants' clinical details, } \\
\text { performed all MRI examinations" } \\
\text { Comment: the radiologist who assessed the resolution of fatty liver (the only } \\
\text { outcome reported in this trial) was blinded to the treatment allocation }\end{array}$ \\
\hline $\begin{array}{l}\text { Incomplete outcome data } \\
\text { (attrition bias) } \\
\text { All outcomes }\end{array}$ & High risk & $\begin{array}{l}\text { Comment: there were post-randomisation dropouts; some were related to the } \\
\text { intervention and outcomes }\end{array}$ \\
\hline $\begin{array}{l}\text { Selective reporting (re- } \\
\text { porting bias) }\end{array}$ & Low risk & $\begin{array}{l}\text { Comment: a pre-published protocol was not available and adverse events } \\
\text { were not reported }\end{array}$ \\
\hline Other bias & Low risk & Comment: no other bias noted \\
\hline
\end{tabular}


Chan 2018

\section{Study characteristics}

\begin{tabular}{ll}
\hline Methods & Randomised clinical trial \\
\hline Participants & Country: China \\
& Period of recruitment: not stated \\
& Number randomised: 52 \\
& Post-randomisation dropouts: $0(0.0 \%)$ \\
& Revised sample size: 52 \\
& Average age (years): 14 \\
& Female: $19(36.5 \%)$ \\
& NASH: 1 (1.9\%) \\
& Diabetes mellitus: not stated \\
& Inclusion criteria: Post-pubertal Chinese adolescents aged $14-18$ years with primary obesity with BMI $\geq$ \\
& 95th centile of a local reference and fatty liver. Post-puberty was defined as either breast or genital Tan- \\
ner stages being stage using a validated self-reported Pubertal Development Scale in Chinese. & Exclusion criteria: history of viral hepatitis, alcohol consumption, concurrent participation in another \\
clinical trial, chronic medical illness or being unwilling to attend regular follow-up appointments
\end{tabular}

Interventions Group 1: Dietary advice plus exercise advice $(n=26)$

Further details: weekly patient-centred dietary consultation sessions for 16 weeks. Each participant was given an individualised menu plan. The dietary component and portion sizes of the menu plan were based on the recommendations of the U.S. Department of Health and Human Services and U.S. Department of Agriculture. Participants were encouraged to undergo 30-min aerobic exercise 2 to 3 times a week

Group 2: No active intervention $(n=26)$

Further details: Usual clinical routine paediatric consultations, providing simple diet and exercise and information on medical complications such as NAFLD and metabolic syndrome, were conducted in the Obesity and Lipid Disorder Clinic every 16 weeks during both phase I and II periods. Participants were encouraged to reduce low-glycaemic index carbohydrate and animal fat intake, and to exercise for at least 2 to 3 times a week, 30 mins per session

Outcomes Outcomes reported: resolution of fatty liver disease

Follow-up (months): 16

Notes

Source of funding (quote): "The project was funded by a grant from the Health and Medical Research Fund, Food and Health Bureau, Hong Kong SAR Government (Ref. no: 11122981) and the Direct Grant for Research (Ref. no: 2014.1.065)."

Trial name/trial registry number: not stated

We tried to contact the authors in December 2020

\section{Risk of bias}

\begin{tabular}{lll}
\hline Bias & Authors' judgement & Support for judgement \\
\hline $\begin{array}{l}\text { Random sequence genera- } \\
\text { tion (selection bias) }\end{array}$ & Low risk & Quote: "randomly assigned by computer generated random numbers" \\
\hline $\begin{array}{l}\text { Allocation concealment } \\
\text { (selection bias) }\end{array}$ & Unclear risk & Comment: this information was not available \\
\hline $\begin{array}{l}\text { Blinding of participants } \\
\text { and personnel (perfor- } \\
\text { mance bias) }\end{array}$ & High risk & $\begin{array}{l}\text { Comment: because of the nature of the intervention, it is not possible to blind } \\
\text { the participants }\end{array}$ \\
\hline $\begin{array}{l}\text { Blinding of outcome as- } \\
\text { sessment (detection bias) }\end{array}$ & Low risk & $\begin{array}{l}\text { Quote: "Measurements were performed by a trained investigator blinded to } \\
\text { group allocation of the study subjects" }\end{array}$ \\
\hline
\end{tabular}


Chan 2018 (Continued)

All outcomes

Incomplete outcome data Low risk Comment: intention to treat analysis was performed
(attrition bias)

(attrition bias)

All outcomes

\begin{tabular}{|c|c|c|}
\hline $\begin{array}{l}\text { Selective reporting (re- } \\
\text { porting bias) }\end{array}$ & High risk & $\begin{array}{l}\text { Comment: a pre-published protocol was not available and adverse events } \\
\text { were not reported }\end{array}$ \\
\hline
\end{tabular}

Other bias Low risk Comment: no other bias noted

Chen 2020

\section{Study characteristics}

\begin{tabular}{ll}
\hline Methods & Randomised clinical trial \\
\hline Participants & Country: China \\
& Number randomised: 44 \\
& Post-randomisation dropouts: not stated \\
& Revised sample size: 44 \\
& Average age: 38 years \\
& Female: 16 (36.4\%) \\
& NASH: not stated \\
Diabetes mellitus: not stated & Inclusion criteria: Participants having NAFLD and meeting the diagnostic criteria in the Guidelines for \\
& Diagnosis and Treatment of Nonalcoholic Fatty Liver Diseases; age 8 - 60 years; and BMI $\geq 25 \mathrm{~kg} / \mathrm{m}^{2}$ \\
& Exclusion criteria: Secondary obesity, such as hypothyroid obesity, pituitary obesity, Cushing-syn- \\
drome-induced obesity, hypothalamic obesity, and hypogonadal obesity; diseases that require con- & trolled protein intake, such as renal disease; psychiatric disease and malignancy; severe gastrointesti- \\
nal disease; currently on a weight-loss diet or medical treatment or having undergone surgery in the \\
preceding 3 months; weight fluctuations of more than 5 kg over the preceding 2 months; history of food \\
allergy; in the gestation, preconception, or lactation period; perimenopausal or postmenopausal; and \\
malformations or chronic infectious diseases
\end{tabular}

Interventions Participants were randomly assigned to 2 groups

Group 1: Carbohydrate-restricted diet plus dietary advice plus exercise advice $(n=22)$

Further details: The percentage of energy from carbohydrates was $20 \%-25 \%$, and food with a low glycaemic index was primarily selected.The main form of education was face-to-face counselling, which was divided into dietary guidance, physical activity guidance, and psychological behavioural counselling

Group 2: dietary advice plus exercise advice $(n=22)$

Further details: The main form of education was face-to-face counselling, which was divided into dietary guidance, physical activity guidance, and psychological behavioural counselling

\begin{tabular}{ll}
\hline Outcomes & None of the outcomes of interest were reported \\
\hline Notes & Source of funding (quote): "This work was supported by the Shanghai Shenkang Hospital Development \\
Center Appropriate Technology Promotion Project: Promotion and Application of Nondrug Treatment \\
Technology for Nonalcoholic Fatty Liver Disease under Grant [number SHDC12012207] and the Shang- \\
hai Health and Family Planning Commission Health Industry Clinical Research Project: "Research on \\
the therapeutic effect of weight management based on wearable devices on nonalcoholic fatty liver \\
disease" under Grant [number 201840164]" \\
Trial name/trial registry number: not stated \\
We tried to contact the authors in March 2021
\end{tabular}


Chen 2020 (Continued)

Risk of bias

\begin{tabular}{|c|c|c|}
\hline Bias & Authors' judgement & Support for judgement \\
\hline $\begin{array}{l}\text { Random sequence genera- } \\
\text { tion (selection bias) }\end{array}$ & Low risk & Quote: "random number table" \\
\hline $\begin{array}{l}\text { Allocation concealment } \\
\text { (selection bias) }\end{array}$ & Unclear risk & Comment: this information was not available \\
\hline $\begin{array}{l}\text { Blinding of participants } \\
\text { and personnel (perfor- } \\
\text { mance bias) } \\
\text { All outcomes }\end{array}$ & High risk & $\begin{array}{l}\text { Comment: because of the nature of the intervention, it is not possible to blind } \\
\text { the participants }\end{array}$ \\
\hline $\begin{array}{l}\text { Blinding of outcome as- } \\
\text { sessment (detection bias) } \\
\text { All outcomes }\end{array}$ & Unclear risk & Comment: this information was not available \\
\hline $\begin{array}{l}\text { Incomplete outcome data } \\
\text { (attrition bias) } \\
\text { All outcomes }\end{array}$ & Unclear risk & Comment: this information was not available \\
\hline $\begin{array}{l}\text { Selective reporting (re- } \\
\text { porting bias) }\end{array}$ & High risk & $\begin{array}{l}\text { Comment: a pre-published protocol was not available and none of the out- } \\
\text { comes of interest were reported }\end{array}$ \\
\hline Other bias & Low risk & Comment: no other bias noted. \\
\hline
\end{tabular}

\section{Cheng 2017}

\section{Study characteristics}

\begin{tabular}{ll}
\hline Methods & Randomised clinical trial \\
\hline Participants & Country: China \\
& Period of recruitment: not stated \\
& Number randomised: 115 \\
& Post-randomisation dropouts: 30 (26.1\%) \\
& Revised sample size: 85 \\
& Reasons for post-randomisation dropouts: Family reasons (6), health problems (5), travel (6), lost inter- \\
& est (5), other reason (8) \\
& Average age (years): 61 \\
& Female: 89 (104.7\%) \\
& NASH: not stated \\
& Diabetes mellitus: 0 (0.0\%) \\
Inclusion criteria: $50-65$ y/o with impaired fasting glucose $(5.6$ - 6.9 mmol/L) or impaired glucose toler- \\
ance (7.8 - 112 hours after intake of 75 g glucose), NAFLD diagnosed by H-MRS and alcohol <21 drinks/ \\
week in men and < 14 in women, no chronic cardiovascular, musculoskeletal or GI problems and not on \\
extreme diets, last menstruation $>6$ months ago but within 10 years \\
Exclusion criteria: BMI > 38, T1DM or T2DM and mental illness
\end{tabular}

Interventions

Group 1: Calorie-restricted diet $(\mathrm{n}=22)$

Further details: The diet group, after baseline assessments, had a daily lunch plus an individual nutritional consultation programme developed by a clinical nutritionist on the basis of each individual's dietary intakes and body weight. During the intervention, participants were given a daily prepared meal (lunch), which accounted for $30-40 \%$ of the total daily energy intake. The meal included $37-40 \%$ 
carbohydrate with 9 - $13 \mathrm{~g}$ as fibre, $35-37 \%$ fat (SAFA 10\%, MUFA $15-20 \%$, PUFA 10\%) and $25-27 \%$ protein. To ensure they consumed sufficient amounts of dietary fibre, $5 \mathrm{~g}$ of soluble fibre (dietary water-soluble fibre) was also added to the lunch

Group 2: Supervised aerobic exercise plus calorie-restricted diet $(n=23)$

Further details: The Exercise plus Diet (AED) group performed the same exercise programme and followed the same diet as described above for exercise and diet groups

Group 3: Supervised aerobic exercise $(n=22)$

Further details: The exercise (AEx) group, after baseline fitness assessments, participated 2 - 3 times a week in a supervised progressive aerobic exercise training programme (such as Nordic brisk walking plus stretching and other group exercises) which was developed by an exercise researcher. The exercise sessions were performed at the community park areas which were close to the participant's home. The intensity and duration of exercise was increased from $60 \%$ to $75 \%$ of the maximum oxygen uptake (estimated from fitness test) and from 30 to 60 mins per session

Group 4: no active intervention $(n=18)$

Further details: The no-intervention (NI) group was advised to maintain their current level of physical activity and eating habits during the intervention

Additional details: 8 months

Outcomes Outcomes reported: resolution of fatty liver disease

Follow-up (months): 8

Notes

Source of funding (quote): "Funding for this study was provided by the China State Sport General Administration (2013B040, 2015B039), the Chinese Nature Science Foundation (NSFC 31571219), and the Shanghai Jiao Tong University Zhiyuan Foundation (CP2014013). Funding to RB was provided by the Sigrid Juselius Foundation, the Instrumentation Research Foundation, the Finnish Medical Foundation, the Paulo Foundation and the Academy of Finland (130557, 270352)."

Trial name/trial registry number: ISRCTN 42622771

We tried to contact the authors in December 2020

\section{Risk of bias}

\begin{tabular}{|c|c|c|}
\hline Bias & Authors' judgement & Support for judgement \\
\hline $\begin{array}{l}\text { Random sequence genera- } \\
\text { tion (selection bias) }\end{array}$ & Low risk & $\begin{array}{l}\text { Quote: "A computer program was used to generate the block randomisation } \\
\text { sequence (block size 20) and was controlled by a researcher not involved in } \\
\text { the selection of the participants" }\end{array}$ \\
\hline $\begin{array}{l}\text { Allocation concealment } \\
\text { (selection bias) }\end{array}$ & Low risk & $\begin{array}{l}\text { Quote: "A computer program was used to generate the block randomisation } \\
\text { sequence (block size 20) and was controlled by a researcher not involved in } \\
\text { the selection of the participants" }\end{array}$ \\
\hline $\begin{array}{l}\text { Blinding of participants } \\
\text { and personnel (perfor- } \\
\text { mance bias) } \\
\text { All outcomes }\end{array}$ & High risk & $\begin{array}{l}\text { Comment: because of the nature of the intervention, it is not possible to blind } \\
\text { the participants }\end{array}$ \\
\hline $\begin{array}{l}\text { Blinding of outcome as- } \\
\text { sessment (detection bias) } \\
\text { All outcomes }\end{array}$ & Low risk & $\begin{array}{l}\text { Quote: "Although lifestyle interventions cannot be performed in a dou- } \\
\text { ble-blinded fashion (since study subjects clearly are aware of the type of inter- } \\
\text { vention), investigators were blinded for the tests and analyses during the en- } \\
\text { tire study" }\end{array}$ \\
\hline $\begin{array}{l}\text { Incomplete outcome data } \\
\text { (attrition bias) } \\
\text { All outcomes }\end{array}$ & High risk & $\begin{array}{l}\text { Comment: there were post-randomisation dropouts; some were related to the } \\
\text { intervention and outcomes }\end{array}$ \\
\hline $\begin{array}{l}\text { Selective reporting (re- } \\
\text { porting bias) }\end{array}$ & High risk & $\begin{array}{l}\text { Comment: a pre-published protocol was not available and adverse events } \\
\text { were not reported }\end{array}$ \\
\hline Other bias & Low risk & Comment: no other bias noted \\
\hline
\end{tabular}


Cuthbertson 2016

\section{Study characteristics}

\begin{tabular}{ll}
\hline Methods & Randomised clinical trial \\
\hline Participants & Country: UK \\
& Period of recruitment: not stated \\
& Number randomised: 69 \\
& Post-randomisation dropouts: 19 (27.5\%) \\
& Revised sample size: 50 \\
& Reasons for post-randomisation dropouts: Discontinued baseline assessment (4), Discontinued inter- \\
& vention (4), Did not maintain habitual diet (2), declined post-intervention assessments (9) \\
& Average age (years): 51 \\
& Female: 11 (22.0\%) \\
& NASH: not stated \\
& Diabetes mellitus: 0 (0.0\%) \\
Inclusion criteria: NAFLD, sedentary lifestyle $(<2 \mathrm{~h} /$ week low-intensity physical activity, no moderate- \\
or high-intensity activity), nonsmokers, alcohol < 14 units (women) and $<21$ units/week (men) \\
Exclusion criteria: other causes of liver disease, T2DM, ischaemic heart disease, contraindication to ex- \\
ercise
\end{tabular}

\begin{tabular}{ll} 
Interventions & $\begin{array}{l}\text { Group 1: Exercise advice }(\mathrm{n}=20) \\
\text { Further details: advice about health benefits of exercise } \\
\text { Group 2: Aerobic exercise }(\mathrm{n}=30) \\
\text { Further details: 3/week 30-min moderate (30\% HRR) aerobic exercise, progressing weekly based on HR } \\
\text { responses (5/week } 45 \text { min at 60\% HRR by week 12) }\end{array}$ \\
\hline Outcomes & None of the outcomes of interest were reported \\
\hline Notes & $\begin{array}{l}\text { Source of funding (quote): "This work was supported by the European Foundation for the Study of Dia- } \\
\text { betes." } \\
\text { Trial name/trial registry number: NCT01834300 } \\
\text { We tried to contact the authors in December } 2020\end{array}$ \\
\hline
\end{tabular}

\section{Risk of bias}

\begin{tabular}{|c|c|c|}
\hline Bias & Authors' judgement & Support for judgement \\
\hline $\begin{array}{l}\text { Random sequence genera- } \\
\text { tion (selection bias) }\end{array}$ & Low risk & $\begin{array}{l}\text { Quote: "patients were randomly assigned on a 1:1 basis using a computer-gen- } \\
\text { erated sequence" }\end{array}$ \\
\hline $\begin{array}{l}\text { Allocation concealment } \\
\text { (selection bias) }\end{array}$ & Unclear risk & Comment: this information was not available \\
\hline $\begin{array}{l}\text { Blinding of participants } \\
\text { and personnel (perfor- } \\
\text { mance bias) } \\
\text { All outcomes }\end{array}$ & High risk & $\begin{array}{l}\text { Comment: because of the nature of the intervention, it is not possible to blind } \\
\text { the participants }\end{array}$ \\
\hline $\begin{array}{l}\text { Blinding of outcome as- } \\
\text { sessment (detection bias) } \\
\text { All outcomes }\end{array}$ & Unclear risk & Comment: this information was not available \\
\hline $\begin{array}{l}\text { Incomplete outcome data } \\
\text { (attrition bias) } \\
\text { All outcomes }\end{array}$ & High risk & $\begin{array}{l}\text { Comment: there were post-randomisation dropouts; some were related to the } \\
\text { intervention and outcomes }\end{array}$ \\
\hline
\end{tabular}


Cuthbertson 2016 (Continued)

\begin{tabular}{|c|c|c|}
\hline $\begin{array}{l}\text { Selective reporting (re- } \\
\text { porting bias) }\end{array}$ & High risk & $\begin{array}{l}\text { Comment: a pre-published protocol was not available and neither mortality } \\
\text { nor resolution of fatty liver was reported }\end{array}$ \\
\hline
\end{tabular}

Other bias Low risk Comment: no other bias noted

De Luis 2010

\section{Study characteristics}

\begin{tabular}{|c|c|}
\hline Methods & Randomised clinical trial \\
\hline Participants & $\begin{array}{l}\text { Country: Spain } \\
\text { Period of recruitment: not stated } \\
\text { Number randomised: } 28 \\
\text { Post-randomisation dropouts: } 0(0.0 \%) \\
\text { Revised sample size: } 28 \\
\text { Average age (years): } 46 \\
\text { Female: } 22 \text { ( } 78.6 \%) \\
\text { NASH: not stated } \\
\text { Diabetes mellitus: } 0 \text { ( } 0.0 \%) \\
\text { Inclusion criteria: Group I: Obese with BMI } \geq 30 \text { and Group II BMI } \geq 30 \text { and ALT } \geq 43 \\
\text { Exclusion criteria: Alcohol, medications: BP-lowering medications, statins, diabetes, IFG, hepatitis B, C, } \\
\text { CMV, EBV, other causes of CLD }\end{array}$ \\
\hline Interventions & $\begin{array}{l}\text { Group 1: Fat-restricted diet }(n=15) \\
\text { Further details: diet I (low fat, } 1500 \mathrm{kcal} / \text { day, } 53 \% \text { carbohydrates, } 20 \% \text { proteins, } 27 \% \text { fats) } \\
\text { Group 2: Carbohydrate-restricted diet }(n=13) \\
\text { Further details: diet II (low carbohydrate: } 1507 \mathrm{kcal} / \text { day, } 38 \% \text { carbohydrates, } 26 \% \text { proteins, } 36 \% \text { fats) }\end{array}$ \\
\hline Outcomes & None of the outcomes of interest were reported \\
\hline Notes & $\begin{array}{l}\text { Source of funding: not stated } \\
\text { Trial name/trial registry number: not stated } \\
\text { We tried to contact the authors in December } 2020\end{array}$ \\
\hline
\end{tabular}

\section{Risk of bias}

\begin{tabular}{lll}
\hline Bias & Authors' judgement & Support for judgement \\
\hline $\begin{array}{l}\text { Random sequence genera- } \\
\text { tion (selection bias) }\end{array}$ & Unclear risk & Comment: this information was not available \\
\hline $\begin{array}{l}\text { Allocation concealment } \\
\text { (selection bias) }\end{array}$ & Unclear risk & Comment: this information was not available \\
\hline $\begin{array}{l}\text { Blinding of participants } \\
\text { and personnel (perfor- } \\
\text { mance bias) }\end{array}$ & Unclear risk & Comment: this information was not available \\
$\begin{array}{l}\text { All outcomes } \\
\begin{array}{l}\text { Blinding of outcome as- } \\
\text { sessment (detection bias) } \\
\text { All outcomes }\end{array}\end{array}$ & Low risk & $\begin{array}{l}\text { Quote: "They were blinded to treatment allocation, clinical information and } \\
\text { laboratory data" } \\
\text { Comment: this refers to assessors of outcomes reported in the trial, none of } \\
\text { which were of interest for this review }\end{array}$ \\
\hline
\end{tabular}


De Luis 2010 (Continued)

Incomplete outcome data Low risk Comment: there were no post-randomisation dropouts

(attrition bias)

All outcomes

\begin{tabular}{|c|c|c|}
\hline $\begin{array}{l}\text { Selective reporting (re- } \\
\text { porting bias) }\end{array}$ & High risk & $\begin{array}{l}\text { Comment: a pre-published protocol was not available and neither mortality } \\
\text { nor resolution of fatty liver was reported }\end{array}$ \\
\hline
\end{tabular}

Other bias Low risk Comment: no other bias noted

De Piano 2012

\section{Study characteristics}

\begin{tabular}{|c|c|}
\hline Methods & Randomised clinical trial \\
\hline Participants & $\begin{array}{l}\text { Country: Brazil } \\
\text { Period of recruitment: not stated } \\
\text { Number randomised: } 58 \\
\text { Post-randomisation dropouts: not stated } \\
\text { Revised sample size: } 58 \\
\text { Average age (years): not stated } \\
\text { Female: not stated } \\
\text { NASH: not stated } \\
\text { Diabetes mellitus: not stated } \\
\text { Inclusion criteria: Adolescents, postpubertal stage } 5 \text {, BMI > 95\% } \\
\text { Exclusion criteria: genetic, metabolic or endocrine disease and previous drug use }\end{array}$ \\
\hline Interventions & $\begin{array}{l}\text { Group 1: Aerobic exercise plus resistance exercise }(n=\text { not stated) } \\
\text { Further details: exercise - aerobic plus resistance training (AT plus RT) } \\
\text { Group 2: Aerobic exercise ( } n=\text { not stated) } \\
\text { Further details: exercise - aerobic (AT) }\end{array}$ \\
\hline Outcomes & None of the outcomes of interest were reported \\
\hline Notes & $\begin{array}{l}\text { Source of funding (quote): "AFIP, FAPESP 2008/53069-0 and 2006/00684-3, FAPESP (CEPID/Sleep } \\
\text { \#9814303-3 S.T) CNPq, CAPES, CENESP, FADA, and UNIFESP-EPM, supported the CEPE-GEO Interdisci- } \\
\text { plinary Obesity Intervention Program." } \\
\text { Trial name/trial registry number: NCT01358773 } \\
\text { We tried to contact the authors in December } 2020\end{array}$ \\
\hline
\end{tabular}

\section{Risk of bias}

\begin{tabular}{lll}
\hline Bias & Authors' judgement & Support for judgement \\
\hline $\begin{array}{l}\text { Random sequence genera- } \\
\text { tion (selection bias) }\end{array}$ & Unclear risk & Comment: this information was not available \\
\hline $\begin{array}{l}\text { Allocation concealment } \\
\text { (selection bias) }\end{array}$ & Unclear risk & Comment: this information was not available \\
\hline $\begin{array}{l}\text { Blinding of participants } \\
\text { and personnel (perfor- } \\
\text { mance bias) }\end{array}$ & Unclear risk & Comment: this information was not available \\
All outcomes & \\
\hline
\end{tabular}


De Piano 2012 (Continued)

Blinding of outcome as- Unclear risk Comment: this information was not available sessment (detection bias)

All outcomes

\begin{tabular}{lll}
$\begin{array}{l}\text { Incomplete outcome data } \\
\text { (attrition bias) } \\
\text { All outcomes }\end{array}$ & Unclear risk & Comment: this information was not available \\
\hline $\begin{array}{l}\text { Selective reporting (re- } \\
\text { porting bias) }\end{array}$ & High risk & $\begin{array}{l}\text { Comment: a pre-published protocol was not available and neither mortality } \\
\text { nor resolution of fatty liver was reported }\end{array}$
\end{tabular}

Other bias Low risk Comment: no other bias noted

Dong 2016

\section{Study characteristics}

\begin{tabular}{|c|c|}
\hline Methods & Randomised clinical trial \\
\hline Participants & $\begin{array}{l}\text { Country: China } \\
\text { Period of recruitment: not stated } \\
\text { Number randomised: } 280 \\
\text { Post-randomisation dropouts: } 15(5.4 \%) \\
\text { Revised sample size: } 265 \\
\text { Reasons for post-randomisation dropouts: Poor compliance (11), declined repeat examinations (4) } \\
\text { Average age (years): } 57 \\
\text { Female: } 0 \text { (0.0\%) } \\
\text { NASH: not stated } \\
\text { Diabetes mellitus: } 0(0.0 \%) \\
\text { Inclusion criteria: NAFLD, } \geq 45 \mathrm{y} / 0, \text { men } \\
\text { Exclusion criteria: Hx of alcohol }>20 \text { g/day or } 140 \text { g/week, viral hepatitis or other causes of CLD, con- } \\
\text { sumption of hypoglycaemic, hypolipidaemic, anti-inflammatory and weight-loss agents, presence of } \\
\text { coronary, renal, pulmonary or thyroid diseases, transaminase levels }>2 x \text { the upper limit of normal }\end{array}$ \\
\hline Interventions & $\begin{array}{l}\text { Group 1: Dietary advice plus exercise advice }(n=132) \\
\text { Further details: All enrolled participants in the test group received lifestyle counselling about their di- } \\
\text { et and physical activity from } 2 \text { professional physicians ( } 1 \text { dietician and } 1 \text { exercise physiologist). Doctors } \\
\text { conducted a phone visit (the duration of a typical phone visit was approximately } 10 \text { minutes) with the } \\
\text { participants in the test group every } 3 \text { months from July } 2012 \text { to July 2014, providing health guidance on } \\
\text { diet and exercise } \\
\text { Group 2: No active intervention ( } n=133) \\
\text { Further details: treatment as usual }\end{array}$ \\
\hline
\end{tabular}

Outcomes

Outcomes reported: mortality at maximum follow-up, resolution of fatty liver disease, fibrosis score Follow-up (months): 24

\section{Notes}
Source of funding (quote): "This work was supported by a grant from the Science and Technology Commission of Shanghai, China (No: 13DZ2260700), Shanghai New Hundred Talents Program (No: XBR2013091), and Shanghai Key Developing Disciplines Program (No: 2015ZB0501)"
Trial name/trial registry number: ChiCTR-IOR-16008949
We tried to contact the authors in December 2020

\section{Risk of bias}


Dong 2016 (Continued)

Random sequence genera- Low risk $\quad$ Quote: "computer-generated randomization sequence"
tion (selection bias)

Allocation concealment
(selection bias) Unclear risk Comment: this information was not available

\begin{tabular}{l}
$\begin{array}{l}\text { Blinding of participants } \\
\begin{array}{l}\text { and personnel (perfor- } \\
\text { mance bias) }\end{array}\end{array}$ \\
$\begin{array}{l}\text { All outcomes risk } \\
\text { blind the participants }\end{array}$ \\
\hline
\end{tabular}

\begin{tabular}{lll}
\hline $\begin{array}{l}\text { Blinding of outcome as- } \\
\text { sessment (detection bias) } \\
\text { All outcomes }\end{array}$ & Unclear risk & Comment: this information was not available \\
\hline $\begin{array}{l}\text { Incomplete outcome data } \\
\text { (attrition bias) }\end{array}$ & High risk & $\begin{array}{l}\text { Comment: there were post-randomisation dropouts; some were related to the } \\
\text { intervention and outcomes }\end{array}$ \\
\hline
\end{tabular}

\begin{tabular}{lll}
\hline $\begin{array}{l}\text { Selective reporting (re- } \\
\text { porting bias) }\end{array}$ & High risk & $\begin{array}{l}\text { Comment: a pre-published protocol was not available and adverse events } \\
\text { were not reported }\end{array}$ \\
\hline Other bias & Low risk & Comment: no other bias noted \\
\hline
\end{tabular}

Dynnyk 2016

\section{Study characteristics}

\begin{tabular}{ll}
\hline Methods & Randomised clinical trial \\
\hline Participants & Country: Ukraine \\
& Period of recruitment: not stated \\
& Number randomised: 58 \\
& Post-randomisation dropouts: not stated \\
& Revised sample size: 58 \\
& Average age (years): not stated \\
& Female: not stated \\
& NASH: not stated \\
& Diabetes mellitus: not stated \\
& Inclusion criteria: NAFLD and visceral obesity \\
\hline Interventions & Group 1: Exercise advice ( $\mathrm{n}=$ not stated) \\
& $\begin{array}{l}\text { Further details: General recommendations of changing sedentary behaviour by improving physical ac- } \\
\text { tivity } \\
\text { Group 2: Aerobic exercise ( } \mathrm{n}=\text { not stated) } \\
\text { Further details: Pedometer with recommendation of walking 10,000 steps a day }\end{array}$ \\
\hline Outcomes & None of the outcomes of interest were reported \\
\hline Notes & Source of funding: not stated \\
Trial name/trial registry number: not stated \\
We tried to contact the authors in December 2020
\end{tabular}

\section{Risk of bias}


Dynnyk 2016 (Continued)

\begin{tabular}{|c|c|c|}
\hline Bias & Authors' judgement & Support for judgement \\
\hline $\begin{array}{l}\text { Random sequence genera- } \\
\text { tion (selection bias) }\end{array}$ & Unclear risk & Comment: this information was not available \\
\hline $\begin{array}{l}\text { Allocation concealment } \\
\text { (selection bias) }\end{array}$ & Unclear risk & Comment: this information was not available \\
\hline $\begin{array}{l}\text { Blinding of participants } \\
\text { and personnel (perfor- } \\
\text { mance bias) } \\
\text { All outcomes }\end{array}$ & Unclear risk & Comment: this information was not available \\
\hline $\begin{array}{l}\text { Blinding of outcome as- } \\
\text { sessment (detection bias) } \\
\text { All outcomes }\end{array}$ & Unclear risk & Comment: this information was not available \\
\hline $\begin{array}{l}\text { Incomplete outcome data } \\
\text { (attrition bias) } \\
\text { All outcomes }\end{array}$ & Unclear risk & Comment: this information was not available \\
\hline $\begin{array}{l}\text { Selective reporting (re- } \\
\text { porting bias) }\end{array}$ & High risk & $\begin{array}{l}\text { Comment: a pre-published protocol was not available and neither mortality } \\
\text { nor resolution of fatty liver was reported }\end{array}$ \\
\hline Other bias & Low risk & Comment: no other bias noted \\
\hline
\end{tabular}

Eckard 2013

\section{Study characteristics}

\begin{tabular}{ll}
\hline Methods & Randomised clinical trial \\
\hline Participants & Country: USA \\
& Period of recruitment: not stated \\
& Number randomised: 56 \\
& Post-randomisation dropouts: $15(26.8 \%)$ \\
& Revised sample size: 41 \\
& Reasons for post-randomisation dropouts: deployed overseas (1), lost to follow-up (7), withdrawn (4), \\
& moved area (1), lost medical benefits (1), transportation conflict $(1)$ \\
& Average age (years): 50 \\
& Female: 25 ( $61.0 \%)$ \\
& NASH: not stated \\
& Diabetes mellitus: $8(19.5 \%)$ \\
& Inclusion criteria: $18-70 \mathrm{y} / 0$, biopsy confirmed NAFLD including NASH within 6 months prior to enrol- \\
& ment \\
& Exclusion criteria: Alcohol $>20 \mathrm{~g} /$ day, other causes of CLD < insulin for diabetes, pregnancy
\end{tabular}
LFDE and MFDE participants attended a specialised nutrition class conducted by a registered dietitian, developed for this protocol. The class provided a nutrition prescription based on individualised calorie needs and macronutrient distribution (using the MyPyramid food group serving sizes) based on group assignment. Calorie (kcal) needs were calculated using the Mifflin-St Jeor equation using initial, actual body weight, and activity factor of 1.5 (light activity) subtracting $500 \mathrm{kcal} /$ day for weight loss of $1 \mathrm{lb}$ per week. Participants were also instructed on estimating portion sizes using the MyPyramid serving size guidelines, received a set of measuring cups and spoons, and were provided with supplemental refer- 
Eckard 2013 (Continued)

ence material on healthy cooking, grocery shopping, and dining out. LFDE and MFDE participants met with 1 of 3 research staff dietitians 3 more times (at 2, 4, and 6 months) for continued guidance on assigned diet

Group 2: Carbohydrate-restricted diet plus aerobic exercise $(n=9)$

Further details: moderate-fat/ low-processed-carbohydrate diet (30\% fat, 50\% carbohydrate, 20\% protein) with moderate exercise (MFDE). LFDE and MFDE participants attended a specialised nutrition class conducted by a registered dietitian, developed for this protocol. The class provided a nutrition prescription based on individualised calorie needs and macronutrient distribution (using the MyPyramid food group serving sizes) based on group assignment. Calorie (kcal) needs were calculated using the Mifflin-St Jeor equation using initial, actual body weight, and activity factor of 1.5 (light activity) subtracting $500 \mathrm{kcal} /$ day for weight loss of $1 \mathrm{lb}$ per week. Participants were also instructed on estimating portion sizes using the MyPyramid serving size guidelines, received a set of measuring cups and spoons, and were provided with supplemental reference material on healthy cooking, grocery shopping, and dining out. LFDE and MFDE participants met with 1 of 3 research staff dietitians 3 more times (at 2, 4, and 6 months) for continued guidance on assigned diet

Group 3: Dietary advice $(\mathrm{n}=11)$

Further details: treatment as usual - SC subgroup participants attended 1 healthy-eating class within 2 weeks of enrolment. This class is regularly taught at BAMC for DoD beneficiaries interested in weight loss or general nutrition guidelines

Group 4: Aerobic exercise $(n=9)$

Further details: moderate exercise only. ME participants did not receive any dietary guidance

\begin{tabular}{ll}
\hline Outcomes & $\begin{array}{l}\text { Outcomes reported: nafld activity score } \\
\text { Follow-up (months): } 6\end{array}$ \\
\hline Notes & $\begin{array}{l}\text { Source of funding (quote): "This research received no specific grant from any funding agency in the } \\
\text { public, commercial, or not-for-profit sectors." } \\
\text { Trial name/trial registry number: not stated } \\
\text { We tried to contact the authors in December } 2020\end{array}$
\end{tabular}

\section{Risk of bias}

\begin{tabular}{lll}
\hline Bias & Authors' judgement & Support for judgement \\
\hline $\begin{array}{l}\text { Random sequence genera- } \\
\text { tion (selection bias) }\end{array}$ & Low risk & $\begin{array}{l}\text { Quote: "Participant randomization occurred by computer-generated ran- } \\
\text { dom-numbers list" }\end{array}$ \\
\hline $\begin{array}{l}\text { Allocation concealment } \\
\text { (selection bias) }\end{array}$ & Low risk & $\begin{array}{l}\text { Quote: "Participant randomization occurred by computer-generated ran- } \\
\text { dom-numbers list in blocks of } 10 \text { with assignments placed in sealed envelopes, } \\
\text { numbered sequentially, and allocated to participants in the order of recruit- } \\
\text { ment by the primary investigator" }\end{array}$ \\
\hline
\end{tabular}

\begin{tabular}{|c|c|c|}
\hline $\begin{array}{l}\text { Blinding of participants } \\
\text { and personnel (perfor- }\end{array}$ & High risk & $\begin{array}{l}\text { Comment: because of the nature of the intervention, it was not possible to } \\
\text { blind the participants }\end{array}$ \\
\hline
\end{tabular}

mance bias)

All outcomes

$\begin{array}{ll}\begin{array}{l}\text { Blinding of outcome as- } \\ \text { sessment (detection bias) }\end{array} & \text { Low risk } \\ \text { All outcomes } & \begin{array}{l}\text { Quote: "a NAS was assigned to each specimen (pre- and post- intervention) by } \\ \text { a single hepatopathologist who was blinded to study randomization" } \\ \text { Comment: the pathologist who assessed the NAS score (the only outcome re- } \\ \text { ported in this trial) was blinded to the treatment allocation }\end{array}\end{array}$

\begin{tabular}{lll}
$\begin{array}{l}\text { Incomplete outcome data } \\
\text { (attrition bias) } \\
\text { All outcomes }\end{array}$ & Unclear risk & $\begin{array}{l}\text { Comment: there were post-randomisation dropouts, but it was not clear } \\
\text { whether these were related to the intervention or outcomes }\end{array}$ \\
$\begin{array}{l}\text { Selective reporting (re- } \\
\text { porting bias) }\end{array}$ & High risk & $\begin{array}{l}\text { Comment: a pre-published protocol was not available and neither mortality } \\
\text { nor resolution of fatty liver was reported }\end{array}$ \\
\hline
\end{tabular}


Eckard 2013 (Continued)

Other bias Low risk Comment: no other bias noted

Goss 2020

\section{Study characteristics}

\begin{tabular}{ll}
\hline Methods & Randomised clinical trial \\
\hline Participants & Country: USA \\
Number randomised: 32 \\
Post-randomisation dropouts: not stated \\
Revised sample size: 32 \\
Average age: 14 years \\
Female: 16 (50\%) \\
NASH: not stated \\
Diabetes mellitus: not stated \\
Inclusion criteria: children ages 9 to 17 years, BMI z-score $>85$ th percentile, diagnosis of NAFLD (ALT > \\
45 and/or perfusely echogenic liver via ultrasound) and sedentary (<2 hours/week of intentional exer- \\
cise, and agreed to maintain their level of activity throughout the study) \\
Exclusion criteria: those with diabetes, unwilling to follow the prescribed diets, recent weight change \\
( \pm 10 lbs. in previous year), history of eating disorder, digestive diseases, major liver dysfunction, cur- \\
rent/recent smoker, current use of oral corticosteroids ( $>5$ days/month) and using medications for \\
treatment of psychosis or manic-depressive illness
\end{tabular}

Interventions

Participants were randomly assigned to 2 groups

Group 1: Carbohydrate-restricted diet $(n=16)$

Further details: The CRD diet was designed to minimise intake of refined $\mathrm{CHO}$ sources such as added sugars, high glycaemic grains and fructose and provided $\leq 25 \%$ energy from $\mathrm{CHO}, 25 \%$ energy from protein and $\geq 50 \%$ energy from fat. $\mathrm{CHO}$ sources were primarily derived from leafy greens and nonstarchy vegetables. Additional $\mathrm{CHO}$ sources included in the diet prescription were nuts and nut butters, unsweetened yoghurt and low glycaemic fruits such as apples and berries. Limited amounts of whole grains. Legumes, root vegetables and 'treats' like dark chocolate were permitted. Protein sources included meat, fish, eggs, poultry and whey protein if appropriate. Saturated fat intake was limited to < $10 \%$ total energy/day. Other permitted fat sources included olive oil, walnut oil and other sources of poly- and mono-unsaturated fatty acids. A multivitamin was also encouraged to ensure all micronutrient requirements were met.

Group 2: fat-restricted diet $(n=16)$

Further details: The FRD comprised low sugar, high-quality foods with low-energy density, which is the standard of care in the dietary management of children with NAFLD. This diet was based on the USDA MyPlate Daily Food Plan for teenagers with 20\% energy from CHO:protein:fat. Participants were asked to avoid consuming foods high in fat such as fried foods, butter, cream cheese and bacon, whereas fruits, vegetables (starchy and non-starchy), whole grains, poultry, lean meats and low-fat dairy products were permitted

Outcomes None of the outcomes of interest were reported

Notes

Source of funding (quote): "Research reported in this publication was supported by the Thrasher Research Fund (TRF13337), the National Institute of Diabetes and Digestive and Kidney Diseases (DK079626), the National Center for Advancing Translational Sciences (1TL1TR001418-01), and the National Institute of General Medical Sciences (NIH T32GM008361)"

Trial name/trial registry number: NCT02787668 We tried to contact the authors in March 2021

\section{Risk of bias}


Goss 2020 (Continued)

Random sequence genera- Low risk Quote: "The random allocation sequence was created using a random number tion (selection bias) generator by PROC PLAN (SAS Version 9.3)".

Allocation concealment Unclear risk

(selection bias)

Quote: "participants were assigned to a diet using a block randomization scheme, and the condition assignments were placed in sealed envelopes that were not opened until a specific participant was assigned".

Comment: further details were not available

\begin{tabular}{|c|c|c|}
\hline $\begin{array}{l}\text { Blinding of participants } \\
\text { and personnel (perfor- }\end{array}$ & High risk & $\begin{array}{l}\text { Quote: "Because this was a diet intervention study, it was not possible for par- } \\
\text { ticipants or study personnel to be blinded to group assignment". }\end{array}$ \\
\hline
\end{tabular}

mance bias)

All outcomes

\begin{tabular}{lll}
\hline $\begin{array}{l}\text { Blinding of outcome as- } \\
\text { sessment (detection bias) }\end{array}$ & High risk & $\begin{array}{l}\text { Quote: "Because this was a diet intervention study, it was not possible for par- } \\
\text { ticipants or study personnel to be blinded to group assignment". }\end{array}$ \\
All outcomes &
\end{tabular}

\begin{tabular}{lll}
\hline $\begin{array}{l}\text { Incomplete outcome data } \\
\text { (attrition bias) } \\
\text { All outcomes }\end{array}$ & Unclear risk & Comment: this information was not available \\
\hline $\begin{array}{l}\text { Selective reporting (re- } \\
\text { porting bias) }\end{array}$ & High risk & $\begin{array}{l}\text { Comment: a published protocol was available, but the publication was after } \\
\text { recruitment began. None of the outcomes of interest for this review were re- } \\
\text { ported }\end{array}$ \\
\hline Other bias & Low risk & Comment: no other bias noted \\
\hline
\end{tabular}

Hallsworth 2011

\section{Study characteristics}

\begin{tabular}{ll}
\hline Methods & Randomised clinical trial \\
\hline Participants & Country: UK \\
& Period of recruitment: not stated \\
& Number randomised: 21 \\
& Post-randomisation dropouts: 2 (9.5\%) \\
& Revised sample size: 19 \\
& Reasons for post-randomisation dropouts: Change in diabetes medication (1); lost $>5 \%$ body weight \\
& during 8-week period (1) \\
Average age (years): 56 & Female: not stated \\
NASH: not stated \\
Diabetes mellitus: not stated \\
Inclusion criteria: Non-advanced NAFLD; sedentary ( $\leq 60$ min vigorous activities per week) \\
Exclusion criteria: Heart or kidney disease; implanted ferrous metal; pre-existing medical conditions \\
preventing participation in the exercise programme; insulin sensitising treatment or dietary change (for \\
people with type 2 diabetes mellitus, diet and metformin were acceptable for inclusion if stable for 6 \\
months); alcohol intake (above 21 units for men or 14 units for women)
\end{tabular}

Interventions

Group 1: Resistance exercise $(n=11)$

Further details: Resistance exercise was performed 3 times a week on nonconsecutive days for 8 weeks. The programme consisted of 8 exercises: biceps curl; calf raise; triceps press; chest press; seated hamstrings curl; shoulder press; leg extension and lateral pull down (Precor, Woodinville, USA). Each session lasted between 45 and 60 mins and consisted of a 10-min warm-up at approximately $60 \%$ maximum heart rate on a cycle ergometer followed by resistance exercise done as a circuit, ending with a repeat of the warm-up described. The one repetition maximum was measured at baseline and fol- 
Hallsworth 2011 (Continued)

lowing the intervention. Initially, participants did 2 circuits using $50 \%$ of their 1 repetition maximum, progressing to 3 circuits, using a minimum $70 \%$ of their 1 repetition maximum by week 7 . Participants were encouraged to increase the resistance used each week when possible. Bi-weekly supervised sessions were used to encourage adherence and progression and to resolve any problems. Heart rate was recorded during each session (Polar RS400; Polar Electro Oy, Kempele, Finland) and was used alongside exercise logs to assess adherence

Group 2: No active intervention $(n=8)$

Further details: treatment as usual

\begin{tabular}{ll}
\hline Outcomes & None of the outcomes of interest were reported \\
\hline Notes & Source of funding (quote): "The research leading to these results has received funding from the Eu- \\
ropean Union Seventh Framework Programme (FP7/2007-2013) under grant agreement no Health- \\
F2-2009-241762, for the project FLIP; the Medical Research Council; the UK National Institute for Health \\
Research Biomedical Research Centre on Ageing and Age-Related Diseases and Diabetes UK." \\
Trial name/trial registry number: not stated \\
We tried to contact the authors in December 2020
\end{tabular}

\section{Risk of bias}

\begin{tabular}{|c|c|c|}
\hline Bias & Authors' judgement & Support for judgement \\
\hline $\begin{array}{l}\text { Random sequence genera- } \\
\text { tion (selection bias) }\end{array}$ & Unclear risk & Comment: this information was not available \\
\hline $\begin{array}{l}\text { Allocation concealment } \\
\text { (selection bias) }\end{array}$ & Unclear risk & Comment: this information was not available \\
\hline $\begin{array}{l}\text { Blinding of participants } \\
\text { and personnel (perfor- } \\
\text { mance bias) } \\
\text { All outcomes }\end{array}$ & High risk & $\begin{array}{l}\text { Comment: because of the nature of the intervention, it was not possible to } \\
\text { blind the participants }\end{array}$ \\
\hline $\begin{array}{l}\text { Blinding of outcome as- } \\
\text { sessment (detection bias) } \\
\text { All outcomes }\end{array}$ & Unclear risk & Comment: this information was not available \\
\hline $\begin{array}{l}\text { Incomplete outcome data } \\
\text { (attrition bias) } \\
\text { All outcomes }\end{array}$ & High risk & $\begin{array}{l}\text { Comment: there were post-randomisation dropouts; some were related to the } \\
\text { intervention and outcomes }\end{array}$ \\
\hline $\begin{array}{l}\text { Selective reporting (re- } \\
\text { porting bias) }\end{array}$ & High risk & $\begin{array}{l}\text { Comment: a pre-published protocol was not available and neither mortality } \\
\text { nor resolution of fatty liver was reported }\end{array}$ \\
\hline Other bias & Low risk & Comment: no other bias noted \\
\hline
\end{tabular}

Hallsworth 2015

\section{Study characteristics}

\begin{tabular}{ll}
\hline Methods & Randomised clinical trial \\
\hline Participants & Country: UK \\
& Period of recruitment: not stated \\
& Number randomised: 29 \\
& Post-randomisation dropouts: 6 (20.7\%) \\
& Revised sample size: 23 \\
\hline
\end{tabular}


Hallsworth 2015 (Continued)

Reasons for post-randomisation dropouts: Discontinued intervention (2); time commitment (1); pro-

longed illness (1); non-adherence (1); missing data (1)

Average age (years): 53

Female: not stated

NASH: not stated

Diabetes mellitus: not stated

Inclusion criteria: Non-advanced NAFLD; sedentary ( $\leq 60$ min vigorous activity per week)

Exclusion criteria: Inability to give informed consent; heart or kidney disease; viral hepatitis; uncontrolled thyroid conditions; haemochromatosis; drug-related steatosis; implanted ferrous material; pre-existing medical conditions preventing participation in the exercise programme; medication for T2DM other than metformin; self-reported weekly alcohol intake (above 21 units for men or 14 units for women)

Interventions

Group 1: Aerobic exercise $(n=12)$

Further details: Participants completed a cycle ergometer-based HIIT protocol 3 times a week on nonconsecutive days for 12 weeks. Intensity was based on the $6-20$ point Borg rating of perceived exertion (RPE). Participants were provided with a portable audio device (iPod shuffle, Apple Inc.) containing pre-recorded and written instructions to guide them through each session. Sessions consisted of a 5-min warm-up progressing from an RPE of 9 - 13 ('very light' to 'somewhat hard') followed by 5 intervals of cycling at an RPE of 16 - 17 ('very hard') interspersed with 3-min recovery periods and followed by a 3-min cool-down after the last interval. Each interval was 2 mins long in the first week with 10 secs added per week, so that intervals were $3 \mathrm{~min}$ and 50 secs long by week 12 . Sessions therefore lasted 30 - 40 min. Recovery periods included 90 secs of passive recovery, 60 secs of light band resisted upper body exercise and 15 secs each to transition off and on the ergometer. One upper body exercise was performed per recovery period in the following order: face-pull, horizontal push, horizontal pull and 30 ${ }^{\circ}$ push. Exercise was performed at commercial fitness facilities, with the first 2 sessions supervised by one of the investigators

Group 2: No active intervention $(n=11)$

Further details: treatment as usual

Outcomes None of the outcomes of interest were reported

Notes

Source of funding (quote): "this work was supported by the European Union Seventh Framework Programme [grant number F2-2009-241762]; the Medical Research Council [grant numbers G0700718 (to K.H.) and G1100160 (to K.G.H.)]; the National Institute for Health Research [grant numbers NIHRSRF-2011-04-017 (to M.I.T.)] and Diabetes, U.K. [grant number 08/0003759 (to C.T.)]. Q.M.A. is the recipient of a Clinical Senior Lectureship Award from the Higher Education Funding Council for England (HEFCE). Q.M.A. and C.P.D. are members of the EPoS (Elucidating Pathways of Steatohepatitis) consortium funded by the Horizon 2020 Framework Programme of the European Union under Grant Agreement 634413."

Trial name/trial registry number: ISRCTN78698481

We tried to contact the authors in December 2020

\section{Risk of bias}

\begin{tabular}{|c|c|c|}
\hline Bias & Authors' judgement & Support for judgement \\
\hline $\begin{array}{l}\text { Random sequence genera- } \\
\text { tion (selection bias) }\end{array}$ & Low risk & $\begin{array}{l}\text { Quote: "Randomization was undertaken via a random allocation sequence } \\
\text { (www.randomization.com)" }\end{array}$ \\
\hline $\begin{array}{l}\text { Allocation concealment } \\
\text { (selection bias) }\end{array}$ & Unclear risk & Comment: this information was not available \\
\hline $\begin{array}{l}\text { Blinding of participants } \\
\text { and personnel (perfor- } \\
\text { mance bias) } \\
\text { All outcomes }\end{array}$ & High risk & $\begin{array}{l}\text { Comment: because of the nature of the intervention, it was not possible to } \\
\text { blind the participants }\end{array}$ \\
\hline $\begin{array}{l}\text { Blinding of outcome as- } \\
\text { sessment (detection bias) }\end{array}$ & Unclear risk & Comment: this information was not available \\
\hline
\end{tabular}


Hallsworth 2015 (Continued)

All outcomes

\begin{tabular}{lll}
$\begin{array}{l}\text { Incomplete outcome data } \\
\text { (attrition bias) } \\
\text { All outcomes }\end{array}$ & High risk & $\begin{array}{l}\text { Comment: there were post-randomisation dropouts; some were related to the } \\
\text { intervention and outcomes }\end{array}$ \\
\hline $\begin{array}{l}\text { Selective reporting (re- } \\
\text { porting bias) }\end{array}$ & High risk & $\begin{array}{l}\text { Comment: a pre-published protocol was not available and neither mortality } \\
\text { nor resolution of fatty liver was reported }\end{array}$ \\
\hline Other bias & Low risk & Comment: no other bias noted \\
\hline
\end{tabular}

Hickman 2013

\section{Study characteristics}

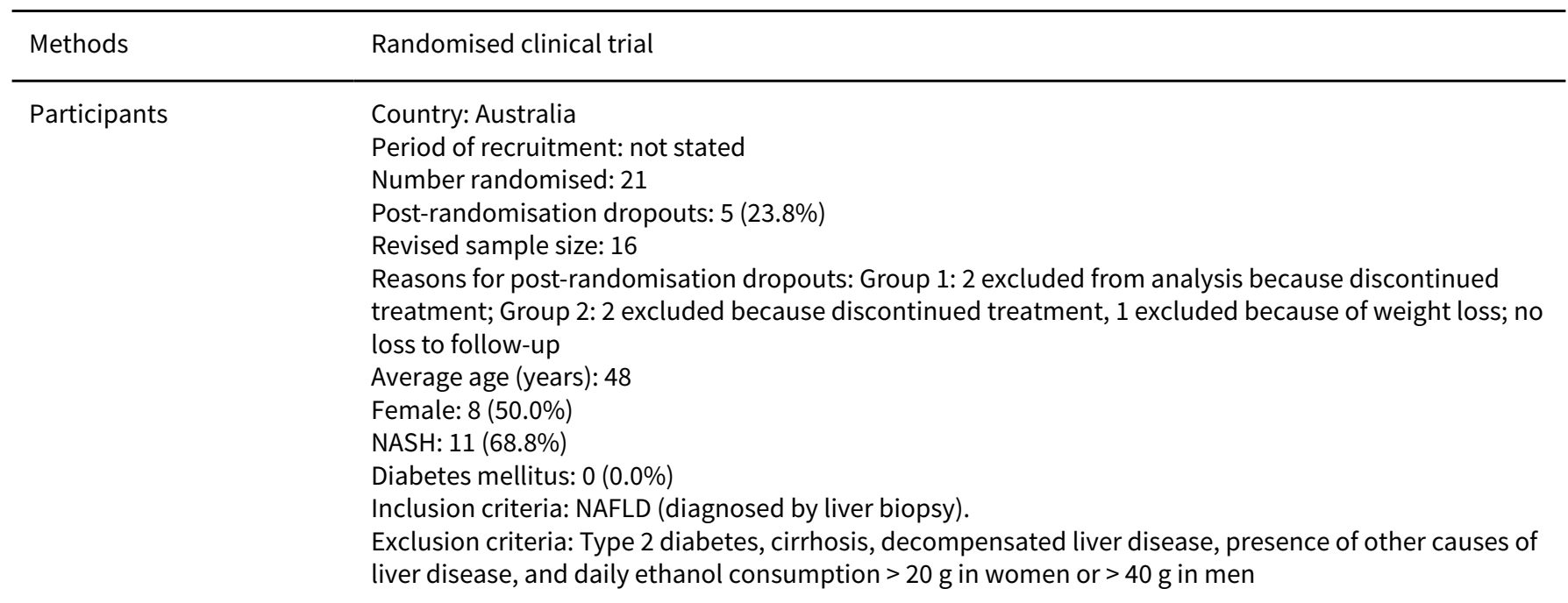

Interventions Group 1: Calorie-restricted diet $(n=8)$

Further details: dietary-induced weight-loss intervention was individually tailored to induce an energy restriction calculated (based on Harris-Benedict predicted energy requirements and sedentary activity factors) for 5 to $10 \%$ body weight loss over a 16-week intensive phase whereby participants were reviewed weekly by a dietician. This was followed by an 8-week weight-maintenance phase involving dietetic review every 2 weeks. Participants were instructed not to change their usual physical activity habits. The intervention was supported by an educational manual, which included information about energy content of food portions, macro- and micronutrient content of individual foods and combination dishes, food-label reading, shopping, cooking and eating-out guidelines, motivational tools and goal-setting skills and activities. A dietary composition of $40 \%$ carbohydrate, $40 \%$ fat and $20 \%$ protein sources of energy was encouraged, with specific advice on reduced saturated fat, lowering sugar (including reduced sugary drinks), avoiding micronutrient poor/energy dense food options and aiming for regular meal patterns. Weekly weight and waist measures and 24-hour diet recall interviewing assisted compliance and encouraged ongoing self-monitoring. Motivational interviewing and behavioural management techniques were used throughout the programme Group 2: Aerobic exercise $(n=13)$ Further details: The exercise programme involved 3 sessions a week of circuit exercise training for 6 months, without dietary changes, with the aim to improve physical fitness and muscle strength without significant body weight loss. Exercise was conducted using pneumatic resistance training equipment (AbHurOy, Kokkola, Finalnd). Each circuit consisted of 15 moderate-intensity resistance exercises covering the main muscular groups. Some machines were bi-functional, allowing participants to exercise 2 different muscular groups, usually antagonistic. On the bi-functional machines, participants exercised alternately the agonist or the antagonist muscle. The training programme consisted of 30second exercise intervals and 30-second rest periods, during which participants moved to the next sta- 
tion and prepared themselves for the following exercise period. A digital timed audio signal was used to indicate the start and the end of the 30 seconds exercise or rest period. Training intensity over the whole duration of the training programme was fixed at $50 \%$ of 1 repetition maximum (1- RM). Number of circuits, and consequently session duration, was progressively increased from 1 circuit (12 mins) in week 1 to 5 circuits in week 12 ( 60 mins) and was kept constant from week 16 to the end of the training programme (week 24). A 1-RM was completed on each of the 15 exercises the week prior to the beginning of the programme, and was then reassessed every 4 weeks to account for any strength adaptations over the course of the training period

Outcomes

Outcomes reported: mortality at maximal follow-up, serious adverse events (number of people), any adverse events (number of people), liver transplantation at maximum follow-up, decompensation (number of people), cirrhosis (number of people), resolution of fatty liver disease, hepatocellular carcinoma, nafld activity score

Follow-up (months): 6

Notes

Source of funding (quote): "The study was funded by the National Health and Medical Research Council of Australia and the Lions Medical Research Foundation."

Trial name/trial registry number: not stated

We tried to contact the authors in December 2020

\section{Risk of bias}

\begin{tabular}{lll}
\hline Bias & Authors' judgement & Support for judgement \\
\hline $\begin{array}{l}\text { Random sequence genera- } \\
\text { tion (selection bias) }\end{array}$ & Low risk & $\begin{array}{l}\text { Quote: "randomised by the study co-ordinator, using random number genera- } \\
\text { tor" }\end{array}$ \\
\hline $\begin{array}{l}\text { Allocation concealment } \\
\text { (selection bias) }\end{array}$ & Low risk & $\begin{array}{l}\text { Quote: "Random allocation to groups was concealed in an envelope by an in- } \\
\text { dependent research assistant who was not involved in recruitment (author } \\
\text { replies)" }\end{array}$
\end{tabular}

\begin{tabular}{|c|c|c|}
\hline $\begin{array}{l}\text { Blinding of participants } \\
\text { and personnel (perfor- }\end{array}$ & High risk & $\begin{array}{l}\text { Comment: because of the nature of the intervention, it was not possible to } \\
\text { blind the participants }\end{array}$ \\
\hline
\end{tabular}

mance bias)

All outcomes

\begin{tabular}{|c|c|c|}
\hline $\begin{array}{l}\text { Blinding of outcome as- } \\
\text { sessment (detection bias) } \\
\text { All outcomes }\end{array}$ & High risk & $\begin{array}{l}\text { Quote: "The assessors for primary outcome histology and body composi- } \\
\text { tion were all blinded to group allocation for the duration of the study (author } \\
\text { replies)" } \\
\text { Comment: the assessors of the clinical outcomes were not blinded }\end{array}$ \\
\hline
\end{tabular}

\begin{tabular}{lll}
\hline $\begin{array}{l}\text { Incomplete outcome data } \\
\text { (attrition bias) } \\
\text { All outcomes }\end{array}$ & High risk & $\begin{array}{l}\text { Comment: there were post-randomisation dropouts; some were related to the } \\
\text { intervention and outcomes }\end{array}$ \\
\hline $\begin{array}{l}\text { Selective reporting (re- } \\
\text { porting bias) }\end{array}$ & Low risk & $\begin{array}{l}\text { Comment: a pre-published protocol was not available, but the study authors } \\
\text { reported mortality, adverse events, and resolution of fatty liver }\end{array}$ \\
\hline Other bias & Low risk & Comment: no other bias noted \\
\hline
\end{tabular}

Houghton 2017

\section{Study characteristics}

\begin{tabular}{ll}
\hline Methods & Randomised clinical trial \\
\hline Participants & Country: UK \\
\hline
\end{tabular}

Lifestyle modifications for nonalcohol-related fatty liver disease: a network meta-analysis (Review) 
Houghton 2017 (Continued)

Period of recruitment: not stated

Number randomised: 26

Post-randomisation dropouts: 2 (7.7\%)

Revised sample size: 24

Reasons for post-randomisation dropouts: Pre-existing knee problem (1); pre-existing back problem (1)

Average age (years): 52

Female: not stated

NASH: $24(100.0 \%)$

Diabetes mellitus: not stated

Inclusion criteria: Biopsy-proven NASH; sedentary ( $\leq 60$ min of moderate-vigorous activity per week) Exclusion criteria: Heart or kidney disease; implanted ferrous metal; pre-existing medical conditions preventing participation in the exercise programme; insulin-sensitising treatment; dietary change over the preceding 6 months; evidence of other liver disease; history of excessive alcohol consumption (alcohol intake $>20 \mathrm{~g} /$ day for women and $>30 \mathrm{~g}$ /day for men)

Interventions

Group 1: Supervised aerobic exercise plus SupResistance exercise $(n=12)$

Further details: Exercise was supervised and performed 3 times a week on nonconsecutive days for 12 weeks. The exercise programme consisted of aerobic (cycling) and resistance training and is detailed in the Supplementary Clinical Trial Study Pro- tocol. The cycling included a 5-minute warm-up and 3 intervals on a fixed bike for 2 minutes with a 1-minute rest in between. Exercise intensity was based on the Borg ( $6-20$ points) rating of perceived exertion with bike intervals corresponding to a rating of perceived exertion of 16 to 18 (very hard). This was followed by a resistance exercise circuit that comprised 5 exercises: hip and knee extension, horizontal row, chest press, vertical row, and knee extension (Precor, Woodinville, WA). Participants were provided with a suitable weight for each resistance exercise based on a rating of perceived exertion of 14 to 16 (hard). The rating of perceived exertion was used to guide intensity for safety, time effectiveness, its translational use in clinical practice, and its effectiveness at determining 1 repetition maximum. Each session lasted between 45 and 60 minutes. All sessions were conducted at an accredited sports centre and supervised by a certified exercise specialist, who recorded progress to ensure adherence and encouraged exercise progression through adding resistance on the bike and increasing the weights lifted as able. This also helped to improve safety, adherence, and the opportunity to resolve any problems

Group 2: No active intervention $(n=12)$

Further details: Standard care consisted of volunteers continuing any prescription medication and going for regular monitoring of their condition(s) with their normal general practitioner or consultant(s), or both

Outcomes Outcomes reported: fibrosis score

Follow-up (months): 3

Notes

Source of funding (quote): "This research has received funding from the European Union Seventh Framework Programme (FP7/2007-2013) under grant agreement Health-F22009-241762 for the Fatty Liver Inhibition of Progression project, The Medical Research Council, Diabetes UK, The Newcastle Centre for Ageing and Vitality, The UK National Institute for Health Research Biomedical Research Centre on Ageing and Age-Related Diseases, and was supported by a Senior Fellowship from the National Institute for Health Research (M.I.T.)."

Trial name/trial registry number: ISRCTN16070927

We tried to contact the authors in December 2020

\section{Risk of bias}

\begin{tabular}{lll}
\hline Bias & Authors' judgement & Support for judgement \\
\hline $\begin{array}{l}\text { Random sequence genera- } \\
\text { tion (selection bias) }\end{array}$ & Unclear risk & Comment: this information was not available \\
\hline $\begin{array}{l}\text { Allocation concealment } \\
\text { (selection bias) }\end{array}$ & Unclear risk & Comment: this information was not available \\
\hline
\end{tabular}


Houghton 2017 (Continued)

Blinding of participants and personnel (perfor-

High risk mance bias)

All outcomes
Comment: because of the nature of the intervention, it was not possible to blind the participants

Blinding of outcome as-
sessment (detection bias) $\quad$ Unclear risk Comment: this information was not available

All outcomes

Incomplete outcome data High risk

(attrition bias)

Comment: there were post-randomisation dropouts; some were related to the

All outcomes intervention and outcomes

\begin{tabular}{|c|c|c|}
\hline $\begin{array}{l}\text { Selective reporting (re- } \\
\text { porting bias) }\end{array}$ & High risk & $\begin{array}{l}\text { Comment: a pre-published protocol was not available and neither mortality } \\
\text { nor resolution of fatty liver was reported }\end{array}$ \\
\hline
\end{tabular}

Other bias Low risk Comment: no other bias noted

Johari 2019

\section{Study characteristics}

\begin{tabular}{|c|c|}
\hline Methods & Randomised clinical trial \\
\hline \multirow[t]{10}{*}{ Participants } & Country: Malaysia \\
\hline & Number randomised: 43 \\
\hline & Post-randomisation dropouts: $0(0 \%)$ \\
\hline & Revised sample size: 43 \\
\hline & Average age: 47 years \\
\hline & Female: $10(23.3 \%)$ \\
\hline & NASH: not stated \\
\hline & Diabetes mellitus: not stated \\
\hline & $\begin{array}{l}\text { Inclusion criteria: NAFLD patients who attended the Gastroenterology Clinic. To be eligible, partici- } \\
\text { pants of either sex were required to have elevated alanine transferase (ALT) and or aspartate trans- } \\
\text { ferase (AST) level (ALT > } 41 \text { and or AST > } 34 \mathrm{IU} / \mathrm{L}) \text {, age that ranged from } 18 \text { to } 70 \text { years old, BMI between }\end{array}$ \\
\hline & $\begin{array}{l}17.5 \text { and } 40 \mathrm{Kg} / \mathrm{m}^{2} \text { and no evidence of other forms of liver diseases. For those with diabetes mellitus } \\
\text { and dyslipidaemia, they must be on a stable therapy for at least } 6 \text { months prior to study enrolment } \\
\text { Exclusion criteria: significant alcohol consumption ( }>1 \text { standard drink per day), pregnancy, and in- } \\
\text { volvement in an active weight loss programme or taking weight-loss medications, substance abuse and } \\
\text { significant psychiatric problems. Withdrawn participants were those unable to tolerate the fasting in- } \\
\text { tervention during the trial and those who dropped out by their own choice }\end{array}$ \\
\hline
\end{tabular}

Interventions Participants were randomly assigned to 2 groups

Group 1: Calorie-restricted diet $(n=33)$

Further details: On fasting day, all participants were instructed to restrict $70 \%$ of their calorie requirement per day and on non-fasting day, they ate ad libitum. They were told to eat on the non-fasting day what they normally ate and to the point of satisfaction but not to intentionally overeat. The calorie-restriction and feeding days began at 9 am each day, but on fasting day, calorie-deficient meals were only consumed between $2 \mathrm{pm}$ and $8 \mathrm{pm}$. Diet plans were not provided to participants but were self-selected using detailed individualised food portion lists, meal plans, and recipes. To ensure maximum adherence to dietary plan, participants received intermittent phone calls from the investigator and 2-weekly appointments (total 4 appointments) with a dietitian. Total duration: 8 weeks.

Group 2: No active intervention $(n=10)$

Outcomes Outcomes reported: mortality

Follow-up (months): 1.84 
Johari 2019 (Continued)

Notes
Source of funding (quote): "We thanked the following grants for funding the current study including USM short term grant (reference no: 304/PPSP/61313173) and Research University Individual (RUI) grant (reference no: 1001/PPSP/812151)"

Trial name/trial registry number: not stated

We tried to contact the authors in March 2021

\section{Risk of bias}

\begin{tabular}{|c|c|c|}
\hline Bias & Authors' judgement & Support for judgement \\
\hline $\begin{array}{l}\text { Random sequence genera- } \\
\text { tion (selection bias) }\end{array}$ & Low risk & Quote: "Random number was generated using the Microsoft Office Excel" \\
\hline $\begin{array}{l}\text { Allocation concealment } \\
\text { (selection bias) }\end{array}$ & Unclear risk & Comment: this information was not available \\
\hline $\begin{array}{l}\text { Blinding of participants } \\
\text { and personnel (perfor- } \\
\text { mance bias) } \\
\text { All outcomes }\end{array}$ & High risk & $\begin{array}{l}\text { Comment: because of the nature of the intervention, it was not possible to } \\
\text { blind the participants }\end{array}$ \\
\hline $\begin{array}{l}\text { Blinding of outcome as- } \\
\text { sessment (detection bias) } \\
\text { All outcomes }\end{array}$ & Unclear risk & Comment: this information was not available \\
\hline $\begin{array}{l}\text { Incomplete outcome data } \\
\text { (attrition bias) } \\
\text { All outcomes }\end{array}$ & Low risk & Comment: there were no post-randomisation dropouts \\
\hline $\begin{array}{l}\text { Selective reporting (re- } \\
\text { porting bias) }\end{array}$ & High risk & $\begin{array}{l}\text { Comment: a pre-published protocol was not available and adverse events } \\
\text { were not reported }\end{array}$ \\
\hline Other bias & Low risk & Comment: no other bias noted \\
\hline
\end{tabular}

\section{Kaliora 2016}

\section{Study characteristics}

\begin{tabular}{ll}
\hline Methods & Randomised clinical trial \\
\hline Participants & Country: Greece \\
Period of recruitment: not stated \\
Number randomised: 55 \\
Post-randomisation dropouts: 11 (20.0\%) \\
Revised sample size: 44 \\
Reasons for post-randomisation dropouts: Personal reasons (5); modified lipid lowering treatment (5); \\
started antimetabolite treatment (1) \\
Average age (years): 51 \\
Female: 32 (72.7\%) \\
NASH: not stated \\
Diabetes mellitus: not stated \\
Inclusion criteria: Age 18 - 65; BMI > 25; Adherence to 'western diet' (Mediterranean diet. Score values < \\
35) \\
Exclusion criteria: Chronic viral hepatitis; congenital or acquired liver disease; prior exposure to hepa- \\
totoxic drugs; liver cirrhosis; bariatric surgery; daily consumption of alcohol more than $20 \mathrm{~g}$ for women \\
and more than 30 g for men (for over 6 months during the last 5 years); medications which could impact
\end{tabular}


Kaliora 2016 (Continued)

on fatty liver disease; psychiatric disorders impairing the patient's ability to provide written informed consent; pregnant or lactating women; supplementation with n-3 fatty acids; probiotics/synbiotics, antioxidants, vitamins and/ or phytochemicals

Interventions

Group 1: Raisins plus dietary advice $(n=23)$

Further details: The aim of nutritional counselling was a weight loss of approximately $5 \%$ of the initial BW within 6 months. Participants attended appointments with experienced dietitians to receive guidance on calorie restriction. Nutritional counselling was centred on the distribution of nutrients for the total caloric value as follows: $30 \%$ of the total energy as fat ( $<10 \%$ as SFAs, $\sim 10 \%$ as MUFAs, and $\sim 10 \%$ as PUFAs), $20 \%$ as protein, $50 \%$ as carbohydrate, $300 \mathrm{mg} \mathrm{d}-1$ as dietary cholesterol, and $20-30 \mathrm{~g}$ fibre per day. Participants in the Control arm received the above dietary counselling. Participants in the Currant arm received dietary counselling and incorporated in their daily diet the consumption of $36 \mathrm{~g}$ of Corinthian currants equal to 2 fruit servings replacing snacks of similar nutritional value (low-fat yogurt, mini-crackers, or bread with low-fat cheese)

Group 2: Dietary advice $(n=21)$

Further details: The aim of nutritional counselling was a weight loss of approximately $5 \%$ of the initial BW within 6 months. Participants attended appointments with experienced dietitians to receive guidance on calorie restriction. Nutritional counselling was centred on the distribution of nutrients in relation to the total caloric value as follows: $30 \%$ of the total energy as fat $(<10 \%$ as SFAs, $\sim 10 \%$ as MUFAs, and $\sim 10 \%$ as PUFAs), $20 \%$ as protein, $50 \%$ as carbohydrate, $300 \mathrm{mg} \mathrm{d}-1$ as dietary cholesterol, and 20 - $30 \mathrm{~g}$ fibre per day. Participants in the Control arm received the above dietary counselling. Participants in the Currant arm received dietary counselling and incorporated in their daily diet the consumption of $36 \mathrm{~g}$ of Corinthian currants equal to 2 fruit servings replacing snacks of similar nutritional value (low-fat yogurt, mini-crackers, or bread with low-fat cheese).

Outcomes Outcomes reported: fibrosis score

Follow-up (months): 6

Notes Source of funding: not stated

Trial name/trial registry number: not stated

We tried to contact the authors in December 2020

\section{Risk of bias}

\begin{tabular}{lll}
\hline Bias & Authors' judgement & Support for judgement \\
\hline $\begin{array}{l}\text { Random sequence genera- } \\
\text { tion (selection bias) }\end{array}$ & Low risk & Quote: "the randomisation sequence was computer generated" \\
\hline $\begin{array}{l}\text { Allocation concealment } \\
\text { (selection bias) }\end{array}$ & Low risk & $\begin{array}{l}\text { Quote: "After randomisation, the statistician sent the randomisation list to the } \\
\text { trial principal investigator who completed a participant form for each subject, } \\
\text { including the treatment and the patient trial number and put it in a sealed en- } \\
\text { velope. Blinding of the allocated treatment was maintained to data analysts } \\
\text { and was exposed only after the assessment of outcomes" }\end{array}$ \\
\hline
\end{tabular}

\begin{tabular}{|c|c|c|}
\hline $\begin{array}{l}\text { Blinding of participants } \\
\text { and personnel (perfor- }\end{array}$ & High risk & $\begin{array}{l}\text { Comment: because of the nature of the intervention, it was not possible to } \\
\text { blind the participants }\end{array}$ \\
\hline
\end{tabular}

mance bias)

All outcomes

Blinding of outcome as- Low risk sessment (detection bias) All outcomes
Quote: "Blinding of the allocated treatment was maintained to data analysts and was exposed only after the assessment of outcomes"

Incomplete outcome data High risk

(attrition bias)

Comment: there were post-randomisation dropouts; some were related to the

All outcomes 
Kaliora 2016 (Continued)

\begin{tabular}{|c|c|c|}
\hline $\begin{array}{l}\text { Selective reporting (re- } \\
\text { porting bias) }\end{array}$ & High risk & $\begin{array}{l}\text { Comment: a pre-published protocol was not available and neither mortality } \\
\text { nor resolution of fatty liver was reported }\end{array}$ \\
\hline
\end{tabular}
nor resolution of fatty liver was reported

Other bias Low risk Comment: no other bias noted

Kani 2014

\section{Study characteristics}

\begin{tabular}{|c|c|}
\hline Methods & Randomised clinical trial \\
\hline Participants & $\begin{array}{l}\text { Country: Iran } \\
\text { Period of recruitment: } 2012 \\
\text { Number randomised: } 45 \\
\text { Post-randomisation dropouts: } 0 \text { (0.0\%) } \\
\text { Revised sample size: } 45 \\
\text { Average age (years): } 48 \\
\text { Female: } 21 \text { (46.7\%) } \\
\text { NASH: not stated } \\
\text { Diabetes mellitus: not stated } \\
\text { Inclusion criteria: diagnosis of NAFLD }\end{array}$ \\
\hline Interventions & $\begin{array}{l}\text { Group 1: Carbohydrate-restricted and calorie-restricted diet }(\mathrm{n}=30) \\
\text { Further details: In addition to focusing on a low-calorie diet, group } 2 \text { also received a low-carbohydrate } \\
\text { diet. In group 3, the composition of the macronutrients was similar to the group } 2 \text { diet except in this di- } \\
\text { et } 30 \mathrm{~g} \text { of soy nut was incorporated instead of } 30 \mathrm{~g} \text { of red meat } \\
\text { Group 2: Calorie-restricted diet ( } \mathrm{n}=15) \\
\text { Further details: The low-calorie diet (group } 1 \text { ) was } 200 \text { to } 500 \text { calories lower than the required calories } \\
\text { for each participant. Calorie restriction was considered according to participant's BMI category. A 200- } \\
\text { calorie reduction was considered for overweight individuals and up to a 500-calorie reduction for obese } \\
\text { participants }\end{array}$ \\
\hline Outcomes & None of the outcomes of interest were reported \\
\hline Notes & $\begin{array}{l}\text { Source of funding (quote): "This study was supported by Food Security Research Center and School of } \\
\text { Nutrition and Food Science, Isfahan University of Medical Sciences, Isfahan, Iran" } \\
\text { Trial name/trial registry number: NCT01419912; IRCT201105282839 N2 } \\
\text { We tried to contact the authors in December 2020. }\end{array}$ \\
\hline
\end{tabular}

\section{Risk of bias}

\begin{tabular}{lll}
\hline Bias & Authors' judgement & Support for judgement \\
\hline $\begin{array}{l}\text { Random sequence genera- } \\
\text { tion (selection bias) }\end{array}$ & Low risk & $\begin{array}{l}\text { Quote: "Participants were randomly assigned to one of three groups in which } \\
\text { sequentially numbered containers were used as a mechanism to implement } \\
\text { the random allocation sequence" }\end{array}$ \\
\hline $\begin{array}{l}\text { Allocation concealment } \\
\text { (selection bias) }\end{array}$ & Low risk & $\begin{array}{l}\text { Quote: "Participants were randomly assigned to one of three groups in which } \\
\text { sequentially numbered containers were used as a mechanism to implement } \\
\text { the random allocation sequence" }\end{array}$ \\
\hline $\begin{array}{l}\text { Blinding of participants } \\
\text { and personnel (perfor- } \\
\text { mance bias) }\end{array}$ & High risk & $\begin{array}{l}\text { Quote: "As this study was a dietary intervention, it was not blinded for the pa- } \\
\text { tients or the dietitian" }\end{array}$ \\
\hline
\end{tabular}


Kani 2014 (Continued)

Blinding of outcome as- Low risk Quote: "However, laboratory staff and individuals who analyzed the data were sessment (detection bias) Blinded to the groups of interventions"

All outcomes

\begin{tabular}{lll}
$\begin{array}{l}\text { Incomplete outcome data } \\
\text { (attrition bias) } \\
\text { All outcomes }\end{array}$ & Low risk & Comment: there were no post-randomisation dropouts \\
\hline $\begin{array}{l}\text { Selective reporting (re- } \\
\text { porting bias) }\end{array}$ & High risk & $\begin{array}{l}\text { Comment: a pre-published protocol was not available and neither mortality } \\
\text { nor resolution of fatty liver was reported }\end{array}$
\end{tabular}

Other bias Low risk Comment: no other bias noted

Katsagoni 2018

\section{Study characteristics}

\begin{tabular}{|c|c|}
\hline Methods & Randomised clinical trial \\
\hline \multirow[t]{9}{*}{ Participants } & Country: Greece \\
\hline & Number randomised: 63 \\
\hline & Post-randomisation dropouts: $0(0.0 \%)$ \\
\hline & Revised sample size: 63 \\
\hline & Female: $20(31.7 \%)$ \\
\hline & NASH: not stated \\
\hline & Diabetes mellitus: $0(0.0 \%)$ \\
\hline & Inclusion criteria: Age 18 - 65; BMI 25 - 40; diagnosis of NAFLD \\
\hline & $\begin{array}{l}\text { Exclusion criteria: Hepatitis B/C or HIV; alcohol consumption ( }>140 \text { g/week for women or }>210 \mathrm{~g} / \text { week } \\
\text { for men); hepatotoxic or steatogenic agents (e.g. amiodarone, tamoxifen, methotrexate); metabolic or } \\
\text { autoimmune liver disease; diabetes; known systemic disease with potential live involvement }\end{array}$ \\
\hline
\end{tabular}

Interventions

Group 1: Mediterranean diet plus dietary advice plus exercise advice $(n=21)$

Further details: all 3 groups were given an indicative energy restriction regimen with similar percentage of macronutrients, namely $45 \%$ carbohydrates, $20 \%$ protein and $35 \%$ lipids, which provided $6276 \mathrm{~kJ}$ (1500 kcal) for women and $7531 \mathrm{~kJ}$ (1800 kcal) for men. Participants in MDG and MLG followed a more intensive counselling programme, consisting of $7 \times 60$-min small-group sessions ( 3 - 5 people), held every 2 weeks for the first 2 months and every month for the next 4 months, co-ordinated by a research dietitian (C. N. K.). Nutritional counselling was based on the goal-setting theory aiming at improving diet quality and promoting energy restriction by enhancing adherence to the Mediterranean food pattern, as described in the MD pyramid and the Dietary Guidelines for Greeks. In the MDG, no further instructions were given for other lifestyle parameters. In the MLG, goals were also set for enhancing activity through a moderate-vigorous intensity physical activity programme of at least $30 \mathrm{~min} / \mathrm{d}$ (fast or very fast walking, slow or fast running, dancing, tennis and so on), as well as for optimal sleep duration (i.e. $\geq 7$ and $\leq 9 \mathrm{~h} / \mathrm{d}$ ) and mid-day rest (e.g. naps, siesta) Group 2: Mediterranean diet plus dietary advice $(n=21)$

Further details: all 3 groups were given an indicative energy restriction regimen with similar percentage of macronutrients, namely $45 \%$ carbohydrates, $20 \%$ protein and $35 \%$ lipids, which provided $6276 \mathrm{~kJ}$ (1500 kcal) for women and $7531 \mathrm{~kJ}$ (1800 kcal) for men. Participants in MDG and MLG followed a more intensive counselling programme, consisting of $7 \times 60$-min small-group sessions ( 3 - 5 people), held every 2 weeks for the first 2 months and every month for the next 4 months, co-ordinated by a research dietitian (C. N. K.). Nutritional counselling was based on the goal-setting theory aiming at improving diet quality and promoting energy restriction by enhancing adherence to the Mediterranean food pattern, as described in the MD pyramid and the Dietary Guidelines for Greeks. In the MDG, no further instructions were given for other lifestyle parameters. In the MLG, goals were also set for enhancing activ- 
ity through a moderate-vigorous intensity physical activity programme of at least $30 \mathrm{~min} / \mathrm{d}$ (fast or very fast walking, slow or fast running, dancing, tennis and so on), as well as for optimal sleep duration (i.e.

$\geq 7$ and $\leq 9 \mathrm{~h} / \mathrm{d}$ ) and mid-day rest (e.g. naps, siesta)

Group 3: Dietary advice $(\mathrm{n}=21)$

Further details: all 3 groups were given an indicative energy restriction regimen with similar percentage of macronutrients, namely $45 \%$ carbohydrates, $20 \%$ protein and $35 \%$ lipids, which provided 6276 kJ (1500 kcal) for women and $7531 \mathrm{~kJ}$ (1800 kcal) for men. The CG received also general written dietary guidelines for a healthy lifestyle at baseline, without any other intervention until the end of the 6month period

\begin{tabular}{ll} 
Outcomes & $\begin{array}{l}\text { Outcomes reported: fibrosis score } \\
\text { Follow-up (months): } 6\end{array}$ \\
\hline Notes & $\begin{array}{l}\text { Source of funding (quote): "This research received no specific grant from any funding agency, commer- } \\
\text { cial or not-for-profit sectors." } \\
\text { Trial name/trial registry number: NCT01894438 } \\
\text { We tried to contact the authors in December } 2020\end{array}$
\end{tabular}

\section{Risk of bias}

\begin{tabular}{|c|c|c|}
\hline Bias & Authors' judgement & Support for judgement \\
\hline $\begin{array}{l}\text { Random sequence genera- } \\
\text { tion (selection bias) }\end{array}$ & Low risk & Quote: "The randomisation was made using a random numbers system" \\
\hline $\begin{array}{l}\text { Allocation concealment } \\
\text { (selection bias) }\end{array}$ & Unclear risk & Comment: this information was not available \\
\hline $\begin{array}{l}\text { Blinding of participants } \\
\text { and personnel (perfor- } \\
\text { mance bias) } \\
\text { All outcomes }\end{array}$ & High risk & $\begin{array}{l}\text { Comment: because of the nature of the intervention, it was not possible to } \\
\text { blind the participants }\end{array}$ \\
\hline $\begin{array}{l}\text { Blinding of outcome as- } \\
\text { sessment (detection bias) } \\
\text { All outcomes }\end{array}$ & Unclear risk & Comment: this information was not available \\
\hline $\begin{array}{l}\text { Incomplete outcome data } \\
\text { (attrition bias) } \\
\text { All outcomes }\end{array}$ & Low risk & Comment: intention-to-treat analysis was performed \\
\hline $\begin{array}{l}\text { Selective reporting (re- } \\
\text { porting bias) }\end{array}$ & High risk & $\begin{array}{l}\text { Comment: a pre-published protocol was not available and neither mortality } \\
\text { nor resolution of fatty liver was reported }\end{array}$ \\
\hline Other bias & Low risk & Comment: no other bias noted \\
\hline
\end{tabular}

Misciagna 2017

\section{Study characteristics}

\begin{tabular}{ll}
\hline Methods & Randomised clinical trial \\
\hline Participants & Country: Italy \\
& Period of recruitment: not stated \\
& Number randomised: 98 \\
& Post-randomisation dropouts: $0(0.0 \%)$ \\
& Revised sample size: 98 \\
\hline
\end{tabular}


Misciagna 2017 (Continued)

Average age (years): not stated

Female: 26 (26.5\%)

NASH: not stated

Diabetes mellitus: $0(0.0 \%)$

Inclusion criteria: Moderate to severe NAFLD

Exclusion criteria: Overt cardiovascular disease and revascularisation procedures; stroke; peripheral artery disease; type 2 diabetes mellitus; alcohol intake (> $20 \mathrm{~g}$ daily); severe medical condition that may impair the person's ability to participate in a nutritional intervention study; following a special diet or involved in a programme for weight loss or recent weight loss; inability to follow a modified diet for religious or other reasons

$\begin{array}{ll}\text { Interventions } & \text { Group 1: Mediterranean diet }(n=50) \\ & \text { Further details: Foods in LGIMD all have all a low glycaemic Index }(G I) \text { and no more than } 10 \% \text { of total } \\ \text { daily calories coming from saturated fats. The LGIMD was high in MUFAs from olive oil and contained al- } \\ \text { so w3PUFAs, from both plant and marine sources } \\ \text { Group 2: No active intervention }(n=48) \\ \text { Further details: No active intervention }\end{array}$

Outcomes

Outcomes reported: mortality at maximum follow-up, serious adverse events (number of people), any adverse events (number of people), liver transplantation at maximum follow-up, decompensation (number of people), cirrhosis (number of people), resolution of fatty liver disease, hepatocellular carcinoma, liver-related mortality

Follow-up (months): 6

\begin{tabular}{ll}
\hline Notes & Source of funding (quote): "this study was funded by a research grant from the Italian Ministry of \\
& Health." \\
& Trial name/trial registry number: NCTO1798719 \\
& We tried to contact the authors in December 2020
\end{tabular}

\section{Risk of bias}

\begin{tabular}{|c|c|c|}
\hline Bias & Authors' judgement & Support for judgement \\
\hline $\begin{array}{l}\text { Random sequence genera- } \\
\text { tion (selection bias) }\end{array}$ & Low risk & Quote: "computerized random numbers sequence" \\
\hline $\begin{array}{l}\text { Allocation concealment } \\
\text { (selection bias) }\end{array}$ & Low risk & $\begin{array}{l}\text { Quote: "Before the recruitment by an operator who followed the allocation } \\
\text { list. Obviously the operator was not the physician or the dietitian who recruit- } \\
\text { ed that day (author replies)" }\end{array}$ \\
\hline $\begin{array}{l}\text { Blinding of participants } \\
\text { and personnel (perfor- } \\
\text { mance bias) } \\
\text { All outcomes }\end{array}$ & Low risk & $\begin{array}{l}\text { Quote: "Double blind...Blinding and equipoise were strictly maintained by em- } \\
\text { phasizing to the intervention staff and participants that each diet adhered to } \\
\text { healthy principles..With the exception of the dietitians, investigators and staff } \\
\text { were unaware of the subjects' diet assignment" }\end{array}$ \\
\hline $\begin{array}{l}\text { Blinding of outcome as- } \\
\text { sessment (detection bias) } \\
\text { All outcomes }\end{array}$ & Low risk & $\begin{array}{l}\text { Quote: "Staff members who obtained outcome measurements were not in- } \\
\text { formed about diet assignment" }\end{array}$ \\
\hline $\begin{array}{l}\text { Incomplete outcome data } \\
\text { (attrition bias) } \\
\text { All outcomes }\end{array}$ & Low risk & Comment: intention-to-treat analysis was performed \\
\hline $\begin{array}{l}\text { Selective reporting (re- } \\
\text { porting bias) }\end{array}$ & Low risk & $\begin{array}{l}\text { Comment: a pre-published protocol was not available, but the study authors } \\
\text { reported mortality, adverse events, and resolution of fatty liver }\end{array}$ \\
\hline Other bias & Low risk & Comment: no other bias noted \\
\hline
\end{tabular}


Monica Dinu 2017

\section{Study characteristics}

\begin{tabular}{|c|c|}
\hline Methods & Randomised clinical trial \\
\hline \multirow[t]{11}{*}{ Participants } & Country: Italy \\
\hline & Period of recruitment: not stated \\
\hline & Number randomised: 40 \\
\hline & Post-randomisation dropouts: $0(0.0 \%)$ \\
\hline & Revised sample size: 40 \\
\hline & Average age (years): 55 \\
\hline & Female: $28(70.0 \%)$ \\
\hline & NASH: not stated \\
\hline & Diabetes mellitus: not stated \\
\hline & $\begin{array}{l}\text { Inclusion criteria: presence of bright liver echotexture based on ultrasonography; at least } 18 \text { years of } \\
\text { age. }\end{array}$ \\
\hline & $\begin{array}{l}\text { Exclusion criteria: wheat allergies including celiac disease and gluten intolerance; excessive alcohol } \\
\text { consumption (> } 30 \text { g daily), T2DM, viral hepatitis, NASH, and other chronic liver diseases (including au- } \\
\text { toimmune hepatitis, primary biliary cirrhosis, primary sclerosing cholangitis, hereditary haemochro- } \\
\text { matosis, Wilson's disease, and alpha- } 1 \text { antitrypsin deficiency) }\end{array}$ \\
\hline
\end{tabular}

$\begin{array}{ll}\text { Interventions } & \text { Group 1: Organic semi-wholegrain wheat diet }(n=20) \\ & \text { Further details: organic semi-whole-grain wheat } \\ \text { Group 2: Khorasan wheat diet }(n=20) \\ \text { Further details: Khorasan wheat }(n=20) \text { or control }(n=20) \text { products in the place of habitually-con- } \\ \text { sumed bakery products }\end{array}$

\begin{tabular}{ll}
\hline Outcomes & Outcomes reported: mortality at maximum follow-up, serious adverse events (number of people), any \\
adverse events (number of people), liver transplantation at maximum follow-up, decompensation \\
(number of people), cirrhosis (number of people), resolution of fatty liver disease, hepatocellular carci- \\
noma, liver-related mortality \\
Follow-up (months): 3
\end{tabular}

Notes Source of funding (quote): "The study was sponsored in part by a grant from the Kamut Enterprise of Europe (KEE), Oudenaarde, Belgium"

Trial name/trial registry number: not stated

We tried to contact the authors in December 2020

\section{Risk of bias}

\begin{tabular}{|c|c|c|}
\hline Bias & Authors' judgement & Support for judgement \\
\hline $\begin{array}{l}\text { Random sequence genera- } \\
\text { tion (selection bias) }\end{array}$ & Low risk & $\begin{array}{l}\text { Quote: "Participants were randomized with a } 1: 1 \text { randomization to study arms } \\
\text { by a statistician, using a web-based online randomization procedure (author } \\
\text { replies)" } \\
\text { Comment: this information was not available }\end{array}$ \\
\hline $\begin{array}{l}\text { Allocation concealment } \\
\text { (selection bias) }\end{array}$ & Low risk & $\begin{array}{l}\text { Quote: "The allocation concealment was ensured using a centralized service, } \\
\text { and was not be possible for the investigators to know the allocation sequence } \\
\text { in advance (author replies)" }\end{array}$ \\
\hline $\begin{array}{l}\text { Blinding of participants } \\
\text { and personnel (perfor- } \\
\text { mance bias) } \\
\text { All outcomes }\end{array}$ & Low risk & $\begin{array}{l}\text { Quote: "double-blind parallel trial" } \\
\text { Comment: the bakery products were produced with a different form of wheat; } \\
\text { so blinding could be achieved }\end{array}$ \\
\hline $\begin{array}{l}\text { Blinding of outcome as- } \\
\text { sessment (detection bias) }\end{array}$ & Low risk & Quote: "double-blind parallel trial" \\
\hline
\end{tabular}

Lifestyle modifications for nonalcohol-related fatty liver disease: a network meta-analysis (Review) 
Monica Dinu 2017 (Continued)

All outcomes
Comment: the bakery products were produced with a different form of wheat; so blinding could be achieved

Incomplete outcome data Low risk Comment: there were no post-randomisation dropouts

(attrition bias)

All outcomes

\begin{tabular}{lll}
\hline $\begin{array}{l}\text { Selective reporting (re- } \\
\text { porting bias) }\end{array}$ & Low risk & $\begin{array}{l}\text { Comment: a pre-published protocol was not available, but the study authors } \\
\text { reported mortality, adverse events, and resolution of fatty liver }\end{array}$ \\
\hline Other bias & Low risk & Comment: no other bias noted \\
\hline
\end{tabular}

\section{Moradi 2020}

\section{Study characteristics}

\begin{tabular}{ll}
\hline Methods & Randomised clinical trial \\
\hline Participants & Country: Iran \\
Number randomised: 45 \\
Post-randomisation dropouts: $0(0 \%)$ \\
Revised sample size: 45 \\
Average age: 65 years \\
Female: $45(100 \%)$ \\
NASH: not stated \\
Diabetes mellitus: not stated \\
Inclusion criteria: being obese, elderly and female in addition to having fatty liver disease, which was \\
confirmed by ultrasonography \\
Exclusion criteria: addiction to smoking, alcohol abuse, doing regular physical exercises in the last 6 \\
months, having lung disease, kidney disease, cardiovascular disease, liver transplantation, oestrogen \\
intake, high blood pressure, chronic disorders, taking special medications such as statins, additive ef- \\
fects on insulin sensitivity, hepatotoxic medications intake, having a special dietary programme
\end{tabular}

Interventions Participants were randomly assigned to 2 groups

Group 1: Resistance exercise $(n=23)$

Further details: Each session took about 60 - 70 mins for main training (plus about 20 mins for warm-up and cool-down), 3 days a week (nonconsecutive) which lasted 12 weeks

Group 2: No active intervention $(n=22)$

Both groups took curcumin or placebo supplementation which was decided at random

\begin{tabular}{|c|c|c|}
\hline Outcomes & \multicolumn{2}{|c|}{$\begin{array}{l}\text { Outcomes reported: mortality } \\
\text { Follow-up (months): } 2.76\end{array}$} \\
\hline Notes & \multicolumn{2}{|c|}{$\begin{array}{l}\text { Source of funding (quote): "Funding: none" } \\
\text { Trial name/trial registry number: IRCT20190103042219N1 } \\
\text { We tried to contact the authors in March } 2021\end{array}$} \\
\hline \multicolumn{3}{|l|}{ Risk of bias } \\
\hline Bias & Authors' judgement & Support for judgement \\
\hline $\begin{array}{l}\text { Random sequence genera- } \\
\text { tion (selection bias) }\end{array}$ & Unclear risk & $\begin{array}{l}\text { Quote: "A third party was asked to classify the participants randomly, using } \\
\text { the (labelled) codes. Study groups had codes instead of names. The laboratory } \\
\text { was uninformed from name of groups and only used the codes. Groups codes } \\
\text { were used for statistical analysis" } \\
\text { Comment: further details of random sequence generation were not available }\end{array}$ \\
\hline
\end{tabular}


Moradi 2020 (Continued)

Allocation concealment (selection bias)
Low risk

Quote: "A third party was asked to classify the participants randomly, using the (labelled) codes. Study groups had codes instead of names. The laboratory was uninformed from name of groups and only used the codes. Groups codes were used for statistical analysis"

\begin{tabular}{|c|c|c|}
\hline $\begin{array}{l}\text { Blinding of participants } \\
\text { and personnel (perfor- }\end{array}$ & High risk & $\begin{array}{l}\text { Comment: because of the nature of the intervention, it was not possible to } \\
\text { blind the participants }\end{array}$ \\
\hline
\end{tabular}

mance bias)

All outcomes

\begin{tabular}{|c|c|c|}
\hline $\begin{array}{l}\text { Blinding of outcome as- } \\
\text { sessment (detection bias) }\end{array}$ & Unclear risk & $\begin{array}{l}\text { Quote: "The laboratory was uninformed from name of groups and only used } \\
\text { the codes". }\end{array}$ \\
\hline All outcomes & & $\begin{array}{l}\text { Comment: it was not clear whether the outcomes assessors of clinical out- } \\
\text { comes were blinded to the groups }\end{array}$ \\
\hline
\end{tabular}

Incomplete outcome data Low risk Comment: there were no post-randomisation dropouts
(attrition bias)

All outcomes

\begin{tabular}{|c|c|c|}
\hline $\begin{array}{l}\text { Selective reporting (re- } \\
\text { porting bias) }\end{array}$ & High risk & $\begin{array}{l}\text { Comment: a pre-published protocol was not available and adverse events } \\
\text { were not reported }\end{array}$ \\
\hline
\end{tabular}

\begin{tabular}{ll}
\hline Other bias $\quad$ Low risk Comment: no other bias noted \\
\hline
\end{tabular}

NCT01327443

\section{Study characteristics}

\begin{tabular}{ll}
\hline Methods & Randomised clinical trial \\
\hline Participants & Country: USA \\
Period of recruitment: not stated & Number randomised: 17 \\
& Post-randomisation dropouts: not stated \\
& Revised sample size: 17 \\
& Average age (years): not stated \\
& Female: not stated \\
& NASH: 17 (100.0\%) \\
& Diabetes mellitus: not stated \\
& Inclusion criteria: sedentary, adults 18 - 60 , elevated Liver Function Tests with fatty liver on ultrasound \\
and biopsy-proven NASH & Exclusion criteria: significant history of alcohol consumption $>20$ gm/day $(>2$ drinks $/$ day), evidence of \\
other causes of hepatitis including positive screening B \& , autoimmune hepatitis, haemochromato- \\
sis, coeliac disease, Wilson's disease, alpha 1 antitrypsin deficiency or medication-induced hepatitis, \\
Patients with planned exercise $>30$ - 60 minutes a week, BMI $<25$ or $>44$ kg/m 2 , clinical or biochemical \\
evidence of decompensated liver disease, advanced cardiac or renal disease, changes in last 3 months \\
to the dose of oral hypoglycaemic medication and statin, positive stress test, pregnant women, de- \\
mented individuals who cannot give consent
\end{tabular}

Interventions

Group 1: Supervised aerobic exercise ( $\mathrm{n}=$ not stated)

Further details: 24 weeks of directly supervised aerobic exercise

Group 2: Dietary advice ( $\mathrm{n}=$ not stated)

Further details: $10 \%$ weight loss in 24 weeks time period through nutritional counselling

Group 3: no active intervention ( $\mathrm{n}=$ not stated)

Further details: No change in usual exercise or food intake 
NCT01327443 (Continued)

Outcomes None of the outcomes of interest were reported

\begin{tabular}{ll}
\hline Notes & Source of funding: not stated \\
& Trial name/trial registry number: NCT01327443 \\
& We tried to contact the authors in December 2020
\end{tabular}

\section{Risk of bias}

\begin{tabular}{|c|c|c|}
\hline Bias & Authors' judgement & Support for judgement \\
\hline $\begin{array}{l}\text { Random sequence genera- } \\
\text { tion (selection bias) }\end{array}$ & Unclear risk & Comment: this information was not available \\
\hline $\begin{array}{l}\text { Allocation concealment } \\
\text { (selection bias) }\end{array}$ & Unclear risk & Comment: this information was not available \\
\hline $\begin{array}{l}\text { Blinding of participants } \\
\text { and personnel (perfor- } \\
\text { mance bias) } \\
\text { All outcomes }\end{array}$ & High risk & Quote: "Open label" \\
\hline $\begin{array}{l}\text { Blinding of outcome as- } \\
\text { sessment (detection bias) } \\
\text { All outcomes }\end{array}$ & High risk & Quote: "Open label" \\
\hline $\begin{array}{l}\text { Incomplete outcome data } \\
\text { (attrition bias) } \\
\text { All outcomes }\end{array}$ & Unclear risk & Comment: this information was not available \\
\hline $\begin{array}{l}\text { Selective reporting (re- } \\
\text { porting bias) }\end{array}$ & High risk & $\begin{array}{l}\text { Comment: a pre-published protocol was not available and neither mortality } \\
\text { nor resolution of fatty liver was reported }\end{array}$ \\
\hline Other bias & Low risk & Comment: no other bias noted \\
\hline
\end{tabular}

\section{NCT02679417}

\section{Study characteristics}

\begin{tabular}{ll}
\hline Methods & Randomised clinical trial \\
\hline Participants & Country: Italy \\
Period of recruitment: not stated & Number randomised: not stated \\
& Post-randomisation drop-outs: not stated \\
& Revised sample size: 0 \\
& Average age (years): not stated \\
& Female: not stated \\
& NASH: not stated \\
& Diabetes mellitus: not stated \\
Inclusion criteria: moderate or severe NAFLD enrolled in nutriep trial (list of patients from primary care & in southern Italy)
\end{tabular}

Interventions

Group 1: Aerobic exercise plus resistance exercise ( $\mathrm{n}=$ not stated)

Further details: Participants have followed a programme combining endurance activity (EA) and resistance training (RT) consisting in a 60-minute work session, 3 times/week consisting of: walk (30 minutes): exercise intensity started from the $60 \%$ of the maximum heart rate and raised up to the $75 \%$. 
NCT02679417 (Continued)

Musculation (30 minutes): training of the bigger muscle groups (chest, shoulders, arms, abdomen, back, glutei and legs). Exercise intensity started from $65 \%$ of the maximum rated load and raised up to $75 \%$

Group 2: Aerobic exercise ( $\mathrm{n}=$ not stated)

Further details: Participants have followed a programme of endurance activity consisting of a 30minute walk, 5 times/week. Exercise intensity started from $60 \%$ of the maximum heart rate and raised up to $75 \%$

\begin{tabular}{ll}
\hline Outcomes & None of the outcomes of interest were reported \\
\hline Notes & Source of funding: not stated \\
& Trial name/trial registry number: NCT02367742 \\
& We tried to contact the authors in December 2020
\end{tabular}

\section{Risk of bias}

\begin{tabular}{|c|c|c|}
\hline Bias & Authors' judgement & Support for judgement \\
\hline $\begin{array}{l}\text { Random sequence genera- } \\
\text { tion (selection bias) }\end{array}$ & Unclear risk & Comment: this information was not available \\
\hline $\begin{array}{l}\text { Allocation concealment } \\
\text { (selection bias) }\end{array}$ & Unclear risk & Comment: this information was not available \\
\hline $\begin{array}{l}\text { Blinding of participants } \\
\text { and personnel (perfor- } \\
\text { mance bias) } \\
\text { All outcomes }\end{array}$ & High risk & Quote: "Single blinded (outcome assessors)" \\
\hline $\begin{array}{l}\text { Blinding of outcome as- } \\
\text { sessment (detection bias) } \\
\text { All outcomes }\end{array}$ & Low risk & Quote: "Single blinded (outcome assessors)" \\
\hline $\begin{array}{l}\text { Incomplete outcome data } \\
\text { (attrition bias) } \\
\text { All outcomes }\end{array}$ & Unclear risk & Comment: this information was not available \\
\hline $\begin{array}{l}\text { Selective reporting (re- } \\
\text { porting bias) }\end{array}$ & High risk & $\begin{array}{l}\text { Comment: a pre-published protocol was not available and neither mortality } \\
\text { nor resolution of fatty liver was reported }\end{array}$ \\
\hline Other bias & Low risk & Comment: no other bias noted \\
\hline
\end{tabular}

NCT03183193

\section{Study characteristics}

\begin{tabular}{ll}
\hline Methods & Randomised clinical trial \\
\hline Participants & Country: Spain \\
& Period of recruitment: not stated \\
& Number randomised: not stated \\
& Post-randomisation dropouts: not stated \\
& Revised sample size: 0 \\
& Average age (years): not stated \\
& Female: not stated \\
& NASH: not stated \\
Diabetes mellitus: not stated
\end{tabular}


NCT03183193 (Continued)

Inclusion criteria: Overweight or obese, diagnosis of NAFLD; age: 30 - 80 years

Exclusion criteria: Known liver disease (other than NAFLD); abuse of alcohol ( $>21$ and $>14$ units of alcohol a week for men and women, respectively, e.g. 1 unit = $125 \mathrm{~mL}$ of wine); drug treatments: immunosuppressants, cytotoxic agents, systemic corticosteroids, agents potentially causing fatty liver disease or abnormal liver tests or weight modifiers, Active cancer or a history of malignancy in the last 5 years, Problems of massive oedemas; obesity known endocrine origin (except treated hypothyroidism); surgical procedure for weight loss, $\geq 3 \mathrm{~kg}$ weight loss in the last 3 months; severe psychiatric disorders; lack of autonomy or inability to follow the diet (including food allergies or intolerances) or/and lifestyle recommendations as well as to follow scheduled visits; consumption of any type of food supplements (antioxidants, prebiotics, probiotics, etc.)

Group 1: Mediterranean diet $(\mathrm{n}=$ not stated)

Further details: The participants follow a strategy based on a distribution of macronutrients $30-35 \%$ lipid (extra virgin olive oil and fatty acids $\Omega 3$ in detriment of saturated, trans and cholesterol)/ protein $25 \%$ (vegetable against animal)/carbohydrates 40 - 45\% (low glycaemic index, fibre 30 - $35 \mathrm{~g} /$ day); high adherence to the Mediterranean diet and natural antioxidants; meal frequency of 7 meals/day; size/ composition of the ration suitable for each moment; including traditional foods with no additional economic cost that will allow diet adherence without abandonment; avoid inappropriate mealtimes and the eating manners as the eating rate. The participants are instructed to follow this strategy within a personalised energy-restricted diet (-30\%) and under healthy lifestyle advice to achieve AASLD objectives

Group 2: No active intervention $(\mathrm{n}=$ not stated)

Further details: The participants follow a conventional and balanced distribution of macronutrients ( $30 \%$ fat, $15 \%$ protein, $55 \%$ carbohydrates), adequate fibre (25 - $30 \mathrm{~g} /$ day) and dietary cholesterol (< $250 \mathrm{mg} /$ day) intake according to AHA guidelines. This strategy was included within a personalised energy-restricted diet (- $30 \%$ individual needs) under healthy lifestyle advice in order to achieve the objectives of AASLD (loss of at least 3 - 5\% of the initial body weight and up to $10 \%$ needed to improve necroinflammation)

\begin{tabular}{|c|c|}
\hline Outcomes & None of the outcomes of interest were reported \\
\hline Notes & $\begin{array}{l}\text { Source of funding (quote): "Clinica Universidad de Navarra, Universidad de Navarra Complejo Hospita- } \\
\text { lario de Navarra" } \\
\text { Trial name/trial registry number: NCT03183193 } \\
\text { We tried to contact the authors in December } 2020\end{array}$ \\
\hline
\end{tabular}

\section{Risk of bias}

\begin{tabular}{lll}
\hline Bias & Authors' judgement & Support for judgement \\
\hline $\begin{array}{l}\text { Random sequence genera- } \\
\text { tion (selection bias) }\end{array}$ & Unclear risk & Comment: this information was not available \\
\hline $\begin{array}{l}\text { Allocation concealment } \\
\text { (selection bias) }\end{array}$ & Unclear risk & Comment: this information was not available \\
\hline $\begin{array}{l}\text { Blinding of participants } \\
\text { and personnel (perfor- } \\
\text { mance bias) }\end{array}$ & High risk & Quote: "Single (participant)" \\
All outcomes & \\
\hline $\begin{array}{l}\text { Blinding of outcome as- } \\
\text { sessment (detection bias) } \\
\text { All outcomes }\end{array}$ & High risk & Quote: "Single (participant)" \\
\hline $\begin{array}{l}\text { Incomplete outcome data } \\
\text { (attrition bias) } \\
\text { All outcomes }\end{array}$ & Unclear risk & Comment: this information was not available \\
\hline
\end{tabular}


NCT03183193 (Continued)

Selective reporting (re- High risk Comment: a pre-published protocol was not available and neither mortality porting bias)

Other bias Low risk Comment: no other bias noted

NCT03461562

\section{Study characteristics}

\begin{tabular}{|c|c|}
\hline Methods & Randomised clinical trial \\
\hline Participants & $\begin{array}{l}\text { Country: Turkey } \\
\text { Period of recruitment: not stated } \\
\text { Number randomised: } 31 \\
\text { Post-randomisation dropouts: not stated } \\
\text { Revised sample size: } 31 \\
\text { Average age (years): not stated } \\
\text { Female: not stated } \\
\text { NASH: not stated } \\
\text { Diabetes mellitus: not stated } \\
\text { Inclusion criteria: Clinical diagnosis of NAFLD, Age } 8 \text { - } 65 \text { years, not in an active exercise programme, not } \\
\text { on an active diet programme } \\
\text { Exclusion criteria: Pregnancy; chronic inflammatory process; rheumatic disease; cognitive disorders; } \\
\text { obstacles to achieve physical performance tests; presence of other conditions that may cause liver } \\
\text { steatosis; Inability to do WBVT or aerobic exercises }\end{array}$ \\
\hline Interventions & $\begin{array}{l}\text { Group 1: Aerobic exercise ( } \mathrm{n}=\text { not stated) } \\
\text { Further details: Aerobic exercise will be held for } 40 \text { minutes. Dynamic exercises will be accompanied by } \\
\text { physiotherapist on the vibration platform for } 15 \text { minutes } \\
\text { Group 2: No active intervention ( } \mathrm{n}=\text { not stated) } \\
\text { Further details: Same exercises will be held on a stable platform (with the devices turned off) by control } \\
\text { group for } 15 \text { minutes }\end{array}$ \\
\hline Outcomes & None of the outcomes of interest were reported \\
\hline Notes & $\begin{array}{l}\text { Source of funding: not stated } \\
\text { Trial name/trial registry number: NCT03461562 } \\
\text { We tried to contact the authors in December } 2020\end{array}$ \\
\hline
\end{tabular}

\section{Risk of bias}

\begin{tabular}{|c|c|c|}
\hline Bias & Authors' judgement & Support for judgement \\
\hline $\begin{array}{l}\text { Random sequence genera- } \\
\text { tion (selection bias) }\end{array}$ & Unclear risk & Comment: this information was not available \\
\hline $\begin{array}{l}\text { Allocation concealment } \\
\text { (selection bias) }\end{array}$ & Unclear risk & Comment: this information was not available \\
\hline $\begin{array}{l}\text { Blinding of participants } \\
\text { and personnel (perfor- } \\
\text { mance bias) } \\
\text { All outcomes }\end{array}$ & Unclear risk & $\begin{array}{l}\text { Quote: "Masking: Double (Participant, Outcomes Assessor)" } \\
\text { Comment: not clear how it is possible to blind the participants to the exercise } \\
\text { they performed }\end{array}$ \\
\hline $\begin{array}{l}\text { Blinding of outcome as- } \\
\text { sessment (detection bias) }\end{array}$ & Low risk & Quote: "Masking: Double (Participant, Outcomes Assessor)" \\
\hline
\end{tabular}


NCT03461562 (Continued)

All outcomes

Incomplete outcome data Unclear risk Comment: this information was not available
(attrition bias)

(attrition bias)

All outcomes

\begin{tabular}{|c|c|c|}
\hline $\begin{array}{l}\text { Selective reporting (re- } \\
\text { porting bias) }\end{array}$ & High risk & $\begin{array}{l}\text { Comment: a pre-published protocol was not available and neither mortality } \\
\text { nor resolution of fatty liver was reported }\end{array}$ \\
\hline
\end{tabular}

porting bias) nor resolution of fatty liver was reported

Other bias Low risk Comment: no other bias noted

Nikroo 2017

\section{Study characteristics}

\begin{tabular}{ll}
\hline Methods & Randomised clinical trial \\
\hline Participants & Country: Iran \\
Period of recruitment: $2010-2011$ \\
Number randomised: 25 \\
Post-randomisation dropouts: 2 (8.0\%) \\
Revised sample size: 23 \\
Reasons for post-randomisation dropouts: Not stated \\
Average age (years): 37 \\
Female: 0 (0.0\%) \\
NASH: 23 (100.0\%) \\
Diabetes mellitus: not stated \\
Inclusion criteria: age 18 - 55. ALT > 1.5 times upper limit of normal, for a minimum period of 3 months, \\
and evidence of fatty liver on liver ultrasonography \\
Exclusion criteria: history of significant alcohol consumption (> 20 gr/day for women, > 30 gr/day for \\
men), and other liver diseases (viral hepatitis B and C, autoimmune hepatitis, coeliac disease, Wilson's \\
Disease, a1-antitrypsin deficiency and haemochromatosis); medical problems such as hypothyroidism, \\
ischaemic heart disease, renal failure and use of hepatotoxic drugs
\end{tabular}

Interventions

Group 1: Supervised aerobic exercise $(n=12)$

Further details: The aerobic training programme designed according to guideline of American College of Sports Medicine (ACSM) and performed by professionally-qualified instructors. Exercises programmes were individualised, under the supervision of experienced exercise physiologists, which allowed participants to achieve their target heart rate reserve (HRR). It consisted of walking, jogging or running, for a period of 8 weeks 3 days a week. The time of exercises were 35 to 50 minutes ( 15 minutes of warm-up, 10 to 25 minutes of aerobic exercise and 10 minutes of cool-down), with $55 \%-60 \%$ of HRR during each training session. The first session of aerobic exercise lasted for 10 minutes and the next sessions, 1 minute added to every aerobic exercise, so by the end of sixth, seventh and eighth weeks duration of aerobic exercises was maintained in 25 minutes

Group 2: Dietary advice $(n=11)$

Further details: diet was individualised after the measurement of body composition and calculation of daily energy requirements of participants. The participants were controlled and managed by a nutritionist. Calorie-restricted diet in both groups included 500 kilocalories (kcal) of energy less than the estimated daily energy requirement. The percentage distribution of macronutrients consisted of $60 \%$ carbohydrate, $25 \%$ fat and $15 \%$ protein with emphasis on selecting a variety of all food groups and reducing saturated fat intake and simple sugar consumption

Outcomes

Outcomes reported: quality of life (maximum follow-up)

Follow-up (months): 1.84

Notes

Source of funding (quote): "This study was funded by the research ethics committee of Mashhad University that project code number was $89878 . "$ 
Nikroo 2017 (Continued)

Trial name/trial registry number: IRCT201104286319N1

We tried to contact the authors in December 2020

\section{Risk of bias}

\begin{tabular}{|c|c|c|}
\hline Bias & Authors' judgement & Support for judgement \\
\hline $\begin{array}{l}\text { Random sequence genera- } \\
\text { tion (selection bias) }\end{array}$ & Unclear risk & Comment: this information was not available \\
\hline $\begin{array}{l}\text { Allocation concealment } \\
\text { (selection bias) }\end{array}$ & Unclear risk & Comment: this information was not available \\
\hline $\begin{array}{l}\text { Blinding of participants } \\
\text { and personnel (perfor- } \\
\text { mance bias) } \\
\text { All outcomes }\end{array}$ & High risk & Quote: "Open label" \\
\hline $\begin{array}{l}\text { Blinding of outcome as- } \\
\text { sessment (detection bias) } \\
\text { All outcomes }\end{array}$ & High risk & Quote: "Open label" \\
\hline $\begin{array}{l}\text { Incomplete outcome data } \\
\text { (attrition bias) } \\
\text { All outcomes }\end{array}$ & Unclear risk & $\begin{array}{l}\text { Comment: there were post-randomisation dropouts, but clear whether these } \\
\text { were related to the intervention or outcomes }\end{array}$ \\
\hline $\begin{array}{l}\text { Selective reporting (re- } \\
\text { porting bias) }\end{array}$ & High risk & $\begin{array}{l}\text { Comment: a pre-published protocol was not available and neither mortality } \\
\text { nor resolution of fatty liver was reported }\end{array}$ \\
\hline Other bias & Low risk & Comment: no other bias noted \\
\hline
\end{tabular}

Nishimori 2018

\section{Study characteristics}

\begin{tabular}{|c|c|}
\hline Methods & Randomised clinical trial \\
\hline Participants & $\begin{array}{l}\text { Country: Japan } \\
\text { Period of recruitment: not stated } \\
\text { Number randomised: } 28 \\
\text { Post-randomisation dropouts: not stated } \\
\text { Revised sample size: } 28 \\
\text { Average age (years): } 50 \\
\text { Female: not stated } \\
\text { NASH: not stated } \\
\text { Diabetes mellitus: } 28 \text { (100.0\%) } \\
\text { Inclusion criteria: NAFLD; type } 2 \text { diabetes mellitus }\end{array}$ \\
\hline Interventions & $\begin{array}{l}\text { Group 1: Carbohydrate-restricted diet }(\mathrm{n}=14) \\
\text { Further details: LCD }(70-130 \mathrm{~g} / \mathrm{day} \text { of carbohydrate) } \\
\text { Group 2: Calorie-restricted diet }(\mathrm{n}=14) \\
\text { Further details: CRD (calories of } 25 \mathrm{kcal} / \mathrm{kg} \text { of ideal body weight per day) }\end{array}$ \\
\hline Outcomes & None of the outcomes of interest were reported \\
\hline Notes & Source of funding: not stated \\
\hline
\end{tabular}


Nishimori 2018 (Continued)

Trial name/trial registry number: not stated

We tried to contact the authors in December 2020.

\section{Risk of bias}

\begin{tabular}{|c|c|c|}
\hline Bias & Authors' judgement & Support for judgement \\
\hline $\begin{array}{l}\text { Random sequence genera- } \\
\text { tion (selection bias) }\end{array}$ & Unclear risk & Comment: this information was not available \\
\hline $\begin{array}{l}\text { Allocation concealment } \\
\text { (selection bias) }\end{array}$ & Unclear risk & Comment: this information was not available \\
\hline $\begin{array}{l}\text { Blinding of participants } \\
\text { and personnel (perfor- } \\
\text { mance bias) } \\
\text { All outcomes }\end{array}$ & High risk & $\begin{array}{l}\text { Comment: because of the nature of the intervention, it was not possible to } \\
\text { blind the participants }\end{array}$ \\
\hline $\begin{array}{l}\text { Blinding of outcome as- } \\
\text { sessment (detection bias) } \\
\text { All outcomes }\end{array}$ & Unclear risk & Comment: this information was not available \\
\hline $\begin{array}{l}\text { Incomplete outcome data } \\
\text { (attrition bias) } \\
\text { All outcomes }\end{array}$ & Unclear risk & Comment: this information was not available \\
\hline $\begin{array}{l}\text { Selective reporting (re- } \\
\text { porting bias) }\end{array}$ & High risk & $\begin{array}{l}\text { Comment: a pre-published protocol was not available and neither mortality } \\
\text { nor resolution of fatty liver was reported }\end{array}$ \\
\hline Other bias & Low risk & Comment: no other bias noted \\
\hline
\end{tabular}

Nourian 2020

\section{Study characteristics}

\begin{tabular}{|c|c|}
\hline Methods & Randomised clinical trial \\
\hline Participants & $\begin{array}{l}\text { Country: Iran } \\
\text { Number randomised: } 82 \\
\text { Post-randomisation dropouts: } 13(15.9 \%) \\
\text { Revised sample size: } 69 \\
\text { Reasons for post-randomisation dropouts: lost to follow-up } \\
\text { Average age: } 49 \text { years } \\
\text { Female: } 47 \text { ( } 68.1 \%) \\
\text { NASH: not stated } \\
\text { Diabetes mellitus: } 4 \text { (5.8\%) } \\
\text { Inclusion criteria: diagnosis of NAFLD by an expert physician (NAFLD was confirmed by sonography, } \\
\text { and was associated with higher levels of both ALT and AST more than } 31 \text { in men and women), aged } 20 \text { - } \\
50 \text { years old; being overweight or obese (BMI } \geq 25) \text {; absence of drinking alcohol; and willingness to par- } \\
\text { ticipate in the study } \\
\text { Exclusion criteria: missing more than } 2 \text { education sessions; weight loss during last } 6 \text { months; } \\
\text { menopause, pregnancy or breastfeeding; any medical condition such as renal disorders, malignancies, } \\
\text { thyroid disorders, psychosis and autoimmune diseases and consumption of some medications such as } \\
\text { anti-oxidant or weight loss supplements }\end{array}$ \\
\hline Interventions & $\begin{array}{l}\text { Participants were randomly assigned to } 2 \text { groups } \\
\text { Group 1: Dietary advice }(n=36)\end{array}$ \\
\hline
\end{tabular}


Nourian 2020 (Continued)

Further details: Participants were encouraged to increase their intake of fruits, vegetables, complex carbohydrate, low dairy fat, healthy fat, white meat and fish and also avoid the intake of unhealthy fats and refined carbohydrate

Group 2: No active intervention $(n=33)$

\begin{tabular}{ll}
\hline Outcomes & $\begin{array}{l}\text { Outcomes reported: resolution of fatty liver disease } \\
\text { Follow-up (months): } 2\end{array}$ \\
\hline Notes & $\begin{array}{l}\text { Source of funding (quote): "This study was supported by the Isfahan University of Medical Sciences, Is- } \\
\text { fahan, Iran" } \\
\text { Trial name/trial registry number: IRCT2014101811763N17 } \\
\text { We tried to contact the authors in March 2021 }\end{array}$
\end{tabular}

\section{Risk of bias}

\begin{tabular}{|c|c|c|}
\hline Bias & Authors' judgement & Support for judgement \\
\hline $\begin{array}{l}\text { Random sequence genera- } \\
\text { tion (selection bias) }\end{array}$ & Low risk & $\begin{array}{l}\text { Quote: "Randomization was done using computer-generated random num- } \\
\text { bers and by a trained personnel who was blinded to participant's characteris- } \\
\text { tics" }\end{array}$ \\
\hline $\begin{array}{l}\text { Allocation concealment } \\
\text { (selection bias) }\end{array}$ & Low risk & $\begin{array}{l}\text { Quote: "Randomization was done using computer-generated random num- } \\
\text { bers and by a trained personnel who was blinded to participant's characteris- } \\
\text { tics" }\end{array}$ \\
\hline $\begin{array}{l}\text { Blinding of participants } \\
\text { and personnel (perfor- } \\
\text { mance bias) } \\
\text { All outcomes }\end{array}$ & High risk & $\begin{array}{l}\text { Comment: because of the nature of the intervention, it was not possible to } \\
\text { blind the participants }\end{array}$ \\
\hline $\begin{array}{l}\text { Blinding of outcome as- } \\
\text { sessment (detection bias) } \\
\text { All outcomes }\end{array}$ & Unclear risk & Comment: this information was not available \\
\hline $\begin{array}{l}\text { Incomplete outcome data } \\
\text { (attrition bias) } \\
\text { All outcomes }\end{array}$ & Unclear risk & $\begin{array}{l}\text { Comment: many participants were excluded, with the reason for exclusion loss } \\
\text { to follow-up. It is not clear whether this may be related to the intervention and } \\
\text { outcomes }\end{array}$ \\
\hline $\begin{array}{l}\text { Selective reporting (re- } \\
\text { porting bias) }\end{array}$ & High risk & $\begin{array}{l}\text { Comment: a pre-published protocol was not available and adverse events } \\
\text { were not reported }\end{array}$ \\
\hline Other bias & Low risk & Comment: no other bias noted \\
\hline
\end{tabular}

Oh 2017

\section{Study characteristics}

\begin{tabular}{ll}
\hline Methods & Randomised clinical trial \\
\hline Participants & Country: Japan \\
& Period of recruitment: not stated \\
& Number randomised: 61 \\
& Post-randomisation dropouts: 9 (14.8\%) \\
& Revised sample size: 52 \\
& Reasons for post-randomisation dropouts: Group 1: 1 lost to follow-up; Group 2: 5 lost to follow-up; 1 \\
& abandoned the study, 2 discontinued intervention \\
& Average age (years): 49 \\
\hline
\end{tabular}


Oh 2017 (Continued)

Female: $0(0.0 \%)$

NASH: not stated

Diabetes mellitus: not stated

Inclusion criteria: NAFLD; sedentary ( $\leq 1$ exercise session per week and $\leq 30$ minutes per session); obese

Exclusion criteria: Adverse medical problems; declined to participate

Interventions

Group 1: Resistance exercise $(n=19)$

Further details: The RT program referred to the ACSM 2009 position paper on "Progression Models in

Resistance Training for Healthy Adults". The programme consisted of 1) sit-ups, 2) leg presses, 3) leg extensions, 4) leg curls, 5) chest presses, 6) seated rows, and 7) pull-downs (Selection MED, Technogym,

Cesena, Italy). The amount of load lifted was updated according to the results of the monthly direct 1-

RM strength test. The total energy expenditure for the RT programme was estimated to be about 180

$\mathrm{kcal}$ in our preliminary experiment. These values are similar to HIAT

Group 2: Aerobic exercise $(n=33)$

Further details: the HIAT consisted of 3 sets of 3-min cycling sessions at $80 \sim 85 \%$ VO2Max with a 2-min active rest at $50 \%$ VO2Max between sets ( $13 \mathrm{mins}, 180 \mathrm{kcal}$ ), the MICT consisted of 40 mins of cycling at $60 \sim 65 \%$ VO2Max (40 min, $360 \mathrm{kcal})$

\begin{tabular}{ll}
\hline Outcomes & Outcomes reported: fibrosis score \\
& Follow-up (months): 3
\end{tabular}

Notes

Source of funding (quote): "This work was supported in part by Grants-in-Aid for Scientific Research from the Ministry of Education, Culture, Sports, Science and Technology, Japan (No. 2604307, No. 15K15037, No. 14F04009, and No. 16H03255)."

Trial name/trial registry number: UMIN000022901

We tried to contact the authors in December 2020

\begin{tabular}{|c|c|c|}
\hline \multicolumn{3}{|l|}{ Risk of bias } \\
\hline Bias & Authors' judgement & Support for judgement \\
\hline $\begin{array}{l}\text { Random sequence genera- } \\
\text { tion (selection bias) }\end{array}$ & Low risk & $\begin{array}{l}\text { Quote: "subjects were assigned in a 1:1:1 ratio to one of the three intervention } \\
\text { groups by a computerized method (EXCEL 2010; Microsoft Corp, Redmond, } \\
\text { USA)" }\end{array}$ \\
\hline $\begin{array}{l}\text { Allocation concealment } \\
\text { (selection bias) }\end{array}$ & Low risk & $\begin{array}{l}\text { Quote: "A research assistant who had no interaction with the subjects generat- } \\
\text { ed the random allocation sequence and enrolled the subjects" }\end{array}$ \\
\hline $\begin{array}{l}\text { Blinding of participants } \\
\text { and personnel (perfor- } \\
\text { mance bias) } \\
\text { All outcomes }\end{array}$ & High risk & $\begin{array}{l}\text { Comment: because of the nature of the intervention, it was not possible to } \\
\text { blind the participants }\end{array}$ \\
\hline $\begin{array}{l}\text { Blinding of outcome as- } \\
\text { sessment (detection bias) } \\
\text { All outcomes }\end{array}$ & Unclear risk & Comment: this information was not available \\
\hline $\begin{array}{l}\text { Incomplete outcome data } \\
\text { (attrition bias) } \\
\text { All outcomes }\end{array}$ & High risk & $\begin{array}{l}\text { Comment: there were post-randomisation dropouts; some were related to the } \\
\text { intervention and outcomes }\end{array}$ \\
\hline $\begin{array}{l}\text { Selective reporting (re- } \\
\text { porting bias) }\end{array}$ & High risk & $\begin{array}{l}\text { Comment: a pre-published protocol was not available and neither mortality } \\
\text { nor resolution of fatty liver was reported }\end{array}$ \\
\hline Other bias & Low risk & Comment: no other bias noted \\
\hline
\end{tabular}


Panganiban 2020

\section{Study characteristics}

\begin{tabular}{|c|c|}
\hline Methods & Randomised clinical trial \\
\hline Participants & $\begin{array}{l}\text { Country: USA } \\
\text { Number randomised: } 42 \\
\text { Post-randomisation dropouts: } 3(7.1 \%) \\
\text { Revised sample size: } 39 \\
\text { Reasons for post-randomisation dropouts: lack of adherence, MRI bore size was exceeded } \\
\text { Average age: not stated } \\
\text { Female: not stated } \\
\text { NASH: not stated } \\
\text { Diabetes mellitus: not stated } \\
\text { Inclusion criteria: Obese children and adolescents with biopsy-proven NAFLD and metabolic syndrome }\end{array}$ \\
\hline Interventions & $\begin{array}{l}\text { Participants were randomly assigned to } 2 \text { groups } \\
\text { Group 1: Carbohydrate-restricted diet ( } n=19 \text { ) } \\
\text { Further details: } 20 \% \text { CHO: } 35 \% \text { protein: } 45 \% \text { fat for } 6 \text { months } \\
\text { Group 2: Calorie-restricted diet ( } n=20 \text { ) } \\
\text { Further details: } 50 \% \text { CHO: } 20 \% \text { protein: } 30 \% \text { fat for } 6 \text { months } \\
\text { Both groups received dietary and behavioural advice }\end{array}$ \\
\hline Outcomes & None of the outcomes of interest were reported \\
\hline Notes & $\begin{array}{l}\text { Source of funding: not stated } \\
\text { Trial name/trial registry number: not stated } \\
\text { We tried to contact the authors in March } 2021\end{array}$ \\
\hline
\end{tabular}

\section{Risk of bias}

\begin{tabular}{|c|c|c|}
\hline Bias & Authors' judgement & Support for judgement \\
\hline $\begin{array}{l}\text { Random sequence genera- } \\
\text { tion (selection bias) }\end{array}$ & Unclear risk & Comment: this information was not available \\
\hline $\begin{array}{l}\text { Allocation concealment } \\
\text { (selection bias) }\end{array}$ & Unclear risk & Comment: this information was not available \\
\hline $\begin{array}{l}\text { Blinding of participants } \\
\text { and personnel (perfor- } \\
\text { mance bias) } \\
\text { All outcomes }\end{array}$ & Unclear risk & Comment: this information was not available \\
\hline $\begin{array}{l}\text { Blinding of outcome as- } \\
\text { sessment (detection bias) } \\
\text { All outcomes }\end{array}$ & Unclear risk & Comment: this information was not available \\
\hline $\begin{array}{l}\text { Incomplete outcome data } \\
\text { (attrition bias) } \\
\text { All outcomes }\end{array}$ & Unclear risk & $\begin{array}{l}\text { Comment: some participants were excluded for lack of adherence- these may } \\
\text { be related to the intervention and the outcomes }\end{array}$ \\
\hline $\begin{array}{l}\text { Selective reporting (re- } \\
\text { porting bias) }\end{array}$ & High risk & $\begin{array}{l}\text { Comment: a pre-published protocol was not available and none of the out- } \\
\text { comes of interest for this review were reported }\end{array}$ \\
\hline Other bias & Low risk & Comment: no other bias noted.ere \\
\hline
\end{tabular}


Properzi 2018

\section{Study characteristics}

\begin{tabular}{|c|c|}
\hline Methods & Randomised clinical trial \\
\hline Participants & $\begin{array}{l}\text { Country: Australia } \\
\text { Period of recruitment: not stated } \\
\text { Number randomised: } 51 \\
\text { Post-randomisation dropouts: } 3 \text { (5.9\%) } \\
\text { Revised sample size: } 48 \\
\text { Reasons for post-randomisation dropouts: Group } 1: 1 \text { withdrawn for personal reason, Group 2: } 1 \\
\text { dropout for non-compliance with diet; } 1 \text { excluded due to excess alcohol } \\
\text { Average age (years): } 52 \\
\text { Female: } 25 \text { ( } 52.1 \% \text { ) } \\
\text { NASH: not stated } \\
\text { Diabetes mellitus: } 15 \text { (31.3\%) } \\
\text { Inclusion criteria: diagnosis of NAFLD, with HS > 5.5\% as determined by MRS; average alcohol con- } \\
\text { sumption of < } 20 \text { g/day or } 140 \text { g/week for women or < } 30 \text { g/day or } 210 \text { g/week for men } \\
\text { Exclusion criteria: secondary causes of NAFLD (e.g. medication-induced); unstable body weight (vari- } \\
\text { ation > } 5 \% \text { within the preceding } 3 \text { months); current use of weight-loss medications (e.g. Orlistat); cur- } \\
\text { rent use of pioglitazone; other liver disease (viral hepatitis, autoimmune or cholestatic liver disease, } \\
\text { Wilson's disease, haemochromatosis, or alpha-1 anti-trypsin deficiency); unstable diabetes (HbA1c } \\
>8.5 \%) \text {; decompensated cirrhosis (international normalised ratio }>1.3 \text {, platelets < } 100 \times 109 / m m \text { biliru- } \\
\text { bin > } 20 \text { mmol/L, albumin }<35 \text { g/L, ascites, or hepatic encephalopathy); renal failure; malignancy (aside } \\
\text { from skin cancer); inability to provide informed consent; claustrophobia preventing MRS examination; } \\
\text { current smoking; atrial fibrillation preventing SphygmoCor assessment; and pregnancy or lactation }\end{array}$ \\
\hline
\end{tabular}

Interventions Group 1: Mediterranean diet $(n=24)$

Further details: The MD was based on analysis of actual foods consumed in traditional Cretan diets (18) with alterations to allow for standardisation of protein intake with the LF diet. Target macronutrient energy contributions were $40 \%$ from carbohydrate; 35 - 40\% from fat (with $<10 \%$ of energy as saturated fat); $20 \%$ of energy as protein

Group 2: Fat restricted diet $(n=24)$

Further details: The LF diet was based on National Health and Medical Research Council and American Heart Association Dietary recommendations. Target macronutrient energy contributions for the LF diet were $50 \%$ from carbohydrate; $30 \%$ from fat (with $<10 \%$ of energy as saturated fat); $20 \%$ from protein. Additional details: 12 weeks

\section{Outcomes}

Outcomes reported: mortality at maximum follow-up, serious adverse events (number of people), any adverse events (number of people), liver transplantation at maximum follow-up, decompensation (number of people), cirrhosis (number of people), resolution of fatty liver disease, hepatocellular carcinoma, quality of life (maximum follow-up), fibrosis score Follow-up (months): 3

\section{Notes}

Source of funding (quote): "Catherine Properzi received an Australian Government Research Training Program Scholarship. Cobram Estate Olive Oil donated a portion of the olive oil supplied on the Mediterranean intervention."

Trial name/trial registry number: not stated

We tried to contact the authors in December 2020

\section{Risk of bias}

\begin{tabular}{lll}
\hline Bias & Authors' judgement & Support for judgement \\
\hline $\begin{array}{ll}\text { Random sequence genera- } \\
\text { tion (selection bias) }\end{array}$ & Unclear risk & $\begin{array}{l}\text { Quote: "Subjects were randomized in a 1:1 fashion using randomly selected } \\
\text { envelope-concealed allocations in blocks of four, which were prepared prior to } \\
\text { trial commencement." } \\
\end{array}$ \\
& \\
Comment: further information was not available
\end{tabular}


Properzi 2018 (Continued)

Allocation concealment (selection bias)
Unclear risk

Quote: "Subjects were randomized in a 1:1 fashion using randomly selected envelope-concealed allocations in blocks of four, which were prepared prior to trial commencement."

Comment: further information was not available
Blinding of participants and personnel (perfor-

mance bias)

All outcomes
Quote: "Patients and principal investigators were blinded (author replies)" Comment: the healthcare professionals were not blinded

\section{Blinding of outcome as-} sessment (detection bias) All outcomes

\section{High risk}

\begin{tabular}{lll}
\hline $\begin{array}{l}\text { Incomplete outcome data } \\
\text { (attrition bias) } \\
\text { All outcomes }\end{array}$ & High risk & $\begin{array}{l}\text { Comment: there were post-randomisation dropouts; some were related to the } \\
\text { intervention and outcomes }\end{array}$ \\
\hline $\begin{array}{l}\text { Selective reporting (re- } \\
\text { porting bias) }\end{array}$ & Low risk & $\begin{array}{l}\text { Comment: a pre-published protocol was not available, but the study authors } \\
\text { reported mortality, adverse events, and resolution of fatty liver }\end{array}$ \\
\hline Other bias & Low risk & Comment: no other bias noted \\
\hline
\end{tabular}

High risk

Quote: "assessor of the primary outcome was blinded (author replies)"

Comment: the assessors of the clinical outcomes were not blinded

Pugh 2014

\section{Study characteristics}

\begin{tabular}{ll}
\hline Methods & Randomised clinical trial \\
\hline Participants & Country: UK \\
& Period of recruitment: not stated \\
Number randomised: 31 & Post-randomisation dropouts: 10 (32.3\%) \\
& Revised sample size: 21 \\
& Reasons for post-randomisation dropouts: discontinued baseline assessment (4), discontinued inter- \\
& vention (1), did not maintain habitual diet (2), declined post-intervention assessments (3) \\
& Average age (years): 48 \\
& Female: 12 ( $57.1 \%)$ \\
& NASH: not stated \\
& Diabetes mellitus: not stated \\
Inclusion criteria: Obese (waist circumference $>94$ cm for men, $>80$ cm for women) and sedentary $(<2$ \\
hours low-intensity physical activity/week, with none performing any structured or vigorous physical \\
activity) "Caucasian", no history of excessive alcohol intake (average weekly consumption $<21$ units \\
for men, $<14$ units for women). No participant had a history of type 2 diabetes mellitus or ischaemic \\
heart disease, nor any contraindications to exercise. Only nonsmokers were recruited. Premenopausal \\
women ( $=4)$ were tested during the early follicular phase of the menstrual cycle (days $1-7$ of the \\
menstrual cycle, immediately following the onset of menstruation)
\end{tabular}

Interventions

Group 1: Supervised aerobic exercise $(n=13)$

Further details: Following a familiarisation session, participants attended the university gymnasium on a weekly basis and were provided with full supervision and guidance from a trained exercise physiologist. Exercise training comprised a combination of treadmill and cycle ergometer-based exercise which progressively increased in both intensity and duration throughout the course of the intervention. Based on individual basal fitness level, participants began the intervention with 30 mins moderate-intensity aerobic exercise 3 times/wk at 30\% of HRR for the initial 4 wks. Intensity increased to $45 \%$ HRR for the following 4 wks, until week 8 , where HRR remained at $45 \%$, but the duration of each session in- 
Pugh 2014 (Continued)

creased to 45 mins. From week 12, participants were exercising 5 times/wk for 45 mins at $60 \%$ of their individual HRR. There were no dietary modifications throughout the course of the exercise intervention, confirmed by the use of a standard food diary. 3-day food diaries were collected immediately prior to and following the exercise intervention and subsequently analysed for macronutrient intake (total energy, carbohydrate, fat, protein, and sugars)

Group 2: Dietary advice plus exercise advice $(n=8)$

Further details: Conventional care consisted of lifestyle advice provided at clinical consultation. Participants were simply advised by their hepatologist or specialist nurse to modify their lifestyle by healthy eating and increasing their physical activity. There was no supervision or guidance beyond the initial advice

\begin{tabular}{ll}
\hline Outcomes & None of the outcomes of interest were reported \\
\hline Notes & Source of funding: "We thank the European Foundation for the Study of Diabetes (EFSD) for funding \\
& this study [09/H1008/1]." \\
& Trial name/trial registry number: not stated \\
& We tried to contact the authors in December 2020
\end{tabular}

\section{Risk of bias}

\begin{tabular}{|c|c|c|}
\hline Bias & Authors' judgement & Support for judgement \\
\hline $\begin{array}{l}\text { Random sequence genera- } \\
\text { tion (selection bias) }\end{array}$ & Low risk & $\begin{array}{l}\text { Quote: "randomly assigned via a single-blinded computer-generated se- } \\
\text { quence" }\end{array}$ \\
\hline $\begin{array}{l}\text { Allocation concealment } \\
\text { (selection bias) }\end{array}$ & Unclear risk & Comment: this information was not available \\
\hline $\begin{array}{l}\text { Blinding of participants } \\
\text { and personnel (perfor- } \\
\text { mance bias) } \\
\text { All outcomes }\end{array}$ & High risk & $\begin{array}{l}\text { Comment: because of the nature of the intervention, it was not possible to } \\
\text { blind the participants }\end{array}$ \\
\hline $\begin{array}{l}\text { Blinding of outcome as- } \\
\text { sessment (detection bias) } \\
\text { All outcomes }\end{array}$ & Unclear risk & Comment: this information was not available \\
\hline $\begin{array}{l}\text { Incomplete outcome data } \\
\text { (attrition bias) } \\
\text { All outcomes }\end{array}$ & High risk & $\begin{array}{l}\text { Comment: there were post-randomisation dropouts; some were related to the } \\
\text { intervention and outcomes }\end{array}$ \\
\hline $\begin{array}{l}\text { Selective reporting (re- } \\
\text { porting bias) }\end{array}$ & High risk & $\begin{array}{l}\text { Comment: a pre-published protocol was not available and neither mortality } \\
\text { nor resolution of fatty liver was reported }\end{array}$ \\
\hline Other bias & Low risk & Comment: no other bias noted \\
\hline
\end{tabular}

Ramirez 2016

\section{Study characteristics}

\begin{tabular}{ll}
\hline Methods & Randomised clinical trial \\
\hline Participants & Country: USA \\
& Period of recruitment: not stated \\
& Number randomised: 19 \\
& Post-randomisation dropouts: not stated \\
& Revised sample size: 19 \\
\hline
\end{tabular}


Ramirez 2016 (Continued)

Average age (years): not stated

Female: $5(26.3 \%)$

NASH: not stated

Diabetes mellitus: not stated

Inclusion criteria: Age 11 - 17 years; metabolic syndrome; biopsy-proven NAFLD

\begin{tabular}{ll}
\hline Interventions & Group 1: Carbohydrate-restricted diet ( $\mathrm{n}=$ not stated) \\
& Further details: carbohydrate-restricted diet ( $20 \%$ carbohydrates, 35\% protein and $45 \%$ fat) \\
& Group 2: Calorie-restricted diet ( $\mathrm{n}=$ not stated) \\
& Further details: calorie-restricted diet (50\% carbohydrate, $15-20 \%$ protein and $30-35 \%$ fat)
\end{tabular}

\begin{tabular}{ll}
\hline Outcomes & None of the outcomes of interest were reported \\
\hline Notes & Source of funding: not stated \\
& Trial name/trial registry number: not stated \\
& We tried to contact the authors in December 2020. \\
\hline
\end{tabular}

\section{Risk of bias}

\begin{tabular}{|c|c|c|}
\hline Bias & Authors' judgement & Support for judgement \\
\hline $\begin{array}{l}\text { Random sequence genera- } \\
\text { tion (selection bias) }\end{array}$ & Unclear risk & Comment: this information was not available \\
\hline $\begin{array}{l}\text { Allocation concealment } \\
\text { (selection bias) }\end{array}$ & Unclear risk & Comment: this information was not available \\
\hline $\begin{array}{l}\text { Blinding of participants } \\
\text { and personnel (perfor- } \\
\text { mance bias) } \\
\text { All outcomes }\end{array}$ & High risk & $\begin{array}{l}\text { Comment: because of the nature of the intervention, it was not possible to } \\
\text { blind the participants }\end{array}$ \\
\hline $\begin{array}{l}\text { Blinding of outcome as- } \\
\text { sessment (detection bias) } \\
\text { All outcomes }\end{array}$ & Unclear risk & Comment: this information was not available \\
\hline $\begin{array}{l}\text { Incomplete outcome data } \\
\text { (attrition bias) } \\
\text { All outcomes }\end{array}$ & Unclear risk & Comment: this information was not available \\
\hline $\begin{array}{l}\text { Selective reporting (re- } \\
\text { porting bias) }\end{array}$ & High risk & $\begin{array}{l}\text { Comment: a pre-published protocol was not available and neither mortality } \\
\text { nor resolution of fatty liver was reported }\end{array}$ \\
\hline Other bias & Low risk & Comment: no other bias noted \\
\hline
\end{tabular}

Ramon-Krauel 2013

\section{Study characteristics}

\begin{tabular}{ll}
\hline Methods & Randomised clinical trial \\
\hline Participants & Country: USA \\
& Period of recruitment: not stated \\
& Number randomised: 17 \\
& Post-randomisation dropouts: $1(5.9 \%)$ \\
& Revised sample size: 16
\end{tabular}


Ramon-Krauel 2013 (Continued)

Reasons for post-randomisation dropouts: Difficulty attending study visits (1)

Average age (years): 13

Female: 3 (18.8\%)

NASH: not stated

Diabetes mellitus: 0 (0.0\%)

Inclusion criteria: Age 8 - 17 years; elevated ALT; obesity defined as a BMI $\geq 95$ th percentile for age and sex; ability to tolerate MRI; willingness to attend study sessions; $\geq 9 \%$ liver fat as measured by MRS

Exclusion criteria: Any major systemic disease (including diabetes); other hepatic disease (including viral or autoimmune hepatitis; Wilson's disease, a-1-antitrypsin deficiency); any alcohol consumption; medication or vitamin supplements that could affect liver fat or body weight; weight > 300 pounds; weight change $>10 \%$ of total body weight within the last 6 months; pregnancy

Interventions

Group 1: Low glycaemic-index diet $(n=7)$

Further details: The diets were prescribed ad libitum, and the participants were educated to eat to satiety and snack when hungry. Both groups had a targeted proportion of energy from protein of $20-$ $25 \%$. The low-GL prescription emphasised the selection of carbohydrate-containing foods with a low to moderate glycaemic load (nonstarchy vegetables, fruits, legumes, and dairy). The targeted proportion of energy from carbohydrate and fat were $40 \%$ and $35-40 \%$, respectively

Group 2: Fat-restricted diet $(n=9)$

Further details: The diets were prescribed ad libitum, and the participants were educated to eat to satiety and snack when hungry. Both groups had a targeted proportion of energy from protein of $20-25 \%$. The low-fat diet was based on 2003 American Diabetes Association and 2002 American Gastroenterological Association recommendations to limit total fat to $<30 \%$ of total calories and saturated fat to $<$ $10 \%$. We aimed for $55-60 \%$ of energy from carbohydrates and $20 \%$ from fat with $<10 \%$ from saturated fat

\begin{tabular}{ll}
\hline Outcomes & None of the outcomes of interest were reported \\
\hline Notes & Source of funding (quote): "This study was supported by grants from the Allen Foundation, the New \\
Balance Foundation, and the National Institute of Diabetes and Digestive and Kidney Diseases (K24D- \\
K082730 and T32DK07699). Additional support was provided from the National Center for Research Re- \\
sources (UL1 RR025758) to the Harvard Catalyst Clinical and Translational Science Center at Harvard \\
University." \\
Trial name/trial registry number: NCT00480922 \\
We tried to contact the authors in December 2020
\end{tabular}

\section{Risk of bias}

\begin{tabular}{|c|c|c|}
\hline Bias & Authors' judgement & Support for judgement \\
\hline $\begin{array}{l}\text { Random sequence genera- } \\
\text { tion (selection bias) }\end{array}$ & Unclear risk & Comment: this information was not available \\
\hline $\begin{array}{l}\text { Allocation concealment } \\
\text { (selection bias) }\end{array}$ & Unclear risk & Comment: this information was not available \\
\hline $\begin{array}{l}\text { Blinding of participants } \\
\text { and personnel (perfor- } \\
\text { mance bias) } \\
\text { All outcomes }\end{array}$ & High risk & $\begin{array}{l}\text { Comment: because of the nature of the intervention, it was not possible to } \\
\text { blind the participants }\end{array}$ \\
\hline $\begin{array}{l}\text { Blinding of outcome as- } \\
\text { sessment (detection bias) } \\
\text { All outcomes }\end{array}$ & Unclear risk & Comment: this information was not available \\
\hline $\begin{array}{l}\text { Incomplete outcome data } \\
\text { (attrition bias) } \\
\text { All outcomes }\end{array}$ & Unclear risk & $\begin{array}{l}\text { Comment: there were post-randomisation dropouts, but it was not clear } \\
\text { whether these were related to the intervention or outcomes }\end{array}$ \\
\hline
\end{tabular}


Ramon-Krauel 2013 (Continued)

\begin{tabular}{|c|c|c|}
\hline $\begin{array}{l}\text { Selective reporting (re- } \\
\text { porting bias) }\end{array}$ & High risk & $\begin{array}{l}\text { Comment: a pre-published protocol was not available and neither mortality } \\
\text { nor resolution of fatty liver was reported }\end{array}$ \\
\hline
\end{tabular}

Other bias Low risk Comment: no other bias noted

Rezende 2016

\section{Study characteristics}

\begin{tabular}{ll}
\hline Methods & Randomised clinical trial \\
\hline Participants & Country: Brazil \\
& Period of recruitment: not stated \\
& Number randomised: 44 \\
& Post-randomisation dropouts: 4 (9.1\%) \\
& Revised sample size: 40 \\
& Reasons for post-randomisation dropouts: Non-adherence to exercise programme (2); non-adherence \\
& to protocol (1); insertion of intra-gastric balloon (1) \\
& Average age (years): 55 \\
& Female: 40 (100.0\%) \\
& NASH: not stated \\
& Diabetes mellitus: 31 (77.5\%) \\
Inclusion criteria: Postmenopausal women; non-smoker; biopsy-proven NAFLD \\
Exclusion criteria: Hormone therapy; alcohol abuse (ethanol consumption $>20$ g/d); HIV, hepatitis B or \\
C; any other chronic liver diseases; any physical or cardiovascular limitation that could preclude the \\
participant from undergoing physical testing or exercise training; significant changes in dietary habits \\
and/or having begun a physical activity programme in the past 3 months; non-adherence to the study \\
protocol
\end{tabular}

Group 1: Supervised aerobic exercise $(n=19)$
Further details: 24 weeks of a supervised exercise training programme, performed twice a week. Train-
ing sessions were composed of a 5-minute warm-up followed by 30 to 50 minutes of treadmill aerobic
exercise and 5 minutes of cooling down. Exercise sessions lasted 30 to 50 minutes, with increases in ex-
ercise duration every 8 weeks. The intensity was increased from VAT up to $10 \%$ below RCP
Group 2: No active intervention $(n=21)$
Further details: control group

Outcomes Outcomes reported: resolution of fatty liver disease

Follow-up (months): 6

Notes

Source of funding (quote): "Funding/support: National Council of Technological and Scientific Development (CNPQ). We thank the Alves de Queiroz Family Fund for Research and CNPq for financial support."

Trial name/trial registry number: NCT02427087

We tried to contact the authors in December 2020

\section{Risk of bias}

\begin{tabular}{lll}
\hline Bias & Authors' judgement & Support for judgement \\
\hline $\begin{array}{l}\text { Random sequence genera- } \\
\text { tion (selection bias) }\end{array}$ & Low risk & Quote: "The random sequence generator was obtained by www.random.org" \\
\hline $\begin{array}{l}\text { Allocation concealment } \\
\text { (selection bias) }\end{array}$ & Unclear risk & Comment: this information was not available \\
\hline
\end{tabular}


Rezende 2016 (Continued)

Blinding of participants High risk Comment: because of the nature of the intervention, it was not possible to and personnel (performance bias)

All outcomes

\section{blind the participants}

$\begin{array}{ll}\text { Blinding of outcome as- } & \text { Unclear risk }\end{array}$ Comment: this information was not available

All outcomes

Incomplete outcome data High risk

(attrition bias)

Comment: there were post-randomisation dropouts; some were related to the

All outcomes intervention and outcomes

$\begin{array}{lll}\begin{array}{l}\text { Selective reporting (re- } \\ \text { porting bias) }\end{array} & \text { High risk } & \begin{array}{l}\text { Comment: a pre-published protocol was not available and adverse events } \\ \text { were not reported }\end{array}\end{array}$

Other bias Low risk Comment: no other bias noted

\section{Rodriguez-Hernandez 2011}

\section{Study characteristics}

\begin{tabular}{ll}
\hline Methods & Randomised clinical trial \\
\hline Participants & Country: Mexico \\
& Period of recruitment: not stated \\
& Number randomised: 59 \\
& Post-randomisation dropouts: $5(8.5 \%)$ \\
& Revised sample size: 54 \\
& Reasons for post-randomisation drop-outs: Lost to follow-up \\
& Average age (years): 46 \\
& Female: 54 (100.0\%) \\
& NASH: not stated \\
& Diabetes mellitus: 8 (14.8\%) \\
Inclusion criteria: obese women, aged 20 to 65 years, healthy, non-pregnant, diagnosis of NAFLD, simi- \\
lar social and economic background \\
Exclusion criteria: Previous diagnosis of hepatic disease, serum creatinine level $>1.5$ mg/dL, severe life- \\
limiting medical illness, pregnancy, active participation in other dietary programme, use of weight-loss \\
drugs, or alcohol consumption $>30$ g per day
\end{tabular}

Interventions

Group 1: Fat-restricted diet $(n=26)$

Further details: LFD was based on $21 \%$ of daily energy intake from fat, $<10 \%$ saturated fat, $25 \%$ pro-

tein, and $54 \%$ carbohydrate

Group 2: Carbohydrate-restricted diet $(n=28)$

Further details: the LCD was based on the following percentage of total energy intake per nutrient: $27 \%$ protein, $28 \%$ fat and $45 \%$ carbohydrate

\begin{tabular}{ll}
\hline Outcomes & None of the outcomes of interest were reported \\
\hline Notes & Source of funding (quote): "This work was partially supported by Fundación IMSS, A.C." \\
& Trial name/trial registry number: not stated \\
& We tried to contact the authors in December 2020
\end{tabular}

\section{Risk of bias}


Rodriguez-Hernandez 2011 (Continued)
Random sequence genera- Unclear risk
Comment: this information was not available tion (selection bias)

Allocation concealment Unclear risk Comment: this information was not available
(selection bias)

Blinding of participants Unclear risk Comment: this information was not available
and personnel (perfor-
mance bias)
All outcomes

\begin{tabular}{lll}
$\begin{array}{l}\text { Blinding of outcome as- } \\
\text { sessment (detection bias) } \\
\text { All outcomes }\end{array}$ & Unclear risk & Comment: this information was not available \\
\hline $\begin{array}{l}\text { Incomplete outcome data } \\
\text { (attrition bias) }\end{array}$ & Unclear risk & $\begin{array}{l}\text { Comment: there were post-randomisation dropouts, but it was not clear } \\
\text { all outcomes }\end{array}$
\end{tabular}

\begin{tabular}{|c|c|c|}
\hline $\begin{array}{l}\text { Selective reporting (re- } \\
\text { porting bias) }\end{array}$ & High risk & $\begin{array}{l}\text { Comment: a pre-published protocol was not available and neither mortality } \\
\text { nor resolution of fatty liver was reported }\end{array}$ \\
\hline
\end{tabular}

\begin{tabular}{ll}
\hline Other bias $\quad$ Low risk $\quad$ Comment: no other bias noted \\
\hline
\end{tabular}

Roy 2017

\section{Study characteristics}

\begin{tabular}{ll}
\hline Methods & Randomised clinical trial \\
\hline Participants & Country: not stated \\
& Period of recruitment: not stated \\
& Number randomised: 60 \\
& Post-randomisation dropouts: not stated \\
& Revised sample size: 60 \\
& Average age (years): not stated \\
& Female: not stated \\
& NASH: not stated \\
& Diabetes mellitus: 60 (100.0\%) \\
& Inclusion criteria: Outpatient type 2 diabetics with NAFLD \\
\hline Interventions & Group 1: Dietary advice plus exercise advice ( $\mathrm{n}=30$ ) \\
& Further details: Lifestyle modification counselling plus standard care \\
& Group 2: No active intervention ( $\mathrm{n}=30$ ) \\
Further details: Standard care \\
\hline Outcomes & Outcomes reported: resolution of fatty liver disease \\
& Follow-up (months): 4 \\
\hline Notes & Source of funding: not stated \\
Trial name/trial registry number: not stated \\
We tried to contact the authors in December 2020
\end{tabular}

\section{Risk of bias}


Roy 2017 (Continued)

\begin{tabular}{lll} 
Bias & Authors' judgement & Support for judgement \\
\hline $\begin{array}{l}\text { Random sequence genera- } \\
\text { tion (selection bias) }\end{array}$ & Unclear risk & Comment: this information was not available \\
\hline $\begin{array}{l}\text { Allocation concealment } \\
\text { (selection bias) }\end{array}$ & Unclear risk & Comment: this information was not available
\end{tabular}

\begin{tabular}{|c|c|c|}
\hline $\begin{array}{l}\text { Blinding of participants } \\
\text { and personnel (perfor- }\end{array}$ & High risk & $\begin{array}{l}\text { Comment: because of the nature of the intervention, it was not possible to } \\
\text { blind the participants }\end{array}$ \\
\hline
\end{tabular}

mance bias)

All outcomes

\begin{tabular}{|c|c|c|}
\hline $\begin{array}{l}\text { Blinding of outcome as- } \\
\text { sessment (detection bias) } \\
\text { All outcomes }\end{array}$ & Unclear risk & Comment: this information was not available \\
\hline $\begin{array}{l}\text { Incomplete outcome data } \\
\text { (attrition bias) } \\
\text { All outcomes }\end{array}$ & Unclear risk & Comment: this information was not available \\
\hline $\begin{array}{l}\text { Selective reporting (re- } \\
\text { porting bias) }\end{array}$ & High risk & $\begin{array}{l}\text { Comment: a pre-published protocol was not available and adverse events } \\
\text { were not reported }\end{array}$ \\
\hline Other bias & Low risk & Comment: no other bias noted \\
\hline
\end{tabular}

Schattenberg 2017

\section{Study characteristics}

\begin{tabular}{|c|c|}
\hline Methods & Randomised clinical trial \\
\hline Participants & $\begin{array}{l}\text { Country: Germany } \\
\text { Period of recruitment: not stated } \\
\text { Number randomised: } 29 \\
\text { Post-randomisation drop-outs: } 1(3.4 \%) \\
\text { Revised sample size: } 28 \\
\text { Reasons for post-randomisation drop-outs: not stated } \\
\text { Average age (years): } 45 \\
\text { Female: } 7(25.0 \%) \\
\text { NASH: } 28 \text { (100.0\%) } \\
\text { Diabetes mellitus: not stated } \\
\text { Inclusion criteria: Histologically-confirmed NASH or a combination of M30 levels above } 200 \mathrm{U} / \mathrm{l} \text { and he- } \\
\text { patic steatosis on ultrasound; age } 18-75\end{array}$ \\
\hline Interventions & $\begin{array}{l}\text { Group 1: Dietary advice }(n=15) \\
\text { Further details: } L c S \text { plus N (Lactobacillus casei Shirota plus dietary counselling): dietary counselling } \\
\text { aiming at a reduction of fructose consumption by } 50 \% \text { compared to screening, } 6.5 \text { x } 109 \text { counts of lac- } \\
\text { tobacillus casei Shirota plus } 2.1 \text { g soluble fibre twice daily } \\
\text { Group 2: No active intervention ( } n=13 \text { ) } \\
\text { Further details: Lactobacillus alone }\end{array}$ \\
\hline Outcomes & $\begin{array}{l}\text { Outcomes reported: mortality at maximal follow-up, serious adverse events (number of people), any } \\
\text { adverse events (number of people), liver transplantation at maximum follow-up, decompensation } \\
\text { (number of people), cirrhosis (number of people) } \\
\text { Follow-up (months): } 3\end{array}$ \\
\hline
\end{tabular}


Schattenberg 2017 (Continued)

Notes

Source of funding (quote): "This study was partly funded by H2020 under grant no. 634413 for the EPoS projects and by Yakult Europe."

Trial name/trial registry number: NCT02366052, NUCES NASH

We tried to contact the authors in December 2020

\section{Risk of bias}

\begin{tabular}{|c|c|c|}
\hline Bias & Authors' judgement & Support for judgement \\
\hline $\begin{array}{l}\text { Random sequence genera- } \\
\text { tion (selection bias) }\end{array}$ & Unclear risk & Comment: this information was not available \\
\hline $\begin{array}{l}\text { Allocation concealment } \\
\text { (selection bias) }\end{array}$ & Unclear risk & Comment: this information was not available \\
\hline $\begin{array}{l}\text { Blinding of participants } \\
\text { and personnel (perfor- } \\
\text { mance bias) } \\
\text { All outcomes }\end{array}$ & High risk & $\begin{array}{l}\text { Comment: because of the nature of the intervention, it was not possible to } \\
\text { blind the participants }\end{array}$ \\
\hline $\begin{array}{l}\text { Blinding of outcome as- } \\
\text { sessment (detection bias) } \\
\text { All outcomes }\end{array}$ & High risk & $\begin{array}{l}\text { Quote: "Blinded lab analysis (author replies)" } \\
\text { Comment: the assessors of the clinical outcomes were not blinded }\end{array}$ \\
\hline $\begin{array}{l}\text { Incomplete outcome data } \\
\text { (attrition bias) } \\
\text { All outcomes }\end{array}$ & Unclear risk & $\begin{array}{l}\text { Comment: there were post-randomisation dropouts, but unclear whether } \\
\text { these were related to the intervention or outcomes }\end{array}$ \\
\hline $\begin{array}{l}\text { Selective reporting (re- } \\
\text { porting bias) }\end{array}$ & Low risk & $\begin{array}{l}\text { Comment: a pre-published protocol was not available, but mortality and ad- } \\
\text { verse events were reported }\end{array}$ \\
\hline Other bias & Low risk & Comment: no other bias noted \\
\hline
\end{tabular}

Selezneva 2014

\section{Study characteristics}

\begin{tabular}{ll}
\hline Methods & Randomised clinical trial \\
\hline Participants & Country: Russia \\
& Period of recruitment: not stated \\
& Number randomised: 174 \\
& Post-randomisation dropouts: not stated \\
& Revised sample size: 174 \\
& Average age (years): not stated \\
& Female: 86 (49.4\%) \\
& NASH: 174 (100.0\%) \\
& Diabetes mellitus: not stated \\
& Inclusion criteria: NASH patients \\
& Group 1: Isocalorie diet ( $\mathrm{n}=116)$ \\
& Further details: for ICD the caloric consumption was established according to the recommended daily \\
& values for proteins, fat and carbohydrates for ideal BMI for every participant \\
& Group 2: Calorie-restricted diet ( $\mathrm{n}=58)$ \\
& Further details: Caloric restriction was achieved by decreasing consumption of carbohydrates and fat \\
Interventions & in LCD
\end{tabular}


Selezneva 2014 (Continued)

Outcomes None of the outcomes of interest were reported

\begin{tabular}{ll}
\hline Notes & Source of funding: not stated \\
& Trial name/trial registry number: not stated \\
& We tried to contact the authors in December 2020
\end{tabular}

\section{Risk of bias}

\begin{tabular}{|c|c|c|}
\hline Bias & Authors' judgement & Support for judgement \\
\hline $\begin{array}{l}\text { Random sequence genera- } \\
\text { tion (selection bias) }\end{array}$ & Unclear risk & Comment: this information was not available \\
\hline $\begin{array}{l}\text { Allocation concealment } \\
\text { (selection bias) }\end{array}$ & Unclear risk & Comment: this information was not available \\
\hline $\begin{array}{l}\text { Blinding of participants } \\
\text { and personnel (perfor- } \\
\text { mance bias) } \\
\text { All outcomes }\end{array}$ & High risk & $\begin{array}{l}\text { Comment: because of the nature of the intervention, it was not possible to } \\
\text { blind the participants }\end{array}$ \\
\hline $\begin{array}{l}\text { Blinding of outcome as- } \\
\text { sessment (detection bias) } \\
\text { All outcomes }\end{array}$ & Unclear risk & Comment: this information was not available \\
\hline $\begin{array}{l}\text { Incomplete outcome data } \\
\text { (attrition bias) } \\
\text { All outcomes }\end{array}$ & Unclear risk & Comment: this information was not available \\
\hline $\begin{array}{l}\text { Selective reporting (re- } \\
\text { porting bias) }\end{array}$ & High risk & $\begin{array}{l}\text { Comment: a pre-published protocol was not available and none of the out- } \\
\text { comes of interest for this review were reported }\end{array}$ \\
\hline Other bias & Low risk & Comment: no other bias noted \\
\hline
\end{tabular}

Shidfar 2018

\section{Study characteristics}

\begin{tabular}{ll}
\hline Methods & Randomised clinical trial \\
\hline Participants & Country: Iran \\
Number randomised: 50 \\
Post-randomisation dropouts: 7 (14\%) \\
Revised sample size: 43 \\
Reasons for post-randomisation dropouts: not stated \\
Average age: 46 years \\
Female: 17 (39.5\%) \\
NASH: not stated \\
Diabetes mellitus: 0 (0\%) \\
Inclusion criteria: increase of the AST and ALT enzymes, the elimination of all other causes for the in- \\
crease in the liver enzymes (other liver diseases), age of $20-65$ years, BMI of $25-40 \mathrm{~kg} / \mathrm{m}^{2}$ \\
Exclusion criteria: no use of hepatotoxic medicines, no history of $\geq 30$ gr/d alcohol consumption, no \\
cardiovascular disease, no diabetes, no pregnancy or breastfeeding, no smoking, no consumption of \\
mineral and multivitamins supplements, no consumption of olive products, and lipid-lowering medi- \\
cines in the last 3 months
\end{tabular}


Shidfar 2018 (Continued)

Interventions
Participants were randomly assigned to 2 groups

Group 1: Mono-unsaturated fatty acid plus calorie-restricted diet $(n=21)$

Further details: hypocaloric diet enriched with olive oil ( $20 \%$ of total energy intake) for 12 weeks

Group 2: Calorie-restricted diet $(\mathrm{n}=22)$

Further details: hypocaloric diet with normal fat for 12 weeks

\begin{tabular}{ll}
\hline Outcomes & None of the outcomes of interest were reported \\
\hline Notes & $\begin{array}{l}\text { Source of funding: "This paper was supported by the Khoramshahr Oil Company. The authors would } \\
\text { like to thank Javad Salimi, head of the oil factory of Ganjeh, Roudbar, and Aboozar Falahzadeh, head of } \\
\text { the oil factory laboratory" } \\
\text { Trial name/trial registry number: IRCT201111022709N20 } \\
\text { We tried to contact the authors in March } 2021\end{array}$ \\
\hline
\end{tabular}

\section{Risk of bias}

\begin{tabular}{|c|c|c|}
\hline Bias & Authors' judgement & Support for judgement \\
\hline $\begin{array}{l}\text { Random sequence genera- } \\
\text { tion (selection bias) }\end{array}$ & Unclear risk & Comment: this information was not available \\
\hline $\begin{array}{l}\text { Allocation concealment } \\
\text { (selection bias) }\end{array}$ & Unclear risk & Comment: this information was not available \\
\hline $\begin{array}{l}\text { Blinding of participants } \\
\text { and personnel (perfor- } \\
\text { mance bias) } \\
\text { All outcomes }\end{array}$ & Unclear risk & $\begin{array}{l}\text { Quote: "None of the participants know about the other group and alternative } \\
\text { treatment". } \\
\text { Comment: information about blinding of healthcare professionals was not } \\
\text { available }\end{array}$ \\
\hline $\begin{array}{l}\text { Blinding of outcome as- } \\
\text { sessment (detection bias) } \\
\text { All outcomes }\end{array}$ & Unclear risk & Comment: this information was not available \\
\hline $\begin{array}{l}\text { Incomplete outcome data } \\
\text { (attrition bias) } \\
\text { All outcomes }\end{array}$ & Unclear risk & $\begin{array}{l}\text { Comment: } 7 \text { participants excluded from analysis: the reasons for exclusion } \\
\text { were not provided. }\end{array}$ \\
\hline $\begin{array}{l}\text { Selective reporting (re- } \\
\text { porting bias) }\end{array}$ & High risk & $\begin{array}{l}\text { Comment: a pre-published protocol was not available and none of the out- } \\
\text { comes of interest for this review were reported }\end{array}$ \\
\hline Other bias & Low risk & Comment: no other bias noted \\
\hline
\end{tabular}

Sima 2014

\section{Study characteristics}

\begin{tabular}{ll}
\hline Methods & Randomised clinical trial \\
\hline Participants & Country: Iran \\
& Period of recruitment: not stated \\
& Number randomised: 25 \\
& Post-randomisation dropouts: not stated \\
& Revised sample size: 25 \\
& Average age (years): not stated \\
& Female: not stated \\
& NASH: $25(100.0 \%)$
\end{tabular}


Sima 2014 (Continued)

Diabetes mellitus: not stated

Inclusion criteria: NASH; age 18 - 55 years

Interventions

Group 1: Calorie-restricted diet plus aerobic exercise $(n=12)$

Further details: Calorie-restricted diet plus aerobic exercise:CR-diet included $500 \mathrm{kcal}$ of energy less

than the estimated daily energy requirement and aerobic exercise consisted of 35 to 50 minutes walk-

ing, jogging and running, for a period of 8 weeks, 3 days a week with $55-60 \%$ of the HRR

Group 2: Calorie-restricted diet $(n=13)$

Further details: Calorie-restricted diet: CR-diet included $500 \mathrm{kcal}$ of energy less than the estimated daily energy requirement

\begin{tabular}{ll}
\hline Outcomes & None of the outcomes of interest were reported \\
\hline Notes & Source of funding: not stated \\
& Trial name/trial registry number: not stated \\
& We tried to contact the authors in December 2020
\end{tabular}

\section{Risk of bias}

\begin{tabular}{|c|c|c|}
\hline Bias & Authors' judgement & Support for judgement \\
\hline $\begin{array}{l}\text { Random sequence genera- } \\
\text { tion (selection bias) }\end{array}$ & Unclear risk & Comment: this information was not available \\
\hline $\begin{array}{l}\text { Allocation concealment } \\
\text { (selection bias) }\end{array}$ & Unclear risk & Comment: this information was not available \\
\hline $\begin{array}{l}\text { Blinding of participants } \\
\text { and personnel (perfor- } \\
\text { mance bias) } \\
\text { All outcomes }\end{array}$ & High risk & $\begin{array}{l}\text { Comment: because of the nature of the intervention, it was not possible to } \\
\text { blind the participants }\end{array}$ \\
\hline $\begin{array}{l}\text { Blinding of outcome as- } \\
\text { sessment (detection bias) } \\
\text { All outcomes }\end{array}$ & Unclear risk & Comment: this information was not available \\
\hline $\begin{array}{l}\text { Incomplete outcome data } \\
\text { (attrition bias) } \\
\text { All outcomes }\end{array}$ & Unclear risk & Comment: this information was not available \\
\hline $\begin{array}{l}\text { Selective reporting (re- } \\
\text { porting bias) }\end{array}$ & High risk & $\begin{array}{l}\text { Comment: a pre-published protocol was not available and neither mortality } \\
\text { nor resolution of fatty liver was reported }\end{array}$ \\
\hline Other bias & Low risk & Comment: no other bias noted \\
\hline
\end{tabular}

Sullivan 2012

\section{Study characteristics}

\begin{tabular}{ll}
\hline Methods & Randomised clinical trial \\
\hline Participants & Country: USA \\
& Period of recruitment: not stated \\
& Number randomised: 33 \\
& Post-randomisation dropouts: $15(45.5 \%)$ \\
& Revised sample size: 18
\end{tabular}


Sullivan 2012 (Continued)

Reasons for post-randomisation dropouts: Dropped out during baseline testing (4); self-withdrew (5); hospitalisation or work-related injury (4); did not follow study protocol (2)

Average age (years): 48

Female: $13(72.2 \%)$

NASH: not stated

Diabetes mellitus: 0 (0.0\%)

Inclusion criteria: Obesity; NAFLD; sedentary ( $<1$ hour of self-reported exercise per week)

Exclusion criteria: Chronic liver disease other than NAFLD; Michigan Alcohol Screening Test score > 4; diabetes; plasma triglyceride concentration $>400 \mathrm{mg} / \mathrm{dL}$

Group 1: Aerobic exercise $(n=12)$
Further details: Participants in the exercise group were instructed to exercise for $30-60$ mins, 5 times a
week at $45 \%$ - $55 \%$ of their $\mathrm{V} O 2$ peak (i.e. brisk walk). Participants initiated their exercise programme by
walking on a treadmill for $15-30$ minutes at a heart rate equivalent to $45-55 \%$ of their pretraining VंO2
peak, and progressively increased the duration of exercise during the initial 4 weeks until $30-60$ mins
of moderate intensity exercise 5 times a week was achieved. Participants exercised under direct super-
vision once a week in our exercise facility; the remaining sessions were completed at home. Compli-
ance with home exercises was assessed by recording heart rate (Polar Electro heart rate monitor, Kem-
pele, Finland) during all exercise sessions. Participants were required to complete 16 weeks of exercise
training; those who completed < 3 exercise sessions in any week were required to extend their training
period by an additional week
Group 2: No active intervention ( $n=6)$
Further details: Participants in the control group were instructed to continue their current activities of
daily living; they were contacted once a week to review compliance with the study protocol and report-
ed to the research centre once a month to obtain accurate body weight measurements

\begin{tabular}{ll}
\hline Outcomes & None of the outcomes of interest were reported \\
\hline Notes & Source of funding (quote): "This research was supported by National Institutes of Health grants UL1 \\
& RR24992 KL2 RR024994 (Washington University Clinical and Translational Science Award), DK052574 \\
& (Digestive Disease Research Core Center), DK56341 (Nutrition Obesity Research Center), DK78738, \\
& DK37948, and HD57796." \\
& Trial name/trial registry number: NCT00771108 \\
& We tried to contact the authors in December 2020. \\
&
\end{tabular}

\section{Risk of bias}

\begin{tabular}{lll}
\hline Bias & Authors' judgement & Support for judgement \\
\hline $\begin{array}{l}\text { Random sequence genera- } \\
\text { tion (selection bias) }\end{array}$ & Low risk & Quote: "computer-generated randomization scheme" \\
\hline $\begin{array}{l}\text { Allocation concealment } \\
\text { (selection bias) }\end{array}$ & Low risk & $\begin{array}{l}\text { Quote: "randomized into the control or the exercise group by an independent } \\
\text { statistician who did not participate in subject enrolment " }\end{array}$ \\
\hline $\begin{array}{l}\text { Blinding of participants } \\
\text { and personnel (perfor- } \\
\text { mance bias) }\end{array}$ & High risk & $\begin{array}{l}\text { Comment: because of the nature of the intervention, it was not possible to } \\
\text { blind the participants }\end{array}$ \\
\hline $\begin{array}{l}\text { Blinding of outcome as- } \\
\text { sessment (detection bias) } \\
\text { All outcomes }\end{array}$ & Unclear risk & \begin{tabular}{l} 
Comment: this information was not available \\
\hline $\begin{array}{l}\text { Incomplete outcome data } \\
\text { (attrition bias) } \\
\text { All outcomes }\end{array}$
\end{tabular} \\
\hline
\end{tabular}


Sullivan 2012 (Continued)

Selective reporting (re- High risk Comment: a pre-published protocol was not available and neither mortality porting bias) nor resolution of fatty liver was reported

Other bias Low risk Comment: no other bias noted

Tutino 2018

\section{Study characteristics}

\begin{tabular}{ll}
\hline Methods & Randomised clinical trial \\
\hline Participants & Country: Italy \\
& Period of recruitment: not stated \\
& Number randomised: 83 \\
& Post-randomisation dropouts: 21 (25.3\%) \\
& Revised sample size: 62 \\
& Reasons for post-randomisation dropouts: not stated \\
& Average age (years): 51 \\
& Female: 34 (54.8\%) \\
& NASH: not stated \\
& Diabetes mellitus: 5 (8.1\%) \\
& Inclusion criteria: Age 30 - $60 ;$ BMI > 25; moderate to severe NAFLD \\
& Exclusion criteria: Stroke; peripheral arterial disease; cardiovascular disease or revascularisation pro- \\
& cedures; treatment with insulin or oral hypoglycaemic drugs; fasting glucose > 126 mg/dL; alcohol in- \\
take $>20 g$ daily; severe medical condition that may impair participation in a nutritional intervention \\
study; special diets or involved in a weight-loss programme; recent weight loss, and those who cannot \\
follow a diet for religious or other reasons
\end{tabular}

Interventions

Group 1: Aerobic exercise plus resistance exercise $(n=29)$

Further details: Physical activity interventions included 2 different types of exercise programmes: PA1 based on the aerobic activity programme and PA2 based on the combination of aerobic activity and resistance training

Group 2: Mediterranean diet $(n=18)$

Further details: Low-glycaemic index Mediterranean diet (LGIMD) based on consumption of bread and pasta derived from real wholemeal flour (not reconstituted), vegetables and seasonal fruit, legumes, nuts, oily fish and white meats in moderate amounts, low-fat cheese and eggs weekly, and extra virgin olive oil

Group 3: no active intervention $(n=15)$

Further details: Control Diet (CD) based on CREA-AN guidelines

\begin{tabular}{ll}
\hline Outcomes & None of the outcomes of interest were reported \\
\hline Notes & Source of funding (quote): "This work was supported by RC 2012-2014, Linea 4, C. 32 (D.D.G. n. \\
& 110/2014) and "PO Puglia FESR 2007-2013, Asse I, Linea 1.2, Accordo di Programma Quadro in mate- \\
& ria di Ricerca Scientifica, intervento “Reti di Laboratori Pubblici di Ricerca", progetto L.A.I.F.F.-RETE DI \\
& LABORATORI PER L'INNOVAZIONE NEL CAMPO DEGLI ALIMENTI FUNZIONALI (codice n. 47)" \\
& Trial name/trial registry number: CTO2347696 \\
& We tried to contact the authors in December 2020
\end{tabular}

\section{Risk of bias}

\begin{tabular}{lll}
\hline Bias & Authors' judgement & Support for judgement \\
\hline $\begin{array}{l}\text { Random sequence genera- } \\
\text { tion (selection bias) }\end{array}$ & Low risk & Quote: "computerized random numbers sequence" \\
\hline
\end{tabular}


Tutino 2018 (Continued)

$\begin{aligned} & \text { Allocation concealment } \\ & \text { (selection bias) }\end{aligned} \quad$ Unclear risk Comment: this information was not available

\begin{tabular}{|c|c|c|}
\hline $\begin{array}{l}\text { Blinding of participants } \\
\text { and personnel (perfor- }\end{array}$ & High risk & $\begin{array}{l}\text { Comment: because of the nature of the intervention, it was not possible to } \\
\text { blind the participants }\end{array}$ \\
\hline
\end{tabular}

mance bias)

All outcomes

\begin{tabular}{|c|c|c|}
\hline $\begin{array}{l}\text { Blinding of outcome as- } \\
\text { sessment (detection bias) }\end{array}$ & Low risk & $\begin{array}{l}\text { Quote: "Interviewers and staff members who obtained outcome measure- } \\
\text { ments, were not informed about diet or physical activity programs assigned" }\end{array}$ \\
\hline
\end{tabular}

All outcomes

\begin{tabular}{|c|c|c|}
\hline $\begin{array}{l}\text { Incomplete outcome data } \\
\text { (attrition bias) }\end{array}$ & Unclear risk & $\begin{array}{l}\text { Comment: there were post-randomisation dropouts, but it was not clear } \\
\text { whether these were related to the intervention or outcomes }\end{array}$ \\
\hline
\end{tabular}

All outcomes

\begin{tabular}{|c|c|c|}
\hline $\begin{array}{l}\text { Selective reporting (re- } \\
\text { porting bias) }\end{array}$ & High risk & $\begin{array}{l}\text { Comment: a pre-published protocol was not available and neither mortality } \\
\text { nor resolution of fatty liver was reported }\end{array}$ \\
\hline
\end{tabular}

\begin{tabular}{ll}
\hline Other bias $\quad$ Low risk $\quad$ Comment: no other bias noted \\
\hline
\end{tabular}

Wang 2008

\section{Study characteristics}

\begin{tabular}{ll}
\hline Methods & Randomised clinical trial \\
\hline Participants & Country: China \\
& Period of recruitment: not stated \\
& Number randomised: 57 \\
& Post-randomisation dropouts: not stated \\
& Revised sample size: 57 \\
& Average age (years): 14 \\
& Female: 24 (42.1\%) \\
& NASH: $57(100.0 \%)$ \\
& Diabetes mellitus: not stated \\
Inclusion criteria: Age 10 - 17 years; obesity \\
Exclusion criteria: History of alcohol intake; positive markers for other liver diseases (e.g. hepatitis) \\
\hline
\end{tabular}

Interventions Group 1: Aerobic exercise plus FatRestrict Calorie-restricted diet $(\mathrm{n}=19)$

Further details: They took part in the summer camp without their parents. The Nuote Nutrient Center which was in charge of the camp, consisted of nutrient experts, physical experts and paediatricians. Physical exercises, including swimming, playing basketball and table tennis, were taken freely for 3 hours of aerobic exercise each day. The diet management followed the principle of low-calorie (high in carbohydrate $(50 \%)$ and low in fat $(10 \%))$ with the aim of a reduction in daily intake by $250 \mathrm{kcal}$. A total daily calorie intake was controlled from $1300 \mathrm{kcal}$ to $1600 \mathrm{kcal}$ based on the individual's age. 2 eggs and a bowl of soy milk were supplied at breakfast. Pork, egg, fish, shrimp, fresh vegetable, rice and corn were served at lunch and dinner. No beverage but mineral water was provided. They were requested to get up at 6:30 am and take aerobic physical exercise in the morning and afternoon. In the evening they did their homework and watched TV for an hour, then went to sleep at 21:00 pm. The summer camp lasted 1 month

Group 2: No active intervention $(n=38)$

Further details: control group

$\begin{array}{ll}\text { Outcomes } & \text { Outcomes reported: resolution of fatty liver disease } \\ & \text { Follow-up (months): } 1\end{array}$


Wang 2008 (Continued)

Notes
Source of funding (quote): "Supported by Science and Technology Department of Zhejiang Province of China, No. 2005C24001, No. 2004C30064"

Trial name/trial registry number: not stated

We tried to contact the authors in December 2020

\section{Risk of bias}

\begin{tabular}{|c|c|c|}
\hline Bias & Authors' judgement & Support for judgement \\
\hline $\begin{array}{l}\text { Random sequence genera- } \\
\text { tion (selection bias) }\end{array}$ & Unclear risk & Comment: this information was not available \\
\hline $\begin{array}{l}\text { Allocation concealment } \\
\text { (selection bias) }\end{array}$ & Unclear risk & Comment: this information was not available \\
\hline $\begin{array}{l}\text { Blinding of participants } \\
\text { and personnel (perfor- } \\
\text { mance bias) } \\
\text { All outcomes }\end{array}$ & High risk & $\begin{array}{l}\text { Comment: because of the nature of the intervention, it was not possible to } \\
\text { blind the participants }\end{array}$ \\
\hline $\begin{array}{l}\text { Blinding of outcome as- } \\
\text { sessment (detection bias) } \\
\text { All outcomes }\end{array}$ & Unclear risk & Comment: this information was not available \\
\hline $\begin{array}{l}\text { Incomplete outcome data } \\
\text { (attrition bias) } \\
\text { All outcomes }\end{array}$ & Unclear risk & Comment: this information was not available \\
\hline $\begin{array}{l}\text { Selective reporting (re- } \\
\text { porting bias) }\end{array}$ & High risk & $\begin{array}{l}\text { Comment: a pre-published protocol was not available and adverse events } \\
\text { were not reported }\end{array}$ \\
\hline Other bias & Low risk & Comment: no other bias noted \\
\hline
\end{tabular}

Wang 2016

\section{Study characteristics}

\begin{tabular}{ll}
\hline Methods & Randomised clinical trial \\
\hline Participants & Country: China \\
& Period of recruitment: 2014 - 2015 \\
& Number randomised: 120 \\
& Post-randomisation dropouts: not stated \\
& Revised sample size: 120 \\
& Average age (years): 37 \\
& Female: 50 (41.7\%) \\
& NASH: not stated \\
& Diabetes mellitus: not stated \\
& Inclusion criteria: diagnosis of NAFLD \\
& Group 1: Aerobic exercise plus calorie-restricted diet $(\mathrm{n}=80)$ \\
& Further details: Exercise outdoors at a speed of $4 \mathrm{~km} / \mathrm{h}$. The total daily caloric intake of all participants \\
& was reduced by $2092 \mathrm{~kJ}$ compared with the initial ( $500 \mathrm{kcal})$ \\
& Group 2: Calorie-restricted diet $(\mathrm{n}=40)$ \\
& Further details: no further details \\
\hline Interventions &
\end{tabular}


Wang 2016 (Continued)

Outcomes None of the outcomes of interest were reported

\begin{tabular}{ll}
\hline Notes & Source of funding: not stated \\
& Trial name/trial registry number: not stated \\
& We tried to contact the authors in December 2020
\end{tabular}

\section{Risk of bias}

\begin{tabular}{|c|c|c|}
\hline Bias & Authors' judgement & Support for judgement \\
\hline $\begin{array}{l}\text { Random sequence genera- } \\
\text { tion (selection bias) }\end{array}$ & Unclear risk & Comment: this information was not available \\
\hline $\begin{array}{l}\text { Allocation concealment } \\
\text { (selection bias) }\end{array}$ & Unclear risk & Comment: this information was not available \\
\hline $\begin{array}{l}\text { Blinding of participants } \\
\text { and personnel (perfor- } \\
\text { mance bias) } \\
\text { All outcomes }\end{array}$ & Unclear risk & Comment: this information was not available \\
\hline $\begin{array}{l}\text { Blinding of outcome as- } \\
\text { sessment (detection bias) } \\
\text { All outcomes }\end{array}$ & Unclear risk & Comment: this information was not available \\
\hline $\begin{array}{l}\text { Incomplete outcome data } \\
\text { (attrition bias) } \\
\text { All outcomes }\end{array}$ & Unclear risk & Comment: this information was not available \\
\hline $\begin{array}{l}\text { Selective reporting (re- } \\
\text { porting bias) }\end{array}$ & High risk & $\begin{array}{l}\text { Comment: a pre-published protocol was not available and neither mortality } \\
\text { nor resolution of fatty liver was reported }\end{array}$ \\
\hline Other bias & Low risk & Comment: no other bias noted \\
\hline
\end{tabular}

Wong 2013

\section{Study characteristics}

\begin{tabular}{ll}
\hline Methods & Randomised clinical trial \\
\hline Participants & Country: Hong Kong \\
& Period of recruitment: not stated \\
Number randomised: 154 \\
Post-randomisation dropouts: 0 (0.0\%) \\
Revised sample size: 154 \\
Average age (years): 51 \\
Female: 82 (53.2\%) \\
NASH: not stated \\
Diabetes mellitus: 12 (7.8\%) \\
Inclusion criteria: Age 18 - 70 years; fatty liver on H-MRS plus ALT above 30 in men and 19 in women \\
Exclusion criteria: Hepatitis B/C; alcohol consumption above 20 g per day in men and $10 \mathrm{~g}$ per day in \\
women; liver decompensation; terminal illness and cancer (including hepatocellular carcinoma) \\
Group 1: Dietary advice plus aerobic exercise ( $n=77$ ) \\
Further details: The participants attended dietary consultation sessions weekly in the first 4 months, \\
and monthly in the following 8 months. Each participant was given an individualised menu plan. The \\
\hline Interventions
\end{tabular}


Wong 2013 (Continued)

dietary component and portion sizes of the menu plan were based on the recommendations of the American Dietetic Association. A varied balanced diet with an emphasis on fruit and vegetables, and moderate-carbohydrate, low-fat, low-glycaemic index and low calorific products in appropriate portions was encouraged. The diet resulted in a relative increase in energy consumption from proteins, which also promoted satiety. moderate-intensity aerobic exercise for $30 \mathrm{mins}, 3$ to 5 days a week Group 2: No active intervention $(n=77)$

Further details: control: participants were encouraged to reduce carbohydrate and fat intake, and to exercise for at least 3 times a week, 30 mins per session

Outcomes

Outcomes reported: mortality at maximum follow-up, liver transplantation at maximum follow-up, decompensation (number of people), cirrhosis (number of people), resolution of fatty liver disease Follow-up (months): 12

Notes

Source of funding (quote): "This study was supported in part by the Nutritional Research Foundation of the United Kingdom, the direct grant of the Chinese University of Hong Kong (ref 2011.1.025) and a grant from the Research Grants Council of the Hong Kong SAR (Project No. SEG CUHK_02)."

Trial name/trial registry number: NCT00868933

We tried to contact the authors in December 2020

\section{Risk of bias}

\begin{tabular}{|c|c|c|}
\hline Bias & Authors' judgement & Support for judgement \\
\hline $\begin{array}{l}\text { Random sequence genera- } \\
\text { tion (selection bias) }\end{array}$ & Low risk & Quote: "computer-generated list of random numbers" \\
\hline $\begin{array}{l}\text { Allocation concealment } \\
\text { (selection bias) }\end{array}$ & Low risk & $\begin{array}{l}\text { Quote: "Treatment assignments were concealed in consecutively-numbered } \\
\text { sealed envelopes, which were opened sequentially upon patient enrolment" }\end{array}$ \\
\hline $\begin{array}{l}\text { Blinding of participants } \\
\text { and personnel (perfor- } \\
\text { mance bias) } \\
\text { All outcomes }\end{array}$ & High risk & $\begin{array}{l}\text { Comment: because of the nature of the intervention, it was not possible to } \\
\text { blind the participants }\end{array}$ \\
\hline $\begin{array}{l}\text { Blinding of outcome as- } \\
\text { sessment (detection bias) } \\
\text { All outcomes }\end{array}$ & Low risk & $\begin{array}{l}\text { Quote: "Clinicians and radiographers who analyzed } 1 \mathrm{H}-\mathrm{MRS} \text { results were blind- } \\
\text { ed to the treatment assignment" }\end{array}$ \\
\hline $\begin{array}{l}\text { Incomplete outcome data } \\
\text { (attrition bias) } \\
\text { All outcomes }\end{array}$ & Low risk & Comment: there were no post-randomisation dropouts \\
\hline $\begin{array}{l}\text { Selective reporting (re- } \\
\text { porting bias) }\end{array}$ & High risk & $\begin{array}{l}\text { Comment: a pre-published protocol was not available and adverse events } \\
\text { were not reported }\end{array}$ \\
\hline Other bias & Low risk & Comment: no other bias noted \\
\hline
\end{tabular}

Yao 2018

\section{Study characteristics}

\begin{tabular}{ll}
\hline Methods & Randomised clinical trial \\
\hline Participants & Country: China \\
& Period of recruitment: not stated \\
& Number randomised: 103 \\
& Post-randomisation dropouts: $12(11.7 \%)$ \\
\hline
\end{tabular}


Yao 2018 (Continued)

Revised sample size: 91

Reasons for post-randomisation dropouts: Group 1: 4 dropped out (2 did not have enough time to participate, 2 refused to answer the phone); 1 lack of compliance; Group 2: 1 lived far away (and dropped out), 1 had fracture from wrestling; 1 lack of compliance; group 3: 1 withdrew, 3 lost to follow-up

Average age (years): 58

Female: 55 (60.4\%)

NASH: not stated

Diabetes mellitus: not stated

Inclusion criteria: consistent with 2010 edition of guidelines for the diagnosis and treatment of NAFLD; grade 5 muscle strength; without regular exercise; aged between 18 and 75 years; conscious and able to communicate

Exclusion criteria: a variety of acute and chronic infections, cancer, and other immune diseases; serious acute and chronic diseases, such as acute cerebral infarction, lumbar disc herniation; proliferative retinopathy; pregnant or lactating women; long-term drinking history defined as a long history of alcohol consumption for more than 5 years, which was equivalent to male alcohol > $140 \mathrm{~g} /$ weeks, female > $70 \mathrm{~g} /$ weeks; had no history of viral and autoimmune hepatitis, and drug-induced liver diseases

Interventions

Group 1: Resistance exercise $(n=31)$

Further details: Resistance training consists of 3 phases: warm-up ( 5 mins joint movement), training (50 mins), and relaxing (5 mins). Participants performed the training from 3 series of 8 repetitions at intensity of $30 \%-40 \%$ of 1 repetition maximum (1RM) for 40 mins per day in the early stage of the exercise (within 2 weeks), gradually moving to 3 series of 10 repetitions at intensity of $60 \%-70 \% 1$ RM for 60 mins per day, with 1 minute of recovery between series. The exercise was performed 3 times per week on non-consecutive days for 22 weeks. The load gradually increased depending on the individual ability of the participant and with consultation of professional personnel. Participants were considered to have finished the study if they attended 66 times or more in 22 weeks. All participants came to centres, and carried out the exercise under the guidance of professional personnel

Group 2: Aerobic exercise $(n=29)$

Further details: aerobic exercise consisted of 3 phases: warming-up ( 5 mins), training ( 50 mins) and relaxing (5 mins). Aerobic exercise progressed from 40 mins per day at $45 \%$ - 55\% maximum heart rate intensity in the initial stage of training (within 2 weeks), and gradually increased to 60 mins per day at $60 \%-70 \%$ maximum heart rate intensity. Exercise was performed 3 times per week on non-consecutive days for 22 weeks. Participants who attended 66 times or more in 22 weeks were considered to have finished the study

Group 3: no active intervention ( $n=31$ )

Further details: Control group

\section{Outcomes}

Outcomes reported: serious adverse events (number of people), any adverse events (number of people)

Follow-up (months): 5.5

Notes

Source of funding (quote): "Funded by National Natural Scientific Foundation of China (81370923) and State Administration of Traditional Chinese Medicine (JDZX2015132)."

Trial name/trial registry number: not stated

We tried to contact the authors in December 2020

\section{Risk of bias}

\begin{tabular}{lll}
\hline Bias & Authors' judgement & Support for judgement \\
\hline $\begin{array}{l}\text { Random sequence genera- } \\
\text { tion (selection bias) }\end{array}$ & Unclear risk & Comment: this information was not available \\
\hline $\begin{array}{l}\text { Allocation concealment } \\
\text { (selection bias) }\end{array}$ & Unclear risk & $\begin{array}{l}\text { Quote: "Patients were randomly divided into three groups including aerobic, } \\
\text { resistance and control group by sealed envelopes" } \\
\text { Comment: further details were not available }\end{array}$ \\
\hline
\end{tabular}


Yao 2018 (Continued)

Blinding of participants High risk Comment: because of the nature of the intervention, it was not possible to and personnel (perforblind the participants

mance bias)

All outcomes
Unclear risk

Comment: this information was not available

sessment (detection bias)

All outcomes

Incomplete outcome data High risk (attrition bias)

All outcomes
Comment: there were post-randomisation dropouts; some were related to the intervention and outcomes

\begin{tabular}{|c|c|c|}
\hline $\begin{array}{l}\text { Selective reporting (re- } \\
\text { porting bias) }\end{array}$ & High risk & $\begin{array}{l}\text { Comment: a pre-published protocol was not available and neither mortality } \\
\text { nor resolution of fatty liver was reported }\end{array}$ \\
\hline
\end{tabular}

Other bias Low risk Comment: no other bias noted

Zade 2016

\section{Study characteristics}

\begin{tabular}{|c|c|}
\hline Methods & Randomised clinical trial \\
\hline \multirow[t]{11}{*}{ Participants } & Country: Iran \\
\hline & Period of recruitment: not stated \\
\hline & Number randomised: 60 \\
\hline & Post-randomisation dropouts: $0(0.0 \%)$ \\
\hline & Revised sample size: 60 \\
\hline & Average age (years): 41 \\
\hline & Female: $30(50.0 \%)$ \\
\hline & NASH: not stated \\
\hline & Diabetes mellitus: not stated \\
\hline & Inclusion criteria: Age 25 - 75; ultrasound-diagnosed NAFLD \\
\hline & $\begin{array}{l}\text { Exclusion criteria: Alcohol consumption; pregnancy and lactation; hereditary haemochromatosis; je- } \\
\text { junoileal bypass surgery or gastroplasty; hepatotoxic drugs (e.g.calcium channel blockers); hypothy- } \\
\text { roidism; Cushing's syndrome; renal failure; kidney stones }\end{array}$ \\
\hline \multirow[t]{7}{*}{ Interventions } & Group 1: FatRestrict Calorie-restricted diet $(n=30)$ \\
\hline & Further details: a DASH eating plan that consisted of $52-55 \%$ carbohydrates, $16-18 \%$ proteins and \\
\hline & $30 \%$ total fats. The DASH diet was rich in fruits, vegetables, whole grains, and low-fat dairy products \\
\hline & and low in saturated fats, cholesterol, refined grains, and sweets. Suggested sodium in the DASH diet \\
\hline & was $<2400 \mathrm{mg} /$ day. both diets were designed to be calorie-restricted \\
\hline & Group 2: Calorie-restricted diet $(n=30)$ \\
\hline & $\begin{array}{l}\text { Further details: The control diet was also designed to contain } 52-55 \% \text { carbohydrates, } 16-18 \% \text { pro- } \\
\text { tein and } 30 \% \text { total fats. Both diets were designed to be calorie-restricted }\end{array}$ \\
\hline Outcomes & None of the outcomes of interest were reported \\
\hline \multirow[t]{3}{*}{ Notes } & $\begin{array}{l}\text { Source of funding (quote): "This study was founded by a grant from the Vicechancellor for Research, } \\
\text { KUMS, and Iran." }\end{array}$ \\
\hline & Trial name/trial registry number: IRCT201311215623N14 \\
\hline & We tried to contact the authors in December 2020 \\
\hline
\end{tabular}

\section{Risk of bias}


Zade 2016 (Continued)
Bias
Authors' judgement Support for judgement

Random sequence genera- Low risk tion (selection bias)

\begin{tabular}{lll}
\hline $\begin{array}{l}\text { Allocation concealment } \\
\text { (selection bias) }\end{array}$ & Low risk & Quote: "Randomization and allocation were done by a trained nutritionist" \\
\hline $\begin{array}{l}\text { Blinding of participants } \\
\begin{array}{l}\text { and personnel (perfor- } \\
\text { mance bias) }\end{array}\end{array}$ & Low risk & $\begin{array}{l}\text { Quote: "Randomization and allocation were done by a trained nutritionist and } \\
\text { were concealed from the researcher and patients until the main analyses were } \\
\text { completed" }\end{array}$ \\
\hline $\begin{array}{l}\text { Blinding of outcome as- } \\
\text { sessment (detection bias) } \\
\text { All outcomes }\end{array}$ & Low risk & $\begin{array}{l}\text { Quote: "Randomization and allocation were done by a trained nutritionist and } \\
\text { were concealed from the researcher and patients until the main analyses were } \\
\text { completed" }\end{array}$ \\
\hline
\end{tabular}

Quote: "Random assignment was performed using computer-generated random numbers"

Incomplete outcome data Low risk Comment: intention-to-treat analysis was performed
(attrition bias)

All outcomes

\begin{tabular}{|c|c|c|}
\hline $\begin{array}{l}\text { Selective reporting (re- } \\
\text { porting bias) }\end{array}$ & Low risk & $\begin{array}{l}\text { Comment: a pre-published protocol was not available and neither mortality } \\
\text { nor resolution of fatty liver was reported }\end{array}$ \\
\hline
\end{tabular}

Selective reporting (re- Low risk

Other bias Low risk Comment: no other bias noted

Zelber-Sagi 2014

\section{Study characteristics}

\begin{tabular}{ll}
\hline Methods & Randomised clinical trial \\
\hline Participants & Country: Israel \\
& Period of recruitment: not stated \\
& Number randomised: 82 \\
& Post-randomisation dropouts: 18 (22.0\%) \\
& Revised sample size: 64 \\
& Reasons for post-randomisation dropouts: Lost to follow up (6); withdrew from study (4); $>3 \mathrm{~kg}$ weight \\
& change (5); adverse events: knee pain (1), shoulder pain (1), back pain (1); \\
& Average age (years): 46 \\
& Female: 30 (46.9\%) \\
& NASH: not stated \\
& Diabetes mellitus: 0 (0.0\%) \\
Inclusion criteria: Age 20 - 65 years; ultrasound-proven fatty liver \\
Exclusion criteria: Known secondary liver disease (including hepatitis B/C); excessive alcohol consump- \\
tion (defined as $\geq 30$ g/day in men or $\geq 20$ g/day in women); medication that may elevate ALT or lead \\
to hepatic steatosis; diabetes; major chronic diseases (e.g. renal, cardiovascular, lung); uncontrolled \\
hypertension; inflammatory bowel disease; active cancer; autoimmune disorders; orthopaedic con- \\
traindications for resistance training; patients regularly performing resistance training
\end{tabular}

Interventions

Group 1: Resistance exercise $(n=33)$

Further details: The RT programme was according to the ACSM 2009 position paper on "Progression Models in Resistance Training for Healthy Adults". Exercises included: leg press, leg extension, leg curl, seated chest press, seated rowing, latissimus pull down, biceps curl and shoulder press with 8 - 12 repetitions, 3 sets for each exercise with $1-2$ mins rest between sets, for a total duration of about 40 mins Group 2: Aerobic exercise $(n=31)$ 
Zelber-Sagi 2014 (Continued)

Further details: 8 stretching exercises for the major muscle/tendon groups using the static stretching technique. The participants performed 4 repetitions of these static stretches each lasting 20 secs. Each session was performed on 3 non-consecutive days a week

\begin{tabular}{ll}
\hline Outcomes & None of the outcomes of interest were reported \\
\hline Notes & Source of funding: not stated \\
& Trial name/trial registry number: NCT01264198 \\
& We tried to contact the authors in December 2020
\end{tabular}

\section{Risk of bias}

\begin{tabular}{lll}
\hline Bias & Authors' judgement & Support for judgement \\
\hline $\begin{array}{l}\text { Random sequence genera- } \\
\text { tion (selection bias) }\end{array}$ & Unclear risk & Comment: this information was not available \\
\hline $\begin{array}{l}\text { Allocation concealment } \\
\text { (selection bias) }\end{array}$ & Unclear risk & Quote: "sealed envelopes randomization stratified by gender" \\
& & Comment: further details were not available \\
\hline $\begin{array}{l}\text { Blinding of participants } \\
\text { and personnel (perfor- } \\
\text { mance bias) }\end{array}$ & High risk & $\begin{array}{l}\text { Comment: because of the nature of the intervention, it is not possible to blind } \\
\text { the participants }\end{array}$ \\
\hline
\end{tabular}

Blinding of outcome as- Unclear risk Comment: this information was not available

sessment (detection bias)

All outcomes

\begin{tabular}{lll}
\hline $\begin{array}{l}\text { Incomplete outcome data } \\
\text { (attrition bias) } \\
\text { All outcomes }\end{array}$ & High risk & $\begin{array}{l}\text { Comment: there were post-randomisation drop-outs; some were related to the } \\
\text { intervention and outcomes }\end{array}$ \\
\hline $\begin{array}{l}\text { Selective reporting (re- } \\
\text { porting bias) }\end{array}$ & High risk & $\begin{array}{l}\text { Comment: a pre-published protocol was not available and neither mortality } \\
\text { nor resolution of fatty liver was reported }\end{array}$ \\
\hline Other bias & Low risk & Comment: no other bias noted \\
\hline
\end{tabular}

Zhang 2016

\section{Study characteristics}

\begin{tabular}{ll}
\hline Methods & Randomised clinical trial \\
\hline Participants & Country: China \\
& Period of recruitment: not stated \\
& Number randomised: 220 \\
& Post-randomisation dropouts: $0(0.0 \%)$ \\
& Revised sample size: 220 \\
& Average age (years): 54 \\
& Female: 149 (67.7\%) \\
& NASH: not stated \\
& Diabetes mellitus: $0(0.0 \%)$ \\
& Inclusion criteria: Age $40-65$ years; central obesity (waist circumference $\geq 90 \mathrm{~cm}$ in men and $\geq 85 \mathrm{~cm}$ in \\
& women); NAFLD
\end{tabular}


Exclusion criteria: Acute or chronic viral hepatitis; drug-induced liver diseases, or autoimmune hepatitis; diabetes; uncontrolled hypertension; chronic kidney disease; hyperthyroidism; myocardial infarction within 6 months, or heart failure (NYHA class III or IV); participating in weight loss programmes; medical condition-limiting exercise capability; alcohol excess, consuming more than a mean of $140 \mathrm{~g}$ of ethanol (10 alcoholic drinks) per week in men and $70 \mathrm{~g}$ of ethanol ( 5 drinks) in women, during the past 6 months

Group 1: Aerobic exercise $(n=146)$
Further details: vigorous-moderate exercise group were instructed to participate in a 6-month vigor-
ous exercise programme followed by a 6-month moderate exercise programme. Vigorous exercise was
jogging on treadmill for 30 mins, 5 sessions a week. Moderate exercise was brisk walking, 120 steps/
minute, 30 min/session, 5 sessions a week. or moderate exercise programme were instructed to partic-
ipate in a 12-month moderate exercise programme. Moderate exercise was brisk walking, 120 steps/
minute, 30 min/session, 5 sessions a week
Group 2: No active intervention ( $n=74)$
Further details: control group

\begin{tabular}{ll}
\hline Outcomes & Outcomes reported: mortality at maximal follow-up \\
& Follow-up (months): 12 \\
\hline Notes & Source of funding (quote): "This study was supported by grant 3502Z20100001 from the First Affiliated \\
& Hospital of Xiamen University and Xiamen Systems Biology Research Program for Metabolic Disease." \\
& Trial name/trial registry number: NCT01418027 \\
& We tried to contact the authors in December 2020
\end{tabular}

\section{Risk of bias}

\begin{tabular}{lll}
\hline Bias & Authors' judgement & Support for judgement \\
\hline $\begin{array}{l}\text { Random sequence genera- } \\
\text { tion (selection bias) }\end{array}$ & Low risk & $\begin{array}{l}\text { Quote: "The randomization schedules were generated using SAS PROC PLAN } \\
\text { in SAS statistical software (SAS Institute Inc) and concealed until an eligible } \\
\text { participant was ready for enrolment" }\end{array}$ \\
\hline $\begin{array}{l}\text { Allocation concealment } \\
\text { (selection bias) }\end{array}$ & Unclear risk & $\begin{array}{l}\text { Quote: "The randomization schedules were generated using SAS PROC PLAN } \\
\text { in SAS statistical software (SAS Institute Inc) and concealed until an eligible } \\
\text { participant was ready for enrolment" } \\
\text { Comment: further details were not available }\end{array}$ \\
\hline
\end{tabular}

\begin{tabular}{|c|c|c|}
\hline $\begin{array}{l}\text { Blinding of participants } \\
\text { and personnel (perfor- } \\
\text { mance bias) }\end{array}$ & High risk & $\begin{array}{l}\text { Comment: because of the nature of the intervention, it was not possible to } \\
\text { blind the participants }\end{array}$ \\
\hline
\end{tabular}

mance bias)

All outcomes

\begin{tabular}{|c|c|c|}
\hline $\begin{array}{l}\text { Blinding of outcome as- } \\
\text { sessment (detection bias) }\end{array}$ & Low risk & $\begin{array}{l}\text { Quote: "study staff who collected data on study outcomes were unaware of } \\
\text { study group assignments" }\end{array}$ \\
\hline
\end{tabular}

All outcomes

Incomplete outcome data Low risk Comment: there were no post-randomisation dropouts
(attrition bias)

All outcomes

\begin{tabular}{|c|c|c|}
\hline $\begin{array}{l}\text { Selective reporting (re- } \\
\text { porting bias) }\end{array}$ & High risk & $\begin{array}{l}\text { Comment: a pre-published protocol was not available and adverse events } \\
\text { were not reported }\end{array}$ \\
\hline
\end{tabular}

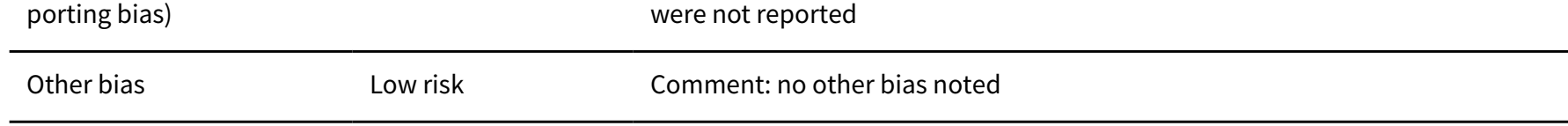

ALT: alanine transaminase; AST: aspartate transaminase; BMI: body mass index; CLD: chronic liver disease; CMV: cytomegalovirus; CVD: cardiovascular disease: EBV: Epstein-Barr virus; GI: gastrointestinal; HRR: heart rate ratio; HTN: hypertension; H-MRS (or 1H-MRS or 
MRS): magnetic resonance spectroscopy; IFG: impaired fasting glycaemia; MUFA: mono-unsaturated fatty acid: NASH: nonalcoholic steatohepatitis; PUFA: poly-unsaturated fatty acid; RCP: respiratory compensation point; T1DM, T2DM: type 1, type 2 diabetes mellitus; US: ultrasound; VAT: ventilatory anaerobic threshold; $y / o$ : years old

Characteristics of excluded studies [ordered by study ID]

\begin{tabular}{|c|c|}
\hline Study & Reason for exclusion \\
\hline Aller 2014 & Comparison of variations in low-calorie diets \\
\hline An 2015 & Comparison of variations in dietary advice \\
\hline Arefhosseini 2011 & Comparison of variations in low-calorie diets \\
\hline Austin 2020 & Comparison of variations in lifestyle advice \\
\hline Baldry 2017 & Comparison of variations in low-calorie diets \\
\hline Dela Cruz 2012 & Comparison of lifestyle intervention with pharmacological intervention or nutritional supplement \\
\hline Dorosti 2020 & Comparison of variations in dietary advice \\
\hline Dynnyk 2017 & Comparison of variations in dietary advice \\
\hline Haidari 2020 & Comparison of variations in low-calorie diets \\
\hline Lim 2020 & Intervention not related to this review \\
\hline Marin-Alejandre 2021 & Comparison of variations in low-calorie diets \\
\hline Nath 2020 & Comparison of variations in aerobic exercise \\
\hline NCT04193982 & Comparison of lifestyle intervention with nutritional and pharmacological intervention \\
\hline NCT04383951 & Comparison of variations in dietary advice \\
\hline NCT04520724 & Comparison of variations in low-calorie diets \\
\hline Negri 2020 & Comparison of variations in low-calorie diets \\
\hline Nigam 2014 & $\begin{array}{l}\text { All groups contained a mixture of PUFA and MUFA. The proportion of PUFA and MUFA differed be- } \\
\text { tween the groups (i.e. comparison of variations in intervention) }\end{array}$ \\
\hline Nobili 2008 & Intervention effects of nutritional supplementation were studied \\
\hline Promrat 2010 & Comparison of variations in dietary advice plus exercise advice \\
\hline Rezaei 2019 & $\begin{array}{l}\text { All groups contained a mixture of PUFA and MUFA. The proportion of PUFA and MUFA differed be- } \\
\text { tween the groups (i.e. comparison of variations in intervention) }\end{array}$ \\
\hline Ristic-Medic 2020 & Comparison of variations in low-calorie diets \\
\hline Ryan 2013 & $\begin{array}{l}\text { In this cross-over trial, the cross-over was at } 6 \text { weeks of intervention and the outcomes were not re- } \\
\text { ported before the cross-over; this study is therefore not designed to address the objectives of this } \\
\text { review and does not provide information to meet the objectives of this review }\end{array}$ \\
\hline Schweinlin 2018 & Comparison of variations in high-protein, low-carbohydrate diet \\
\hline
\end{tabular}




\begin{tabular}{ll}
\hline Study & Reason for exclusion \\
\hline Simons 2021 & Comparison of variations in low-carbohydrate diet \\
\hline St George 2009 & Comparison of variations in exercise advice \\
\hline Sun 2012 & Comparison of variations in dietary advice \\
\hline TCTR20200411004 & Intervention not related to this review \\
\hline Vilar Gomez 2009 & $\begin{array}{l}\text { Intervention effects of nutritional supplementation was studied (i.e. not an intervention of interest } \\
\text { for this review) }\end{array}$ \\
\hline Whyte 2020 & Included participants with suspected NAFLD rather than those diagnosed with NAFLD \\
\hline
\end{tabular}

Characteristics of studies awaiting classification [ordered by study ID]

Bahrololumi 2014

\begin{tabular}{ll}
\hline Methods & Randomised clinical trial \\
\hline Participants & People with fatty liver \\
\hline Interventions & Olive oil versus other oil \\
\hline Outcomes & None of the outcomes of interest were reported in the abstract \\
\hline Notes & $\begin{array}{l}\text { Awaiting full text to confirm the composition of 'other oil' was different from that of olive oil (i.e. } \\
\text { whether these were simply variations of lifestyle modification) and whether any outcomes of inter- } \\
\text { est are reported in this trial }\end{array}$ \\
\hline
\end{tabular}

Grove 2020

\begin{tabular}{ll}
\hline Methods & Randomised clinical trial \\
\hline Participants & People with fatty liver \\
\hline Interventions & Dietary intervention versus not clear \\
\hline Outcomes & None of the outcomes of interest were reported in the abstract \\
\hline Notes & $\begin{array}{l}\text { Awaiting full publication to confirm what the control group was and whether the trial will be eligi- } \\
\text { ble for the review }\end{array}$ \\
\hline
\end{tabular}

Jia 2018

\begin{tabular}{ll}
\hline Methods & Possible randomised clinical trial \\
\hline Participants & People with fatty liver \\
\hline
\end{tabular}


Jia 2018 (Continued)

Interventions
Aerobic exercise plus dietary advice versus resistance exercise plus dietary advice versus dietary advice alone

None of the outcomes of interest were reported in the abstract

Awaiting full text to confirm whether this is a randomised clinical trial and whether any outcomes of interest are reported in this trial

Characteristics of ongoing studies [ordered by study ID]

IRCT20100524004010N31

\begin{tabular}{ll}
\hline Study name & IRCT20100524004010N31 \\
\hline Methods & Randomised clinical trial \\
\hline Participants & People with NASH \\
\hline Interventions & Hypocaloric diet (2 versions) versus no active intervention \\
\hline Outcomes & None of the outcomes of interest for this review will be measured in this trial \\
\hline Starting date & 2020 \\
\hline Contact information & Azita Hekmatdoost (hekmat@sina.tums.ac.ir) \\
\hline Notes & \\
\hline
\end{tabular}

NCT03354247

\begin{tabular}{ll}
\hline Study name & NCT03354247 \\
\hline Methods & Randomised clinical trial \\
\hline Participants & People with fatty liver \\
\hline Interventions & $\begin{array}{l}\text { Mediterranean diet plus dietary advice plus exercise advice versus dietary advice plus exercise ad- } \\
\text { vice }\end{array}$ \\
\hline Outcomes & The only outcome of interest for this review in this trial is resolution of fatty liver \\
\hline Starting date & 2017 \\
\hline Contact information & Piero Portincasa (NCT03354247, piero.portincasa@uniba.it) \\
\hline Notes & \\
\hline
\end{tabular}

Study name NCT03354247


NCT03518294 (Continued)

\begin{tabular}{ll} 
Methods & Randomised clinical trial \\
\hline Participants & People with non-alcoholic steatohepatitis (NASH) \\
\hline Interventions & Supervised aerobic exercise versus no active intervention \\
\hline Outcomes & $\begin{array}{l}\text { The only outcomes of interest for this review in this trial are health-related quality of life and fibro- } \\
\text { sis }\end{array}$ \\
\hline Starting date & 2018 \\
\hline Contact information & Gloriany Rivas (NCT03518294, grivas@pennstatehealth.psu.edu) \\
\hline Notes & \\
\hline
\end{tabular}

\section{NCT04283942}

\begin{tabular}{ll}
\hline Study name & NCT04283942 \\
\hline Methods & Randomised clinical trial \\
\hline Participants & People with NAFLD \\
\hline Interventions & Hypocaloric diet versus no active intervention \\
\hline Outcomes & None of the outcomes of interest for this review will be assessed in this trial \\
\hline Starting date & 2020 \\
\hline Contact information & Hua Bian (NCT04283942, bianhuaer@126.com) \\
\hline Notes & \\
\hline
\end{tabular}

\begin{tabular}{ll} 
NCT04355910 & NCT04283942 \\
\hline Study name & Randomised clinical trial \\
\hline Participants & People with NAFLD \\
\hline Interventions & Hypocaloric diet versus no active intervention \\
\hline Outcomes & None of the outcomes of interest for this review will be assessed in this trial \\
\hline Starting date & 2020 \\
\hline Contact information & Peiwen Zhang (NCT04355910, 313743920@qq.com) \\
\hline Notes & \\
\hline
\end{tabular}


NCT04369521

\begin{tabular}{ll}
\hline Study name & NCT04440540 \\
\hline Methods & Randomised clinical trial \\
\hline Participants & People with NAFLD \\
\hline Interventions & $\begin{array}{l}\text { Calorie restricted diet plus dietary advice plus exercise advice versus dietary advice plus exer- } \\
\text { cise advice }\end{array}$ \\
\hline Outcomes & Liver fibrosis \\
\hline Starting date & 2020 \\
\hline Contact information & Azita Hekmatdoost (NCT04369521,a_hekmat2000@yahoo.com) \\
\hline Notes & \\
\hline
\end{tabular}

\section{NCT04440540}

\begin{tabular}{ll}
\hline Study name & NCT04440540 \\
\hline Methods & Randomised clinical trial \\
\hline Participants & People with NAFLD \\
\hline Interventions & Dietary advice versus no active intervention \\
\hline Outcomes & None of the outcomes of interest for this review will be assessed in this trial \\
\hline Starting date & 2020 \\
\hline Contact information & Winnie CW Chu (NCT04440540, winniechu@cuhk.edu.hk) \\
\hline
\end{tabular}

Notes

\section{ADDITIONAL TABLES}

Table 1. Summary of characteristics of included studies

\begin{tabular}{|c|c|}
\hline Variables & Summary \\
\hline Participant characteristics & $\begin{array}{l}\text { The mean or median age in the trials ranged from } 13 \text { to } 65 \text { years in the trials that reported this in- } \\
\text { formation (Wang 2008; De Luis 2010; Hallsworth 2011; Rodriguez-Hernandez 2011; Sullivan 2012; } \\
\text { Bacchi 2013; Eckard 2013; Hickman 2013; Ramon-Krauel 2013; Wong 2013; Kani 2014; Pugh 2014; } \\
\text { Zelber-Sagi 2014; Hallsworth 2015; Abd El-Kader 2016; Cuthbertson 2016; Dong 2016; Kaliora 2016; } \\
\text { Rezende 2016; Wang 2016; Zade 2016; Zhang 2016; Arab 2017; Axley 2017; Cheng 2017; Houghton } \\
\text { 2017; Monica Dinu 2017; Nikroo 2017; Oh 2017; Schattenberg 2017; Asghari 2018; Chan 2018; Kat- } \\
\text { sagoni 2018; Nishimori 2018; Properzi 2018; Shidfar 2018; Tutino 2018; Yao 2018; Abdelbasset 2019; } \\
\text { Johari 2019; Abdelbasset 2020; Chen 2020; Goss 2020; Moradi 2020; Nourian 2020; Abbate 2021). }\end{array}$ \\
\hline
\end{tabular}

Four trials included male participants only (Al-Jiffri 2013; Dong 2016; Nikroo 2017; Oh 2017). 
Table 1. Summary of characteristics of included studies (Continued)

Four trials included female participants only (Rodriguez-Hernandez 2011; Rezende 2016; Cheng 2017; Moradi 2020).

In the remaining trials that reported the number of female participants, the proportion ranged from 18.8\% to 86.4\% (Wang 2008; De Luis 2010; Sullivan 2012; Bacchi 2013; Eckard 2013; Hickman 2013; Ramon-Krauel 2013; Wong 2013; Kani 2014; Pugh 2014; Selezneva 2014; Zelber-Sagi 2014; Abd El-Kader 2016; Cuthbertson 2016; Kaliora 2016; Ramirez 2016; Wang 2016; Zade 2016; Zhang 2016; Arab 2017; Axley 2017; Misciagna 2017; Monica Dinu 2017; Schattenberg 2017; Asghari 2018; Chan 2018; Katsagoni 2018; Properzi 2018; Shidfar 2018; Tutino 2018; Yao 2018; Abdelbasset 2019; Johari 2019; Abdelbasset 2020; Chen 2020; Goss 2020; Nourian 2020; Abbate 2021).

Ten trials reported the proportion of participants who had NASH: eight trials included only participants with NASH (Wang 2008; Selezneva 2014; Sima 2014; Abd El-Kader 2016; Houghton 2017; Nikroo 2017; Schattenberg 2017; NCT01327443); in the remaining two trials, the proportion of participants who had NASH were 1.9\% (Chan 2018) and 68.8\% (Hickman 2013).

Twenty-eight trials reported the proportion of participants who had diabetes mellitus: in 13 trials, none of the participants had diabetes mellitus (De Luis 2010; Sullivan 2012; Hickman 2013; Ramon-Krauel 2013; Zelber-Sagi 2014; Cuthbertson 2016; Dong 2016; Zhang 2016; Cheng 2017; Misciagna 2017; Asghari 2018; Katsagoni 2018; Shidfar 2018); in six trials, all the participants had diabetes mellitus (Al-Jiffri 2013; Bacchi 2013; Roy 2017; Nishimori 2018; Abdelbasset 2019; Abdelbasset 2020); in the remaining nine trials, the proportion of participants who had diabetes mellitus ranged from 5.8\% to 77.5\% (Rodriguez-Hernandez 2011; Eckard 2013; Wong 2013; Rezende 2016; Axley 2017; Properzi 2018; Tutino 2018; Nourian 2020; Abbate 2021).

The diagnosis of NAFLD was made using biopsy (seven trials: Al-Jiffri 2013; Eckard 2013; Hickman 2013; Rezende 2016; Houghton 2017; Panganiban 2020; NCT01327443); ultrasound (10 trials: Zelber-Sagi 2014; Abd El-Kader 2016; Kaliora 2016; Misciagna 2017; Monica Dinu 2017; Nikroo 2017; Asghari 2018; Shidfar 2018; Abbate 2021; Moradi 2020); ultrasound and transaminases (10 trials: Wang 2008; Kani 2014; Dong 2016; Zade 2016; Arab 2017; Axley 2017; Oh 2017; Katsagoni 2018; Goss 2020; Nourian 2020); ultrasound and M30 (biomarker of liver damage) or biopsy (one trial: Schattenberg 2017); BMI and transaminases (one trial: De Luis 2010); magnetic resonance spectroscopy (seven trials: Sullivan 2012; Wong 2013; Cuthbertson 2016; Zhang 2016; Cheng 2017; Chan 2018; Properzi 2018); magnetic resonance spectroscopy and transaminases (one trial: Ramon-Krauel 2013); transaminases (two trials: Pugh 2014; Johari 2019); CT scan (one trial: Nishimori 2018); and clinical diagnosis (one trial: NCT03461562). The method of diagnosis of NAFLD was not stated in 18 trials (Hallsworth 2011; Rodriguez-Hernandez 2011; De Piano 2012; Bacchi 2013; Selezneva 2014; Sima 2014; Hallsworth 2015; Dynnyk 2016; Ramirez 2016; Wang 2016; Roy 2017; Tutino 2018; Yao 2018; Abdelbasset 2019; Abdelbasset 2020; Chen 2020; NCT02679417; NCT03183193).

Interventions compared

\section{Trials reporting outcomes}

The interventions compared in these 59 trials included: dietary advice, exercise advice, dietary advice plus exercise advice, aerobic exercise, resistance exercise, aerobic exercise plus resistance exercise, supervised aerobic exercise, supervised aerobic exercise plus resistance exercise, calorie-restricted diet, carbohydrate-restricted diet, fat-restricted diet, Mediterranean diet, fat- and calorie-restricted diet, carbohydrate- and calorie-restricted diet, isocaloric diet, low glycaemic index diet, Khorasan wheat diet, organic semi-wholegrain wheat diet, aerobic exercise plus dietary advice, aerobic exercise plus calorie-restricted diet, raisins plus dietary advice, Mediterranean diet plus dietary advice, Mediterranean diet plus dietary advice plus exercise advice, aerobic exercise plus carbohydrate-restricted diet, aerobic exercise plus fat-restricted diet, aerobic exercise plus calorieand fat-restricted diet, supervised aerobic exercise plus calorie-restricted diet, mono-unsaturated fatty acid plus calorie-restricted diet, Mediterranean diet plus exercise advice, Mediterranean diet plus supervised aerobic exercise, carbohydrate-restricted diet plus dietary advice plus exercise advice, calorie-restricted diet plus exercise advice, and no active intervention.

28 trials reported one or more outcomes for this review (Wang 2008; Al-Jiffri 2013; Bacchi 2013; Eckard 2013; Hickman 2013; Wong 2013; Abd El-Kader 2016; Dong 2016; Kaliora 2016; Rezende 2016; Zhang 2016; Axley 2017; Cheng 2017; Houghton 2017; Misciagna 2017; Monica Dinu 2017; Nikroo 2017; Oh 2017; Roy 2017; Schattenberg 2017; Chan 2018; Katsagoni 2018; Properzi 2018; Yao 2018; Abdelbasset 2019; Johari 2019; Moradi 2020; Nourian 2020).

\section{Follow-up} The follow-up period in the trials ranged from 1 to 24 months in the trials that reported this information. 
Table 1. Summary of characteristics of included studies (Continued)

In 28 trials, the follow-up was up to 3 months (Wang 2008; Hallsworth 2011; Kani 2014; Selezneva 2014; Sima 2014; Zelber-Sagi 2014; Hallsworth 2015; Abd El-Kader 2016; Cuthbertson 2016; Dynnyk 2016; Zade 2016; Arab 2017; Houghton 2017; Monica Dinu 2017; Nikroo 2017; Oh 2017; Schattenberg 2017; Nishimori 2018; Properzi 2018; Shidfar 2018; Tutino 2018; Abdelbasset 2019; Johari 2019; Abdelbasset 2020; Chen 2020; Goss 2020; Moradi 2020; Nourian 2020);

In 25 trials, the follow-up was between 3 months and 24 months (De Luis 2010; Rodriguez-Hernandez 2011; De Piano 2012; Sullivan 2012; Al-Jiffri 2013; Eckard 2013; Hickman 2013; Ramon-Krauel 2013; Wong 2013; Pugh 2014; Dong 2016; Kaliora 2016; Ramirez 2016; Rezende 2016; Wang 2016; Zhang 2016; Cheng 2017; Misciagna 2017; Roy 2017; Asghari 2018; Katsagoni 2018; Yao 2018; Panganiban 2020; Abbate 2021; NCT01327443);

In the remaining six trials, the follow-up period was not reported (Bacchi 2013; Axley 2017; Chan 2018; NCT02679417; NCT03183193; NCT03461562).

\section{Funding}

The source of funding for four trials was industrial organisations who would benefit from the results of the study (Axley 2017; Schattenberg 2017; Properzi 2018; Shidfar 2018); 39 trials were funded by neutral organisations who have no vested interests in the results of the study (Wang 2008; Hallsworth 2011; De Piano 2012; Sullivan 2012; Al-Jiffri 2013; Bacchi 2013; Eckard 2013; Hickman 2013; Ramon-Krauel 2013; Wong 2013; Kani 2014; Pugh 2014; Hallsworth 2015; Abd El-Kader 2016; Cuthbertson 2016; Dong 2016; Rezende 2016; Zade 2016; Zhang 2016; Arab 2017; Cheng 2017; Houghton 2017; Misciagna 2017; Monica Dinu 2017; Nikroo 2017; Oh 2017; Chan 2018; Katsagoni 2018; Tutino 2018; Yao 2018; Abdelbasset 2019; Johari 2019; Abbate 2021; Chen 2020; Goss 2020; Abdelbasset 2020; Nourian 2020; Moradi 2020; NCT03183193); The source of funding for the remaining 16 trials was unclear (De Luis 2010; Rodriguez-Hernandez 2011; Selezneva 2014; Sima 2014; Zelber-Sagi 2014; Dynnyk 2016; Kaliora 2016; Ramirez 2016; Wang 2016; Roy 2017; Asghari 2018; Nishimori 2018; Panganiban 2020; NCT01327443; NCT02679417; NCT03461562). 


\begin{tabular}{|c|c|c|c|c|c|c|c|}
\hline Study name & $\begin{array}{l}\text { Intervention } 1 \text { (number of participants) } \\
\text { versus intervention } 2 \text { (number of partici- } \\
\text { pants) }\end{array}$ & NASH only & $\begin{array}{l}\text { Diabetes melli- } \\
\text { tus }\end{array}$ & $\begin{array}{l}\text { Period of re- } \\
\text { cruitment }\end{array}$ & $\begin{array}{l}\text { Diagnosis of } \\
\text { fatty liver }\end{array}$ & $\begin{array}{l}\text { Follow-up in } \\
\text { months }\end{array}$ & $\begin{array}{l}\text { Overall risk } \\
\text { of bias }\end{array}$ \\
\hline $\begin{array}{l}\text { Abdelbasset } \\
2019\end{array}$ & $\begin{array}{l}\text { Aerobic exercise }(n=16) \text { versus no active in- } \\
\text { tervention }(n=16)\end{array}$ & Not stated & $\begin{array}{l}\text { All participants } \\
\text { had diabetes } \\
\text { mellitus }\end{array}$ & 2017 & Not stated & 1.84 & High \\
\hline $\begin{array}{l}\text { Abdelbasset } \\
2020\end{array}$ & $\begin{array}{l}\text { Aerobic exercise }(n=31) \text { versus no active in- } \\
\text { tervention }(n=16)\end{array}$ & Not stated & $\begin{array}{l}\text { All participants } \\
\text { had diabetes } \\
\text { mellitus }\end{array}$ & Not stated & Not stated & 1.84 & High \\
\hline $\begin{array}{l}\text { Hallsworth } \\
2015\end{array}$ & $\begin{array}{l}\text { Aerobic exercise }(n=12) \text { versus no active in- } \\
\text { tervention }(n=11)\end{array}$ & Not stated & Not stated & Not stated & Not stated & 3 & High \\
\hline NCT03461562 & $\begin{array}{l}\text { Aerobic exercise }(n=\text { not stated }) \text { versus no ac- } \\
\text { tive intervention }(n=\text { not stated })\end{array}$ & Not stated & Not stated & Not stated & $\begin{array}{l}\text { Clinical diag- } \\
\text { nosis }\end{array}$ & Not stated & High \\
\hline Sullivan 2012 & $\begin{array}{l}\text { Aerobic exercise }(n=12) \text { versus no active in- } \\
\text { tervention }(n=6)\end{array}$ & Not stated & $\begin{array}{l}\text { No participants } \\
\text { had diabetes } \\
\text { mellitus }\end{array}$ & Not stated & $\begin{array}{l}\text { Magnetic res- } \\
\text { onance spec- } \\
\text { troscopy }\end{array}$ & 4 & High \\
\hline Yao 2018 & $\begin{array}{l}\text { Aerobic exercise }(n=29) \text { versus no active in- } \\
\text { tervention }(n=31)\end{array}$ & Not stated & Not stated & Not stated & Not stated & 5.5 & High \\
\hline Zhang 2016 & $\begin{array}{l}\text { Aerobic exercise }(n=146) \text { versus no active in- } \\
\text { tervention }(n=74)\end{array}$ & Not stated & $\begin{array}{l}\text { No participants } \\
\text { had diabetes } \\
\text { mellitus }\end{array}$ & Not stated & $\begin{array}{l}\text { Magnetic res- } \\
\text { onance spec- } \\
\text { troscopy }\end{array}$ & 12 & High \\
\hline Asghari 2018 & $\begin{array}{l}\text { Calorie restricted diet }(n=30) \text { versus no ac- } \\
\text { tive intervention }(n=30)\end{array}$ & Not stated & $\begin{array}{l}\text { No participants } \\
\text { had diabetes } \\
\text { mellitus }\end{array}$ & Not stated & Ultrasound & 3 & High \\
\hline Cheng 2017 & $\begin{array}{l}\text { Calorie restricted diet }(n=22) \text { versus no ac- } \\
\text { tive intervention }(n=18)\end{array}$ & Not stated & $\begin{array}{l}\text { No participants } \\
\text { had diabetes } \\
\text { mellitus }\end{array}$ & Not stated & $\begin{array}{l}\text { Magnetic res- } \\
\text { onance spec- } \\
\text { troscopy }\end{array}$ & 8 & High \\
\hline Johari 2019 & $\begin{array}{l}\text { Calorie restricted diet }(n=33) \text { versus no ac- } \\
\text { tive intervention }(n=10)\end{array}$ & Not stated & $\begin{array}{l}\text { Participants with } \\
\text { and without dia- } \\
\text { betes mellitus }\end{array}$ & $2015-2016$ & $\begin{array}{l}\text { Transaminas- } \\
\text { es }\end{array}$ & 1.84 & High \\
\hline
\end{tabular}




\begin{tabular}{|c|c|c|c|c|c|c|c|}
\hline NCT01327443 & $\begin{array}{l}\text { Dietary advice }(n=\text { not stated }) \text { versus no ac- } \\
\text { tive intervention }(n=\text { not stated })\end{array}$ & $\begin{array}{l}\text { All partici- } \\
\text { pants had } \\
\text { NASH }\end{array}$ & Not stated & Not stated & Biopsy & 6 & High \\
\hline Nourian 2020 & $\begin{array}{l}\text { Dietary advice }(n=36) \text { versus no active inter- } \\
\text { vention }(n=33)\end{array}$ & Not stated & $\begin{array}{l}\text { Participants with } \\
\text { and without dia- } \\
\text { betes mellitus }\end{array}$ & $2017-2018$ & $\begin{array}{l}\text { Ultrasound } \\
\text { and transami- } \\
\text { nases }\end{array}$ & 2 & High \\
\hline $\begin{array}{l}\text { Schattenberg } \\
2017\end{array}$ & $\begin{array}{l}\text { Dietary advice }(n=15) \text { versus no active inter- } \\
\text { vention }(n=13)\end{array}$ & $\begin{array}{l}\text { All partici- } \\
\text { pants had } \\
\text { NASH }\end{array}$ & Not stated & Not stated & $\begin{array}{l}\text { Ultrasound } \\
\text { and increased } \\
\text { M30 (bio- } \\
\text { marker of se- } \\
\text { vere liver dis- } \\
\text { ease) }\end{array}$ & 3 & High \\
\hline Cheng 2017 & $\begin{array}{l}\text { Supervised aerobic exercise }(n=22) \text { versus no } \\
\text { active intervention }(n=18)\end{array}$ & Not stated & $\begin{array}{l}\text { No participants } \\
\text { had diabetes } \\
\text { mellitus }\end{array}$ & Not stated & $\begin{array}{l}\text { Magnetic res- } \\
\text { onance spec- } \\
\text { troscopy }\end{array}$ & 8 & High \\
\hline NCT01327443 & $\begin{array}{l}\text { Supervised aerobic exercise }(n=\text { not stated }) \\
\text { versus no active intervention }(n=\text { not stated })\end{array}$ & $\begin{array}{l}\text { All partici- } \\
\text { pants had } \\
\text { NASH }\end{array}$ & Not stated & Not stated & Biopsy & 6 & High \\
\hline $\begin{array}{l}\text { Rezende } \\
2016\end{array}$ & $\begin{array}{l}\text { Supervised aerobic exercise }(n=19) \text { versus no } \\
\text { active intervention }(n=21)\end{array}$ & Not stated & $\begin{array}{l}\text { Participants with } \\
\text { and without dia- } \\
\text { betes mellitus }\end{array}$ & Not stated & Biopsy & 6 & High \\
\hline Arab 2017 & $\begin{array}{l}\text { Dietary advice plus exercise advice }(n=41) \\
\text { versus no active intervention }(n=41)\end{array}$ & Not stated & Not stated & Not stated & $\begin{array}{l}\text { Ultrasound } \\
\text { and transami- } \\
\text { nases }\end{array}$ & 2 & High \\
\hline Axley 2017 & $\begin{array}{l}\text { Dietary advice plus exercise advice }(n=8) \text { ver- } \\
\text { sus no active intervention }(n=14)\end{array}$ & $\begin{array}{l}\text { Participants } \\
\text { with and with- } \\
\text { out NASH }\end{array}$ & $\begin{array}{l}\text { Participants with } \\
\text { and without dia- } \\
\text { betes mellitus }\end{array}$ & Not stated & $\begin{array}{l}\text { Ultrasound } \\
\text { and transami- } \\
\text { nases }\end{array}$ & 6 & High \\
\hline Chan 2018 & $\begin{array}{l}\text { Dietary advice plus exercise advice }(n=26) \\
\text { versus no active intervention }(n=26)\end{array}$ & $\begin{array}{l}\text { Participants } \\
\text { with and with- } \\
\text { out NASH }\end{array}$ & Not stated & Not stated & $\begin{array}{l}\text { Magnetic res- } \\
\text { onance spec- } \\
\text { troscopy }\end{array}$ & 16 & High \\
\hline Dong 2016 & $\begin{array}{l}\text { Dietary advice plus exercise advice }(n=132) \\
\text { versus no active intervention }(n=133)\end{array}$ & Not stated & $\begin{array}{l}\text { No participants } \\
\text { had diabetes } \\
\text { mellitus }\end{array}$ & Not stated & $\begin{array}{l}\text { Ultrasound } \\
\text { and transami- } \\
\text { nases }\end{array}$ & 24 & High \\
\hline
\end{tabular}




\begin{tabular}{|c|c|c|c|c|c|c|c|}
\hline Roy 2017 & $\begin{array}{l}\text { Dietary advice plus exercise advice }(n=30) \\
\text { versus no active intervention }(n=30)\end{array}$ & Not stated & $\begin{array}{l}\text { All participants } \\
\text { had diabetes } \\
\text { mellitus }\end{array}$ & Not stated & Not stated & 4 & High \\
\hline $\begin{array}{l}\text { Hallsworth } \\
2011\end{array}$ & $\begin{array}{l}\text { Resistance exercise }(n=11) \text { versus no active } \\
\text { intervention }(n=8)\end{array}$ & Not stated & Not stated & Not stated & Not stated & 2 & High \\
\hline Moradi 2020 & $\begin{array}{l}\text { Resistance exercise }(n=23) \text { versus no active } \\
\text { intervention }(n=22)\end{array}$ & Not stated & Not stated & Not stated & Ultrasound & 2.76 & High \\
\hline Yao 2018 & $\begin{array}{l}\text { Resistance exercise }(n=31) \text { versus no active } \\
\text { intervention }(n=31)\end{array}$ & Not stated & Not stated & Not stated & Not stated & 5.5 & High \\
\hline $\begin{array}{l}\text { Misciagna } \\
2017\end{array}$ & $\begin{array}{l}\text { Mediterranean diet }(n=50) \text { versus no active } \\
\text { intervention }(n=48)\end{array}$ & Not stated & $\begin{array}{l}\text { No participants } \\
\text { had diabetes } \\
\text { mellitus }\end{array}$ & Not stated & Ultrasound & 6 & Low \\
\hline NCT03183193 & $\begin{array}{l}\text { Mediterranean diet ( } n=\text { not stated) versus no } \\
\text { active intervention ( } n=\text { not stated) }\end{array}$ & Not stated & Not stated & Not stated & Not stated & not stated & High \\
\hline Tutino 2018 & $\begin{array}{l}\text { Mediterranean diet }(n=18) \text { versus no active } \\
\text { intervention }(n=15)\end{array}$ & Not stated & $\begin{array}{l}\text { Participants with } \\
\text { and without dia- } \\
\text { betes mellitus }\end{array}$ & Not stated & Not stated & 1.5 & High \\
\hline Tutino 2018 & $\begin{array}{l}\text { Aerobic exercise plus resistance exercise }(n= \\
29) \text { versus no active intervention }(n=15)\end{array}$ & Not stated & $\begin{array}{l}\text { Participants with } \\
\text { and without dia- } \\
\text { betes mellitus }\end{array}$ & Not stated & Not stated & 1.5 & High \\
\hline $\begin{array}{l}\text { Abd El-Kader } \\
2016\end{array}$ & $\begin{array}{l}\text { Aerobic exercise plus calorie restricted diet ( } \\
=50) \text { versus no active intervention }(n=50)\end{array}$ & $\begin{array}{l}\text { All partici- } \\
\text { pants had } \\
\text { NASH }\end{array}$ & Not stated & Not stated & Ultrasound & 3 & High \\
\hline Cheng 2017 & $\begin{array}{l}\text { Supervised aerobic exercise plus calorie re- } \\
\text { stricted diet }(n=23) \text { versus no active inter- } \\
\text { vention }(n=18)\end{array}$ & Not stated & $\begin{array}{l}\text { No participants } \\
\text { had diabetes } \\
\text { mellitus }\end{array}$ & Not stated & $\begin{array}{l}\text { Magnetic res- } \\
\text { onance spec- } \\
\text { troscopy }\end{array}$ & 8 & High \\
\hline Wong 2013 & $\begin{array}{l}\text { Aerobic exercise plus dietary advice }(n=77) \\
\text { versus no active intervention }(n=77)\end{array}$ & Not stated & $\begin{array}{l}\text { Participants with } \\
\text { and without dia- } \\
\text { betes mellitus }\end{array}$ & Not stated & $\begin{array}{l}\text { Magnetic res- } \\
\text { onance spec- } \\
\text { troscopy }\end{array}$ & 12 & High \\
\hline $\begin{array}{l}\text { Houghton } \\
2017\end{array}$ & $\begin{array}{l}\text { Supervised aerobic exercise plus resistance } \\
\text { exercise }(n=12) \text { versus no active intervention } \\
(n=12)\end{array}$ & $\begin{array}{l}\text { All partici- } \\
\text { pants had } \\
\text { NASH }\end{array}$ & Not stated & Not stated & Biopsy & 3 & High \\
\hline
\end{tabular}




\begin{tabular}{|c|c|c|c|c|c|c|c|}
\hline Wang 2008 & $\begin{array}{l}\text { Aerobic exercise plus calorie and fat restrict- } \\
\text { ed diet }(n=19) \text { versus no active intervention } \\
(n=38)\end{array}$ & $\begin{array}{l}\text { All partici- } \\
\text { pants had } \\
\text { NASH }\end{array}$ & Not stated & Not stated & $\begin{array}{l}\text { Ultrasound } \\
\text { plus ALT }>=1.5 \\
\text { times normal }\end{array}$ & 1 & High \\
\hline $\begin{array}{l}\text { Hickman } \\
2013\end{array}$ & $\begin{array}{l}\text { Calorie restricted diet }(n=8) \text { versus aerobic } \\
\text { exercise }(n=13)\end{array}$ & $\begin{array}{l}\text { Participants } \\
\text { with and with- } \\
\text { out NASH }\end{array}$ & $\begin{array}{l}\text { No participants } \\
\text { had diabetes } \\
\text { mellitus }\end{array}$ & Not stated & Biopsy & 6 & High \\
\hline Eckard 2013 & $\begin{array}{l}\text { Dietary advice }(n=11) \text { versus aerobic exercise } \\
(n=9)\end{array}$ & $\begin{array}{l}\text { Participants } \\
\text { with and with- } \\
\text { out NASH }\end{array}$ & $\begin{array}{l}\text { Participants with } \\
\text { and without dia- } \\
\text { betes mellitus }\end{array}$ & Not stated & Biopsy & 6 & High \\
\hline Bacchi 2013 & $\begin{array}{l}\text { Resistance exercise }(n=17) \text { versus aerobic ex- } \\
\text { ercise }(n=13)\end{array}$ & $\begin{array}{l}\text { Participants } \\
\text { with and with- } \\
\text { out NASH }\end{array}$ & $\begin{array}{l}\text { All participants } \\
\text { had diabetes } \\
\text { mellitus }\end{array}$ & Not stated & Unclear & 4 & High \\
\hline Oh 2017 & $\begin{array}{l}\text { Resistance exercise }(n=19) \text { versus aerobic ex- } \\
\text { ercise }(n=33)\end{array}$ & Not stated & Not stated & Not stated & $\begin{array}{l}\text { Ultrasound } \\
\text { and transami- } \\
\text { nases }\end{array}$ & 3 & High \\
\hline Yao 2018 & $\begin{array}{l}\text { Resistance exercise }(n=31) \text { versus aerobic ex- } \\
\text { ercise }(n=29)\end{array}$ & Not stated & Not stated & Not stated & Not stated & 5.5 & High \\
\hline $\begin{array}{l}\text { Zelber-Sagi } \\
2014\end{array}$ & $\begin{array}{l}\text { Resistance exercise }(n=33) \text { versus aerobic ex- } \\
\text { ercise }(n=31)\end{array}$ & Not stated & $\begin{array}{l}\text { No participants } \\
\text { had diabetes } \\
\text { mellitus }\end{array}$ & Not stated & Ultrasound & 3 & High \\
\hline $\begin{array}{l}\text { De Piano } \\
2012\end{array}$ & $\begin{array}{l}\text { Aerobic exercise plus resistance exercise }(n \\
=\text { not stated) versus aerobic exercise }(n=\text { not } \\
\text { stated) }\end{array}$ & Not stated & Not stated & Not stated & Not stated & 12 & High \\
\hline NCT02679417 & $\begin{array}{l}\text { Aerobic exercise plus resistance exercise }(\mathrm{n} \\
=\text { not stated) versus aerobic exercise }(\mathrm{n}=\text { not } \\
\text { stated) }\end{array}$ & Not stated & Not stated & Not stated & Not stated & not stated & High \\
\hline Eckard 2013 & $\begin{array}{l}\text { Aerobic exercise plus carbohydrate restricted } \\
\text { diet }(n=9) \text { versus aerobic exercise }(n=9)\end{array}$ & $\begin{array}{l}\text { Participants } \\
\text { with and with- } \\
\text { out NASH }\end{array}$ & $\begin{array}{l}\text { Participants with } \\
\text { and without dia- } \\
\text { betes mellitus }\end{array}$ & Not stated & Biopsy & 6 & High \\
\hline Eckard 2013 & $\begin{array}{l}\text { Aerobic exercise plus fat restricted diet }(n= \\
\text { 12) versus aerobic exercise }(n=9)\end{array}$ & $\begin{array}{l}\text { Participants } \\
\text { with and with- } \\
\text { out NASH }\end{array}$ & $\begin{array}{l}\text { Participants with } \\
\text { and without dia- } \\
\text { betes mellitus }\end{array}$ & Not stated & Biopsy & 6 & High \\
\hline
\end{tabular}




\begin{tabular}{|c|c|c|c|c|c|c|c|}
\hline $\begin{array}{l}\text { Cuthbertson } \\
2016\end{array}$ & $\begin{array}{l}\text { Exercise advice }(n=20) \text { versus aerobic exer- } \\
\text { cise }(n=30)\end{array}$ & Not stated & $\begin{array}{l}\text { No participants } \\
\text { had diabetes } \\
\text { mellitus }\end{array}$ & Not stated & $\begin{array}{l}\text { Magnetic res- } \\
\text { onance spec- } \\
\text { troscopy }\end{array}$ & 4 & High \\
\hline Dynnyk 2016 & $\begin{array}{l}\text { Exercise advice }(n=\text { not stated) versus aerobic } \\
\text { exercise }(n=\text { not stated })\end{array}$ & Not stated & $\begin{array}{l}\text { Participants with } \\
\text { and without dia- } \\
\text { betes mellitus }\end{array}$ & Not stated & Not stated & 2.76 & High \\
\hline Cheng 2017 & $\begin{array}{l}\text { Supervised aerobic exercise }(n=22) \text { versus } \\
\text { calorie restricted diet }(n=22)\end{array}$ & Not stated & $\begin{array}{l}\text { No participants } \\
\text { had diabetes } \\
\text { mellitus }\end{array}$ & Not stated & $\begin{array}{l}\text { Magnetic res- } \\
\text { onance spec- } \\
\text { troscopy }\end{array}$ & 8 & High \\
\hline $\begin{array}{l}\text { Nishimori } \\
2018\end{array}$ & $\begin{array}{l}\text { Carbohydrate restricted diet }(n=14) \text { versus } \\
\text { calorie restricted diet }(n=14)\end{array}$ & Not stated & $\begin{array}{l}\text { All participants } \\
\text { had diabetes } \\
\text { mellitus }\end{array}$ & Not stated & CT scan & 3 & High \\
\hline $\begin{array}{l}\text { Panganiban } \\
2020\end{array}$ & $\begin{array}{l}\text { Carbohydrate restricted diet }(n=19) \text { versus } \\
\text { calorie restricted diet }(n=20)\end{array}$ & Not stated & Not stated & Not stated & Biopsy & 6 & High \\
\hline Ramirez 2016 & $\begin{array}{l}\text { Carbohydrate restricted diet }(n=\text { not stated }) \\
\text { versus calorie restricted diet }(n=\text { not stated })\end{array}$ & Not stated & Not stated & Not stated & Not stated & 6 & High \\
\hline Al-Jiffri 2013 & $\begin{array}{l}\text { Aerobic exercise plus calorie restricted diet ( } \\
=50) \text { versus calorie restricted diet }(n=50)\end{array}$ & $\begin{array}{l}\text { Participants } \\
\text { with and with- } \\
\text { out NASH }\end{array}$ & $\begin{array}{l}\text { All participants } \\
\text { had diabetes } \\
\text { mellitus }\end{array}$ & Not stated & Biopsy & 3 & High \\
\hline Sima 2014 & $\begin{array}{l}\text { Aerobic exercise plus calorie restricted diet ( } \\
=12 \text { ) versus calorie restricted diet }(n=13)\end{array}$ & $\begin{array}{l}\text { All partici- } \\
\text { pants had } \\
\text { NASH }\end{array}$ & Not stated & Not stated & Not stated & 3 & High \\
\hline Wang 2016 & $\begin{array}{l}\text { Aerobic exercise plus calorie restricted diet ( } n \\
=80) \text { versus calorie restricted diet }(n=40)\end{array}$ & Not stated & Not stated & 2014-2015 & Not stated & 5.54 & High \\
\hline Cheng 2017 & $\begin{array}{l}\text { Supervised aerobic exercise plus calorie re- } \\
\text { stricted diet }(n=23) \text { versus calorie restricted } \\
\text { diet }(n=22)\end{array}$ & Not stated & $\begin{array}{l}\text { No participants } \\
\text { had diabetes } \\
\text { mellitus }\end{array}$ & Not stated & $\begin{array}{l}\text { Magnetic res- } \\
\text { onance spec- } \\
\text { troscopy }\end{array}$ & 8 & High \\
\hline Kani 2014 & $\begin{array}{l}\text { Carbohydrate and calorie restricted diet }(n= \\
\text { 12) versus calorie restricted diet }(n=13)\end{array}$ & Not stated & Not stated & Not stated & Not stated & 1.84 & High \\
\hline $\begin{array}{l}\text { Selezneva } \\
2014\end{array}$ & $\begin{array}{l}\text { Isocalorie diet }(n=116) \text { versus calorie restrict- } \\
\text { ed diet }(n=58)\end{array}$ & $\begin{array}{l}\text { All partici- } \\
\text { pants had } \\
\text { NASH }\end{array}$ & Not stated & Not stated & Not stated & 1 & High \\
\hline
\end{tabular}




\begin{tabular}{|c|c|c|c|c|c|c|c|}
\hline Shidfar 2018 & $\begin{array}{l}\text { Mono unsaturated fatty acid plus calorie re- } \\
\text { stricted diet }(n=21) \text { versus calorie restricted } \\
\text { diet }(n=22)\end{array}$ & Not stated & $\begin{array}{l}\text { No participants } \\
\text { had diabetes } \\
\text { mellitus }\end{array}$ & Not stated & Ultrasound & 2.76 & High \\
\hline Zade 2016 & $\begin{array}{l}\text { Fat and calorie restricted diet }(n=30) \text { versus } \\
\text { calorie restricted diet }(n=30)\end{array}$ & Not stated & Not stated & Not stated & $\begin{array}{l}\text { Ultrasound } \\
\text { and increased } \\
\text { levels of } \\
\text { serum ALT }\end{array}$ & 2 & High \\
\hline NCT01327443 & $\begin{array}{l}\text { Supervised aerobic exercise }(n=\text { not stated }) \\
\text { versus dietary advice }(n=\text { not stated })\end{array}$ & $\begin{array}{l}\text { All partici- } \\
\text { pants had } \\
\text { NASH }\end{array}$ & Not stated & Not stated & Biopsy & 6 & High \\
\hline Nikroo 2017 & $\begin{array}{l}\text { Supervised aerobic exercise }(n=12) \text { versus di- } \\
\text { etary advice }(n=11)\end{array}$ & $\begin{array}{l}\text { All partici- } \\
\text { pants had } \\
\text { NASH }\end{array}$ & Not stated & $2010-2011$ & Ultrasound & 1.84 & High \\
\hline Eckard 2013 & $\begin{array}{l}\text { Aerobic exercise plus carbohydrate restricted } \\
\text { diet }(n=9) \text { versus dietary advice }(n=11)\end{array}$ & $\begin{array}{l}\text { Participants } \\
\text { with and with- } \\
\text { out NASH }\end{array}$ & $\begin{array}{l}\text { Participants with } \\
\text { and without dia- } \\
\text { betes mellitus }\end{array}$ & Not stated & Biopsy & 6 & High \\
\hline Eckard 2013 & $\begin{array}{l}\text { Aerobic exercise plus fat restricted diet }(n= \\
\text { 12) versus dietary advice }(n=11)\end{array}$ & $\begin{array}{l}\text { Participants } \\
\text { with and with- } \\
\text { out NASH }\end{array}$ & $\begin{array}{l}\text { Participants with } \\
\text { and without dia- } \\
\text { betes mellitus }\end{array}$ & Not stated & Biopsy & 6 & High \\
\hline $\begin{array}{l}\text { Katsagoni } \\
2018\end{array}$ & $\begin{array}{l}\text { Mediterranean diet plus dietary advice }(n= \\
21) \text { versus dietary advice }(n=21)\end{array}$ & Not stated & $\begin{array}{l}\text { No participants } \\
\text { had diabetes } \\
\text { mellitus }\end{array}$ & Not stated & $\begin{array}{l}\text { Ultrasound } \\
\text { plus raised } \\
\text { ALT or biopsy }\end{array}$ & 6 & High \\
\hline $\begin{array}{l}\text { Katsagoni } \\
2018\end{array}$ & $\begin{array}{l}\text { Mediterranean diet plus dietary advice plus } \\
\text { exercise advice }(n=21) \text { versus dietary advice } \\
(n=21)\end{array}$ & Not stated & $\begin{array}{l}\text { No participants } \\
\text { had diabetes } \\
\text { mellitus }\end{array}$ & Not stated & $\begin{array}{l}\text { Ultrasound } \\
\text { plus raised } \\
\text { ALT or biopsy }\end{array}$ & 6 & High \\
\hline Kaliora 2016 & $\begin{array}{l}\text { Raisins plus dietary advice }(n=23) \text { versus di- } \\
\text { etary advice }(n=21)\end{array}$ & Not stated & Not stated & Not stated & Ultrasound & 6 & High \\
\hline Cheng 2017 & $\begin{array}{l}\text { Supervised aerobic exercise plus calorie re- } \\
\text { stricted diet }(n=23) \text { versus supervised aero- } \\
\text { bic exercise }(n=22)\end{array}$ & Not stated & $\begin{array}{l}\text { No participants } \\
\text { had diabetes } \\
\text { mellitus }\end{array}$ & Not stated & $\begin{array}{l}\text { Magnetic res- } \\
\text { onance spec- } \\
\text { troscopy }\end{array}$ & 8 & High \\
\hline Pugh 2014 & $\begin{array}{l}\text { Supervised aerobic exercise }(n=13) \text { versus di- } \\
\text { etary advice plus exercise advice }(n=8)\end{array}$ & Not stated & Not stated & Not stated & $\begin{array}{l}\text { Raised } \\
\text { transaminas- } \\
\text { es }\end{array}$ & 3.68 & High \\
\hline
\end{tabular}




\begin{tabular}{|c|c|c|c|c|c|c|c|}
\hline Chen 2020 & $\begin{array}{l}\text { Carbohydrate restricted diet plus dietary ad- } \\
\text { vice plus exercise advice }(n=22) \text { versus di- } \\
\text { etary advice plus exercise advice }(n=22)\end{array}$ & Not stated & Not stated & $2015-2017$ & Not stated & 2 & High \\
\hline De Luis 2010 & $\begin{array}{l}\text { Fat restricted diet }(n=15) \text { versus carbohy- } \\
\text { drate restricted diet }(n=13)\end{array}$ & Not stated & $\begin{array}{l}\text { No participants } \\
\text { had diabetes } \\
\text { mellitus }\end{array}$ & Not stated & $\begin{array}{l}\mathrm{BMI}>=30 \text { and } \\
\mathrm{ALT}>=43 \mathrm{UI} / \mathrm{L}\end{array}$ & 3 & High \\
\hline $\begin{array}{l}\text { Ro- } \\
\text { driguez-Her- } \\
\text { nandez } 2011\end{array}$ & $\begin{array}{l}\text { Fat restricted diet }(n=26) \text { versus carbohy- } \\
\text { drate restricted diet }(n=28)\end{array}$ & Not stated & $\begin{array}{l}\text { Participants with } \\
\text { and without dia- } \\
\text { betes mellitus }\end{array}$ & Not stated & Not stated & 6 & High \\
\hline Goss 2020 & $\begin{array}{l}\text { Carbohydrate restricted diet }(n=16) \text { versus } \\
\text { fat restricted diet }(n=16)\end{array}$ & Not stated & Not stated & $2016-2017$ & $\begin{array}{l}\text { Ultrasound } \\
\text { and transami- } \\
\text { nases }\end{array}$ & 1.84 & High \\
\hline $\begin{array}{l}\text { Properzi } \\
2018\end{array}$ & $\begin{array}{l}\text { Mediterranean diet }(n=24) \text { versus fat restrict- } \\
\text { ed diet }(n=24)\end{array}$ & $\begin{array}{l}\text { Participants } \\
\text { with and with- } \\
\text { out NASH }\end{array}$ & Not stated & Not stated & $\begin{array}{l}\text { Magnetic res- } \\
\text { onance spec- } \\
\text { troscopy }\end{array}$ & 3 & High \\
\hline $\begin{array}{l}\text { Ra- } \\
\text { mon-Krauel } \\
2013\end{array}$ & $\begin{array}{l}\text { Low glycaemic index diet }(n=7) \text { versus fat re- } \\
\text { stricted diet }(n=9)\end{array}$ & Not stated & $\begin{array}{l}\text { No participants } \\
\text { had diabetes } \\
\text { mellitus }\end{array}$ & Not stated & $\begin{array}{l}\text { Magnetic res- } \\
\text { onance spec- } \\
\text { troscopy plus } \\
\text { raised ALT }\end{array}$ & 6 & High \\
\hline Tutino 2018 & $\begin{array}{l}\text { Aerobic exercise plus resistance exercise }(n= \\
\text { 29) versus Mediterranean diet }(n=18)\end{array}$ & Not stated & $\begin{array}{l}\text { Participants with } \\
\text { and without dia- } \\
\text { betes mellitus }\end{array}$ & Not stated & Not stated & 1.5 & High \\
\hline Eckard 2013 & $\begin{array}{l}\text { Aerobic exercise plus fat restricted diet }(n= \\
12) \text { versus aerobic exercise plus carbohydrate } \\
\text { restricted diet }(n=9)\end{array}$ & $\begin{array}{l}\text { Participants } \\
\text { with and with- } \\
\text { out NASH }\end{array}$ & $\begin{array}{l}\text { Participants with } \\
\text { and without dia- } \\
\text { betes mellitus }\end{array}$ & Not stated & Biopsy & 6 & High \\
\hline Abbate 2021 & $\begin{array}{l}\text { Mediterranean diet plus exercise advice }(n= \\
\text { 43) versus calorie restricted diet plus exercise } \\
\text { advice }(n=42)\end{array}$ & Not stated & $\begin{array}{l}\text { Participants with } \\
\text { and without dia- } \\
\text { betes mellitus }\end{array}$ & $2018-2020$ & Ultrasound & 6 & High \\
\hline Abbate 2021 & $\begin{array}{l}\text { Mediterranean diet plus supervised aerobic } \\
\text { exercise }(n=43) \text { versus calorie restricted diet } \\
\text { plus exercise advice }(n=42)\end{array}$ & Not stated & $\begin{array}{l}\text { Participants with } \\
\text { and without dia- } \\
\text { betes mellitus }\end{array}$ & $2018-2020$ & Ultrasound & 6 & High \\
\hline
\end{tabular}




\begin{tabular}{|c|c|c|c|c|c|c|c|}
\hline Abbate 2021 & $\begin{array}{l}\text { Mediterranean diet plus supervised aerobic } \\
\text { exercise }(n=43) \text { versus Mediterranean diet } \\
\text { plus exercise advice }(n=43)\end{array}$ & Not stated & $\begin{array}{l}\text { Participants with } \\
\text { and without dia- } \\
\text { betes mellitus }\end{array}$ & $2018-2020$ & Ultrasound & 6 & High \\
\hline $\begin{array}{l}\text { Katsagoni } \\
2018\end{array}$ & $\begin{array}{l}\text { Mediterranean diet plus dietary advice plus } \\
\text { exercise advice }(n=21) \text { versus Mediterranean } \\
\text { diet plus dietary advice }(n=21)\end{array}$ & Not stated & $\begin{array}{l}\text { No participants } \\
\text { had diabetes } \\
\text { mellitus }\end{array}$ & Not stated & $\begin{array}{l}\text { Ultrasound } \\
\text { plus raised } \\
\text { ALT or biopsy }\end{array}$ & 6 & High \\
\hline $\begin{array}{l}\text { Monica Dinu } \\
2017\end{array}$ & $\begin{array}{l}\text { Organic semi-wholegrain wheat diet }(n=20) \\
\text { versus Khorasan wheat diet }(n=20)\end{array}$ & Not stated & Not stated & Not stated & Ultrasound & 3 & Low \\
\hline
\end{tabular}


Table 3. Summary of risk of bias

Domain Classification

\section{Allocation (selection bias)}

29 trials were at low risk of selection bias due to lack of random sequence generation (Sullivan 2012; Eckard 2013; Hickman 2013; Wong 2013; Kani 2014; Pugh 2014; Hallsworth 2015; Abd El-Kader 2016; Cuthbertson 2016; Dong 2016; Kaliora 2016; Rezende 2016; Zade 2016; Zhang 2016; Arab 2017; Axley 2017; Cheng 2017; Misciagna 2017; Monica Dinu 2017; Oh 2017; Asghari 2018; Chan 2018; Katsagoni 2018; Tutino 2018; Johari 2019; Chen 2020; Goss 2020; Nourian 2020; Abbate 2021); the remaining 30 trials, which did not provide sufficient information, were at unclear risk of sequence generation bias (Wang 2008; De Luis 2010; Hallsworth 2011; Rodriguez-Hernandez 2011; De Piano 2012; Al-Jiffri 2013; Bacchi 2013; Ramon-Krauel 2013; Selezneva 2014; Sima 2014; Zelber-Sagi 2014; Dynnyk 2016; Wang 2016; Ramirez 2016; Houghton 2017; Nikroo 2017; Roy 2017; Schattenberg 2017; Nishimori 2018; Properzi 2018; Shidfar 2018; Yao 2018; Abdelbasset 2019; Abdelbasset 2020; Moradi 2020; Panganiban 2020; NCT01327443; NCT02679417; NCT03183193; NCT03461562).

Seventeen trials were at low risk of selection bias due to lack of allocation concealment (Sullivan 2012; Eckard 2013; Hickman 2013; Wong 2013; Kani 2014; Abd El-Kader 2016; Kaliora 2016; Zade 2016; Axley 2017; Cheng 2017; Misciagna 2017; Monica Dinu 2017; Oh 2017; Abdelbasset 2020; Moradi 2020; Nourian 2020; Abbate 2021); the remaining 42 trials, which did not provide sufficient information, were at unclear risk of allocation concealment bias (Wang 2008; De Luis 2010; Hallsworth 2011; Rodriguez-Hernandez 2011; De Piano 2012; Al-Jiffri 2013; Bacchi 2013; Ramon-Krauel 2013; Pugh 2014; Selezneva 2014; Sima 2014; Zelber-Sagi 2014; Hallsworth 2015; Cuthbertson 2016; Dong 2016; Dynnyk 2016; Ramirez 2016; Rezende 2016; Wang 2016; Zhang 2016; Arab 2017; Houghton 2017; Nikroo 2017; Roy 2017; Schattenberg 2017; Asghari 2018; Chan 2018; Katsagoni 2018; Nishimori 2018; Properzi 2018; Shidfar 2018; Tutino 2018; Yao 2018; Abdelbasset 2019; Johari 2019; Chen 2020; Goss 2020; Panganiban 2020; NCT01327443; NCT02679417; NCT03183193; NCT03461562).

\section{Blinding (performance bias and detection bias)}

Three trials were at low risk of performance bias as the participants and healthcare providers were blinded (Zade 2016; Misciagna 2017; Monica Dinu 2017); eight trials, which did not provide sufficient information, were at unclear risk of performance bias (De Luis 2010; Rodriguez-Hernandez 2011; De Piano 2012; Dynnyk 2016; Wang 2016; Shidfar 2018; Panganiban 2020; NCT03461562); the remaining 48 trials were at high risk of performance bias (Wang 2008; Hallsworth 2011; Sullivan 2012; Al-Jiffri 2013; Bacchi 2013; Eckard 2013; Hickman 2013; Ramon-Krauel 2013; Wong 2013; Kani 2014; Pugh 2014; Selezneva 2014; Sima 2014; Zelber-Sagi 2014; Hallsworth 2015; Abd El-Kader 2016; Cuthbertson 2016; Dong 2016; Kaliora 2016; Ramirez 2016; Rezende 2016; Zhang 2016; Arab 2017; Axley 2017; Cheng 2017; Houghton 2017; Nikroo 2017; Oh 2017; Roy 2017; Schattenberg 2017; Asghari 2018; Chan 2018; Katsagoni 2018; Nishimori 2018; Properzi 2018; Tutino 2018; Yao 2018; Abdelbasset 2019; Johari 2019; Abdelbasset 2020; Chen 2020; Goss 2020; Moradi 2020; Nourian 2020; Abbate 2021; NCT01327443; NCT02679417; NCT03183193).

Seventeen trials were at low risk of detection bias (De Luis 2010; Bacchi 2013; Eckard 2013; Wong 2013; Kani 2014; Abd El-Kader 2016; Kaliora 2016; Zade 2016; Zhang 2016; Axley 2017; Cheng 2017; Misciagna 2017; Monica Dinu 2017; Chan 2018; Tutino 2018; NCT02679417; NCT03461562); 35 trials, which did not provide sufficient information, were at unclear risk of detection bias (Wang 2008; Hallsworth 2011; Rodriguez-Hernandez 2011; De Piano 2012; Sullivan 2012; Al-Jiffri 2013; Ramon-Krauel 2013; Pugh 2014; Selezneva 2014; Sima 2014; Zelber-Sagi 2014; Hallsworth 2015; Cuthbertson 2016; Dong 2016; Dynnyk 2016; Ramirez 2016; Rezende 2016; Wang 2016; Arab 2017; Houghton 2017; Oh 2017; Roy 2017; Asghari 2018; Katsagoni 2018; Nishimori 2018; Shidfar 2018; Yao 2018; Abdelbasset 2019; Johari 2019; Abdelbasset 2020; Chen 2020; Moradi 2020; Nourian 2020; Panganiban 2020; Abbate 2021); the remaining seven trials were at high risk of detection bias (Hickman 2013; Nikroo 2017; Schattenberg 2017; Properzi 2018; Goss 2020; NCT01327443; NCT03183193).

\section{Incomplete outcome data (attrition bias)}

Fourteen trials were at low risk of attrition bias as there were no post-randomisation dropouts or an intention-to-treat analysis was used (De Luis 2010; Al-Jiffri 2013; Wong 2013; Kani 2014; Zade 2016; Zhang 2016; Misciagna 2017; Monica Dinu 2017; Asghari 2018; Chan 2018; Katsagoni 2018; Abdelbasset 2019; Johari 2019; Moradi 2020);

28 trials were at unclear risk of incomplete outcome data bias (Wang 2008; Rodriguez-Hernandez 2011; De Piano 2012; Eckard 2013; Ramon-Krauel 2013; Selezneva 2014; Sima 2014; Abd El-Kad- 
Table 3. Summary of risk of bias (Continued)

er 2016; Dynnyk 2016; Ramirez 2016; Wang 2016; Axley 2017; Nikroo 2017; Roy 2017; Schattenberg 2017; Nishimori 2018; Tutino 2018; Shidfar 2018; Abdelbasset 2020; Chen 2020; Goss 2020; Nourian 2020; Panganiban 2020; Abbate 2021; NCT01327443; NCT02679417; NCT03183193; NCT03461562), because it was not clear whether there were post-randomisation dropouts or whether the post-randomisation dropouts were related to the outcomes (if there were post-randomisation dropouts); the remaining 17 trials were at high risk of attrition bias (Hallsworth 2011; Sullivan 2012; Bacchi 2013; Hickman 2013; Pugh 2014; Zelber-Sagi 2014; Hallsworth 2015; Cuthbertson 2016; Dong 2016; Kaliora 2016; Rezende 2016; Arab 2017; Cheng 2017; Houghton 2017; Oh 2017; Properzi 2018; Yao 2018), as the post-randomisation dropouts were probably related to the outcomes.

Selective reporting (reporting bias)
Eight trials were at low risk of selective outcome reporting bias (Al-Jiffri 2013; Hickman 2013; Abd El-Kader 2016; Axley 2017; Misciagna 2017; Monica Dinu 2017; Schattenberg 2017; Properzi 2018), as the important clinical outcomes expected to be reported in such trials were reported; the remaining 51 trials were at high risk of selective outcome reporting bias (Wang 2008; De Luis 2010; Hallsworth 2011; Rodriguez-Hernandez 2011; De Piano 2012; Sullivan 2012; Bacchi 2013; Eckard 2013; Ramon-Krauel 2013; Wong 2013; Kani 2014; Pugh 2014; Selezneva 2014; Sima 2014; Zelber-Sagi 2014; Hallsworth 2015; Cuthbertson 2016; Dong 2016; Dynnyk 2016; Kaliora 2016; Ramirez 2016; Rezende 2016; Zade 2016; Zhang 2016; Wang 2016; Arab 2017; Cheng 2017; Houghton 2017; Nikroo 2017; Oh 2017; Roy 2017; Asghari 2018; Chan 2018; Katsagoni 2018; Nishimori 2018; Shidfar 2018; Tutino 2018; Yao 2018; Abdelbasset 2019; Johari 2019; Abdelbasset 2020; Chen 2020; Goss 2020; Moradi 2020; Nourian 2020; Panganiban 2020; Abbate 2021; NCT01327443; NCT02679417; NCT03183193; NCT03461562), as a protocol published prior to recruitment was not available and clinically relevant and reasonably expected outcomes were not reported. 


\begin{tabular}{|c|c|c|c|c|c|c|c|c|c|}
\hline $\begin{array}{l}\text { Study } \\
\text { name }\end{array}$ & $\begin{array}{l}\text { Intervention } 1 \text { (number of participants) } \\
\text { versus intervention } 2 \text { (number of partici- } \\
\text { pants) }\end{array}$ & $\begin{array}{l}\text { Sequence } \\
\text { genera- } \\
\text { tion }\end{array}$ & $\begin{array}{l}\text { Allocation } \\
\text { conceal- } \\
\text { ment }\end{array}$ & $\begin{array}{l}\text { Blinding } \\
\text { of partici- } \\
\text { pants and } \\
\text { health- } \\
\text { care } \\
\text { providers }\end{array}$ & $\begin{array}{l}\text { Blinding } \\
\text { of out- } \\
\text { come as- } \\
\text { sessors }\end{array}$ & $\begin{array}{l}\text { Missing } \\
\text { outcome } \\
\text { bias }\end{array}$ & $\begin{array}{l}\text { Selective } \\
\text { outcome } \\
\text { reporting }\end{array}$ & $\begin{array}{l}\text { Other } \\
\text { bias }\end{array}$ & $\begin{array}{l}\text { Overall } \\
\text { risk of } \\
\text { bias }\end{array}$ \\
\hline $\begin{array}{l}\text { Abdelbas- } \\
\text { set } 2019\end{array}$ & $\begin{array}{l}\text { Aerobic exercise }(n=16) \text { versus no active in- } \\
\text { tervention }(n=16)\end{array}$ & Unclear & Unclear & High & Unclear & Low & High & Low & High \\
\hline $\begin{array}{l}\text { Abdelbas- } \\
\text { set } 2020\end{array}$ & $\begin{array}{l}\text { Aerobic exercise }(n=31) \text { versus no active in- } \\
\text { tervention }(n=16)\end{array}$ & Unclear & Low & High & Unclear & Unclear & High & Low & High \\
\hline $\begin{array}{l}\text { Hallsworth } \\
2015\end{array}$ & $\begin{array}{l}\text { Aerobic exercise }(n=12) \text { versus no active in- } \\
\text { tervention }(n=11)\end{array}$ & Low & Unclear & High & Unclear & High & High & Low & High \\
\hline \multicolumn{2}{|c|}{$\begin{aligned} \text { NCT03461562Aerobic exercise }(n & =\text { not stated) versus no ac- } \\
\text { tive intervention }(n=\text { not stated }) & \end{aligned}$} & Unclear & Unclear & Unclear & Low & Unclear & High & Low & High \\
\hline $\begin{array}{l}\text { Sullivan } \\
2012\end{array}$ & $\begin{array}{l}\text { Aerobic exercise }(n=12) \text { versus no active in- } \\
\text { tervention }(n=6)\end{array}$ & Low & Low & High & Unclear & High & High & Low & High \\
\hline Yao 2018 & $\begin{array}{l}\text { Aerobic exercise }(n=29) \text { versus no active in- } \\
\text { tervention }(n=31)\end{array}$ & Unclear & Unclear & High & Unclear & High & High & Low & High \\
\hline $\begin{array}{l}\text { Zhang } \\
2016\end{array}$ & $\begin{array}{l}\text { Aerobic exercise }(n=146) \text { versus no active in- } \\
\text { tervention }(n=74)\end{array}$ & Low & Unclear & High & Low & Low & High & Low & High \\
\hline $\begin{array}{l}\text { Asghari } \\
2018\end{array}$ & $\begin{array}{l}\text { Calorie restricted diet }(n=30) \text { versus no ac- } \\
\text { tive intervention }(n=30)\end{array}$ & Low & Unclear & High & Unclear & Low & High & Low & High \\
\hline $\begin{array}{l}\text { Cheng } \\
2017\end{array}$ & $\begin{array}{l}\text { Calorie restricted diet }(n=22) \text { versus no ac- } \\
\text { tive intervention }(n=18)\end{array}$ & Low & Low & High & Low & High & High & Low & High \\
\hline $\begin{array}{l}\text { Johari } \\
2019\end{array}$ & $\begin{array}{l}\text { Calorie restricted diet }(n=33) \text { versus no ac- } \\
\text { tive intervention }(n=10)\end{array}$ & Low & Unclear & High & Unclear & Low & High & Low & High \\
\hline NCT0132744 & $\begin{array}{l}\text { 3Dietary advice }(n=\text { not stated }) \text { versus no ac- } \\
\text { tive intervention }(n=\text { not stated) }\end{array}$ & Unclear & Unclear & High & High & Unclear & High & Low & High \\
\hline $\begin{array}{l}\text { Nourian } \\
2020\end{array}$ & $\begin{array}{l}\text { Dietary advice }(n=36) \text { versus no active inter- } \\
\text { vention }(n=33)\end{array}$ & Low & Low & High & Unclear & Unclear & High & Low & High \\
\hline
\end{tabular}




\begin{tabular}{|c|c|c|c|c|c|c|c|c|c|}
\hline $\begin{array}{l}\text { Schatten- } \\
\text { berg } 2017\end{array}$ & $\begin{array}{l}\text { Dietary advice }(n=15) \text { versus no active inter- } \\
\text { vention }(n=13)\end{array}$ & Unclear & Unclear & High & High & Unclear & Low & Low & High \\
\hline $\begin{array}{l}\text { Cheng } \\
2017\end{array}$ & $\begin{array}{l}\text { Supervised aerobic exercise }(n=22) \text { versus no } \\
\text { active intervention }(n=18)\end{array}$ & Low & Low & High & Low & High & High & Low & High \\
\hline NCT0132744 & $\begin{array}{l}3 \text { SSupervised aerobic exercise }(\mathrm{n}=\text { not stated }) \\
\text { versus no active intervention }(\mathrm{n}=\text { not stated })\end{array}$ & Unclear & Unclear & High & High & Unclear & High & Low & High \\
\hline $\begin{array}{l}\text { Rezende } \\
2016\end{array}$ & $\begin{array}{l}\text { Supervised aerobic exercise }(n=19) \text { versus no } \\
\text { active intervention }(n=21)\end{array}$ & Low & Unclear & High & Unclear & High & High & Low & High \\
\hline Arab 2017 & $\begin{array}{l}\text { Dietary advice plus exercise advice }(n=41) \\
\text { versus no active intervention }(n=41)\end{array}$ & Low & Unclear & High & Unclear & High & High & Low & High \\
\hline $\begin{array}{l}\text { Axley } \\
2017\end{array}$ & $\begin{array}{l}\text { Dietary advice plus exercise advice }(n=8) \text { ver- } \\
\text { sus no active intervention }(n=14)\end{array}$ & Low & Low & High & Low & Unclear & Low & Low & High \\
\hline $\begin{array}{l}\text { Chan } \\
2018\end{array}$ & $\begin{array}{l}\text { Dietary advice plus exercise advice }(n=26) \\
\text { versus no active intervention }(n=26)\end{array}$ & Low & Unclear & High & Low & Low & High & Low & High \\
\hline $\begin{array}{l}\text { Dong } \\
2016\end{array}$ & $\begin{array}{l}\text { Dietary advice plus exercise advice }(n=132) \\
\text { versus no active intervention }(n=133)\end{array}$ & Low & Unclear & High & Unclear & High & High & Low & High \\
\hline Roy 2017 & $\begin{array}{l}\text { Dietary advice plus exercise advice }(n=30) \\
\text { versus no active intervention }(n=30)\end{array}$ & Unclear & Unclear & High & Unclear & Unclear & High & Low & High \\
\hline $\begin{array}{l}\text { Hallsworth } \\
2011\end{array}$ & $\begin{array}{l}\text { Resistance exercise }(n=11) \text { versus no active } \\
\text { intervention }(n=8)\end{array}$ & Unclear & Unclear & High & Unclear & High & High & Low & High \\
\hline $\begin{array}{l}\text { Moradi } \\
2020\end{array}$ & $\begin{array}{l}\text { Resistance exercise }(n=23) \text { versus no active } \\
\text { intervention }(n=22)\end{array}$ & Unclear & Low & High & Unclear & Low & High & Low & High \\
\hline Yao 2018 & $\begin{array}{l}\text { Resistance exercise }(n=31) \text { versus no active } \\
\text { intervention }(n=31)\end{array}$ & Unclear & Unclear & High & Unclear & High & High & Low & High \\
\hline $\begin{array}{l}\text { Misciagna } \\
2017\end{array}$ & $\begin{array}{l}\text { Mediterranean diet }(n=50) \text { versus no active } \\
\text { intervention }(n=48)\end{array}$ & Low & Low & Low & Low & Low & Low & Low & Low \\
\hline \multicolumn{2}{|c|}{$\begin{array}{c}\text { NCT03183193Mediterranean diet }(\mathrm{n}=\text { not stated) versus no } \\
\text { active intervention }(\mathrm{n}=\text { not stated })\end{array}$} & Unclear & Unclear & High & High & Unclear & High & Low & High \\
\hline
\end{tabular}




\begin{tabular}{|c|c|c|c|c|c|c|c|c|c|}
\hline $\begin{array}{l}\text { Tutino } \\
2018\end{array}$ & $\begin{array}{l}\text { Mediterranean diet }(n=18) \text { versus no active } \\
\text { intervention }(n=15)\end{array}$ & Low & Unclear & High & Low & Unclear & High & Low & High \\
\hline $\begin{array}{l}\text { Tutino } \\
2018\end{array}$ & $\begin{array}{l}\text { aerobic exercise plus resistance exercise }(n= \\
\text { 29) versus no active intervention }(n=15)\end{array}$ & Low & Unclear & High & Low & Unclear & High & Low & High \\
\hline $\begin{array}{l}\text { Abd El- } \\
\text { Kader } \\
2016\end{array}$ & $\begin{array}{l}\text { Aerobic exercise plus calorie restricted diet ( } \\
=50) \text { versus no active intervention }(n=50)\end{array}$ & Low & Low & High & Low & Unclear & Low & Low & High \\
\hline $\begin{array}{l}\text { Cheng } \\
2017\end{array}$ & $\begin{array}{l}\text { Supervised aerobic exercise plus calorie re- } \\
\text { stricted diet }(n=23) \text { versus no active inter- } \\
\text { vention }(n=18)\end{array}$ & Low & Low & High & Low & High & High & Low & High \\
\hline $\begin{array}{l}\text { Wong } \\
2013\end{array}$ & $\begin{array}{l}\text { Aerobic exercise plus dietary advice }(n=77) \\
\text { versus no active intervention }(n=77)\end{array}$ & Low & Low & High & Low & Low & High & Low & High \\
\hline $\begin{array}{l}\text { Houghton } \\
2017\end{array}$ & $\begin{array}{l}\text { Supervised aerobic exercise plus resistance } \\
\text { exercise }(n=12) \text { versus no active intervention } \\
(n=12)\end{array}$ & Unclear & Unclear & High & Unclear & High & High & Low & High \\
\hline $\begin{array}{l}\text { Wang } \\
2008\end{array}$ & $\begin{array}{l}\text { Aerobic exercise plus calorie and fat restrict- } \\
\text { ed diet }(n=19) \text { versus no active intervention } \\
(n=38)\end{array}$ & Unclear & Unclear & High & Unclear & Unclear & High & Low & High \\
\hline $\begin{array}{l}\text { Hickman } \\
2013\end{array}$ & $\begin{array}{l}\text { Calorie restricted diet }(n=8) \text { versus aerobic } \\
\text { exercise }(n=13)\end{array}$ & Low & Low & High & High & High & Low & Low & High \\
\hline $\begin{array}{l}\text { Eckard } \\
2013\end{array}$ & $\begin{array}{l}\text { Dietary advice }(n=11) \text { versus aerobic exercise } \\
(n=9)\end{array}$ & Low & Low & High & Unclear & Unclear & High & Low & High \\
\hline $\begin{array}{l}\text { Bacchi } \\
2013\end{array}$ & $\begin{array}{l}\text { Resistance exercise }(n=17) \text { versus aerobic ex- } \\
\text { ercise }(n=13)\end{array}$ & Unclear & Unclear & High & Low & High & High & Low & High \\
\hline Oh 2017 & $\begin{array}{l}\text { Resistance exercise }(n=19) \text { versus aerobic ex- } \\
\text { ercise }(n=33)\end{array}$ & Low & Low & High & Unclear & High & High & Low & High \\
\hline Yao 2018 & $\begin{array}{l}\text { Resistance exercise }(n=31) \text { versus aerobic ex- } \\
\text { ercise }(n=29)\end{array}$ & Unclear & Unclear & High & Unclear & High & High & Low & High \\
\hline $\begin{array}{l}\text { Zel- } \\
\text { ber-Sagi } \\
2014\end{array}$ & $\begin{array}{l}\text { Resistance exercise }(n=33) \text { versus aerobic ex- } \\
\text { ercise }(n=31)\end{array}$ & Unclear & Unclear & High & Unclear & High & High & Low & High \\
\hline
\end{tabular}




\begin{tabular}{|c|c|c|c|c|c|c|c|c|c|}
\hline $\begin{array}{l}\text { De Piano } \\
2012\end{array}$ & $\begin{array}{l}\text { aerobic exercise plus resistance exercise }(\mathrm{n} \\
=\text { not stated) versus aerobic exercise }(\mathrm{n}=\text { not } \\
\text { stated) }\end{array}$ & Unclear & Unclear & Unclear & Unclear & Unclear & High & Low & High \\
\hline NCT026794 & $\begin{array}{l}1 \text { 7aerobic exercise plus resistance exercise }(\mathrm{n} \\
=\text { not stated) versus aerobic exercise ( } \mathrm{n}=\text { not } \\
\text { stated) }\end{array}$ & Unclear & Unclear & High & Low & Unclear & High & Low & High \\
\hline $\begin{array}{l}\text { Eckard } \\
2013\end{array}$ & $\begin{array}{l}\text { Aerobic exercise plus carbohydrate restricted } \\
\text { diet }(n=9) \text { versus aerobic exercise }(n=9)\end{array}$ & Low & Low & High & Unclear & Unclear & High & Low & High \\
\hline $\begin{array}{l}\text { Eckard } \\
2013\end{array}$ & $\begin{array}{l}\text { Aerobic exercise plus fat restricted diet }(n= \\
\text { 12) versus aerobic exercise }(n=9)\end{array}$ & Low & Low & High & Unclear & Unclear & High & Low & High \\
\hline $\begin{array}{l}\text { Cuthbert- } \\
\text { son } 2016\end{array}$ & $\begin{array}{l}\text { Exercise advice }(n=20) \text { versus aerobic exer- } \\
\text { cise }(n=30)\end{array}$ & Low & Unclear & High & Unclear & High & High & Low & High \\
\hline $\begin{array}{l}\text { Dynnyk } \\
2016\end{array}$ & $\begin{array}{l}\text { Exercise advice }(n=\text { not stated }) \text { versus aerobic } \\
\text { exercise }(n=\text { not stated })\end{array}$ & Unclear & Unclear & Unclear & Unclear & Unclear & High & Low & High \\
\hline $\begin{array}{l}\text { Cheng } \\
2017\end{array}$ & $\begin{array}{l}\text { Supervised aerobic exercise }(n=22) \text { versus } \\
\text { calorie restricted diet }(n=22)\end{array}$ & Low & Low & High & Low & High & High & Low & High \\
\hline $\begin{array}{l}\text { Nishimori } \\
2018\end{array}$ & $\begin{array}{l}\text { Carbohydrate restricted diet }(n=14) \text { versus } \\
\text { calorie restricted diet }(n=14)\end{array}$ & Unclear & Unclear & High & Unclear & Unclear & High & Low & High \\
\hline $\begin{array}{l}\text { Pangani- } \\
\text { ban } 2020\end{array}$ & $\begin{array}{l}\text { Carbohydrate restricted diet }(n=19) \text { versus } \\
\text { calorie restricted diet }(n=20)\end{array}$ & Unclear & Unclear & Unclear & Unclear & Unclear & High & Low & High \\
\hline $\begin{array}{l}\text { Ramirez } \\
2016\end{array}$ & $\begin{array}{l}\text { Carbohydrate restricted diet }(n=\text { not stated }) \\
\text { versus calorie restricted diet }(n=\text { not stated })\end{array}$ & Unclear & Unclear & High & Unclear & Unclear & High & Low & High \\
\hline $\begin{array}{l}\text { Al-Jiffri } \\
2013\end{array}$ & $\begin{array}{l}\text { Aerobic exercise plus calorie restricted diet ( } \\
=50) \text { versus calorie restricted diet }(n=50)\end{array}$ & Unclear & Unclear & High & Unclear & Low & High & Low & High \\
\hline Sima 2014 & $\begin{array}{l}\text { Aerobic exercise plus calorie restricted diet ( } \\
=12 \text { ) versus calorie restricted diet }(n=13)\end{array}$ & Unclear & Unclear & High & Unclear & Unclear & High & Low & High \\
\hline $\begin{array}{l}\text { Wang } \\
2016\end{array}$ & $\begin{array}{l}\text { Aerobic exercise plus calorie restricted diet ( } \mathrm{n} \\
=80 \text { ) versus calorie restricted diet }(n=40)\end{array}$ & Unclear & Unclear & Unclear & Unclear & Unclear & High & Low & High \\
\hline
\end{tabular}




\begin{tabular}{|c|c|c|c|c|c|c|c|c|c|}
\hline $\begin{array}{l}\text { Cheng } \\
2017\end{array}$ & $\begin{array}{l}\text { Supervised aerobic exercise plus calorie re- } \\
\text { stricted diet }(n=23) \text { versus calorie restricted } \\
\text { diet }(n=22)\end{array}$ & Low & Low & High & Low & High & High & Low & High \\
\hline Kani 2014 & $\begin{array}{l}\text { Carbohydrate and calorie restricted diet }(n= \\
12) \text { versus calorie restricted diet }(n=13)\end{array}$ & Low & Low & High & Low & Low & High & Low & High \\
\hline $\begin{array}{l}\text { Selezneva } \\
2014\end{array}$ & $\begin{array}{l}\text { isocaloric diet }(n=116) \text { versus calorie restrict- } \\
\text { ed diet }(n=58)\end{array}$ & Unclear & Unclear & High & Unclear & Unclear & High & Low & High \\
\hline $\begin{array}{l}\text { Shidfar } \\
2018\end{array}$ & $\begin{array}{l}\text { Mono unsaturated fatty acid plus calorie re- } \\
\text { stricted diet }(n=21) \text { versus calorie restricted } \\
\text { diet }(n=22)\end{array}$ & Unclear & Unclear & Unclear & Unclear & Unclear & High & Low & High \\
\hline Zade 2016 & $\begin{array}{l}\text { Fat and calorie restricted diet }(n=30) \text { versus } \\
\text { calorie restricted diet }(n=30)\end{array}$ & Low & Low & Low & Low & Low & High & Low & High \\
\hline NCT013274 & $\begin{array}{l}3 \text { Supervised aerobic exercise }(\mathrm{n}=\text { not stated }) \\
\text { versus dietary advice }(\mathrm{n}=\text { not stated })\end{array}$ & Unclear & Unclear & High & High & Unclear & High & Low & High \\
\hline $\begin{array}{l}\text { Nikroo } \\
2017\end{array}$ & $\begin{array}{l}\text { Supervised aerobic exercise }(n=12) \text { versus di- } \\
\text { etary advice }(n=11)\end{array}$ & Unclear & Unclear & High & High & Unclear & High & Low & High \\
\hline $\begin{array}{l}\text { Eckard } \\
2013\end{array}$ & $\begin{array}{l}\text { Aerobic exercise plus carbohydrate restricted } \\
\text { diet }(n=9) \text { versus dietary advice }(n=11)\end{array}$ & Low & Low & High & Unclear & Unclear & High & Low & High \\
\hline $\begin{array}{l}\text { Eckard } \\
2013\end{array}$ & $\begin{array}{l}\text { Aerobic exercise plus fat restricted diet }(n= \\
\text { 12) versus dietary advice }(n=11)\end{array}$ & Low & Low & High & Unclear & Unclear & High & Low & High \\
\hline $\begin{array}{l}\text { Katsagoni } \\
2018\end{array}$ & $\begin{array}{l}\text { Mediterranean diet plus dietary advice }(n= \\
21) \text { versus dietary advice }(n=21)\end{array}$ & Low & Unclear & High & Unclear & Low & High & Low & High \\
\hline $\begin{array}{l}\text { Katsagoni } \\
2018\end{array}$ & $\begin{array}{l}\text { Mediterranean diet plus dietary advice plus } \\
\text { exercise advice }(n=21) \text { versus dietary advice } \\
(n=21)\end{array}$ & Low & Unclear & High & Unclear & Low & High & Low & High \\
\hline $\begin{array}{l}\text { Kaliora } \\
2016\end{array}$ & $\begin{array}{l}\text { Raisins plus dietary advice }(n=23) \text { versus di- } \\
\text { etary advice }(n=21)\end{array}$ & Low & Low & High & Low & High & High & Low & High \\
\hline $\begin{array}{l}\text { Cheng } \\
2017\end{array}$ & $\begin{array}{l}\text { Supervised aerobic exercise plus calorie re- } \\
\text { stricted diet }(n=23) \text { versus supervised aero- } \\
\text { bic exercise }(n=22)\end{array}$ & Low & Low & High & Low & High & High & Low & High \\
\hline
\end{tabular}




\begin{tabular}{|c|c|c|c|c|c|c|c|c|c|}
\hline $\begin{array}{l}\text { Pugh } \\
2014\end{array}$ & $\begin{array}{l}\text { Supervised aerobic exercise }(n=13) \text { versus di- } \\
\text { etary advice plus exercise advice }(n=8)\end{array}$ & Low & Unclear & High & Unclear & High & High & Low & High \\
\hline Chen 2020 & $\begin{array}{l}\text { Carbohydrate restricted diet plus dietary ad- } \\
\text { vice plus exercise advice }(n=22) \text { versus di- } \\
\text { etary advice plus exercise advice }(n=22)\end{array}$ & Low & Unclear & High & Unclear & Unclear & High & Low & High \\
\hline $\begin{array}{l}\text { De Luis } \\
2010\end{array}$ & $\begin{array}{l}\text { Fat restricted diet }(n=15) \text { versus carbohy- } \\
\text { drate restricted diet }(n=13)\end{array}$ & Unclear & Unclear & Unclear & Low & Low & High & Low & High \\
\hline $\begin{array}{l}\text { Ro- } \\
\text { driguez-Her- } \\
\text { nandez } \\
2011\end{array}$ & $\begin{array}{l}\text { Fat restricted diet }(n=26) \text { versus carbohy- } \\
\text { - drate restricted diet }(n=28)\end{array}$ & Unclear & Unclear & Unclear & Unclear & Unclear & High & Low & High \\
\hline Goss 2020 & $\begin{array}{l}\text { Carbohydrate restricted diet }(n=16) \text { versus } \\
\text { fat restricted diet }(n=16)\end{array}$ & Low & Unclear & High & High & Unclear & High & Low & High \\
\hline $\begin{array}{l}\text { Properzi } \\
2018\end{array}$ & $\begin{array}{l}\text { Mediterranean diet }(n=24) \text { versus fat restrict- } \\
\text { ed diet }(n=24)\end{array}$ & Unclear & Unclear & High & High & High & Low & Low & High \\
\hline $\begin{array}{l}\text { Ra- } \\
\text { mon-Krauel } \\
2013\end{array}$ & $\begin{array}{l}\text { Low glycaemic index diet }(n=7) \text { versus fat re- } \\
\text { stricted diet }(n=9)\end{array}$ & Unclear & Unclear & High & Unclear & Unclear & High & Low & High \\
\hline $\begin{array}{l}\text { Tutino } \\
2018\end{array}$ & $\begin{array}{l}\text { aerobic exercise plus resistance exercise }(n= \\
29) \text { versus Mediterranean diet }(n=18)\end{array}$ & Low & Unclear & High & Low & Unclear & High & Low & High \\
\hline $\begin{array}{l}\text { Eckard } \\
2013\end{array}$ & $\begin{array}{l}\text { Aerobic exercise plus fat restricted diet }(n= \\
\text { 12) versus aerobic exercise plus carbohydrate } \\
\text { restricted diet }(n=9)\end{array}$ & Low & Low & High & Unclear & Unclear & High & Low & High \\
\hline $\begin{array}{l}\text { Abbate } \\
2021\end{array}$ & $\begin{array}{l}\text { Mediterranean diet plus exercise advice }(n= \\
43) \text { versus calorie restricted diet plus exercise } \\
\text { advice }(n=42)\end{array}$ & Low & Low & High & Unclear & Unclear & High & Low & High \\
\hline $\begin{array}{l}\text { Abbate } \\
2021\end{array}$ & $\begin{array}{l}\text { Mediterranean diet plus supervised aerobic } \\
\text { exercise }(n=43) \text { versus calorie restricted diet } \\
\text { plus exercise advice }(n=42)\end{array}$ & Low & Low & High & Unclear & Unclear & High & Low & High \\
\hline $\begin{array}{l}\text { Abbate } \\
2021\end{array}$ & $\begin{array}{l}\text { Mediterranean diet plus supervised aerobic } \\
\text { exercise }(n=43) \text { versus Mediterranean diet } \\
\text { plus exercise advice }(n=43)\end{array}$ & Low & Low & High & Unclear & Unclear & High & Low & High \\
\hline
\end{tabular}




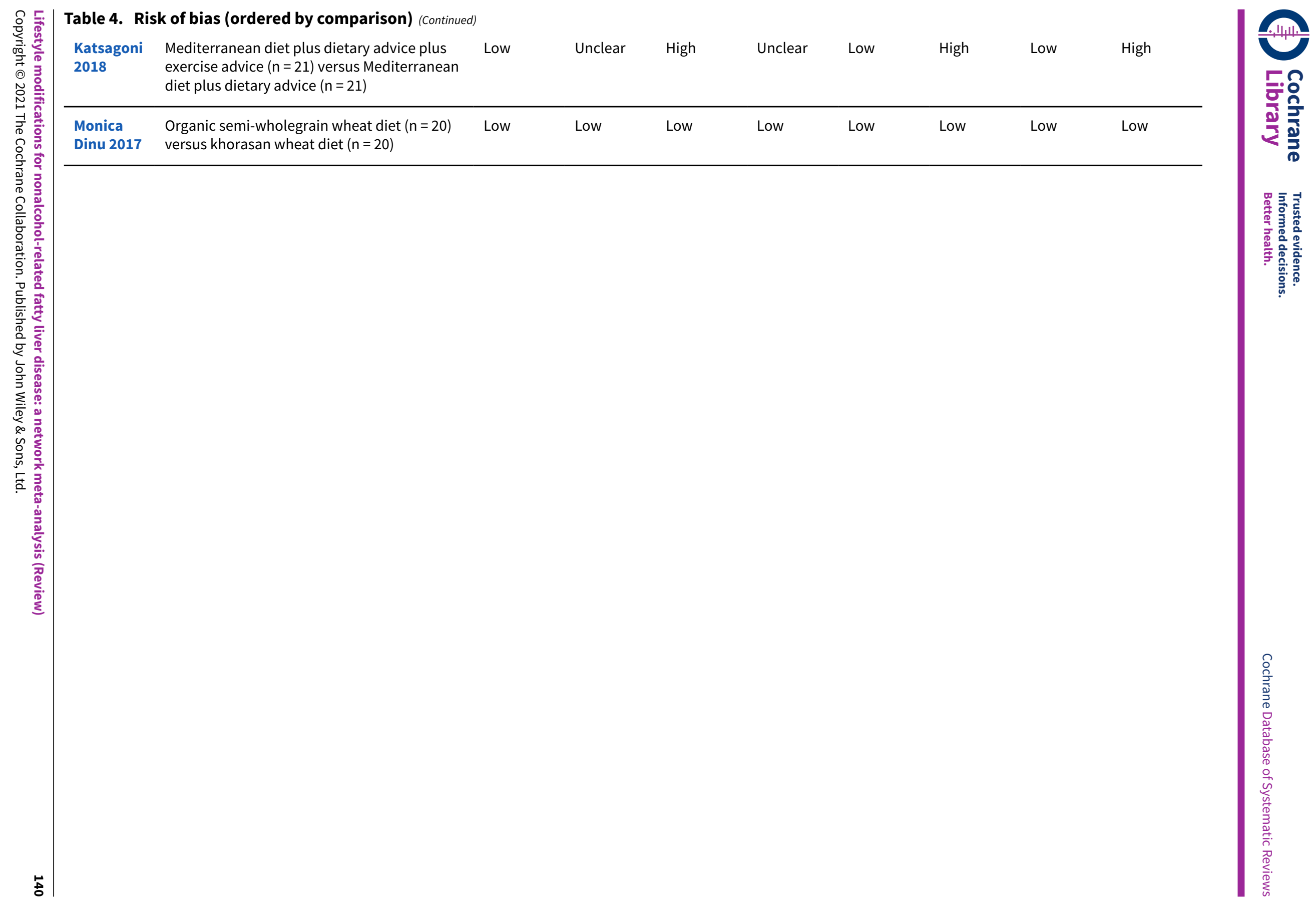


Table 5. Fit statistics for fixed-effect, random-effects, and inconsistency model

\begin{tabular}{|c|c|c|c|}
\hline Fatty Liver & Fixed-effect model & Random-effects model & Inconsistency model \\
\hline Dbar & 103.4 & 90.03 & 90.15 \\
\hline DIC & 122 & 110.6 & 110.8 \\
\hline pD & 18.6 & 20.56 & 20.63 \\
\hline Fibrosis Score & Fixed-effect model & Random-effects model & Inconsistency model \\
\hline Dbar & 0.6826 & - & - \\
\hline DIC & 4.692 & - & - \\
\hline pD & 4.009 & - & - \\
\hline NAFLD Activity Score & Fixed-effect model & Random-effects model & Inconsistency model \\
\hline Dbar & 8.662 & - & - \\
\hline DIC & 14.61 & - & - \\
\hline pD & 5.952 & - & - \\
\hline
\end{tabular}

Dbar: posterior mean of deviance; DIC: deviance information criteria; pD: effective number of parameters or leverage.

Empty cells for random-effects model indicate that the presence of only a single trial for all comparisons of any two interventions; empty cells for inconsistency model indicates absence of direct and indirect effect estimates for all comparisons of any two interventions for the outcome.

\section{Table 6. Effect estimates}

This table is too wide to be displayed in RevMan. A picture of this table can be found in Figure 6 . The full table can be found here.

The table provides the effect estimates of each pairwise comparison for the different outcomes (hazard ratio and its $95 \%$ credible interval (Crl) for resolution of fatty liver and mean difference and its $\mathrm{Crl}$ for fibrosis score and nonalcohol-related fatty liver disease (NAFLD) activity score. The top half of the table indicates the effect estimates from the direct comparisons. The bottom half of the table indicates the effect estimates from the network meta-analysis. For network meta-analysis, to identify the effect estimate of a comparison, say A versus $B$, look at the cell that occupies the row corresponding to intervention $A$ and the column corresponding to intervention $B$ for the effect estimate that is obtained directly. For example, if you wanted to know the effect of supervised aerobic exercise versus calorie-restricted diet, the network meta-analysis estimates are available in cell D7, which corresponds to the supervised aerobic exercise in row 7 and calorie-restricted diet in column D.

For direct comparisons, this is exactly the opposite; look at the cell that occupies the column corresponding to intervention A and the row corresponding to intervention B for the direct effect estimate. For example, if you wanted to know the effect of supervised aerobic exercise versus calorie-restricted diet, the direct comparison estimates are available in cell $\mathrm{G} 4$, which corresponds to the supervised aerobic exercise in column $\mathrm{G}$ and calorie-restricted diet in row 4.

If that cell is empty, look at the column corresponding to intervention B and the row corresponding to intervention $A$. Take the inverse of this number (i.e. 1 /number for hazard ratio and change signs for mean differences) to arrive at the treatment effect of $A$ versus $B$. If the cell corresponding to $B$ versus $A$ is also missing in direct comparisons, this means that there was no direct comparison.

Statistically significant results are shown in italics. Green colour indicates that intervention A is better than B and red colour indicates that intervention A is worse than B.

The results of resolution of fatty liver have extremely wide credible intervals. This was because of sparse data with heterogeneity. 


\section{APPENDICES}

\section{Appendix 1. Search strategies}

\begin{tabular}{|c|c|c|}
\hline Database & Time span & Search strategy \\
\hline $\begin{array}{l}\text { Cochrane Central Reg- } \\
\text { ister of Controlled Tri- } \\
\text { als (CENTRAL) in the } \\
\text { Cochrane Library }\end{array}$ & 2021 , Issue 2 & 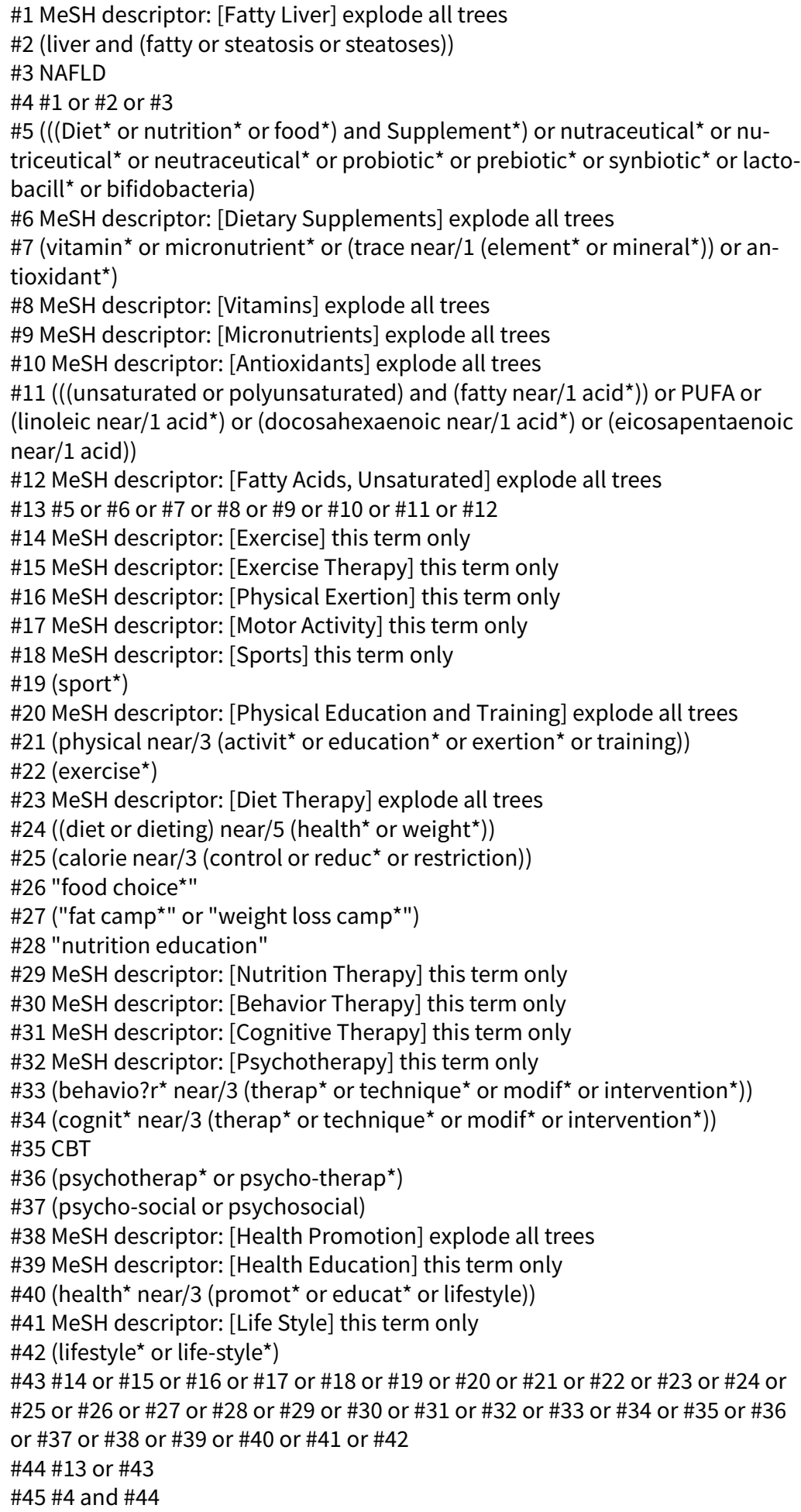 \\
\hline
\end{tabular}


(Continued)

MEDLINE Ovid
January 1947 to February 2021
1. randomized controlled trial.pt.

2. controlled clinical trial.pt.

3. randomized.ab.

4. placebo.ab.

5. drug therapy.fs.

6. randomly.ab.

7. trial.ab.

8. groups.ab.

9. 1 or 2 or 3 or 4 or 5 or 6 or 7 or 8

10. exp animals/ not humans.sh.

11.9 not 10

12. exp Fatty Liver/

13. (liver and (fatty or steatosis or steatoses)).ti,ab.

14. NAFLD.ti,ab.

15. 12 or 13 or 14

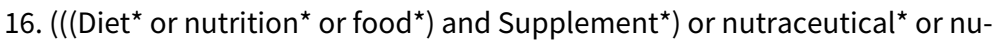
triceutical $^{\star}$ or neutraceutical ${ }^{\star}$ or probiotic ${ }^{\star}$ or prebiotic ${ }^{\star}$ or synbiotic* or lactobacill* $^{*}$ or bifidobacteria).ti,ab.

17. exp Dietary Supplements/

18. (vitamin ${ }^{\star}$ or micronutrient ${ }^{\star}$ or (trace adj1 (element ${ }^{\star}$ or mineral $\left.{ }^{\star}\right)$ ) or antioxidant $\left.{ }^{\star}\right) . t i, a b$.

19. exp Vitamins/ or exp MICRONUTRIENTS/ or exp ANTIOXIDANTS/

20. (((unsaturated or polyunsaturated) and (fatty adj1 acid*)) or PUFA or (linoleic adj1 acid $^{\star}$ ) or (docosahexaenoic adj1 acid ${ }^{\star}$ ) or (eicosapentaenoic adj1 acid)).ti,ab.

21. exp Fatty Acids, Unsaturated/

22. 16 or 17 or 18 or 19 or 20 or 21

23. Exercise/ or Exercise Therapy/ or Physical Exertion/ or Motor Activity/ or Sports/

24. sport*.tw.

25. exp "Physical Education and Training"/

26. (physical adj3 (activit* or education* or exertion* or training)).tw.

27. exercise ${ }^{\star}$. tw.

28. exp diet therapy/

29. ((diet or dieting) adj5 (health* or weight $\left.\left.{ }^{\star}\right)\right)$.tw.

30. (calorie adj3 (control or reduc* or restriction)).tw.

31. food choice*.tw.

32. (fat camp* or weight loss camp $\left.{ }^{\star}\right)$.tw.

33. nutrition education.tw.

34. Nutrition Therapy/ or behavior therapy/ or Cognitive Therapy/ or psychotherapy/

35. (behavio? ${ }^{\star}$ adj3 (therap ${ }^{\star}$ or technique* or modif* or intervention $\left.{ }^{\star}\right)$ ).tw. 36. (cognit ${ }^{\star}$ adj3 (therap ${ }^{\star}$ or technique ${ }^{\star}$ or modif* or intervention $\left.^{\star}\right)$ ).tw.

37. CBT.tw.

38. (psychotherap* or psycho-therap*).tw.

39. (psycho-social or psychosocial).tw.

40. exp Health Promotion/ or Health Education/

41. (health ${ }^{\star}$ adj3 (promot ${ }^{\star}$ or educat* or lifestyle)).tw.

42. lifestyle/

43. (lifestyle ${ }^{\star}$ or life-style $\left.{ }^{\star}\right)$.tw.

44.23 or 24 or 25 or 26 or 27 or 28 or 29 or 30 or 31 or 32 or 33 or 34 or 35 or 36 or 37 or 38 or 39 or 40 or 41 or 42 or 43

45. 22 or 44

46. 11 and 15 and 45

Embase Ovid

January 1974 to Febru-

ary 2021
1. exp crossover-procedure/ or exp double-blind procedure/ or exp randomized controlled trial/ or single-blind procedure/

2. ( ( (( $\left(\right.$ random $^{\star}$ or factorial ${ }^{\star}$ or crossover ${ }^{\star}$ or cross over ${ }^{\star}$ or cross-over $^{\star}$ or placebo $^{\star}$ or double ${ }^{\star}$ ) adj blind ${ }^{\star}$ ) or single* ) adj blind ${ }^{\star}$ ) or assign ${ }^{\star}$ or allocat ${ }^{\star}$ or volunteer $\left.{ }^{\star}\right)$.af. 
3. 1 or 2

4. exp fatty liver/

5. (liver and (fatty or steatosis or steatoses)).ti,ab.

6. NAFLD.ti,ab.

7. 4 or 5 or 6

8. (((Diet ${ }^{\star}$ or nutrition $^{\star}$ or food $\left.^{\star}\right)$ and Supplement $\left.{ }^{\star}\right)$ or nutraceutical ${ }^{\star}$ or nutriceutical ${ }^{\star}$ or neutraceutical ${ }^{*}$ or probiotic ${ }^{\star}$ or prebiotic ${ }^{\star}$ or synbiotic ${ }^{\star}$ or lactobacill $^{\star}$ or bifidobacteria).ti,ab.

9. exp dietary supplement/ or probiotic agent/ or prebiotic agent/ or synbiotic agent/

10. (vitamin ${ }^{\star}$ or micronutrient ${ }^{\star}$ or (trace adj1 (element ${ }^{\star}$ or mineral $\left.{ }^{\star}\right)$ ) or antioxidant $\left.{ }^{\star}\right)$.ti,ab.

11. exp vitamin/ or exp trace element/ or exp antioxidant/

12. (((unsaturated or polyunsaturated) and (fatty adj1 acid $\left.\left.^{\star}\right)\right)$ or PUFA or (linoleic adj1 acid $^{\star}$ ) or (docosahexaenoic adj1 acid*) or (eicosapentaenoic adj1 acid)).ti,ab.

13. exp polyunsaturated fatty acid/

14. 8 or 9 or 10 or 11 or 12 or 13

15. exercise/ or kinesiotherapy/ or motor activity/ or sport/

16. sport*.tw.

17. (physical adj3 (activit* or education ${ }^{\star}$ or exertion ${ }^{\star}$ or training)).tw.

18. exercise ${ }^{\star} . t w$.

19. exp diet therapy/

20. ((diet or dieting) adj5 (health* or weight $\left.{ }^{\star}\right)$ ).tw.

21. (calorie adj3 (control or reduc* or restriction)).tw.

22. food choice ${ }^{\star}$.tw.

23. (fat camp* or weight loss camp ${ }^{\star}$ ).tw.

24. nutrition education.tw.

25. behavior therapy/or Cognitive Therapy/ or psychotherapy/

26. (behavio? ${ }^{\star}$ adj3 (therap* or technique* or modif* or intervention*)).tw.

27. (cognit* adj3 (therap ${ }^{\star}$ or technique ${ }^{\star}$ or modif* ${ }^{\star}$ or intervention $\left.{ }^{\star}\right)$ ).tw.

28. CBT.tw.

29. (psychotherap* or psycho-therap*).tw.

30. (psycho-social or psychosocial).tw.

31. exp Health Promotion/ or Health Education/

32. (health* adj3 (promot ${ }^{\star}$ or educat $^{\star}$ or lifestyle)).tw.

33. lifestyle/ or lifestyle modification/

34. (lifestyle* or life-style*).tw.

35. 15 or 16 or 17 or 18 or 19 or 20 or 21 or 22 or 23 or 24 or 25 or 26 or 27 or 28 or 29 or 30 or 31 or 32 or 33 or 34

36.14 or 35

37.3 and 7 and 36

Science Citation Index Expanded (Web of Science)
January 1945 to February 2021
\#1 TS = ((liver and (fatty or steatosis or steatoses)) or NAFLD)

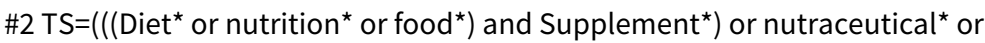
nutriceutical $^{\star}$ or neutraceutical ${ }^{*}$ or probiotic ${ }^{\star}$ or prebiotic ${ }^{\star}$ or synbiotic ${ }^{\star}$ or lactobacill* or bifidobacterial or vitamin ${ }^{\star}$ or micronutrient ${ }^{\star}$ or (trace near1 (element $^{\star}$ or mineral $\left.{ }^{\star}\right)$ ) or ((unsaturated or polyunsaturated) and (fatty near1 acid $\left.^{\star}\right)$ ) or antioxidant ${ }^{\star}$ or PUFA or (linoleic near1 acid*) or (docosahexaenoic near1 acid $^{\star}$ ) or (eicosapentaenoic near1 acid))

\#3 TS=(sport ${ }^{\star}$ or (physical near/3 (activit ${ }^{*}$ or education ${ }^{\star}$ or exertion ${ }^{\star}$ or training)) or exercise* or ((diet or dieting) near/5 (health* or weight $\left.{ }^{\star}\right)$ ) or (calorie near/3 (control or reduc* or restriction)) or "food choice*" or "fat camp " or $^{*}$ "weight loss camp*" or "nutrition education" or (behavio?r* near/3 (therap* or technique* or modif* or intervention $\left.{ }^{\star}\right)$ ) or (cognit* near/3 (therap* or technique $^{\star}$ or modif* or intervention $\left.{ }^{\star}\right)$ ) or CBT or psychotherap* or psycho-ther$\mathrm{ap}^{\star}$ or psycho-social or psychosocial or (health* near/3 (promot* or educat $^{\star}$ or lifestyle)) or lifestyle* or life-style* or (alcohol ${ }^{\star}$ near $/ 2$ (drink ${ }^{\star}$ or intoxicat ${ }^{\star}$ or 
use $^{\star}$ or abus ${ }^{\star}$ or misus ${ }^{\star}$ or risk ${ }^{\star}$ or consum ${ }^{\star}$ or withdraw ${ }^{\star}$ or detox ${ }^{\star}$ or treat ${ }^{\star}$ or therap ${ }^{\star}$ or excess ${ }^{\star}$ or reduc $c^{\star}$ or cessation or intervention $\left.{ }^{\star}\right)$ ))

\#4 \#3 OR \#2

\#5 TS=(random ${ }^{\star}$ OR rct* OR crossover OR masked OR blind* OR placebo* OR meta-analysis OR systematic review* ${ }^{\star}$ OR meta-analys ${ }^{\star}$ )

\#6 \#5 AND \#4 AND \#1

Conference Proceedings Citation Index-Science (Web of Science)
January 1990 to February 2021
\#1 TS = ((liver and (fatty or steatosis or steatoses) $)$ or NAFLD)

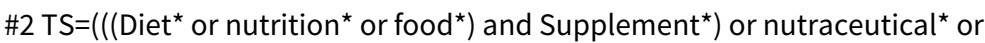
nutriceutical ${ }^{\star}$ or neutraceutical ${ }^{\star}$ or probiotic ${ }^{\star}$ or prebiotic ${ }^{\star}$ or synbiotic ${ }^{*}$ or lactobacill ${ }^{\star}$ or bifidobacterial or vitamin ${ }^{\star}$ or micronutrient ${ }^{\star}$ or (trace near1 (element $^{\star}$ or mineral $\left.{ }^{\star}\right)$ ) or ((unsaturated or polyunsaturated) and (fatty near1 acid $\left.^{\star}\right)$ ) or antioxidant ${ }^{\star}$ or PUFA or (linoleic nearl acid ${ }^{\star}$ ) or (docosahexaenoic near1 acid*) or (eicosapentaenoic near1 acid))

\#3 TS=(sport* or (physical near/3 (activit* or education * or exertion* or training)) or exercise* or ((diet or dieting) near/5 (health* or weight $\left.{ }^{\star}\right)$ ) or (calorie near/3 (control or reduc* or restriction)) or "food choice* or "fat camp" or "weight loss camp*" or "nutrition education" or (behavio? ${ }^{\star}$ near/3 (therap* or technique* or modif* or intervention $\left.{ }^{\star}\right)$ ) or (cognit* near/3 (therap* or technique $^{\star}$ or modif* or intervention $\left.{ }^{\star}\right)$ ) or CBT or psychotherap* or psycho-ther$\mathrm{ap}^{\star}$ or psycho-social or psychosocial or (health* near/3 (promot* or educat* or lifestyle)) or lifestyle* or life-style* or (alcohol ${ }^{\star}$ near/2 (drink ${ }^{\star}$ or intoxicat $^{\star}$ or use $^{\star}$ or abus or misus $^{\star}$ or risk or consum $^{\star}$ or withdraw ${ }^{\star}$ or detox ${ }^{\star}$ or treat ${ }^{\star}$ or therap ${ }^{\star}$ or excess ${ }^{\star}$ or reduc ${ }^{\star}$ or cessation or intervention $\left.{ }^{\star}\right)$ ))

\section{\#4 \#3 OR \#2}

\#5 TS=(random ${ }^{\star}$ OR rct* OR crossover OR masked OR blind ${ }^{\star}$ OR placebo* OR meta-analysis OR systematic review* OR meta-analys ${ }^{\star}$ )

\#6 \#5 AND \#4 AND \#1

"fatty liver" and Study design: "Randomised: yes" (after importing the refer-
World Health Organiza-

cal Trials Registry Plat-

form (apps.who.int/tri-

alsearch/Default.aspx) ences into Excel file)

25 February 2021

25 February 2021

Fatty Liver, Nonalcoholic | Phase 2, 3, 4

European Medical 25 February $2021 \quad$ "Fatty liver"

Agency (www.ema.europa.eu/ema/)

US Food and Drug Ad- 25 February $2021 \quad$ "Fatty liver"
ministration (www.f-
da.gov)

Footnote: These are common search strategies that were used for this review and nutritional supplementation review (Komolafe 2021).

\section{Appendix 2. Data}

This table is too wide to be displayed in RevMan. This table can be found here. 


\section{Appendix 3. Abbreviations}

AdviceDiet: dietary advice

AdviceDiet+AerobicEx: aerobic exercise plus dietary advice

AdviceDiet+Raisins: raisins plus dietary advice

AdviceDietEx: dietary advice plus exercise advice

AdviceEx: exercise advice

AerobicEx: aerobic exercise

AerobicEx+CalRestrictDiet: aerobic exercise plus calorie restricted diet

AerobicEx+FatRestrictCalRestrictDiet: aerobic exercise plus calorie and fat restricted diet

AerobicEx+ResistEx: aerobic exercise plus resistance exercise

CalRestrictDiet: calorie restricted diet

CalRestrictDiet+AerobicEx: aerobic exercise plus calorie restricted diet

CarbRestrictCalRestrictDiet: carbohydrate and calorie restricted diet

CarbRestrictDiet: carbohydrate restricted diet

CarbRestrictDiet+AerobicEx: aerobic exercise plus carbohydrate restricted diet

FatRestrictCalRestrictDiet: fat and calorie restricted diet

FatRestrictDiet: fat restricted diet

FatRestrictDiet+AerobicEx: aerobic exercise plus fat restricted diet

FattyLiver: fatty liver

FibrosisScore: fibrosis score

IsoCalorieDiet: isocalorie diet

KhorasanWheatDiet: Khorasan wheat diet

LowGIDiet: low glycaemic index diet

MedDiet: Mediterranean diet

MedDiet+AdviceDiet: Mediterranean diet plus dietary advice

MedDiet+AdviceDietEx: Mediterranean diet plus dietary advice plus exercise advice

NAFLDActivity: NAFLD activity score (NAS)

NoActivelntervention: no active intervention

ResistEx: resistance exercise

Semi-OrganicWheatDiet: organic semi-wholegrain wheat diet

SupAerobicEx: supervised aerobic exercise

SupAerobicEx+CalRestrictDiet: supervised aerobic exercise plus calorie restricted diet

SupAerobicEx+SupResistEx: supervised aerobic exercise plus resistance exercise

\section{H I S T ORY}

Protocol first published: Issue 10, 2018

Lifestyle modifications for nonalcohol-related fatty liver disease: a network meta-analysis (Review) 


\section{CONTRIBUTIONS OF AUTHORS}

\section{Protocol}

Conceiving the protocol: $\mathrm{KG}$

Designing the protocol: $K G$

Co-ordinating the protocol: $K G$

Designing search strategies: KG

Writing the protocol: KG

Providing general advice on the protocol: $E T, A M$

Securing funding for the protocol: KG

All authors approved of the current protocol version

Performing previous work that was the foundation of the current study: not applicable

\section{Review}

Co-ordinating the review: KG

Study selection: KG, EB

Data extraction: KG, EB, AL, DR, TC, AY, LB, DF

Writing the review: KG

Providing advice on the review: SF, AJS, NC, AM, KW, EJM, CP, BRD, ET

Securing funding for the review: KG

All authors approved the current review version for publication.

\section{DECLARATIONSOF INTEREST}

None known for any of the authors

\section{SOURCES OF SUPPORT}

\section{Internal sources}

- University College London, UK

Writing equipment, software, etc

\section{External sources}

- National Institute for Health Research, UK

Payment for writing reviews, writing equipment, software

\section{DIFFERENCES BETWEEN PROTOCOLANDREVIEW}

- We have added information about treatment nodes and the decision set in the Types of interventions section.

- We removed the sentence "We excluded such quasi-randomised studies" from the two risk of bias domains on randomisation sequence and concealment. Instead, we made it clear at the beginning of 'Study design' section that we will exclude quasi-randomised studies.

- We have added liver-related mortality and MELD score based on the coreNASH project (Clearfield 2021). This was a planned modification mentioned in the protocol.

- We have removed the sentence "In general, we will classify the risk of bias as low if the method used for allocation concealment suggested that it was extremely likely that the sequence was generated randomly (for example, use of interactive voice response system)". We have also removed: 'For profit bias'. These changes were made following the current guidance for risk of bias classification of CHB Group.

- We did not perform Trial Sequential Analysis (TSA) because of the current Cochrane guidance not to use the sequential methods to draw main conclusions (Cochrane Scientific Committee 2018).

- We used the latest guidance from the GRADE Working group (Brignardello-Petersen 2018; Yepes-Nunez 2019) rather than the previous guidance (Puhan 2014) for presenting the summary of findings table.

- We used 30,000 iterations (instead of 10,000 iterations) as a minimum for burn-in of the simulation sampler used to estimate quantities in the statistical models to ensure convergence of the simulation sampler.

- We did not present some information such as ranking probability tables, rankograms, and surface area under the curve (SUCRA) plots because of concern about the misinterpretation of the results. We have highlighted this clearly within the text of the review, along with the reasons for not presenting them. 


\section{NOTES}

The Methods section of this review is based on a standard Cochrane Hepato-Biliary Group template incorporating advice by the Complex Reviews Support Unit for a network meta-analysis protocol (Best 2018). 